\title{
Skimming the surface
}

A surface structural approach to understanding silver ion release from silver nanoparticles

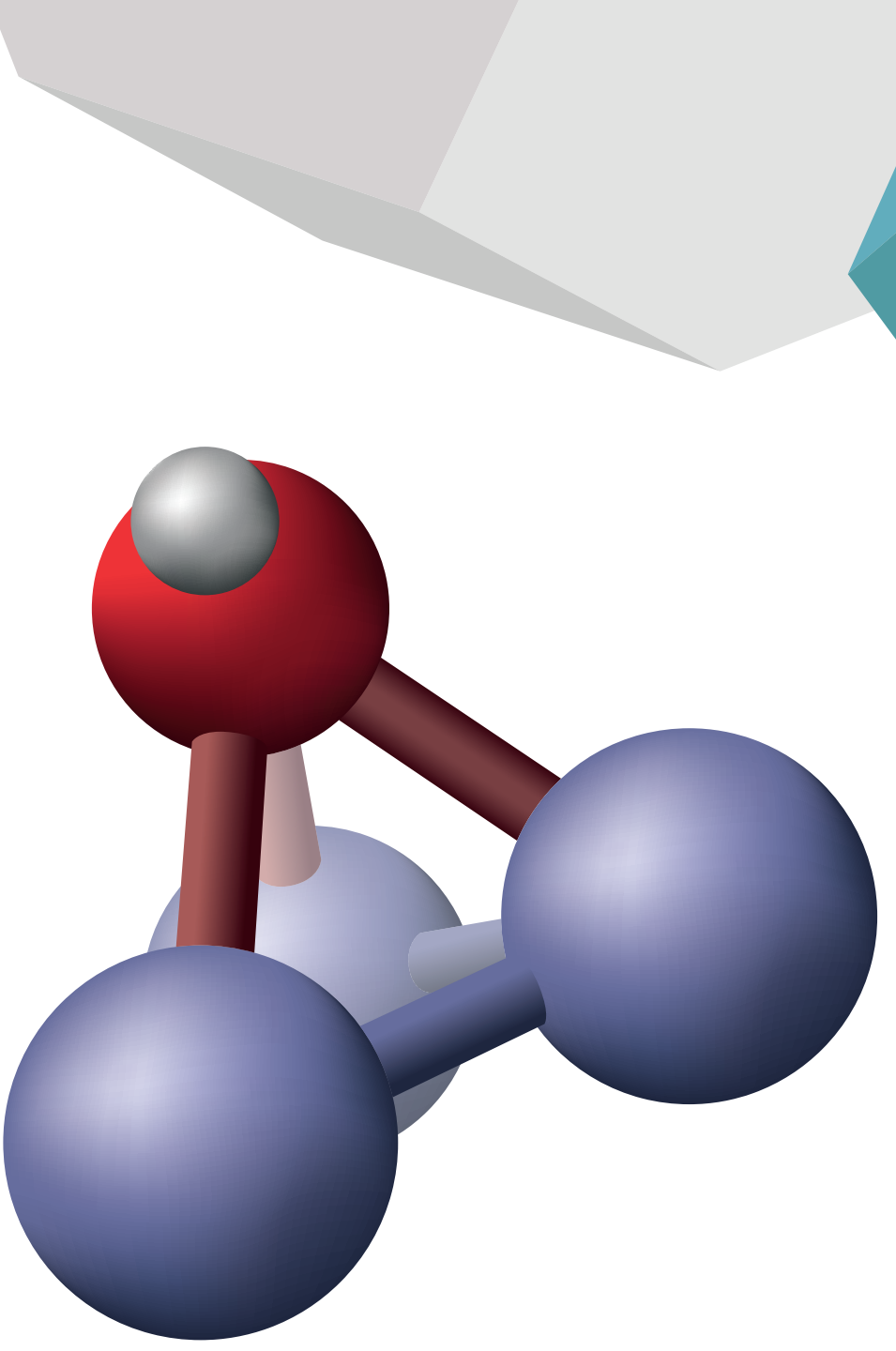

Bastiaan Molleman

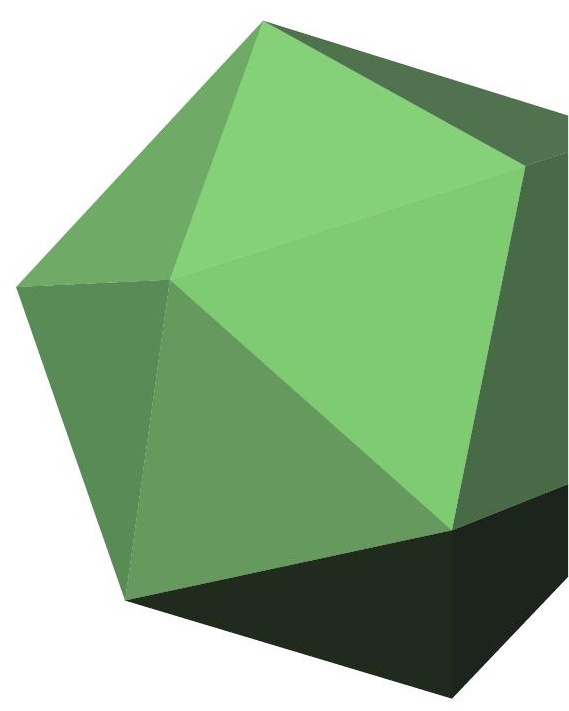





\section{Propositions}

1. Silver nanoparticles are chemically stabilized against full oxidation by two subvalent surface (hydr)oxide structures which are in a metastable equilibrium with the solution phase.

(this thesis)

2. The supposed highly elevated surface energy of metallic nano-sized particles (Nanda et al., 2003, Physical review letters) is in conflict with the limited energy difference between edge and corner atoms and face atoms.

(this thesis)

3. The positive correlation between toxicity of AgNPs and salinity (Kataoka et al., 2015, Environmental Science: Nano) suggest that binding of $\mathrm{Ag}^{+}$to extremely high affinity ligands in cell materials, e.g. sulfide groups, is an important toxicity mechanism.

4. Due to their accumulation in the human body (Lin et al., 2015, Wiley Interdisciplinary Reviews: Nanomedicine and Nanobiotechnology), it is unlikely that metallic nanoparticles will find clinical use as carriers for targeted drug delivery to tumors.

5. Gender neutral pronouns reinforce existing gender patterns as much as they are a result of it.

6. With automation making an ever increasing portion of the human labor force obsolete, a social system providing a basic income to citizens becomes not only desirable, but ultimately unavoidable.

Propositions belonging to the thesis, entitled: 'Skimming the Surface: A surface structural approach to understanding silver ion release from silver nanoparticles'.

Bastiaan Molleman

Wageningen, 11 October 2019 



\section{Skimming the Surface}

\section{A surface structural approach to understanding silver ion release from silver nanoparticles}




\section{Thesis committee}

\section{Promotors}

Prof. Dr R.N.J Comans

Professor of Soil Chemistry and Chemical Soil Quality

Wageningen University and Research

Co-promotor

Dr T. Hiemstra

Assistant professor, Soil Chemistry and Chemical Soil Quality Wageningen University and Research

Other members

Prof. Dr A.H. Velders - Wageningen University and Research

Prof. Dr A.P. Philipse - Utrecht University

Prof. Dr P.E. de Jongh - Utrecht University

Dr R.J.B. Peters - BU Contaminanten \& Toxines, Wageningen

This research was conducted under the auspices of the Graduate School for SocioEconomic and Natural Sciences of the Environment (SENSE) 


\section{Skimming the surface}

\section{A surface structural approach to understanding silver ion release from silver nanoparticles}

Bastiaan Molleman

\section{Thesis}

submitted in fulfilment of the requirements for the degree of doctor at Wageningen University

by the authority of the Rector Magnificus,

Prof. Dr A.P.J. Mol,

in the presence of the

Thesis Committee appointed by the Academic Board

to be defended in public

on Friday 11 October 2019

at 11 a.m. in the Aula 


\section{Bastiaan Molleman}

Skimming the Surface - A surface structural approach to understanding silver ion release from silver nanoparticles, 236 pages.

PhD thesis, Wageningen University, Wageningen, the Netherlands (2019)

With references, with summary in English

ISBN: 978-94-6395-072-5

DOI: $10.18174 / 497760$ 


\section{Abstract}

In the last decades, there has been an exponential increase in the number of publication on the topic of silver nanoparticles. However, little is yet understood about the fundamental processes that underlie the dissolution of silver nanoparticles, which one of the most significant aspects of silver nanoparticle behavior for both application and environmental health. This thesis constitutes a considerable advance towards closing that knowledge gap. A subvalent surface oxide structure is proposed consisting of a single layer of neutral $\equiv \mathrm{Ag}_{3} \mathrm{OH}$ units. When these surface become oxidized, ionic silver is released and a second surface layer is formed, with oxidation over multiple layers. An equilibrium is thought to exist between the two surface strucures, which stabilizes the silver nanoparticle from further oxidation. The subvalent $\equiv \mathrm{Ag}_{3} \mathrm{OH}$ structure is consistent with crystallographic data and computation modelling results. A surface complexation model is designed based on the proposed structure, which is tested and refined through a set of dissolution experiments in which the $\mathrm{pH}$ dependency of silver ion release is monitored for particles of different size. Both equilibrium concentrations and the kinetics of silver ion release are consistent with the model. Kinetic data additionally reveal a rate limiting step which is thought to involve the adsorption of molecular oxygen to the particle surface. Equilibrium data suggest the existence two oxidation processes: controlled, reversible oxidation at mildly oxidative conditions, and irreversible oxidation at more oxidative, i.e. acidic, conditions in which complete surface layers are stripped by lateral growth of critical cavities. Equilibrium data also reveal a size dependency which is us used to calculate a surface free energy value for silver nanoparticles covered by the subvalent surface layer. The importance of surface energy for silver nanoparticles, and indeed nanoparticles in general, is such that it warrants an in depth study of the topic, which is performed in the latter two research chapters of this thesis. A long standing controversy on the behaviour of surface energy at the extreme end of the nanoscale is tackled by applying the thermodynamic approach by Tolman to computational data. Using these data, the thermodynamically consistent surface, the surface of tension, is localized for metallic nanoparticles, and found to coincide with the physical surface. When scaled to the latter, surface energies are shown to vary minimally with size, as is also found when using the Tolman lengths that correspond to the physical surface. Lastly, the influence of edge and corner atoms on the stability and the surface energy of metallic nanoparticles is investigated. Using coordination numbers and surface densities of various atoms, a model is developed to which accurately describe the excess energy of nanoparticles with respect to bulk metal. The model can be directly applied to predict the energy of edge and corner atoms. Additionally, the model is used to isolate the energy of twinning from total particle energies as determined by computational modelling. The model is applied to predict the surface energy of the different crystallographic surfaces of various FCC metals, the relative stability of a variety of nanoparticle morphologies and the surface energy of metallic nanoparticles at room temperature. 



\section{Table of Contents}

Chapter 1

Chapter 2

Chapter 3

Chapter 4

Chapter 5

Chapter 6

Appendix A

Appencix B

Appendix C

Appendix D
General introduction

Surface structure of silver nanoparticles as model for understanding oxidative dissolution of silver ions

Time, $\mathrm{pH}$, and size dependency of silver nanoparticle dissolution: the road to equilibrium

Size and shape dependency of surface energy of metallic nanoparticles: Unifying the atomic and thermodynamic approach 75 Structural approach to surface energy of nanoparticles: Role of corners, edges, faces, crystal twinning, and internal strain 101

General discussion 129

Supporting information to Chapter 2 157

Supporting information to Chapter 3 171

Supporting information to Chapter 4 187

Supporting information to Chapter 5 205

Summary 225

List of publications 233 



\section{Chapter 1}

General introduction

Bastiaan Molleman 


\subsection{Preface}

This thesis has been a project within the risk analysis and technology assessment theme of the NanoNextNL research program. The aim of this research, as defined by the research program, was to gain an understanding environmental fate processes of inorganic manufactured nanoparticles. Being highly reactive, nanoparticles are expected to undergo a variety of changes in the environment, which will change their properties. Therefore, as part of the joint effort of understanding the influence of environmental release of nanoparticles, it is essential to not only study the effect of nanoparticles on the environment but also the effect of the environment on nanoparticles. Within the rather broad topic of inorganic nanoparticles, I have chosen to exclusively focus on silver nanoparticles, as their widespread use in consumer products and proven toxicity make them a highly relevant topic.

\subsection{A new class of materials}

In recent decades, there has been an ever increasing scientific interest in nanomaterials. As a result of the large amounts of money being invested into nano-research and some of the more well-marketed nano-applications, media attention and public awareness, too, have been on the rise. Nanomaterials can be surrounded by a somewhat mystical aura due to their unexpected, and sometimes baffling properties. Therefore, before zooming in on the actual topic of the thesis, I will first address the basic question: "What exactly are nanomaterials?"

Nanomaterials are officially defined as any material measuring less than $100 \mathrm{~nm}$ in one or more dimensions. This definition encompasses thin sheets and wires, but most prominently particles of a variety of shapes and sizes. Nanomaterials can be made from a variety of chemical substances, but most fall in one of the following three categories: organic nanomaterials, metal oxide nanomaterials, and metallic nanomaterials.

Nanotechnology has sometimes been portrayed as an entirely new field of science, and nanomaterials, as a result, have become associated with a certain sense of futurism. Yet the fact of the matter is that some types of nanoparticles have been around for a very long time. Iron oxide, for example, is present in all soils and has been isolated from soils in sizes as small as $2 \mathrm{~nm},{ }^{1}$ while soot contains small quantities of the famous Buckminster fullerenes. ${ }^{2}$ When discussing nanoparticles as an emerging contaminant, it is therefore common to also distinguish between these naturally occurring nanoparticles and man-made or engineered nanoparticles.

A common characteristic for all nanomaterials is their high specific surface area. This property is inversely related to particle size and can be up to hundreds of square meters per gram of material. The creation of surfaces requires an investment of energy, which means that nanomaterials have a higher energy than bulk materials, leading to a decreased intrinsic chemical stability. In addition, due to the high surface area, a large number of potential sites are available for surface interactions, such as adsorption. ${ }^{3}$ As a result, nanoparticles do not 
only have a high propensity to react with other substances, but also a very large interface on which to do so.

Beside a high surface area, nanomaterials, whether naturally occurring, engineered or incidental, can have additional properties that are not found in the bulk material from which they are derived. Some of these properties can be used in exciting new applications, such as self-cleaning surfaces with nano-titanium oxide, ${ }^{4}$ stronger than steel composites containing carbon nanotubes, ${ }^{5}$ or biosensors enhanced with metallic nanoparticles. ${ }^{6}$ However, these new properties also imply that nanoparticles may not interact with the environment as is expected based on their bulk counterparts. In relation to human and environmental safety, nanomaterials are therefore treated as new materials.

\subsection{Silver nanoparticles}

Silver nanoparticles can be produced using a variety of processes, where wet chemical synthesis offers the best control over shape and size. ${ }^{7,8}$ Generally speaking, silver ions are dissolved in an aqueous or liquid organic phase, and are subsequently reduced to zero-valent silver by addition of a reducing agent. Various reductants can be used, ranging from weakly reducing, e.g. glucose or citrate, to highly reducing, e.g. $\mathrm{NaBH}_{4}$.

Particle formation occurs through a process of nucleation, coalescence and growth. Initial oligomeric nuclei fuse together into tiny particles $(<1 \mathrm{~nm})$, which may grow by surface reduction or coalesce into larger polycrystalline particles. ${ }^{9}$ In principle, nucleation may continue after initially formed nuclei have started fusing and growing or coalescing, resulting in high polydispersity. Conversely, if the growth stage mainly takes place after completion of the nucleation stage, a more monodisperse collection of particles will be obtained. This will depend on the kinetics of the reactions at the different stages of particle synthesis, which can be controlled to a certain degree by choosing different concentrations and qualities of reductants and capping agents.

Coalescence of particles may be prevented by colloidal stabilization, which is done with the help of capping agents. These are generally organic molecules which attach to the surface and prevent collisions between nanoparticles either by introducing a surface charge, e.g. citrate, and/or by steric hindrance, e.g. PVP. This can be used to prevent or slow down coalescence during particle synthesis, leading to more monodisperse particle suspensions. Capping agents can additionally be used to block certain surfaces or alter surface energies. ${ }^{10}$ This promotes anisotropic growth leading to a variety of desirable shapes, such as rods, prisms, cubes, etcetera. This shape-control is of great importance for the various applications of silver nanoparticles. ${ }^{8}$ Finally, capping agents are used to ensure that particles in suspension do not stick together forming aggregates.

In science, silver nanoparticles are frequently used for their optical properties. Due to their small size, light of a specific wavelength can induce an oscillation of electrons in the 
nanoparticles, leading to absorption of light of that wavelength. ${ }^{11}$ This phenomenon is referred to as plasmon resonance, and the wavelength of maximum absorption $\lambda_{\max }$ changes with particle size and shape, as well as the medium surrounding the particle. ${ }^{12}$ The excitation of electrons by light can be used in applications such as photocatalysis ${ }^{13,14}$ or tissue imaging. ${ }^{15}$

Another promising application of AgNPs is catalysis. Silver in the microscopic form is widely applied for the oxidation of methanol to formaldehyde. ${ }^{16}$ More recently, it has been found that AgNPs have good yields in the catalytic reduction of $p$-nitrophenol, ${ }^{17,18}$ an intermediate in the synthesis of paracetamol.

Silver nanoparticles further find application in surface enhanced Raman spectroscopy, ${ }^{19}$ which is used to detect biomolecules in extremely low concentrations. For this application, a high surface area is of the essence, as it creates more hotspots, which greatly enhances detection limits. The shape of particles is thought to control the effective spectral range. ${ }^{7}$

Additionally extensive research is done in using silver nanoparticles as carriers for anticancer treatment, ${ }^{20,21}$ though the unknown interaction of these particles with the human body may prevent such technologies from ever seeing clinical use. ${ }^{22}$

\subsection{Silver nanoparticle toxicity}

As indicated above, silver nanoparticles have a wide range of useful applications, however, they are best known to the general public for their antibacterial functioning. Because of this, they are used in clothing, ${ }^{23,}{ }^{24}$ household appliances ${ }^{25}$ and cosmetics, but also in bandages, ${ }^{26}$ wound dressings, and prosthetic implants. ${ }^{27-29}$

Presence of silver nanoparticles has been shown to inhibit growth of a wide range of bacteria. ${ }^{30}$ Moreover, negative effects have also been registered for soil fauna, such as earthworms $^{31,32}$ and nematodes, ${ }^{33}$ plants, and aquatic organisms, such as daphnids ${ }^{34,35}$ and zebrafish. $^{36,37}$ The concentrations at which AgNPs exhibit toxicity varies widely between organisms and medium, with reported $\mathrm{LC}_{50}$ values of $0.4 \mu \mathrm{g} \mathrm{L}^{-1}$ for daphnids $\mathrm{s}^{34,35}$ to $84 \mu \mathrm{g} \mathrm{\textrm {L } ^ { - 1 }}$ for zebrafish, ${ }^{37}$ and whereas for earthworms a soil loading of $700 \mathrm{mg} \mathrm{kg}^{-1}$ was required to see negative effects. ${ }^{31,32}$ At present, predicted environmental concentrations of AgNPs are extremely low, and acute toxicity is not expected. ${ }^{38}$ However, as the effects of chronic exposure are poorly documented, environmental risk cannot be excluded. Moreover, continued environmental release will lead to higher environmental concentrations in the future.

The mechanism of toxicity is still disputed, but convincing evidence exists to suggest that the release of $\mathrm{Ag}^{+}$ions is the main driver for antimicrobial effects. In a detailed toxicological study, Shen et al. ${ }^{34}$ showed that the same silver ion concentrations were present at the different $\mathrm{LC}_{50}$ values for daphnids found for variously sized AgNPs. Xiu et al. ${ }^{39}$ demonstrated that the toxic effects of AgNPs to E. coli were completely absent if oxygen was excluded, suppressing $\mathrm{Ag}^{+}$ 
release. However, Yin et al. ${ }^{40}$ found that silver nanoparticles inhibited growth of ryegrass more strongly than $\mathrm{AgNO}_{3}$ when added at similar concentrations. Moreover, when cysteine was added, the toxicity of $\mathrm{AgNO}_{3}$ was negated while the effect of AgNP did not change. Various reasons have been suggested for these differences, such as the production of radical oxygen species, and adsorption of AgNPs to the root surface. The close proximity to the cell-wall could lead to increased release of $\mathrm{Ag}^{+}$due to root exudates, and to a lower $\mathrm{Ag}^{+}$-complexation by cysteine due to immediate binding to biotic ligands and absorption into the cell after release. These results demonstrate that AgNP toxicity is a complex problem with many unanswered questions. However, there is no doubt that $\mathrm{Ag}^{+}$release, whether it occurs in solution, on the cell-surface, or inside the cell, is one of the central aspects of AgNP toxicity.

\subsection{Environmental fate of silver nanoparticles}

If silver nanoparticles are released from consumer products, such as various antibacterial fabrics ${ }^{23,41}$ and cosmetics, ${ }^{42}$ they will end up in wastewater systems. It has been demonstrated that silver nanoparticles are efficiently (>99\%) removed from wastewater. ${ }^{43}$ Nanoparticles find their way into the environment when the nutrient-rich sludge is applied to soils. ${ }^{44}$

Once silver nanoparticles end up in the environment, they can undergo a large number of physical and chemical transformations. Strong aggregation is observed when AgNPs are added to soil extracts, ${ }^{45}$ but this may be less important at environmentally relevant AgNP concentrations. AgNPs can adsorb organic matter, forming large flocs, ${ }^{46}$ and there is strong evidence suggesting AgNPs have a high affinity for clay particles. ${ }^{45}$ These processes suggest that mobility of AgNPs in soils could be severely limited, leading to accumulation.

In the presence of sulfide, AgNPs may partly transform into $\mathrm{Ag}_{2} \mathrm{~S}^{47}$ This is observed in sewage sludge, but may also be relevant in strongly reduced soils. If the free $\mathrm{Ag}^{+}$concentrations are controlled by equilibrium with $\mathrm{Ag}_{2} \mathrm{~S}$, which is highly insoluble, barely perceptible levels are expected. Nevertheless, inhibition of microbial activity has been recorded in soils amended with nearly fully sulfidized AgNPs. ${ }^{48}$ Presence of chloride may lead to the precipitation of solid $\mathrm{AgCl}$. However, at predicted environmental concentrations of AgNPs found by emission modeling, ${ }^{38}$ i.e. less than $1 \mathrm{ng} \mathrm{L^{-1 }}$ for surface water, and between 0.1 and $1 \mu \mathrm{g} \mathrm{kg}^{-1}$ for soil, solid $\mathrm{AgCl}$ will not be formed.

Presence of organic matter may lead to complexation of dissolved silver, lowering free concentrations of the highly toxic silver(I) ion. Moreover, ionic silver may be reduced and reprecipitated to form silver nanoparticles. ${ }^{49}$ The latter has been observed in presence of oxygen and at room temperature, and may thus occur if ionic silver is present in the environment.

A final transformation, which can be expected to occur under aerobic conditions is the dissolution of AgNPs with release of $\mathrm{Ag}^{+}$. It is generally observed that $\mathrm{Ag}^{+}$is released from AgNPs in presence of dissolved oxygen. This topic has been widely studied ${ }^{50-59}$ but little insight 


\section{Chapter 1}

into the mechanisms of $\mathrm{Ag}^{+}$release has been generated. Given the toxicological evidence briefly touched upon above, it is imperative for our understanding of the environmental impact of AgNPs that we learn more about the process in which the toxic silver ions are released.

\subsection{Objectives}

Silver ion release has been studied to a certain degree, but the mechanism of release is poorly understood. In principle, metallic silver may react with dissolved oxygen according to:

$$
\mathrm{Ag}^{0}(\mathrm{~s})+1 / 4 \mathrm{O}_{2}(\mathrm{aq})+\mathrm{H}^{+}(\mathrm{aq}) \Leftrightarrow \mathrm{Ag}^{+}(\mathrm{aq})+1 / 2 \mathrm{H}_{2} \mathrm{O}(\mathrm{l})
$$

This reaction has an equilibrium constant of $\log K=7.98^{60}$ implying that in aqueous systems open to ambient air, concentrations in the range of $1 \mathrm{~mol} \mathrm{~L}^{-1}$ of ionic silver are expected at circumneutral $\mathrm{pH}$. This is in striking contrast to literature data for AgNP dissolution, which universally show that, after an initial stage of fast dissolution, $\mathrm{Ag}^{+}$concentrations stabilize, long before the equilibrium condition of the above reaction is reached. ${ }^{50,51,55,56,58,61}$

Dissolution comes to a halt before reactants are used up or full thermodynamic equilibrium is reached, which implies that oxygen may be prevented from reacting with the metallic silver. It has been suggested in literature that formation of an oxide layer could be responsible for this passivation of the AgNP surface. However, regular silver oxide $\mathrm{Ag}_{2} \mathrm{O}$ is not a likely candidate. The dissolution reaction of regular silver oxide:

$$
1 / 2 \mathrm{Ag}_{2} \mathrm{O}(\mathrm{s})+\mathrm{H}^{+}(\mathrm{aq}) \Leftrightarrow \mathrm{Ag}^{+}(\mathrm{aq})+1 / 2 \mathrm{H}_{2} \mathrm{O}(\mathrm{l})
$$

has an equilibrium constant of $\log K=6.30,62$ leading to an equilibrium concentration for $\mathrm{Ag}^{+}$ in the order of $1 \mathrm{~mol} \mathrm{~L}^{-1}$ at circumneutral $\mathrm{pH}$. It implies that regular silver oxide cannot be expected to form a stable surface oxide at the experimental conditions where dissolution of AgNPs is slowed down and a stable $\mathrm{Ag}^{+}$concentration is attained. It is clear therefore, that if a passivating surface layer is present, it must be of a different nature. The identification of the nature of this surface layer is one of the most important challenges in understanding the dissolution of silver nanoparticles, and will be one of the main objectives of this thesis (Chapter 2).

In addition to identifying the nature of the surface of silver nanoparticles, the amount of silver ions that are released is a topic of interest. As discussed above, the release of ionic silver plays a major role in the antibacterial and general toxic effects of silver nanoparticles. Therefore, the environmental impact of silver nanoparticles will, to a large extent, depend on the amount of $\mathrm{Ag}^{+}$that is released into the environment. However, the reported concentrations of ionic silver after stabilization of the AgNP dissolution vary widely between different literature sources. ${ }^{51,52,55,56,58}$ While certain trends have been observed, such as a higher release at low 
$\mathrm{pH}^{50}$ there is no mechanistic and quantitative understanding of $\mathrm{Ag}^{+}$release from $\mathrm{AgNPs}$ in literature.

The dissolution of AgNPs has every appearance of reaching an equilibrium state. In presence of a passivating layer, it follows that this layer is one of the components of the $\mathrm{Ag}^{+}$release reaction and equilibration. Based on the nature of the surface, to be studied in this thesis, a reaction mechanism for the release of ionic silver, will be formulated. Based on the defined reaction, a thermodynamic model will be developed, which will be parameterized through a series of experiments (Chapter 3 ).

It is generally believed that smaller particles lead to higher equilibrium concentrations of $\mathrm{Ag}^{+}$. These higher $\mathrm{Ag}^{+}$concentrations have been linked to the concept of surface energy. ${ }^{53}$ While this is intuitively correct, it has so far remained unclear to which equilibrium condition the surface energy must be applied. The size dependency of silver ion release from silver nanoparticles will be investigated in this work. Using the thermodynamic model for the release of ionic silver, the development of which is one of the objectives of this thesis, the influence of surface energy can be described in a theoretically consistent framework and the value of surface energy of AgNP in aqueous solutions at ambient conditions can be evaluated (Chapter 3).

As mentioned above, surface energy is critical for our understanding of $\mathrm{Ag}^{+}$release. Surface energy leads to a size-dependency of the chemical stability and therefore of the dissolution reaction of AgNPs, but the property of surface energy may in itself be size dependent. In the literature, a higher surface free energy has been reported in nanoparticles, compared to the bulk. ${ }^{63}$ Moreover, data calculated by computational methods also indicate that surface energy increases at smaller size. ${ }^{64,65}$ However, the thermodynamic work of Tolman ${ }^{66-68}$ is often cited to point out that, in fact, a lower (!) surface energy is expected at the nanoscale. This issue may have important consequences for the expected release of $\mathrm{Ag}^{+}$from $\mathrm{AgNPs}$ and for the stability of nanoparticles in general. However, no satisfactory explanation has been proposed for the apparent contradiction between classical thermodynamics and computational chemistry. This topic will be treated in depth, critically evaluating all aspects of experimental and computational results, as well as the application of Tolman's theories to metallic nanoparticles (Chapter 4).

Silver nanoparticles and other metallic nanoparticles are often faceted, and the different facets have different surface energies, ${ }^{69,70,72}$ leading to a different overall surface energy and thus a different size-dependency of stability and $\mathrm{Ag}^{+}$release. In addition to the surface energy of facets, which is related to the atomic surface structure and the number of bonds on the surface atoms, ${ }^{71}$ a different energy contribution of edge and corner atoms is expected. It is suggested that this may lead to a higher surface energy in very small nanoparticles, as the fraction of edge and corner atoms on the surface increases at decreasing size. ${ }^{65}$ Additionally, internal restructuring, particularly so-called crystal twinning, can also lead to higher particle energy.$^{73}$ While the surface energy of the surface facets has been extensively calculated with 
computational methods, ${ }^{69,70,72,74-76}$ no data are available for the energy of edge and corner atoms, or for the energy cost of twinning. However, these energy contributions are central to the total energy and the stability of nanoparticles and this information is thus of great importance for a detailed understanding of how $\mathrm{Ag}^{+}$release may vary for AgNPs of different shapes and sizes. Therefore, the different contributions to the energy of nanoparticles will be investigated, aiming to develop a model for the total energy of nanoparticles (Chapter 5).

The above research objectives are intended to contribute to fundamental insights into the essential process of silver ion release from silver nanoparticles and a deeper understanding of the stability of silver nanoparticles in the environment.

\subsection{References}

1. I. C. Regelink, L. Weng, G. F. Koopmans and W. H. Van Riemsdijk, Geoderma, 2013, 202, 134-141.

2. J. B. Howard, J. T. McKinnon, Y. Makarovsky, A. L. Lafleur and M. E. Johnson, Nature, 1991, 352, 139.

3. T. Hiemstra and W. Zhao, Environmental Science: Nano, 2016, 3, 1265-1279.

4. E. Quagliarini, F. Bondioli, G. B. Goffredo, C. Cordoni and P. Munafò, Construction and Building Materials, 2012, 37, 51-57.

5. E. T. Thostenson, Z. Ren and T.-W. Chou, Composites science and technology, 2001, 61, 1899-1912.

6. Y. Li, H. J. Schluesener and S. Xu, Gold Bulletin, 2010, 43, 29-41.

7. B. Wiley, Y. Sun, B. Mayers and Y. Xia, Chem. Eur. J., 2005, 11, 454-463.

8. Z. Wu, S. Yang and W. Wu, Nanoscale, 2016, 8, 1237-1259.

9. A. Henglein and M. Giersig, The Journal of Physical Chemistry B, 1999, 103, 9533-9539.

10. P. Liu, R. Qin, G. Fu and N. Zheng, Journal of the American Chemical Society, 2017, 139, 2122-2131.

11. S. Eustis and M. A. El-Sayed, Chemical Society Reviews, 2006, 35, 209-217.

12. A. González, C. Noguez, J. Beránek and A. Barnard, The Journal of Physical Chemistry C, 2014, 118, 9128-9136.

13. H. Yang, Z. H. Wang, Y. Y. Zheng, L. Q. He, C. Zhan, X. Lu, Z. Q. Tian, P. P. Fang and Y. Tong, Journal of the American Chemical Society, 2016, 138, 16204-16207.

14. W. H. Hung, M. Aykol, D. Valley, W. Hou and S. B. Cronin, Nano letters, 2010, 10, 13141318.

15. A. M. Syed, S. Sindhwani, S. Wilhelm, B. R. Kingston, D. S. W. Lee, J. L. Gommerman and W. C. W. Chan, Journal of the American Chemical Society, 2017, 139, 9961-9971.

16. I. E. Wachs and R. J. Madix, Surface Science, 1978, 76, 531-558.

17. S. Saha, A. Pal, S. Kundu, S. Basu and T. Pal, Langmuir, 2010, 26, 2885-2893.

18. A. M. Signori, K. d. O. Santos, R. Eising, B. L. Albuquerque, F. C. Giacomelli and J. B. Domingos, Langmuir, 2010, 26, 17772-17779.

19. Y. Yang, S. Matsubara, L. Xiong, T. Hayakawa and M. Nogami, The Journal of Physical Chemistry C, 2007, 111, 9095-9104.

20. M. I. Sriram, S. B. M. Kanth, K. Kalishwaralal and S. Gurunathan, International Journal of Nanomedicine, 2010, 5, 753-762. 
21. M. Jeyaraj, G. Sathishkumar, G. Sivanandhan, D. MubarakAli, M. Rajesh, R. Arun, G. Kapildev, M. Manickavasagam, N. Thajuddin, K. Premkumar and A. Ganapathi, Colloids and Surfaces B: Biointerfaces, 2013, 106, 86-92.

22. G. Vaz, personal communication.

23. T. M. Benn and P. Westerhoff, Environ. Sci. Technol., 2008, 42, 4133-4139.

24. T. Walser, E. Demou, D. J. Lang and S. Hellweg, Environ. Sci. Technol., 2011, 45, 45704578.

25. J. Farkas, H. Peter, P. Christian, J. A. G. Urrea, M. Hassellöv, J. Tuoriniemi, S. Gustafsson, E. Olsson, K. Hylland and K. V. Thomas, Environment international, 2011, 37, 1057-1062.

26. L. Pourzahedi and M. J. Eckelman, Environ. Sci. Technol., 2014, 49, 361-368.

27. J. Gallo, A. Panacek, R. Prucek, E. Kriegova, S. Hradilova, M. Hobza and M. Holinka, Materials, 2016, 9, 337.

28. A. Shivaram, S. Bose and A. Bandyopadhyay, Acta biomaterialia, 2017, 58, 550-560.

29. E. Alarcon, B. Vulesevic, A. Argawal, A. Ross, P. Bejjani, J. Podrebarac, R. Ravichandran, J. Phopase, E. Suuronen and M. Griffith, Nanoscale, 2016, 8, 6484-6489.

30. S. Chernousova and M. Epple, Angewandte Chemie International Edition, 2013, 52, 1636-1653.

31. M. J. C. van der Ploeg, R. D. Handy, P. L. Waalewijn-Kool, J. H. J. van den Berg, Z. E. Herrera Rivera, J. Bovenschen, B. Molleman, J. M. Baveco, P. Tromp, R. J. B. Peters, G. F. Koopmans, I. M. C. M. Rietjens and N. W. van den Brink, Environmental Toxicology and Chemistry, 2014, 33, 743-752.

32. W. A. Shoults-Wilson, B. C. Reinsch, O. V. Tsyusko, P. M. Bertsch, G. V. Lowry and J. M. Unrine, Nanotoxicology, 2011, 5, 432-444.

33. X. Yang, A. P. Gondikas, S. M. Marinakos, M. Auffan, J. Liu, H. Hsu-Kim and J. N. Meyer, Environ. Sci. Technol., 2011, 46, 1119-1127.

34. M. H. Shen, X. X. Zhou, X. Y. Yang, J. B. Chao, R. Liu and J. F. Liu, Scientific Reports, 2015, $5,9674$.

35. H. C. Poynton, J. M. Lazorchak, C. A. Impellitteri, B. J. Blalock, K. Rogers, H. J. Allen, A. Loguinov, J. L. Heckman and S. Govindasmawy, Environ. Sci. Technol., 2012, 46, 62886296.

36. S. Böhme, H. J. Stärk, T. Reemtsma and D. Kühnel, Environmental Science: Nano, 2015, 2, 603-614.

37. K. Bilberg, M. B. Hovgaard, F. Besenbacher and E. Baatrup, Journal of toxicology, 2012, 2012.

38. T. Y. Sun, F. Gottschalk, K. Hungerbühler and B. Nowack, Environmental Pollution, 2014, $185,69-76$

39. Z. M. Xiu, Q. B. Zhang, H. L. Puppala, V. L. Colvin and P. J. J. Alvarez, Nano Letters, 2012, $12,4271-4275$.

40. L. Yin, Y. Cheng, B. Espinasse, B. P. Colman, M. Auffan, M. Wiesner, J. Rose, J. Liu and E.

S. Bernhardt, Environ. Sci. Technol., 2011, 45, 2360-2367.

41. N. S. Tulve, A. B. Stefaniak, M. E. Vance, K. Rogers, S. Mwilu, R. F. LeBouf, D. SchweglerBerry, R. Willis, T. A. Thomas and L. C. Marr, International journal of hygiene and environmental health, 2015, 218, 345-357.

42. M. E. Vance, T. Kuiken, E. P. Vejerano, S. P. McGinnis, M. F. Hochella Jr, D. Rejeski and M. S. Hull, Beilstein Journal of Nanotechnology, 2015, 6, 1769-1780.

43. R. Kaegi, A. Voegelin, C. Ort, B. Sinnet, B. Thalmann, J. Krismer, H. Hagendorfer, M. Elumelu and E. Mueller, Water Research, 2013, 47, 3866-3877. 
44. N. C. Mueller and B. Nowack, Environ. Sci. Technol., 2008, 42, 4447-4453.

45. G. Koopmans, T. Hiemstra, I. Regelink, B. Molleman and R. Comans, Journal of Chromatography A, 2015, 1392, 100-109.

46. S. Klitzke, G. Metreveli, A. Peters, G. E. Schaumann and F. Lang, Science of the Total Environment, 2015, 535, 54-60.

47. C. Levard, B. C. Reinsch, F. M. Michel, C. Oumahi, G. V. Lowry and G. E. Brown Jr., Environ. Sci. Technol., 2011, 45, 5260-5266.

48. M. Kraas, K. Schlich, B. Knopf, F. Wege, R. Kägi, K. Terytze and K. Hund-Rinke, Environmental Toxicology and Chemistry, 2017, 36, 3305-3313.

49. N. Akaighe, R. I. MacCuspie, D. A. Navarro, D. S. Aga, S. Banerjee, M. Sohn and V. K. Sharma, Environ. Sci. Technol., 2011, 45, 3895-3901.

50. J. Liu and R. H. Hurt, Environ. Sci. Technol., 2010, 44, 2169-2175.

51. S. Kittler, C. Greulich, J. Diendorf, M. Köller and M. Epple, Chemistry of Materials, 2010, 22, 4548-4554.

52. W. Zhang, Y. Yao, N. Sullivan and Y. Chen, Environ. Sci. Technol., 2011, 45, 4422-4428.

53. R. Ma, C. m. Levard, S. M. Marinakos, Y. Cheng, J. Liu, F. M. Michel, G. E. Brown Jr. and G. V. Lowry, Environ. Sci. Technol., 2012, 46, 752-759.

54. G. A. Sotiriou, A. Meyer, J. T. N. Knijnenburg, S. Panke and S. E. Pratsinis, Langmuir, 2012, 28, 15929-15936.

55. A. M. Mittelman, A. Taghavy, Y. Wang, L. M. Abriola and K. D. Pennell, Journal of Nanoparticle Research, 2013, 15, 1765.

56. K. Loza, J. Diendorf, C. Sengstock, L. Ruiz-Gonzalez, J. M. Gonzalez-Calbet, M. Vallet-Regi, M. Köller and M. Epple, Journal of Materials Chemistry B, 2014, 2, 1634-1643.

57. D. M. Mitrano, J. F. Ranville, A. Bednar, K. Kazor, A. S. Hering and C. P. Higgins, Environmental Science: Nano, 2014, 1, 248-259.

58. T. S. Peretyazhko, Q. Zhang and V. L. Colvin, Environ. Sci. Technol., 2014, 48, 1195411961.

59. Z. Adamczyk, M. Oćwieja, H. Mrowiec, S. Walas and D. Lupa, Journal of Colloid and Interface Science, 2016, 469, 355-364.

60. W. M. Haynes, T. J. Bruno and D. R. Lide, CRC Handbook of chemistry and physics, CRC press, [Boca Raton, FL], 2014.

61. J. Liu, D. A. Sonshine, S. Shervani and R. H. Hurt, ACS Nano, 2010, 4, 6903-6913.

62. L. Duro, M. Grivé, E. Cera, C. Domènech and J. Bruno, Update of a thermodynamic database for radionuclides to assist solubility limits calculation for performance assessment, 2006.

63. K. Nanda, A. Maisels, F. Kruis, H. Fissan and S. Stappert, Physical Review Letters, 2003, 91, 106102.

64. B. Medasani, Y. H. Park and I. Vasiliev, Physical Review B, 2007, 75, 235436.

65. S. Ali, V. S. Myasnichenko and E. C. Neyts, Physical Chemistry Chemical Physics, 2016, 18, 792-800.

66. R. C. Tolman, The journal of chemical physics, 1948, 16, 758-774.

67. R. C. Tolman, The journal of chemical physics, 1949, 17, 333-337.

68. R. C. Tolman, The journal of chemical physics, 1949, 17, 118-127.

69. I. Galanakis, G. Bihlmayer, V. Bellini, N. Papanikolaou, R. Zeller, S. Blügel and P. Dederichs, EPL (Europhysics Letters), 2002, 58, 751.

70. R. Tran, Z. Xu, D. W. Balachandran Radhakrishnan, W. Sun, K. A. Persson and S. P. Ong, Scientific Data, 2016, 3. 
71. M. Methfessel, D. Hennig and M. Scheffler, Applied Physics A, 1992, 55, 442-448.

72. N. E. Singh-Miller and N. Marzari, Physical Review B, 2009, 80, 235407.

73. A. Barnard, The Journal of Physical Chemistry B, 2006, 110, 24498-24504.

74. A. Patra, J. E. Bates, J. Sun and J. P. Perdew, Proceedings of the National Academy of Sciences, 2017, 201713320.

75. L. Vega, J. Ruvireta, F. Viñes and F. Illas, Journal of chemical theory and computation, 2018, 14, 395-403.

76. J. Wang and S.-Q. Wang, Surface Science, 2014, 630, 216-224. 



\section{Chapter 2}

Surface structure of silver nanoparticles as model for understanding oxidative dissolution of silver ions

Bastiaan Molleman and Tjisse Hiemstra 


\section{Abstract}

Toxicity of silver nanoparticles (AgNP) has been related to the release of ionic silver. This process is influenced by a large variety of factors and is poorly understood. Key for understanding $\mathrm{Ag}^{+}$-release by AgNP is subvalency. This is a fundamental property of $\mathrm{Ag}$ that can be elucidated by analyzing the crystal structures of a specific class of Ag materials as well as MO/DFT optimized $\mathrm{Ag}_{13}(\mathrm{OH})_{4}$ clusters, being precursors of AgNP. Semi-metallic silver at the [111] faces of $\mathrm{AgNP}$ has a subvalency of $+1 / 3$ v.u., forming $\equiv \mathrm{Ag}_{3} \mathrm{OH}^{\circ}$ surface groups with a maximum site density of $4.7 \mathrm{~nm}^{-2}$. Oxidative dissolution may remove these groups with simultaneous formation of oxygen radicals that may further interact with the surface via different pathways. Reactive oxygen species (ROS) can create a circular process with dissolution of $\equiv \mathrm{Ag}_{3} \mathrm{OH}^{0}$, exposure of new metallic sites at the underlying lattice, and subsequent oxidation to $\equiv \mathrm{Ag}_{3} \mathrm{OH}^{0}$. This regeneration process is interrupted by penetration of $\mathrm{O}$ • radicals into the lattice forming highly stable $\mathrm{Ag}_{6} \mathrm{O}$ octahedra with subvalent silver that protects AgNP from further oxidation. A thermodynamic model has been developed that quantitatively describes the equilibrium condition between $\equiv \mathrm{Ag}_{3} \mathrm{OH}^{0}$ and $\equiv \mathrm{Ag}_{6} \mathrm{O}$ and explains a large variety of collectively observed phenomena. 


\subsection{Introduction}

\subsubsection{Silver nanoparticles}

Nanotechnology is a rapidly developing field generating great interest from both the scientific and the industrial community. Nanoparticles (NP) are extremely small leading to a very high surface area per unit mass, and thus to a high fraction of surface atoms with specific properties contributing to surface Gibbs free energy. ${ }^{1}$ Nanoparticles create reactivity at low inputs of natural resources, which is increasingly important in today's society and economy.

Classically, silver has been used as catalyst in chemical processes, ${ }^{2-6}$ but currently, silver is most widely applied as nanoparticles (AgNP) in consumer products ${ }^{7}$ serving as an antimicrobial agent. AgNP are used in textiles, cosmetics, paints, and a variety of household applications. It has been shown on multiple occasions, that AgNP may become disentangled from their product matrices, ${ }^{8,9}$ which contributes to their spreading in the environment.

AgNP have been shown to inhibit growth of microorganisms ${ }^{10-13}$ and are potentially harmful to a wide variety of soil biota, ${ }^{14-16}$, to plants, ${ }^{17}$ and to aquatic organisms. ${ }^{18,}{ }^{19}$ Although the mechanisms of AgNP toxicity are not yet fully understood, there are strong indications that the release of ionic silver $\left(\mathrm{Ag}^{+}\right)$is a highly relevant factor in this respect ${ }^{20,21}$ and that formation of reactive oxygen species (ROS) may play a role in this.

\subsubsection{Silver ion release}

Upon dilution of AgNP suspensions, release of silver ions is commonly observed. One process, which may lead to release of $\mathrm{Ag}^{+}$in aerated systems, is oxidative dissolution:

$\mathrm{Ag}^{0}(\mathrm{~s})+1 / 4 \mathrm{O}_{2}(\mathrm{aq})+\mathrm{H}^{+}(\mathrm{aq}) \Leftrightarrow \mathrm{Ag}^{+}(\mathrm{aq})+1 / 2 \mathrm{H}_{2} \mathrm{O}(\mathrm{l})$

This reaction is highly exergonic, and it can be shown thermodynamically that AgNP will fully oxidize at atmospheric oxygen pressures. ${ }^{22}$ Astonishingly, ${ }^{23}$ however, this is usually not at all observed.

Published data on oxidative dissolution of AgNP almost invariable show that, initially, $\mathrm{Ag}^{+}-$ release is fast and solution concentrations increase rapidly. ${ }^{24-28}$ However, the process gradually slows down and $\mathrm{Ag}^{+}$-concentrations stabilize before complete dissolution of AgNP. ${ }^{24,26-28}$ As shown in Figure $\mathrm{A} 1$, the $\mathrm{Ag}^{+}$-concentrations may then remain constant for months. ${ }^{24,26}$

Stabilization times as well as the concentration levels of $\mathrm{Ag}^{+}$vary widely between and within various AgNP studies. Release may slow down and stop within minutes, ${ }^{27}$ or after much longer times of reaction ranging from several days ${ }^{28}$ up to even some months. ${ }^{24}$ Ion release from AgNP is reported to stabilize at concentrations ranging from less than a micromolar ${ }^{26,28,29}$ up to almost a millimolar. ${ }^{27}$ As these data were collected for $\mathrm{pH} \leq 8$ and in absence of complexing 
agents (e.g. $\mathrm{Cl}^{-}$or $\mathrm{S}^{2-}$ ), no equilibrium with any known silver precipitate can explain stabilization of the recorded concentrations.

Both the initial rate of release and the concentration level reached may strongly vary, depending on experimental conditions and nanoparticle properties. The rate of release is shown to change with particle size ${ }^{28}$ and aggregation ${ }^{30-32}$ and is strongly influenced by $\mathrm{pH}^{22}$ $\mathrm{Ag}^{+}$-concentrations that are ultimately reached vary with particle size, ${ }^{26-29,33}$ capping agent, ${ }^{24,}$ ${ }^{33}$ applied solid-solution ratio, ${ }^{24,} 28$ acidity, ${ }^{26}$ and pre-treatments such as reduction with $\mathrm{H}_{2}$-gas or application of a washing procedure. ${ }^{27}$ In addition, the dissolution is strongly enhanced in the presence of $\mathrm{H}_{2} \mathrm{O}_{2}$ as oxidator. ${ }^{22,23,34,35}$

A large variety of explanations have been put forward to rationalize observed behaviors, but to date no articulated, structural and mechanistic view exists on the underlying processes. Peretyazhko et al. ${ }^{26}$ suggested that the rate of release may slow down because of stabilization by capping agents or by $\mathrm{Ag}^{+}$-adsorption. Higher $\mathrm{Ag}^{+}$-concentrations at acid conditions have been linked to a supposed destabilization of surface oxides. ${ }^{26}$ Another suggestion is that solubility is just an intrinsic AgNP property that is not governed by solution conditions. ${ }^{24}$ Furthermore, it has been proposed that the particle size dependency of the AgNP solubility is controlled by surface tension. ${ }^{29}$ However, a reasonable reaction mechanism remains unspecified.

The above rationales are fragmentary and no coherent picture is yet available. In the present study, the goal is to develop a mechanistic framework and quantitative approach that is able to understand and describe the landscape of observations presented in literature in an integrative manner. Therefore, a structural view on the surface of AgNP is needed.

\subsubsection{AgNP surface}

Metallic Ag surfaces may interact with oxygen as observed with spectroscopy. ${ }^{6,36}$ In Ag-melts, this interaction may decrease the surface tension of the liquid-gas interface as a function of the partial pressure of oxygen gas. ${ }^{37}$ For the solid-gas interface of AgNP, a continuum of oxidic surface structures may form. ${ }^{36}$ For the solid-water interface, it has been suggested that dissolution of a Ag-oxide coating could be responsible for $\mathrm{Ag}^{+}$-release from AgNP. ${ }^{38}$ The amounts may be equivalent to 1-2 monolayers of $\mathrm{Ag}_{2} \mathrm{O}$, as it was called. ${ }^{27}$

Conceptually, dissolution of $\mathrm{Ag}_{2} \mathrm{O}$ is completely independent from the presence of oxygen gas. However, it has been shown ${ }^{21-23,39}$ that $\mathrm{Ag}^{+}$-release can be strongly diminished if dissolved oxygen gas is excluded in experiments (as illustrated later in Figure 2.6a). It suggests that the presence of oxygen is essential for $\mathrm{Ag}^{+}$-release and gives credit to supplemental oxidation as part of the process of $\mathrm{Ag}^{+}$-release from $\mathrm{AgNP}$ rather than dissolution of $\mathrm{Ag}_{2} \mathrm{O}$, exclusively.

It is evident that for improving our understanding more insight is needed in the structure of AgNP surfaces, and how structure is related to the nature of processes of $\mathrm{Ag}^{+}$-release. In the next section, we will explore what can be learned from the crystal structures of various Ag- 
oxide materials, creating a molecular view on the AgNP-water interface (Section 3). The analysis will be used for developing a mechanistic model for understanding AgNP reactivity in a coherent manner (Section 4), which will be applied in Section 5.

\subsection{Crystal structures of silver and silver compounds}

The formal oxidation states of silver in solids can be given as $0, \mathrm{I}, \mathrm{II}$, and III (supporting information). At atmospheric conditions, the most common oxidation state of silver is I, which is found in well-known minerals, such as $\mathrm{Ag}_{2} \mathrm{O}(\mathrm{s}), \mathrm{AgCl}(\mathrm{s})$, and $\mathrm{Ag}_{2} \mathrm{~S}(\mathrm{~s})$. At high oxygen pressures, solids with higher oxidation states (II, III) can be formed, whereas metallic silver is only thermodynamically stable in absence of oxygen, i.e. at conditions of chemical reduction.

\subsubsection{Structure of metallic silver}

Metallic silver has a face-centered cubic (FCC) crystal structure with Ag-Ag distances of 288 pm. ${ }^{40-42}$ FCC structures are commonly seen in many noble metals, for instance Au and Pt. ${ }^{40}$

FCC lattices are bounded by low index crystal planes such as the (100) and [111] faces that have high atom densities. The [111] face has the highest metal density (14 $\left.\mathrm{Ag} \mathrm{nm}^{-2}\right)$ and the lowest surface tension, ${ }^{43}$ i.e. it is the most stable face of the $\mathrm{Ag}$ metal. The structure of the [111] face of Ag is shown in Figure 2.1a as a collection of empty octahedra with $\mathrm{Ag}$ atoms at the corners. Due to its low surface tension, the [111] face may be expected to be the dominant surface in nanoparticles.

Well-structured, spheroidal AgNP are reported to have either a cuboctahedral or an icosahedral morphology. ${ }^{44}$ Cuboctahedral AgNP are singly crystalline, whereas icosahedral AgNP may form due to five-fold twinning, which is a common lattice rearrangement for $\mathrm{AgNP}^{44}$ as well as other metallic nanoparticles. ${ }^{45}$ Cuboctahedra have both the (100) and the [111] face (Figure A2), but the [111] face is dominant; icosahedral AgNP are bounded by [111] faces only (Figure A2). 

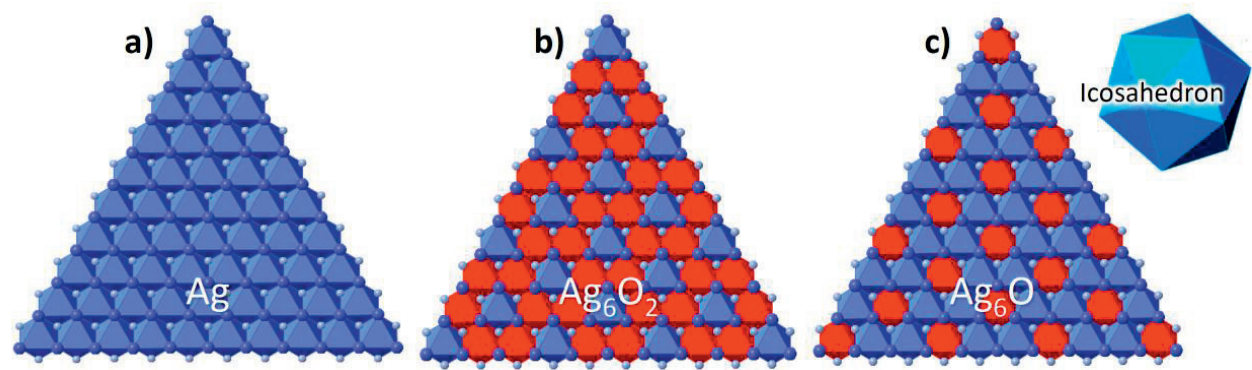

Figure 2.1 Icosahedron of metallic Ag bounded by twenty [111] faces. (a) Schematic atomic arrangement at the [111] face of metallic $\mathrm{Ag}$, (b) the structure of the [001] face of $\mathrm{Ag}_{6} \mathrm{O}_{2}$, and (c) an $\mathrm{Ag}_{6} \mathrm{O}$ surface structure that may develop at the [111] face of metallic $\mathrm{Ag}$. $\mathrm{Ag}$ is shown with blue spheres. The blue $\mathrm{Ag}_{6}$ octahedra are empty and the red $\mathrm{Ag}_{6} \mathrm{O}$ octahedra have an oxygen ion in the center. In the $\mathrm{Ag}_{6} \mathrm{O}_{2}$ structure (b), the $\mathrm{Ag}_{6} \mathrm{O}$ octahedra share edges. In the $\mathrm{Ag}_{6} \mathrm{O}$ structure (c), individual $\mathrm{Ag}_{6} \mathrm{O}$ octahedra (red) without edge-sharing are present surrounded by empty $\mathrm{Ag}_{6}$ octahedra (blue). In the $\mathrm{Ag}_{6} \mathrm{O}$ structure (c), all silver ions are singly coordinated to an oxygen ion whereas in $\mathrm{Ag}_{6} \mathrm{O}_{2}$, the silver ions are doubly coordinated. The given triangular [111] face has 55 octahedra and is representative for an icosahedral AgNP with a size of $d \sim 4.6 \mathrm{~nm}$ and a specific surface area of $A \sim 100 \mathrm{~m}^{2} \mathrm{~g}^{-1}$. Such icosahedral AgNP contain $\sim 2870 \mathrm{Ag}$ of which $28 \%$ is at the surface (Figure A3). For these calculated results, we refer to Appendix A. Figures have been made using CrystalMaker ${ }^{\circledR}$.

\subsubsection{Structure of $\mathrm{Ag}_{2} \mathrm{O}$}

Regular silver $(\mathrm{I})$ oxide $\left(\mathrm{Ag}_{2} \mathrm{O}\right)$ was among the earliest minerals whose structure was determined using $\mathrm{X}$-ray diffraction, ${ }^{46,47}$ then a novel technique. $\mathrm{Ag}_{2} \mathrm{O}$ has a body-centered cubic (BCC) crystal structure, which translates to a 3-dimensional atomic arrangement in which every silver atom is connected to two oxygen atoms in linear bonds. This arrangement has a lower packing density than the FCC crystal structure of metallic Ag.

Mineral structures can be evaluated using the Pauling bond valence approach. The Pauling bond valence $(v)$ is defined as: ${ }^{48}$

$v_{\mathrm{i}}=\mathrm{z}_{\mathrm{i}} / \mathrm{CN}_{\mathrm{i}}$

in which $z$ is the valence and $\mathrm{CN}$ is the coordination number. The bond valence of silver in $\mathrm{Ag}_{2} \mathrm{O}$ is equal to $v_{\mathrm{Ag}}=z_{\mathrm{Ag}} / \mathrm{CN}_{\mathrm{Ag}}=+1 / 2 \mathrm{v}$.u. (valence units). As minerals have a zero net charge, the sum of bond valences surrounding an anion fully neutralize its charge. ${ }^{48}$ According to the Pauling rule of local electroneutrality, a number of $n=4 \mathrm{Ag}^{+}$ions is needed to neutralize the charge $\left(z_{0}\right)$ of the oxygen ions in $\mathrm{Ag}_{2} \mathrm{O}$, i.e. $z_{\mathrm{O}}+n \cdot v_{\mathrm{Ag}}=0$.

Evaluation of the $\mathrm{Ag}_{2} \mathrm{O}$ structure in relation to the structure of metallic $\mathrm{Ag}$ shows that there is a mismatch in the atomic arrangement between both lattices. The $\mathrm{Ag}-\mathrm{Ag}$ distances in the oxide lattice are considerably longer $(337 \mathrm{pm})^{47}$ than in the metal lattice $(288 \mathrm{pm}) .^{40}$ Therefore, $\mathrm{Ag}_{2} \mathrm{O}$ will not be able to form a stable coating with atomic connectivity to the underlying metallic lattice. 


\subsubsection{Structure of $\mathrm{Ag}_{6} \mathrm{O}_{2}$}

In 1963, an alternative crystal structure was reported for a silver oxide, ${ }^{49}$ which was initially thought to be $\mathrm{Ag}_{2} \mathrm{O}$. However, around two decades later the crystal structure was revisited and reported as $\mathrm{Ag}_{6} \mathrm{O}_{2} \cdot{ }^{50}$ This material can be formed from $\mathrm{AgO}(\mathrm{s})$ and $\mathrm{Ag}(\mathrm{s})$ at high pressures ${ }^{51}$ and has a structure which is remarkably different from the classical $\mathrm{Ag}_{2} \mathrm{O}$ oxide described in the previous section.

In the $\mathrm{Ag}_{6} \mathrm{O}_{2}$ structure, the silver and oxygen ions are organized in alternating, parallel layers, whereas $\mathrm{Ag}_{2} \mathrm{O}$ has a 3-dimensional silver-oxygen network. ${ }^{52}$ In the $\mathrm{Ag}_{6} \mathrm{O}_{2}$ structure, each layer of oxygen is covered on either side by a layer of silver atoms. These $\mathrm{Ag}-\mathrm{O}-\mathrm{Ag}$ slabs are stacked to make up a structure consisting of double Ag-layers alternated by single O-layers (Figure A4a).

Each oxygen ion in $\mathrm{Ag}_{6} \mathrm{O}_{2}$ is surrounded by six silver atoms forming an octahedron. These octahedra thus have anions $\left(\mathrm{O}^{2-}\right)$ in the center, and cations (ionic $\mathrm{Ag}$ ) at the corners, which is the inverse of the traditional view on octahedra. These remarkable $\mathrm{Ag}_{6} \mathrm{O}$ octahedra are organized in a di-octahedral structure, i.e. 2 out of 3 octahedra are filled; this pattern is also found in e.g. gibbsite, $\mathrm{Al}(\mathrm{OH})_{3}$. The surface structure of the $(001)$ face of $\mathrm{Ag}_{6} \mathrm{O}_{2}$ is given in Figure 1b. The empty $\mathrm{Ag}_{6}$ octahedra are given in blue and the edge-sharing $\mathrm{Ag}_{6} \mathrm{O}$ octahedra are shown in red.

$\mathrm{Ag}_{6} \mathrm{O}_{2}$ has more silver per oxygen than $\mathrm{Ag}_{2} \mathrm{O}$, implying that the silver ions in its structure are, on average, less oxidized. The chemical formula of $\mathrm{Ag}_{6} \mathrm{O}_{2}$ or $\mathrm{Ag}_{3} \mathrm{O}$ could suggest the presence of $\mathrm{Ag}$ in two oxidation states, e.g. 0 and $\mathrm{I}$, appearing in a 1:2 ratio. However, the $\mathrm{Ag}-\mathrm{O}$ distances in $\mathrm{Ag}_{6} \mathrm{O}_{2}$ are all equal, ${ }^{50}$ implying that all silver ions equally contribute to the neutralization of the oxygen ions. If all $\mathrm{Ag}$-ions behave equally, the valence of $\mathrm{Ag}$ in $\mathrm{Ag}_{6} \mathrm{O}_{2}$ will be $z_{\mathrm{Ag}}=+2 / 3 \mathrm{v}$.u.

The valence $z_{\mathrm{Ag}}=+2 / 3$ v.u. can also be rationalized using the Pauling rules. Each $\mathrm{O}\left(z_{\mathrm{O}}=-2\right.$ v.u. $)$ coordinates to the $6 \mathrm{Ag}$ at the corners of $\mathrm{Ag}_{6} \mathrm{O}$ octahedron $\left(\mathrm{CN}_{\mathrm{O}}=6\right)$ and, due to edge sharing, every $\mathrm{Ag}$ contributes charge to the central $\mathrm{O}$ of two different octahedra $\left(\mathrm{CN}_{\mathrm{Ag}}=2\right)$. Equal bond lengths imply equal distribution of charge, yielding a bond valence of the oxygen equal to $v_{0}$ $=z_{0} / C N_{O}=-2 / 6=-1 / 3 v$ v.u. (eq 2 ). For the same bond, counter-ions have the same bond valence, but with opposite sign. We may therefore write for the bond valence $v_{\mathrm{Ag}}=+1 / 3 \mathrm{~V}$.u., leading to a valence of the $\mathrm{Ag}$ in $\mathrm{Ag}_{6} \mathrm{O}_{2}$ equal to $z_{\mathrm{Ag}}=v_{\mathrm{Ag}} \cdot \mathrm{CN}_{\mathrm{Ag}}=+2 / 3 \mathrm{v} \cdot \mathrm{u}$.

The above calculated value of the bond valence of $\mathrm{Ag}\left(v_{\mathrm{Ag}}=+1 / 3 \mathrm{v} . \mathrm{u}\right.$. $)$ is lower than that for $\mathrm{Ag}^{+}$ in $\mathrm{Ag}_{2} \mathrm{O}$ ( $v_{\mathrm{Ag}}=+1 / 3 \mathrm{v}$.u.), i.e. the bond strength will be less. This corresponds very well to a larger bond length or $\mathrm{Ag}-\mathrm{O}$ distance as observed for $\mathrm{Ag}_{6} \mathrm{O}_{2}\left(d_{\mathrm{Ag}-\mathrm{O}}=230 \mathrm{pm}\right)^{50}$ compared to $\mathrm{Ag}_{2} \mathrm{O}$ $\left(d_{\mathrm{Ag}-\mathrm{O}}=206 \mathrm{pm}\right){ }^{40}$ The relationship between the bond valence $v$ and bond length $R$ can be described empirically with: ${ }^{53}$

$v=\mathrm{e}^{-\left(\mathrm{R}-\mathrm{R}_{0}\right) / \mathrm{B}}$ 
in which $B$ is a chosen constant $(B=37 \mathrm{pm})$ and $R_{0}$ is a reference distance $(p m)$ derived by analysis of a large collection of minerals containing Ag. The relationship of Brown and Altermatt ${ }^{53}$ is given in Figure 2.2 as a dotted line and the data points show the actual bond valences in relation to the $\mathrm{Ag}-\mathrm{O}$ distance. The figure shows that at increasing bond lengths, $\mathrm{Ag}$ ions contribute less to the neutralization of an oxygen ion, i.e. the bond valence is less.

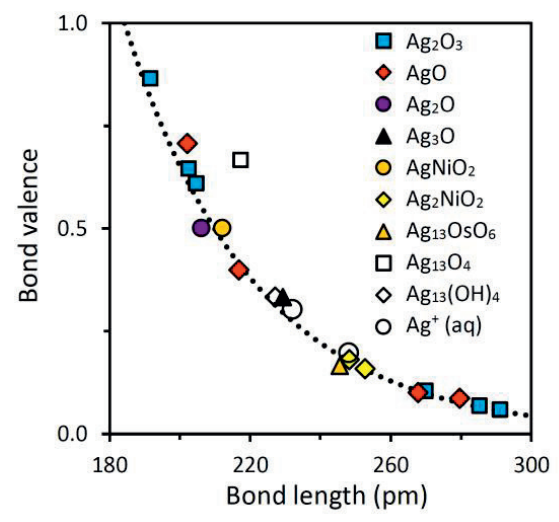

Figure 2.2 Relationship between bond valence of $\mathrm{Ag}$ and bond length in a large series of crystal structures with Ag. Bond lengths were taken from crystallographic data (colored symbols) or calculated with MO/DFT (open symbols). Bond valences were calculated using equation 3 with optimized $R_{0}$ values that correctly describe the sum of the bond valences in each polyhedron being equal to the charge $z$ of the cation $\left(\mathrm{Ag}^{2+}\right)$. The line gives the bond valence-distance relation (eq 3 ) using the $\mathrm{R}_{0}$ value given by Brown and Altermatt ${ }^{53}$. The bond valence of $\mathrm{Ag}$ ions in the hypothetical $\mathrm{Ag}_{13} \mathrm{O}_{4}$ cluster mismatches with the MO/DFT calculated bond length indicating that the actual bond valence is less and that the (surface) oxygen is insufficiently neutralized. For details concerning the calculations and crystallographic references, we refer to the supporting information.

\subsubsection{Subvalency of Ag}

Usually, mineral structures can be evaluated using formal valences that have an integer value. Above, we demonstrated for $\mathrm{Ag}_{6} \mathrm{O}_{2}$ the principle of a non-integer value for the ionic charge. For $\mathrm{Ag}$, subvalency is found in a very specific class of minerals having double sheets of silver as common characteristic. A classic example of a $\mathrm{Ag}$ compound with subvalency is silver subfluoride, $\mathrm{Ag}_{2} \mathrm{~F}^{54}$ In analogy to $\mathrm{Ag}_{6} \mathrm{O}_{2}$, this mineral (Figure $\mathrm{A} 4 \mathrm{~b}$ ) consists of stacked $\mathrm{Ag}-\mathrm{F}-\mathrm{Ag}$ slabs containing octahedra with six cations surrounding a central anion $\left(\mathrm{F}^{-}\right)$. Due to the lower charge of $\mathrm{F}^{-}$compared to $\mathrm{O}^{2-}$, all octahedra in a $\mathrm{Ag}-\mathrm{F}-\mathrm{Ag}$ slab have an anion in the center, i.e. the compound has a tri-octahedral structure, which is also found in e.g. brucite, $\mathrm{Mg}(\mathrm{OH})_{2}$. The bond valence of the central fluoride anion is $\nu_{\mathrm{F}}=z_{\mathrm{F}} / C N_{\mathrm{F}}=-1 / 6 \mathrm{~V}$.u. (eq 2). In the tri-octahedral structure, each silver ion coordinates to three fluoride anions, yielding a subvalence for $\mathrm{Ag}$ in $\mathrm{Ag}_{2} \mathrm{~F}$ equal to $z_{\mathrm{Ag}}=v_{\mathrm{Ag}} \cdot \mathrm{CN}_{\mathrm{Ag}}=3 \cdot+1 / 6=+1 / 2 \mathrm{v} \cdot \mathrm{u}$.

The same subvalent state $\left(z_{\mathrm{Ag}}=+1 / 2 \mathrm{v} . \mathrm{u}\right)$ is also found in other $\mathrm{Ag}$ compounds in which a bilayer of $\mathrm{Ag}$ is present, e.g. $\mathrm{Ag}_{2} \mathrm{NiO}_{2}$ (Figure $\mathrm{A} 4 \mathrm{c}$ ). Although the chemical formula may suggest the 
presence of $\mathrm{Ag}(\mathrm{I})$ and $\mathrm{Ni}(\mathrm{II})$, this is not the case, ${ }^{55}$ as is supported by a structural analysis. $\mathrm{Ag}_{2} \mathrm{NiO}_{2}$ consists of double sheets of $\mathrm{Ag}$, alternated with tri-octahedral sheets of $\mathrm{NiO}_{2}$. The oxygen ions, located at the six corners of the octahedra, are coordinated to three $\mathrm{Ni}(\mathrm{III})$ ions ${ }^{55}$ each contributing $v_{\mathrm{Ni}}=3 \cdot+1 / 6=+1 / 2 \mathrm{v}$.u. To neutralize the residual $\mathrm{O}^{2-}$ charge, a charge of $+1 / 2 \mathrm{v} . \mathrm{u}$. is to be generated by three coordinating $\mathrm{Ag}$, each donating $v_{\mathrm{Ag}}=+1 / 6 \mathrm{v}$.u. The low value for the bond valence of $\mathrm{Ag}\left(v_{\mathrm{Ag}}\right)$ agrees well with the observed bond length, being relatively large (250 $\mathrm{pm}),{ }^{55}$ in agreement with the bond valence distance relationship of eq 2.3 , as shown in Figure 2.2.

The existence of subvalent silver in the mentioned solids is the result of an interaction between the electron structures of two adjacent Ag layers, ${ }^{56}$ giving rise to delocalization of electrons. Delocalized electrons are typical for metallic lattices, and their existence is the reason for the high electrical conductivity of metals, which is also seen in the above subvalent Ag compounds with double sheets of silver. ${ }^{55}$ Delocalization of electrons underlines the semimetallic character of $\mathrm{Ag}_{6} \mathrm{O}_{2}$ compared to purely ionic minerals.

To illustrate the importance of a bi-layer of silver for the formation of the subvalent state, one may compare $\mathrm{Ag}_{2} \mathrm{NiO}_{2}$ to $\mathrm{AgNiO}_{2}$ (Figure $\mathrm{A} 4 \mathrm{~d}$ ). Only a single layer of $\mathrm{Ag}$ is found in $\mathrm{AgNiO}_{2}$, and consequently, the silver ions are able to form $\mathrm{O}-\mathrm{Ag}-\mathrm{O}$ bonds with the $\mathrm{Ni}(\mathrm{III}) \mathrm{O}_{2}$ slabs on either side. Such $\mathrm{O}-\mathrm{Ag}-\mathrm{O}$ bonds, which are also seen in $\mathrm{Ag}_{2} \mathrm{O}$, allow silver to get a valence of $z_{\mathrm{Ag}}=+1 \mathrm{v} . \mathrm{u}$. In contrast, the $\mathrm{Ag}$ ions in the bilayer of $\mathrm{Ag}_{2} \mathrm{NiO}_{2}$ form $\mathrm{O}-\mathrm{Ag}-\mathrm{Ag}-\mathrm{O}$ bonds and the valence of the $\mathrm{Ag}$ ion coordinating to the oxygen is $z_{\mathrm{Ag}}=+1 / 2 \mathrm{v} . \mathrm{u}$.

Subvalency is also found in $\mathrm{Ag}_{13} \mathrm{OsO}_{6}{ }^{57}$ This crystal structure contains icosahedral $\mathrm{Ag}_{13}{ }^{4+}$ clusters connected by osmium oxyanions $\left(\mathrm{OsO}_{6}{ }^{4-}\right)$. Such $\mathrm{Ag}_{13}$ clusters can be considered as a model for AgNP. An icosahedral $\mathrm{Ag}_{13}$ cluster can be built from $12 \mathrm{Ag}$-ions surrounding a central $\mathrm{Ag}$-atom in agreement with the first Pauling rule. Distributing the cluster charge of $+4 \mathrm{v}$.u. over the 12 surface atoms yields a valence of $z_{\mathrm{Ag}}=+1 / 3 \mathrm{v}$.u. Since the silver ion is coordinated to two oxygen ions in the $\mathrm{Ag}_{13} \mathrm{OsO}_{6}$ structure, the charge per bond or bond valence will be $v_{\mathrm{Ag}}=+1 / 6 \mathrm{~V}$.u. This low value for the bond valence is in line with the relatively long $\mathrm{Ag}-\mathrm{O}$ bond length that is observed in this structure $(246 \mathrm{pm}),{ }^{57}$ again in agreement with the relation given in Figure 2.2.

\subsection{Surface oxide structure}

\subsubsection{Surface oxide formation}

Subvalent silver may also exist at the surface of AgNP as result of surface oxidation. Oxidation of AgNP has been studied by Henglein ${ }^{58}$ in an important experiment. AgNP ( 7 nm) were produced under strictly anoxic conditions by UV-illumination of a $0.4 \mathrm{mM} \mathrm{AgClO}_{4}$ solution in the presence of an organic reductant. The final suspension is acidic, containing $0.4 \mathrm{mM} \mathrm{HClO}_{4}$ $\left(\mathrm{pH}\right.$ 3.4). When $\mathrm{Ag}^{+}$ions were added to a suspension of these particles, the absorption 
maximum of the plasmon band increased from $\lambda_{0}=378 \mathrm{~nm}$ to $\lambda=389 \mathrm{~nm}$, which was reached at an addition of $\sim 20 \mu \mathrm{M}$ (Figure 2.3 ).

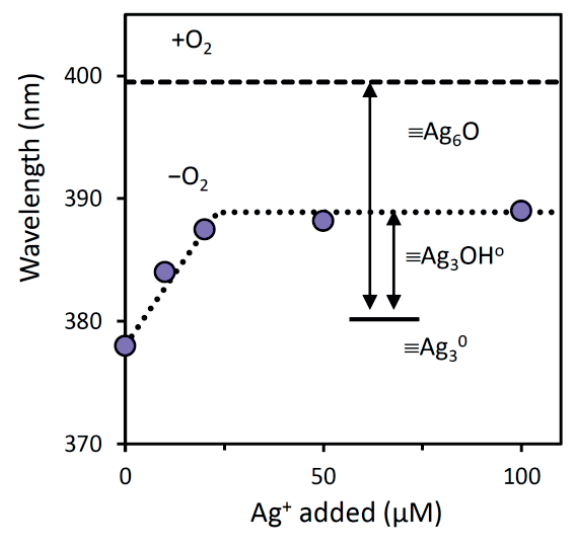

Figure 2.3 Wavelength of the plasmon band of $7 \mathrm{~nm}$ AgNP present in an anoxic suspension containing $400 \mu \mathrm{M}$ of $\mathrm{Ag}$ as $\mathrm{AgNP}$ upon addition of $\mathrm{Ag}^{+}$ions (blue spheres). The dotted line is the expected behavior at formation of $\equiv \mathrm{Ag}_{3} \mathrm{OH}^{0}$ surface sites with a density of 4 sites $\mathrm{nm}^{-2}$. The dashed line represents the wavelength of the band for the same AgNP in the presence of $\mathrm{O}_{2}$ (but without additions of $\mathrm{Ag}^{+}$), which can be attributed to subsurface oxidation of silver that may result in formation of $\equiv \mathrm{Ag}_{6} \mathrm{O}$ (see text). The increase in wavelength at oxidation with $\mathrm{O}_{2}$ corresponds to a doubling of the electron deficiency (or $\mathrm{Ag}^{+}$-loading) compared to the experiment with addition of $\mathrm{Ag}^{+}$ions in the absence of $\mathrm{O}_{2}$.

Uptake of $\mathrm{Ag}^{+}$by the metallic lattice decreases the electron density of the AgNP and this can be seen as partial oxidation. If the adsorbed $\mathrm{Ag}$ ions fuse with the AgNP particle, the resonating electron gas of the AgNP is spread over more Ag-cores. The electron density is thus reduced, which moves the wavelength of the plasmon band $(\lambda)$ to higher values. One may calculate the shift of the plasmon band as a function of adsorbed $\mathrm{Ag}^{+}$, following the approach of Henglein, ${ }^{58}$

$$
\lambda=\lambda_{0}\left[1+\frac{\Gamma_{\mathrm{Ag}^{+}}}{\mathrm{Ag}^{0}}\right]^{1 / 2}
$$

in which $\lambda_{0}$ is the absorption maximum of the plasmon band of a purely metallic particle, $\Gamma_{\mathrm{Ag}^{+}}$ is the amount of $\mathrm{Ag}^{+}$bound by the particle and $\mathrm{Ag}^{0}$ is the initial amount of metallic $\mathrm{Ag}$ present. The change of the plasmon wavelength ( $y$-axis) as well as the position where it reaches its maximum (x-axis), is consistent with a surface loading of $4 \mathrm{Ag}$ per $\mathrm{nm}^{2}$. This surface density can be interpreted as the presence of $\equiv_{\mathrm{Ag}_{3}}{ }^{+}$sites in which each $\mathrm{Ag}$ has a subvalence of $z_{\mathrm{Ag}}=+1 / 3$ v.u. Neutralization of the $\equiv \mathrm{Ag}_{3}{ }^{+}$charge by binding of a hydroxyl ion will result in the formation of neutral $\equiv \mathrm{Ag}_{3} \mathrm{OH}^{0}$ surface groups.

In principle, a $\equiv \mathrm{Ag}_{3} \mathrm{OH}^{0}$ surface species may deprotonate according to $\equiv \mathrm{Ag}_{3} \mathrm{OH}^{0} \Leftrightarrow \equiv \mathrm{Ag}_{3} \mathrm{O}^{-}+$ $\mathrm{H}^{+}(\mathrm{aq})$. The protonation constant of a surface ligand is related to the local neutralization of 
the oxygen ion by the cations in the coordination sphere. ${ }^{59} \mathrm{~A}$ strong undersaturation of the oxygen charge leads to a high proton affinity $\left(\log K_{\mathrm{H}}\right)$. Locally, the oxygen of $\mathrm{A}_{\mathrm{Ag}} \mathrm{O}^{-}$is neutralized by three coordinating $\mathrm{Ag}$ ions, each donating $+1 / 3$ v.u. In addition, there is interaction with water via hydrogen bonding, typically contributing about $0.2 \mathrm{v} . \mathrm{u}$. to the oxygen. ${ }^{59}$ Overall, this results in a very high net charge for the oxygen ion, being $-2+3 \cdot 1 / 3+0.2$ $=-0.8 \mathrm{v} . \mathrm{u}$. The corresponding proton affinity is very high, $\log K_{\mathrm{H} 1} \approx 16 .{ }^{59}$ This high affinity implies that $\equiv \mathrm{Ag}_{3} \mathrm{O}^{-}$will protonate forming $\equiv \mathrm{Ag}_{3} \mathrm{OH}^{0}$. In principle, the $\mathrm{OH}$ ligand may protonate in a second step forming $\mathrm{H}_{2} \mathrm{O}$. Between two successive protonation steps at the same ligand, the difference in $\log K$ is typically $\Delta \log K_{\mathrm{H}} \approx 12 .{ }^{59}$ It suggests a protonation constant in the order of $\log K_{\mathrm{H} 2} \approx 4$ for the transformation of the surface hydroxyl into a non-coordinative water molecule, i.e. formation of $\equiv \mathrm{Ag}_{3}{ }^{+}$under very acid conditions. In conclusion, the above analysis advocates $\equiv \mathrm{Ag}_{3} \mathrm{OH}^{0}$ as the representative species at the [111] face of metallic silver at neutral $\mathrm{pH}$. This structure is shown in Figure 2.4.

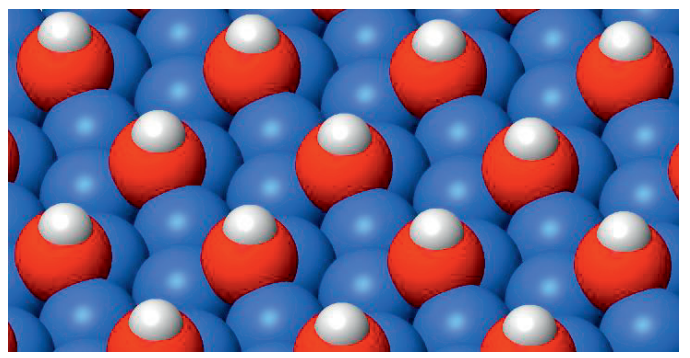

Figure 2.4 Idealized surface structure of a fully hydroxylated AgNP, showing the (111) face of the $\mathrm{Ag}$ lattice with hydroxyls at a density of 4.7 sites $\mathrm{nm}^{-2}$. The $\mathrm{Ag}$ ions of $\equiv \mathrm{Ag}_{3} \mathrm{OH}^{0}$ have a subvalency of $Z_{\mathrm{Ag}}=+1 / 3 \mathrm{v}$.u. and a bond valence of $v_{\mathrm{Ag}}=+1 / 3$ v.u. equivalent with a $\mathrm{Ag}-\mathrm{O}$ distance of $\sim 230 \mathrm{pm}$. The hydrogen positions have been optimized with a molecular mechanical approach available in CrystalMaker ${ }^{\circledR}$.

Importantly, Henglein ${ }^{58}$ described a second oxidation experiment in which the same AgNP were brought in contact with oxygen. The frequency of the plasmon band rapidly increased and stabilized within 20 minutes at a value close to $400 \mathrm{~nm}$ (Figure 2.3). This value can also be interpreted in terms of a deficiency of electrons. In case of oxidation by oxygen, the deficiency accurately doubles in comparison to the value that can be reached by the addition of $\mathrm{Ag}^{+}$ions.

At a first glance, doubling of the oxidation state might be point to doubling of the subvalency of $\mathrm{Ag}$ reaching a value of $\mathrm{Z}_{\mathrm{Ag}}=+2 / 3 \mathrm{v}$.u. and formation of $\equiv \mathrm{Ag}_{3} \mathrm{O}^{0}$ surface groups. However, this suggestion would result in a very high value for the bond valence being $v_{\mathrm{Ag}}=+2 / 3 \mathrm{v}$.u. in $\equiv \mathrm{Ag}_{3} \mathrm{O}^{0}$. Such high bond valences are only observed for highly oxidized Ag-compounds, such as $\mathrm{Ag}_{2} \mathrm{O}_{3}(\mathrm{~s})$ and $\mathrm{AgO}(\mathrm{s})$, both containing trivalent $\mathrm{Ag}^{3+}$ ions (Figure 2.2).

The higher electron deficiency can be better explained by considering oxidation in two layers of $\mathrm{Ag}$ rather than in a single layer at the surface. In this view, the oxygen is located internally. 
A subsurface oxygen species, located in octahedral spaces between the first two layers of silver, is reported for the solid-gas interface of bulk Ag-metal. ${ }^{6}$ If the oxygen ions are located between two $\mathrm{Ag}$ layers, the oxygen may form separate $\mathrm{Ag}_{6} \mathrm{O}$ octahedra in which the silver ions have a subvalence of only $z_{\mathrm{Ag}}=+1 / 3 \mathrm{v}$.u.

In Figure 2.1c, a possible surface structure with $\mathrm{Ag}_{6} \mathrm{O}$ is shown. It can be built from a collection of individual $\mathrm{Ag}_{6} \mathrm{O}$ octahedra. The oxygen density in a sheet of $\mathrm{Ag}_{6} \mathrm{O}$ is half that in $\mathrm{Ag}_{6} \mathrm{O}_{2}$, resulting in a subvalency of the silver ions $\left(z_{\mathrm{Ag}}=+1 / 3 \mathrm{v}\right.$.u. $)$ that is also half of the value in $\mathrm{Ag}_{6} \mathrm{O}_{2}$ $\left(z_{\mathrm{Ag}}=+2 / 3\right.$ v.u. $)$. However, note that in both structures, the silver ions have the same bond valence $\left(v_{\mathrm{Ag}}=+1 / 3\right)$.

In summary, silver at the surface of AgNP can be oxidized to a subvalent state of $z_{\mathrm{Ag}}=+1 / 3 \mathrm{v}$.u. In case of $\equiv \mathrm{Ag}_{3} \mathrm{OH}^{0}$ groups (Figure 2.4), the presence of subvalent silver ions is restricted to a single surface layer with Ag. In contrast, the first two silver layers are oxidized in case of a

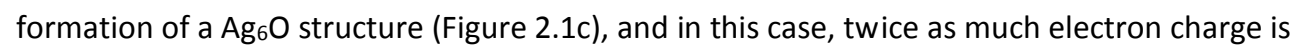
involved, in agreement with the data of Henglein ${ }^{58}$ presented in Figure 2.3.

\subsubsection{Molecular orbital calculations}

To further explore the structures of the AgNP surface, we have constructed an icosahedron of metallic $\mathrm{Ag}_{13}$ and optimized its geometry with molecular orbital (MO) calculations applying density functional theory (DFT) using the EDF2 functional with LACVP* pseudopotentials as defined in Spartan'06. The EDF2 functional has previously been tested and adequately represents the structure of aqueous $\mathrm{Ag}\left(\mathrm{OH}_{2}\right)_{2}\left(\mathrm{OH}_{2}\right)_{2}{ }^{+}{ }^{60}$ For $\mathrm{Ag}{ }_{13}$, a multiplicity of $\mathrm{M}=6$ was used which is equivalent with 5 unpaired electrons. ${ }^{61}$ The MO/DFT calculations show that electron charge is transferred from the outer shell $\mathrm{Ag}$ atoms to the inner atom, i.e. the surface atoms tend to charge positively. The optimized $\mathrm{Ag}_{13}$ cluster (Figure 2.5a) has an icosahedral structure with a single $\mathrm{Ag}-\mathrm{Ag}$ distance of $282 \mathrm{pm}$.

Next, the $\mathrm{Ag}_{13}$ cluster was partially oxidized by coordinating a hydroxyl to each of the four triplets of surface atoms, resulting in $\mathrm{Ag}_{13}(\mathrm{OH})_{4}{ }^{0}$. This structure is equivalent to the smallest imaginable AgNP with a $\equiv \mathrm{Ag}_{3} \mathrm{OH}^{0}$ surface structure. Using $\mathrm{M}=2$, the geometry was fully relaxed, drifting away from the icosahedral structure found for $\mathrm{Ag}_{13}$ yielding larger $\mathrm{Ag}-\mathrm{Ag}$ distances around $298 \pm 12 \mathrm{pm}$ (Figure 2.5b). The optimized geometry has a mean $\mathrm{Ag}-\mathrm{O}$ distance of $228 \pm 1 \mathrm{pm}$. This distance is equivalent with a bond valence of $v_{\mathrm{Ag}}=+1 / 3 \mathrm{v}$.u. (Figure 2.2 ) in agreement with our expectations. 
a)

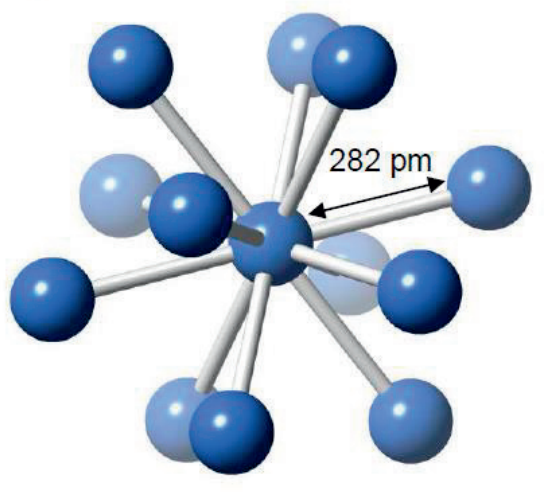

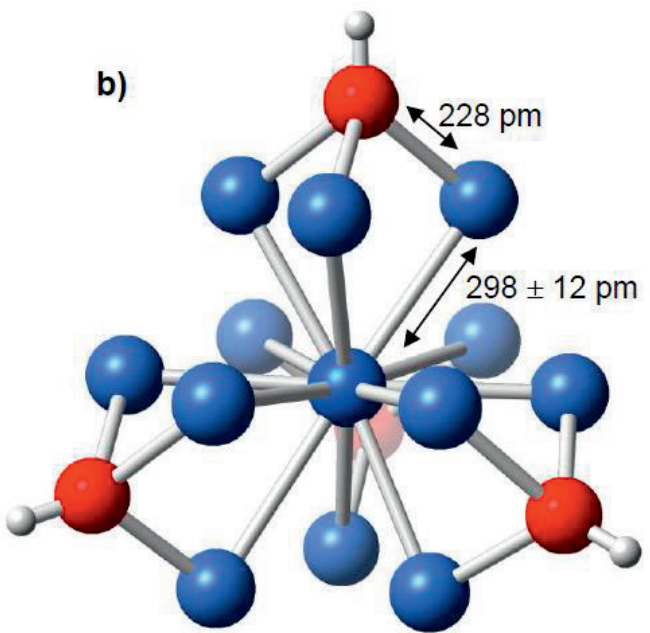

Figure 2.5 MO/DFT optimized geometry of an icosahedral $\mathrm{Ag}_{13}$ and an uncharged $\mathrm{Ag}_{13}(\mathrm{OH})_{4}$ cluster of which the surface $\mathrm{Ag}$ is partially oxidized having a subvalence of $z_{\mathrm{Ag}}=+1 / 3 \mathrm{v}$.u. Oxygen is in red, hydrogen is in white, and silver is in blue. The Ag-O bond length is $228 \pm 1 \mathrm{pm}$ in agreement with a bond valence of $v_{A g}=+1 / 3$ v.u. (Figure 2.2). Considering $\mathrm{Ag}_{13}$ as the smallest icosahedral AgNP having an equivalent spherical diameter of $0.75 \mathrm{~nm}$, the highest specific surface area for AgNP will be $\sim 760 \mathrm{~m}^{2} \mathrm{~g}^{-1}$ (see Figure A3).

MO/DFT optimizations were also performed for the same cluster but with $\mathrm{O}^{2-}$ ions bound to the silver triplets of $\mathrm{Ag}_{13}$, resulting in a neutral $\mathrm{Ag}_{13} \mathrm{O}_{4}$ cluster (Figure A5). This structure would have a surface oxidation state corresponding to that calculated for AgNP in Section 3.1 after 20 minutes of oxygen exposure. ${ }^{58}$ The energy of $\mathrm{Ag}_{13} \mathrm{O}_{4}{ }^{0}$ is extremely high in comparison to $\mathrm{Ag}_{13}(\mathrm{OH})_{4}{ }^{0}$. The large Gibbs free energy difference $\left(\Delta \mathrm{G}_{\mathrm{R}}{ }^{0} \sim+180 \mathrm{~kJ} \mathrm{~mol}^{-1}\right)$ for the equilibrium $\mathrm{Ag}_{13}(\mathrm{OH})_{4}+\mathrm{O}_{2} \Leftrightarrow \mathrm{Ag}_{13} \mathrm{O}_{4}+2 \mathrm{H}_{2} \mathrm{O}$ indicates that $\mathrm{Ag}_{13} \mathrm{O}_{4}$ is highly unstable at atmospheric conditions (for details, see supporting information).

As described above, full neutralization of the oxygen charge by a single layer of surface-Ag would yield bond valences of $v_{\mathrm{Ag}}=+2 / 3 \mathrm{v}$.u., which corresponds to very short bond lengths only found in highly oxidized $\mathrm{Ag}$ (III)-compounds. Our MO/DFT calculations for $\mathrm{Ag}_{13} \mathrm{O}_{4}$ yield a much larger bond length $(219 \pm 3 \mathrm{pm})$ than expected $(\sim 199 \mathrm{pm})$ for $v_{\mathrm{Ag}}=+2 / 3$ v.u. (Figure 2.2). This indicates that the three silver ions of $\equiv \mathrm{Ag}_{3} \mathrm{O}$ are unable to fully neutralize the triply coordinated oxygen ion. A gap in charge-neutralization remains.

A higher neutralization for oxygen may be attained by coordinating to a larger number of $\mathrm{Ag}$ ions as found for the gas-solid interface. ${ }^{36}$ Raman spectroscopy suggests the formation of a subsurface oxygen species ${ }^{6}$ that can be represented as $\equiv \mathrm{Ag}_{6} \mathrm{O}$. This octahedral species can explain the higher state of oxidation of AgNP upon interaction with oxygen as found by Henglein ${ }^{58}$ for AgNP in an acid solution. 


\subsection{Surface complexation and silver ion release}

\subsubsection{Oxidative $\mathrm{Ag}^{+}$-release}

As discussed in the previous section, oxidation may result in the formation of subvalent Ag. At circum-neutral $\mathrm{pH}$ values, silver may be present at the surface as $\equiv \mathrm{Ag}_{3} \mathrm{OH}^{0}$. This silver may be released by oxidation. Liu and Hurt ${ }^{22}$ have shown that during oxidative release of $\mathrm{Ag}^{+}$, also some $\mathrm{H}_{2} \mathrm{O}_{2}$ can be released, i.e. reactive oxygen species (ROS) may appear during oxidation. In a 2-electron reaction, such as the oxidation of $\equiv \mathrm{Ag}_{3} \mathrm{OH}^{0}$, a variety of ROS may be produced through different pathways. ${ }^{62,63}$ One set of pathways leads to the production of adsorbed atomic oxygen. The 2 -electron reaction with $\mathrm{Ag}^{+}$-release may be given as:

$\equiv \mathrm{Ag}_{3} \mathrm{OH}^{0}+1 \mathrm{O}_{2}+3 \mathrm{H}^{+}(\mathrm{aq}) \Leftrightarrow 3 \mathrm{Ag}^{+}(\mathrm{aq})+2 \mathrm{H}_{2} \mathrm{O}(\mathrm{l})+\mathrm{O}^{\bullet}$

The oxygen radical $\mathrm{O}^{\bullet}$ formed at dissociation of an $\mathrm{O}_{2}$ molecule may immediately react with metallic $\mathrm{Ag}$ forming $\mathrm{Ag}_{6} \mathrm{O}$ octahedra according to the reaction:

$\equiv \mathrm{Ag}_{6}{ }^{0}+\mathrm{O}^{\bullet} \Leftrightarrow \mathrm{Ag}_{6} \mathrm{O}^{0}$

in which $\equiv \mathrm{Ag}_{6}{ }^{0}$ represents the underlying metallic $\mathrm{Ag}$ lattice. In combination, an overall reaction can be formulated as:

$\equiv \mathrm{Ag}_{6} \mathrm{Ag}_{3} \mathrm{OH}^{0}+1 \mathrm{O}_{2}+3 \mathrm{H}^{+}(\mathrm{aq}) \Leftrightarrow \equiv \mathrm{Ag}_{6} \mathrm{O}^{0}+3 \mathrm{Ag}^{+}(\mathrm{aq})+2 \mathrm{H}_{2} \mathrm{O}(\mathrm{l})$

For brevity, $\equiv \mathrm{Ag}_{3} \mathrm{OH}^{0}$ will be used to refer to $\equiv \mathrm{Ag}_{6} \mathrm{Ag}_{3} \mathrm{OH}^{0}$ in the text.

The process described with eq $2.6 \mathrm{~b}$ requires flexibility of the lattice in order to allow penetration of the oxygen. $\mathrm{Ag}$ is mobile in $\mathrm{AgNP}^{64}$ and this may regenerate a closed surface. The reaction results in an increase of the amount of subvalent silver in the interface. It is accompanied by dissolution of $\mathrm{Ag}$ and is favored by oxidizing conditions and low $\mathrm{pH}$, all in agreement with the observations of Henglein. ${ }^{58}$

As will be shown in detail later, additional $\mathrm{Ag}^{+}$can be released in excess to the above given equilibrium reaction (eq 2.6c). Excess $\mathrm{Ag}^{+}$-release is possible if the oxygen atom, released at the dissolution of $\equiv \mathrm{Ag}_{3} \mathrm{OH}^{0}$ (eq 2.6a), does not instantaneously react with the underlying lattice but is transformed into other reactive oxygen species (ROS), such as $\mathrm{OH}^{\bullet}$ and $\mathrm{H}_{2} \mathrm{O}_{2}$. Formation as well as decay of $\operatorname{ROS}\left(\mathrm{O}^{\circ}, \mathrm{OH}^{\bullet}, \mathrm{H}_{2} \mathrm{O}_{2}\right)$ are well known for metals such as $\mathrm{Pt},{ }^{63,65}$ $\mathrm{Cu}^{66}$ and $\mathrm{Ag} \cdot{ }^{67,68} \mathrm{~A} \mathrm{H}_{2} \mathrm{O}_{2}$ molecule is able to accept two electrons and thus a single molecule may oxidize another $\equiv \mathrm{Ag}_{3} \mathrm{OH}^{0}$ site, creating an unstable bare $\equiv \mathrm{Ag}_{3}{ }^{0}$ site at dissolution. Deliberate addition of $\mathrm{H}_{2} \mathrm{O}_{2}{ }^{22,23,34}$ will enhance this process significantly.

The bare $\mathrm{Ag}$ lattice sites, generated during $\equiv \mathrm{Ag}_{3} \mathrm{OH}^{0}$ dissolution, may subsequently be oxidized leading to the formation of a new $\equiv \mathrm{Ag}_{3} \mathrm{OH}^{0}$ group. Once formed, the silver ions of the newly created $\equiv \mathrm{Ag}_{3} \mathrm{OH}^{0}$ surface group can release $\mathrm{Ag}^{+}$by oxidative dissolution as formulated in 
eq 2.6a, resulting in a circular process of silver release. This process can be interrupted by formation of a subsurface $\mathrm{Ag}_{6} \mathrm{O}$ octahedron, according to eq 2.6b. When finally reaching equilibrium, the ratio of $\equiv \mathrm{Ag}_{3} \mathrm{OH}^{0}$ and $\equiv \mathrm{Ag}_{6} \mathrm{O}^{0}$ sites will depend on the $\mathrm{Ag}^{+}$-concentration. The concentration of $\mathrm{Ag}^{+}$will be enhanced depending on the contribution of the circular dissolution process with reformation of $\equiv \mathrm{Ag}_{3} \mathrm{OH}^{0}$. Refreshment of the solution after reaching equilibrium restarts the oxidative dissolution process until a new equilibrium is reached. ${ }^{23}$

The above view is very different from the idea that $\mathrm{Ag}^{+}$-release is due to removal a soluble silver oxide coating. ${ }^{38} \mathrm{The}^{\mathrm{Ag}} \mathrm{g}^{+}$-release is rather the result of the formation of a layer of oxidized silver that kinetically protects AgNP against full oxidation of the metallic lattice.

\subsubsection{Surface complexation modelling.}

The above equilibrium (eq 2.6c) can be used in surface complexation modelling (SCM) for analyzing the behavior of AgNP suspensions and testing it against data available in literature. ECOSAT software ${ }^{69}$ was used for the equilibrium speciation calculations. The surface reaction can be defined with a tableau of surface species and components as given in Table 2.1.

Table 2.1 Tableau defining the formation reactions of surface species using $\equiv \mathrm{Ag}_{6} \mathrm{Ag}_{3} \mathrm{OH}^{0}$ as component. A Stern model approach is used with a capacitance value $C_{1}=0.3 \mathrm{~F} \mathrm{~m}^{-2}$ for the compact part of the EDL. The applied affinity constant is $\log K_{1}=-1$. The site density $N_{\mathrm{S}}\left(=4.7\right.$ sites $\left.\mathrm{nm}^{-2}\right)$ is set by the surface structure of the [111] face of AgNP. Any excess release of $\mathrm{Ag}^{+}$, which may occur when protective surface species are not properly formed, can be implemented in the calculation scheme to characterize the equilibrium state with protecting $\equiv \mathrm{Ag}_{6} \mathrm{O}$ and $\equiv \mathrm{Ag}_{6} \mathrm{Ag}_{3} \mathrm{OH}$ surface groups.

\begin{tabular}{|c|c|c|c|c|c|c|c|}
\hline Surface species ${ }^{a}$ & $\Delta \mathrm{z}_{0}$ & $\Delta \mathrm{z}_{1}$ & $\equiv \mathrm{Ag}_{6} \mathrm{Ag}_{3} \mathrm{OH}^{0}$ & $\mathrm{Ag}^{+}$ & $\mathrm{H}^{+}$ & $\mathrm{O}_{2}$ & $\log K$ \\
\hline$\equiv \mathrm{Ag}_{6} \mathrm{Ag}_{3} \mathrm{OH}^{0}$ & 0.5 & -0.5 & 1 & 0 & 0 & 0 & 0 \\
\hline$\equiv \mathrm{Ag}_{6} \mathrm{O}^{0}$ & 0 & 0 & 1 & -3 & +3 & 1 & $\log K_{1}$ \\
\hline
\end{tabular}

Formation of $\equiv \mathrm{Ag}_{6} \mathrm{O}^{0}$ is $\mathrm{pH}$ dependent (eq 2.6c). In the model, the $\mathrm{pH}$ dependency can be influenced by defining electrostatic interactions. In Table 2.1, charge separation is specified for $\equiv \mathrm{Ag}_{6} \mathrm{Ag}_{3} \mathrm{OH}^{0}$ by allocating charge of silver and $\mathrm{OH}$ to two different electrostatic planes that are separated by a so-called Stern layer. ${ }^{70}$ No charge separation is defined within the solid, i.e. the coefficients for $\equiv \mathrm{Ag}_{6} \mathrm{O}$ are set to zero. The introduction of charge separation broadens the $\mathrm{pH}$ range over which the transformation of $\equiv \mathrm{Ag}_{6} \mathrm{Ag}_{3} \mathrm{OH}^{0}$ to $\equiv \mathrm{Ag}_{6} \mathrm{O}^{0}$ occurs while without it, the model predicts a relatively narrow $\mathrm{pH}$ range (2-3 $\mathrm{pH}$ units)

\subsection{Results and discussion}

Our conceptual approach will be used to interpret a large range of phenomena, such as incomplete dissolution of AgNP, 24, 26-29 influence of particle size ${ }^{26,28,29}$ and solid-solution ratio, ${ }^{24,28}$ as well as the influence of $\mathrm{pH}^{22,26}$ and dissolved oxygen. ${ }^{21,22}$ 
In literature, individual datasets often refer to differently prepared AgNP materials. Moreover, AgNP behavior is typically studied under ill-defined conditions that are sparsely varied. In addition, the contribution of circular dissolution may vary between datasets. Therefore, our model can presently not be parameterized with certainty, but a first estimate will be given as far as data allow us.

\subsection{1 $\mathrm{pH}$ dependency of $\mathrm{Ag}^{+}$-release}

Almost no information on the $\mathrm{pH}$ dependency of the ionic $\mathrm{Ag}^{+}$-release is available in literature. A higher release has been reported when the $\mathrm{pH}$ value was lowered. ${ }^{22,}{ }^{26}$ Liu and Hurt ${ }^{22}$ measured a $\mathrm{pH}$ dependent $\mathrm{Ag}^{+}$-release after one day of reaction (Figure 2.6a). This experimental $\mathrm{Ag}^{+}$-release varies over a broad $\mathrm{pH}$ range. For modeling, the assumption is that the measured $\mathrm{Ag}^{+}$-concentrations correspond to the oxidative desorption of $\equiv \mathrm{Ag}_{3} \mathrm{OH}^{0} \sec$ (eq 2.6c) and that equilibrium is reached in this short period. With these assumptions, we have described the data with the model (Figure 2.6a) using the solid solution ratio (SSR) reported by Liu and Hurt ${ }^{22}$ and a calculated specific surface area based on the TEM size. Figure 2.6b illustrates the corresponding transformation between the two states of the AgNP surface. At neutral and high $\mathrm{pH}$, there is dominance of $\equiv \mathrm{Ag}_{3} \mathrm{OH}^{0}$, and at low $\mathrm{pH}$ there is dominance of subvalent $\mathrm{Ag}$ coordinating to a subsurface oxygen forming a $\mathrm{Ag}_{6} \mathrm{O}$ octahedron.
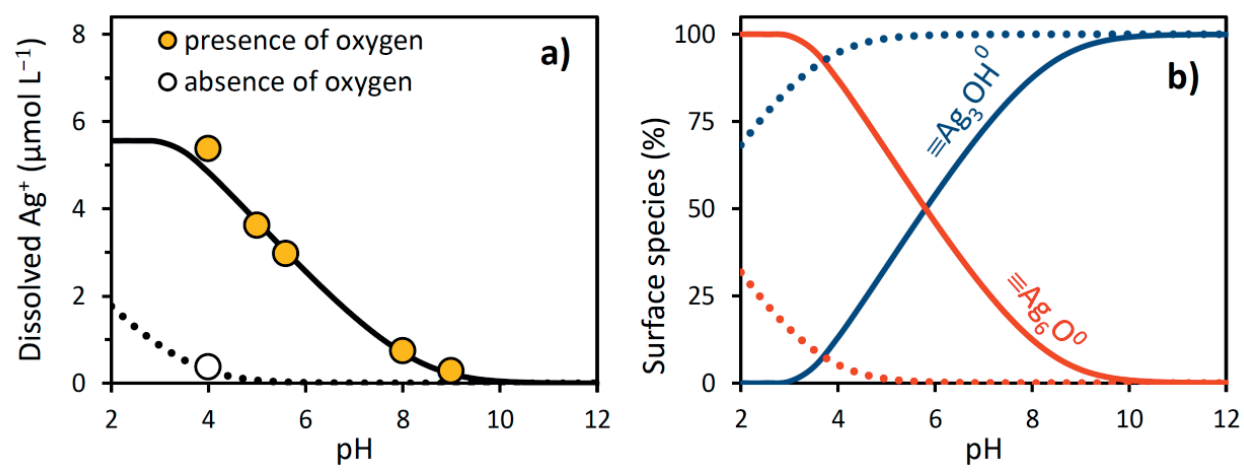

Figure 2.6 (a) $\mathrm{Ag}^{+}$-release after 1 day of reaction (symbols), measured by Liu and Hurt ${ }^{22}$ for a range of $\mathrm{pH}$ values using $5 \mathrm{mM}$ acetate and borate as buffers. The full line is a model calculation (Table 1) using a surface-solution ratio of $0.24 \mathrm{~m}^{2} \mathrm{~L}^{-1}$, which is based on the TEM size $(4.8 \pm 1.6 \mathrm{~nm})$ and SSR $\left(2 \mathrm{mg} \mathrm{L}^{-1}\right)$ reported by Liu and Hurt. ${ }^{22}$ The dotted arrow indicates the decrease of $\mathrm{Ag}^{+}$-release if the $\mathrm{AgNP}$ suspension is Ar-purged. In that case, no dissolved oxygen is available for oxidative release. (b) Relative surface speciation corresponding to the equilibrium line of Figure 2.6a, showing the oxidative removal of silver with formation of $\equiv \mathrm{Ag}_{6} \mathrm{O}^{\circ}$ at decrease of $\mathrm{pH}$. The dotted lines refer to an anoxic system with a chosen partial oxygen pressure of $\log p_{02}=-15$.

In our model, the $\mathrm{pH}$ dependency of the equilibrium process is related to value of the charge distribution $\left(\Delta z_{0}, \Delta z_{1}\right)$ at a given Stern layer capacitance. ${ }^{71}$ Rather arbitrary, the capacitance value for our model has presently been set to the mean of the value for the inner and outer 
capacitance of $\mathrm{Agl}^{60}$. The charge distribution was then chosen (Table 2.1) to obtain a gradual change of the $\mathrm{Ag}^{+}$-release as a function of $\mathrm{pH}$. Without charge separation, there are no electrostatic interactions, which results in a narrower $\mathrm{pH}$ range of transformation. At the fitted charge distribution, $\log K_{1}=-1$ for eq $2.6 \mathrm{c}$.

Data on the $\mathrm{Ag}^{+}$-release upon acidification as measured by Peretyazhko et al. ${ }^{26}$ can also be interpreted quantitatively, but this will be discussed later in Section 2.5.4.

\subsubsection{Influence of surface area on $\mathrm{Ag}^{+}$-release}

If the release of $\mathrm{Ag}^{+}$is due to surface processes, it will be directly related to the total amount of surface area available in an experiment. This number depends on the specific surface area $A$ of the particles $\left(\mathrm{m}^{2} \mathrm{~g}^{-1}\right)$, as well as on the solid-solution ratio of the AgNP suspension $\left(\mathrm{g} \mathrm{L}^{-1}\right)$ used. Therefore, data should be evaluated using the surface-solution ratio $\left(\mathrm{m}^{2} \mathrm{~L}^{-1}\right)$, rather than only the specific surface area or size of the particles used in the experiments.

In Figure 2.7, the experimental equilibrium concentrations reached at near-neutral pH values have been plotted versus the total surface area per liter used in the various experiments. The total surface area has been calculated from the reported particle sizes (as determined by TEM) and solid-solution ratios $\left(\mathrm{g} \mathrm{L}^{-1}\right)$. In all data sets, the reported equilibrium concentrations increase with the total AgNP surface area, following in most cases a near-linear trend (Figure 2.7). It suggests that the equilibrium concentration is regulated by a surface process rather than a bulk process.

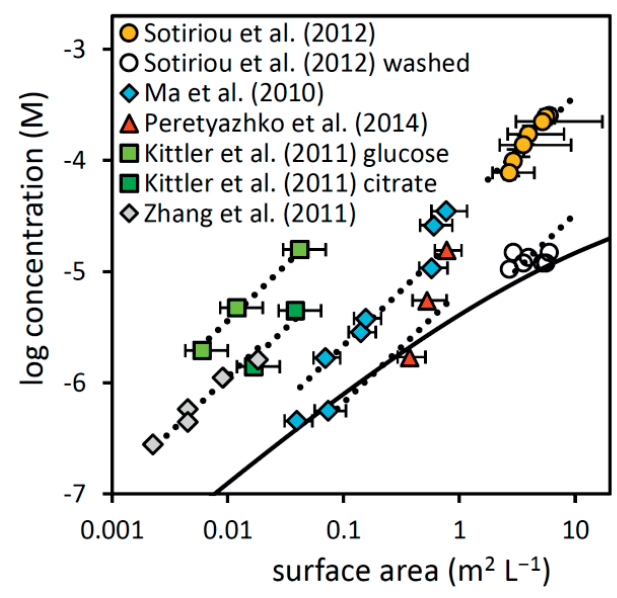

Figure 2.7 $\mathrm{Ag}^{+}$-concentrations reported by various authors in the neutral $\mathrm{pH}$ range in the presence of oxygen (Table A2) plotted against the calculated AgNP surface area $\left(\mathrm{m}^{2} \mathrm{~L}^{-1}\right)$. The full line refers to the predicted concentration if $\mathrm{Ag}^{+}$is released only from $\equiv \mathrm{Ag}_{3} \mathrm{OH}^{0}$, using the model parameters of Table 1 . The AgNP in the datasets of Sotiriou et al. ${ }^{27}$ differ in pretreatment. In one set, AgNP have been used as is, and in the other, the AgNP have been washed prior to use. The two datasets of Kittler et al. ${ }^{24}$ differ in the choice of the reductant (either glucose or citrate) used during in-home preparation. 


\subsubsection{Excess $\mathrm{Ag}^{+}$-release}

When data sets of various laboratory experiments are compared, one observes significant differences in the equilibrium concentration reached. Assuming a linear relationship between final concentration and total surface area in the experiments, the mean release of $\mathrm{Ag}$ can be represented in Figure 2.7 by dotted lines. The corresponding average release of silver at nearneutral $\mathrm{pH}$ can be expressed in a fraction of a monolayer $(\mathrm{ML})$ of silver present at the [111] face $\left(1 \mathrm{ML}=23.4 \mu \mathrm{mol} \mathrm{m}{ }^{-2}\right)$. These values are given in Table $\mathrm{A} 2$.

If $\mathrm{Ag}^{+}$-release is restricted to a stoichiometric release given by the equilibration reaction according to eq $2.6 \mathrm{c}$, only a small amount of $\mathrm{Ag}^{+}$is released from the $\equiv \mathrm{Ag}_{3} \mathrm{OH}^{0}$ sites at circumneutral $\mathrm{pH}$ according to Figure 2.6. The corresponding amount of $\mathrm{Ag}^{+}$-release is then typically in the order of 1-2 $\mu \mathrm{mol} \mathrm{m} \mathrm{m}^{-2}$. In many cases (Figure 2.7), the silver release is higher than explained by the surface desorption reaction only. Large excess release may have at least two different causes.

A) The particles of Sotiriou et al. ${ }^{27}$ have been made at high temperatures (dry powder synthesis) which may have resulted in the formation of some fully oxidized $\mathrm{Ag}_{2} \mathrm{O}$ on their surfaces, as suggested by the authors. This idea agrees with the rate of $\mathrm{Ag}^{+}$-release. An almost instantaneous ( $\sim 15$ minutes) and very large release of $\mathrm{Ag}^{+}$is observed when these samples are used (colored spheres in Figure 2.7), while oxidative desorption and dissolution of the metallic lattice may have approximate time scales of respectively days and weeks. ${ }^{24,26,28}$ If the original samples of Sotiriou et al. ${ }^{27}$ were washed first, the $\mathrm{Ag}^{+}$-release is much lower (open spheres in Figure 2.7) and much closer to the model calculation without excess silver release (full line in Figure 2.7). Annealing of the sample during the high temperature synthesis may have contributed to this.

B) The data in Figure 2.7 suggest a very high excess release for the particles used by Kittler et al. ${ }^{24}$ and Zhang et al. ${ }^{28}$ The equivalent of several monolayers of Ag is released (Table A2). Kittler et al. ${ }^{24}$ report that their particles were crystalline, but highly twinned. Zhang et al. ${ }^{28}$ interpret the multi-ringed electron diffraction pattern as an indication of poly-crystallinity. Henglein and Giersig ${ }^{44}$ suggested that at too low concentrations of a stabilizing agent (citrate), nucleated $\mathrm{Ag}$ crystallites may coalesce during synthesis resulting in formation of polycrystalline AgNP with multiple twinning. These phenomena are observed by Kittler et al. ${ }^{24}$ and Zhang et al. ${ }^{28}$ It suggests low crystallinity in these AgNP samples and this may readily prevent formation of a sealing surface layer of $\equiv \mathrm{Ag}_{3} \mathrm{OH}^{0}$ and $\equiv \mathrm{Ag}_{6} \mathrm{O}^{0}$. Instead, a relatively long time of restructuring is needed and more $\mathrm{Ag}^{+}$can be released by the circular process with continuous dissolution and reformation of $\equiv \mathrm{Ag}_{3} \mathrm{OH}^{0}$.

Ma et al. ${ }^{29}$ have used a series of differently produced AgNP samples (Table A2). Their samples have been washed twice with demineralized water prior to use and have been equilibrated for up to 80 days in an air-saturated $1 \mathrm{mM} \mathrm{NaHCO}_{3}$ solution ( $\left.\mathrm{pH} \sim 8\right)$. The particles with a low specific surface area equilibrate according to our model, but for smaller particles with a higher surface area, excess release is found which is close to a monolayer of Ag. This upward trend is 
also found for the particles of Peretyazhko et al., ${ }^{26}$ studying the release at $\mathrm{pH} \sim 7$, although their excess release is significantly less. A possible reason for a lower excess might be the difference in $\mathrm{pH}$ used. Ho et al. ${ }^{34}$ found a tenfold increase of the rate of $\mathrm{Ag}^{+}$release per increased $\mathrm{pH}$ unit, which was attributed to the proton dissociation of $\mathrm{H}_{2} \mathrm{O}_{2}$ forming very reactive $\mathrm{HO}_{2}^{-}$. This may stimulate the circular process with excess $\mathrm{Ag}^{+}$-release.

\subsubsection{Surface release at acidification}

Peretyazhko et al. ${ }^{26}$ have measured the equilibrium $\mathrm{Ag}^{+}$-release at both, acid $(\mathrm{pH} \sim 3)$ and neutral $(\mathrm{pH} \sim 7)$ conditions. This equilibrium release can quantitatively be related to the surface structure proposed in Figure 2.4. As shown in Figure 2.6a, nearly all $\mathrm{Ag}^{+}$can be released from the $\equiv \mathrm{Ag}_{3} \mathrm{OH}^{0}$ groups upon acidification to $\mathrm{pH}=3$, and therefore, the increase in $\mathrm{Ag}^{+}-$ release might be a measure for the site density of the $\equiv \mathrm{Ag}_{3} \mathrm{OH}^{0}$ groups.

The difference in $\mathrm{Ag}^{+}$-release upon acidification has been calculated for the data of Peretyazhko et al..$^{26}$ and plotted in Figure 2.8 against AgNP surface area $\left(\mathrm{m}^{2} \mathrm{~L}^{-1}\right)$. An additional data point can be found by extrapolation of the data of Liu and Hurt. ${ }^{22}$ Even though differently produced particles were used, a near-linear relationship is observed. The model prediction is given with the dotted line that was calculated with the $\equiv \mathrm{Ag}_{3} \mathrm{OH}^{0}$ site density $\left(4.7\right.$ sites $\left.\mathrm{nm}^{-2}\right)$, which corresponds to the surface structure of Figure 2.4. The good agreement between model and data gives credit to the proposed surface structure.

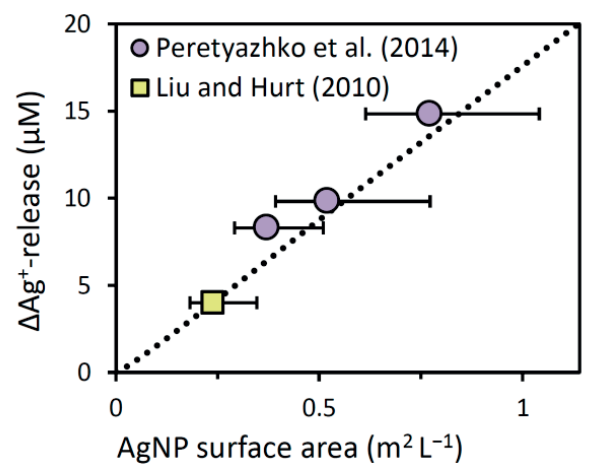

Figure 2.8 Calculated difference $(\Delta)$ between concentrations of $\mathrm{Ag}^{+}$at $\mathrm{pH} \sim 7$ and $\mathrm{pH} \sim 3$ for $\mathrm{AgNP}$ of different sizes, ranging from $6-70 \mathrm{~nm}$ (Table A2). The dotted line represents the difference in $\mathrm{Ag}^{+}-$ release $(\mu \mathrm{M})$ between $\mathrm{pH} \sim 3$ and $\mathrm{pH} \sim 7$ depending on surface area $\left(\mathrm{m}^{2} \mathrm{~L}^{-1}\right)$ as predicted by the model.

\subsubsection{Oxygen dependency}

An important point to address is the oxygen dependency of the formation of surface species and its relation to the stability of AgNP. Under oxidized conditions, $\equiv \mathrm{Ag}_{3} \mathrm{OH}^{0}$ species can transform to $\equiv \mathrm{Ag}_{6} \mathrm{O}^{\circ}$ depending on solution conditions such as $\mathrm{pH}$ and silver ion concentration. The transformation will also depend on the partial oxygen pressure according to eq 2.6c. 
In Figure 2.9, the relative distribution of surface species is given as a function of the partial oxygen pressure. The system was defined with exactly enough $\mathrm{Ag}^{+}$to form a full monolayer of $\equiv \mathrm{Ag}_{3} \mathrm{OH}^{0}$ groups. Under oxygen rich conditions and neutral $\mathrm{pH}$, only a small fraction of $\equiv \mathrm{Ag}_{3} \mathrm{OH}^{0}$ will transform to $\equiv \mathrm{Ag}_{6} \mathrm{O}^{0}$ due to oxidative release. The contribution of the surface species with less subvalent silver (i.e. $\equiv \mathrm{Ag}_{3} \mathrm{OH}^{0}$ ) will increase further when the system is deoxygenated. At low $\mathrm{pH}$ (dotted lines), $\equiv \mathrm{Ag}_{6} \mathrm{O}^{0}$ is dominant in aerated systems, as we think occurred in the work of Henglein ${ }^{58}$ when AgNP were exposed to oxygen in an acid solution (Figure 2.3). However, at a low partial pressure of $\mathrm{O}_{2}, \equiv \mathrm{Ag}_{3} \mathrm{OH}^{0}$ will be dominant. In principle, transformation to a bare metallic surface with $\equiv \mathrm{Ag}_{3}{ }^{0}$ sites will occur if the redox potential is strongly decreased, but the corresponding conditions cannot be quantified yet.

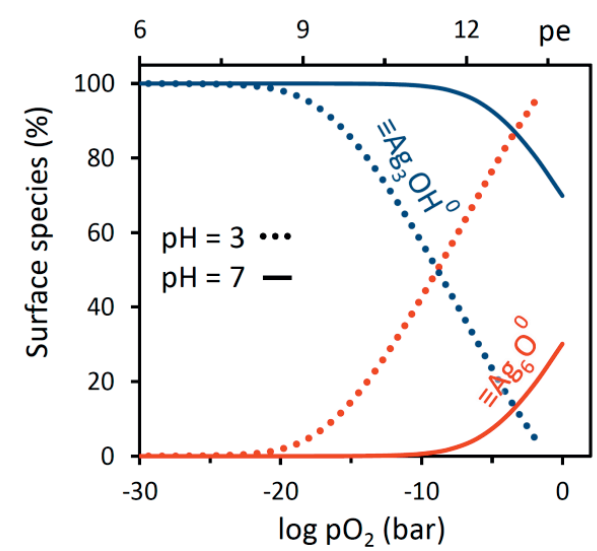

Figure 2.9 Surface speciation of AgNP as a function of redox condition expressed in the partial pressure $p_{02}$ (primary $\mathrm{x}$-axis) and pe-value (secondary $\mathrm{x}$-axis) for two different $\mathrm{pH}$ values at a surface solution ratio of $0.3 \mathrm{~m}^{2} \mathrm{~L}^{-1}$, showing high stability of $\equiv \mathrm{Ag}_{3} \mathrm{OH}^{0}$ in neutral, oxygenated water and dominance of $\equiv \mathrm{Ag}_{6} \mathrm{O}^{\circ}$ at low $\mathrm{pH}$ in oxygenated water. Solid and dotted lines represent simulations at $\mathrm{pH} 7$ and $\mathrm{pH} 3$, respectively. The calculations are made for a system with AgNP that were initially fully covered by $\equiv \mathrm{Ag}_{3} \mathrm{OH}^{0}$ surface groups.

\subsection{6 $\mathrm{Ag}^{+}$-concentration dependency}

From the reaction scheme for $\mathrm{Ag}^{+}$-release (Table 2.1), it can be seen that besides protons and oxygen, ionic silver concentrations will also affect the desorption equilibrium. Silver concentrations in AgNP systems can be influenced by variation in solid-solution ratios, excess $\mathrm{Ag}^{+}$-release, and $\mathrm{Ag}^{+}$-complexing agents present in solution.

In Figure 2.10, the effect of the free silver activity on surface speciation has been plotted for two $\mathrm{pH}$ values in a system as defined in the legend. Lowering the $\mathrm{Ag}^{+}$-activity leads to destabilization of $\equiv \mathrm{Ag}_{3} \mathrm{OH}^{0}$ and formation of $\equiv \mathrm{Ag}_{6} \mathrm{O}^{0}$. Under oxidized conditions at low $\mathrm{pH}$, $\equiv \mathrm{Ag}_{6} \mathrm{O}^{0}$ is stable below $\log \left(\mathrm{Ag}^{+}\right) \sim-5$, whereas at $\mathrm{pH} 7, \equiv \mathrm{Ag}_{3} \mathrm{OH}^{0}$ is fully dominant above this $\mathrm{Ag}^{+}$-activity. 


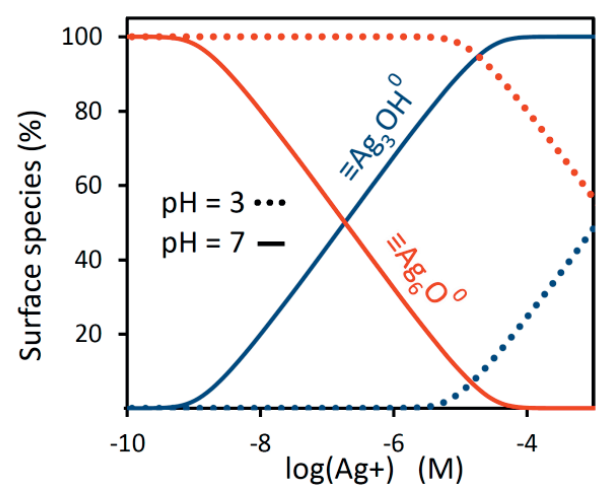

Figure 2.10 Surface speciation of $\mathrm{AgNP}$ as a function of $\mathrm{Ag}^{+}$-activity for $\mathrm{pH} 7$ (full lines) and $\mathrm{pH} 3$ (dotted lines), at atmospheric oxygen pressure ( 0.2 bar). At very low $\mathrm{Ag}^{+}$-activities, $\equiv \mathrm{Ag}_{3} \mathrm{OH}^{0}$ groups fully oxidize and desorb, even at neutral conditions

When $\mathrm{Ag}^{+}$is already present before adding the $\mathrm{AgNP}$, less $\equiv \mathrm{Ag}_{3} \mathrm{OH}^{0}$ groups will become oxidized and desorb. This agrees qualitatively with experimental observations made by Liu and Hurt, ${ }^{22}$ who found that much less silver was released from their $\mathrm{AgNP}$ when $\mathrm{AgClO}_{4}$ was added to the reaction medium. ${ }^{22}$ This excess $\mathrm{Ag}^{+}$will contribute to the stabilization of $\equiv \mathrm{Ag}_{3} \mathrm{OH}^{0}$.

In environmental systems with AgNP, the surface-solution ratio will be very low. Silver ions released by oxidative desorption will diffuse away in the large matrix and the free $\mathrm{Ag}^{+}$concentration will be low. Our calculations show (Figure 2.10) that under these conditions $\equiv \mathrm{Ag}_{6} \mathrm{O}^{0}$ can be the dominant species that may contribute to the stabilization of the particle if a well-structured surface can be formed.

\subsubsection{Particle charge and zeta-potential}

The electrophoretic mobility of AgNP has received some interest in recent years. Experiments show that AgNP without capping agents may have a $\mathrm{pH}$-dependent particle charge. ${ }^{72,73}$ Under mildly acid conditions $(\mathrm{pH}<3)$, the particle is uncharged or even positively charged. The low value of the isoelectric point (IEP) indicates that the AgNP are negatively charged in the $\mathrm{pH}$ range that is generally used in dissolution experiments. However, in our model, all surface species are uncharged (Table 2.1).

In literature, it has been suggested that negative zeta-potentials can be created on hydrophobic surfaces by interrupting the network of hydrogen bonds in water. In the model of Lützenkirchen et al. ${ }^{74}$ orientation of water leads to interfacial charge that is compensated by $\mathrm{OH}$ in the water network at some distance. ${ }^{75}$ The model may also be applied to AgNP, introducing charge in the interface. If this charge coincides with the location of the $\mathrm{OH}$ ions of $\equiv \mathrm{Ag}_{3} \mathrm{OH}^{0}$, there is no influence on the transformation defined in eq 2.6c. Model calculations show that the potential difference $\left(\psi_{0}-\psi_{1}\right)$ between the 0 - and 1-plane is not influenced by introducing charge at the 1-plane, i.e. the $\mathrm{pH}$ dependency is not affected. It implies that 
introduction of charge by capping agents (e.g. citrate) will likewise have no influence on the $\mathrm{pH}$ dependency of $\mathrm{Ag}^{+}$-release according to the model.

\subsection{Conclusions and summary}

The above can be summarized in a number of conclusions.

Subvalence of $\mathrm{Ag}$ is the key for understanding the oxidative release of ionic $\mathrm{Ag}$ from AgNP. Subvalence can be created at partial oxidation of the surfaces of AgNP. Subvalence is a fundamental property of $\mathrm{Ag}$ in a specific class of materials comprising $\mathrm{Ag}_{6} \mathrm{O}_{2}, \mathrm{Ag}_{2} \mathrm{~F}$, and $\mathrm{Ag}_{2} \mathrm{NiO}_{2}$ (Figures S4). These minerals all have double sheets of $\mathrm{Ag}$ in their crystal structure. Subvalence is also found for $\mathrm{Ag}_{13}$ clusters (Figure 2.5), being a precursor for AgNP.

The surface structure of AgNP is determined by silver in a subvalent state. Oxidation of $\mathrm{Ag}$ at the [111] face of metallic $\mathrm{Ag}$ (Figure 2.1) creates semi-metallic silver with a formal charge of $Z_{\mathrm{Ag}}=+1 / 3 \mathrm{v}$.u. that can be neutralized by an $\mathrm{OH}$ group forming $\equiv \mathrm{Ag}_{3} \mathrm{OH}^{0}$ at the surface (Figure 2.4), having a bond valence of $v_{\mathrm{Ag}}=+1 / 3 \mathrm{v}$.u. The surface oxidation can be doubled (Figure 2.3) by the formation of a double layer of subvalent silver present in $\mathrm{Ag}_{6} \mathrm{O}$ octahedra (Figure 2.1c), having the same valence $\left(z_{\mathrm{Ag}}\right)$ and bond valence $\left(v_{\mathrm{Ag}}\right)$ as the $\equiv \mathrm{Ag}_{3} \mathrm{OH}^{0}$ groups at the external surface.

The solid-water interface of $\mathrm{AgNP}$ will release $\mathrm{Ag}^{+}$-ions upon oxidative dissolution of $\equiv \mathrm{Ag}_{3} \mathrm{OH}^{0}$ groups (Figure 2.4) with a two-electron step (eq 6a), releasing radicals that contribute to the formation of subsurface oxygens with related subvalent silver $\left(\equiv \mathrm{Ag}_{6} \mathrm{O}^{\circ}\right)$. This process can be described with surface complexation modeling (Table 1 ). The modeling predicts a $\mathrm{pH}$ dependent $\mathrm{Ag}^{+}$-release that is only significant in oxygenated conditions (Figure 2.6), but very little appropriate data exists to establish proper parameters. The $\mathrm{Ag}^{+}$-release is close to 18 $\mu \mathrm{mol} \mathrm{m} \mathrm{m}^{-2}$ (Figure 2.8) when systems are acidified from $\mathrm{pH} \sim 7$ to $\mathrm{pH} \sim 3$. The changes in surface speciation as a function of $\mathrm{pH}$ and oxygen pressure are respectively given in Figure 2.6 and Figure 2.9.

Many types of AgNP may release additional $\mathrm{Ag}^{+}$(Figure 2.7, Table $\mathrm{A} 2$ ) that can be attributed to a circular process with dissolution of $\equiv \mathrm{Ag}_{3} \mathrm{OH}^{0}$, creation of new metallic sites at the underlying lattice, and subsequent oxidation to $\equiv \mathrm{Ag}_{3} \mathrm{OH}^{0}$. This process is driven by reactive oxygen species (ROS) created and consumed by oxidative dissolution of $\equiv \mathrm{Ag}_{3} \mathrm{OH}^{0}$. However, this regeneration process is interrupted by penetration of $\mathrm{O}^{\bullet}$ radicals into the lattice forming highly stable $\mathrm{Ag}_{6} \mathrm{O}$ octahedra with subvalent silver that protects $\mathrm{AgNP}$ for further oxidation. The efficiency of $\equiv \mathrm{Ag}_{6} \mathrm{O}^{0}$ formation depends on the initial crystallinity and the ability of AgNP to restructure during the oxidative dissolution process.

Our view is very different from the idea that $\mathrm{Ag}^{+}$-release is due to removal of a silver oxide coating. $\mathrm{Ag}^{+}$-release is rather the result of formation of a protective oxidized $\mathrm{Ag}$ layer that kinetically prevents full oxidation of AgNP. 
Based on our structural analysis, a model has been developed that describes the release of silver ions as a function of $\mathrm{pH}$ (Figures 2.6, and 2.8), $\mathrm{Ag}^{+}$-concentration (Figure 2.10), partial pressure of oxygen (Figure 2.9), as well as other experimental conditions such as the solidsolution ratio, particle size, and initial state of oxidation of AgNP (Figure 2.7). At low oxygen pressure, the surface is dominated by $\equiv \mathrm{Ag}_{3} \mathrm{OH}^{0}$. In the presence of oxygen, $\equiv \mathrm{Ag}_{6} \mathrm{O}^{0}$ is stable at low $\mathrm{pH}$ and/or at a low activity of $\mathrm{Ag}^{+}$in solution. Our model can be improved by studying the $\mathrm{pH}$ dependency of desorption and dissolution processes with more detail.

\subsection{References}

1. T. Hiemstra, Geochimica et Cosmochimica Acta, 2015, 158, 179-198.

2. G. Merga, R. Wilson, G. Lynn, B. H. Milosavljevic and D. Meisel, The Journal of Physical Chemistry C, 2007, 111, 12220-12226.

3. N. Pradhan, A. Pal and T. Pal, Langmuir, 2001, 17, 1800-1802.

4. S. Saha, A. Pal, S. Kundu, S. Basu and T. Pal, Langmuir, 2009, 26, 2885-2893.

5. A. M. Signori, K. d. O. Santos, R. Eising, B. L. Albuquerque, F. C. Giacomelli and J. B. Domingos, Langmuir, 2010, 26, 17772-17779.

6. G. I. N. Waterhouse, G. A. Bowmaker and J. B. Metson, Applied Surface Science, 2003, 214, 36-51.

7. M. E. Vance, T. Kuiken, E. P. Vejerano, S. P. McGinnis, M. F. Hochella, Jr., D. Rejeski and M. S. Hull, Beilstein Journal of Nanotechnology, 2015, 6, 1769-1780.

8. T. M. Benn and P. Westerhoff, Environ. Sci. Technol., 2008, 42, 4133-4139.

9. R. Kaegi, B. Sinnet, S. Zuleeg, H. Hagendorfer, E. Mueller, R. Vonbank, M. Boller and M. Burkhardt, Environmental Pollution, 2010, 158, 2900-2905.

10. O. Choi and Z. Hu, Environ. Sci. Technol., 2008, 42, 4583-4588.

11. J. Fabrega, J. C. Renshaw and J. R. Lead, Environ. Sci. Technol., 2009, 43, 9004-9009.

12. C. N. Lok, C. M. Ho, R. Chen, Q. Y. He, W. Y. Yu, H. Sun, P. K. H. Tam, J. F. Chiu and C. M. Che, Journal of Proteome Research, 2006, 5, 916-924.

13. K. Schlich, T. Klawonn, K. Terytze and K. Hund-Rinke, Environmental Sciences Europe, 2013, 25, 17.

14. W. A. Shoults-Wilson, B. C. Reinsch, O. V. Tsyusko, P. M. Bertsch, G. V. Lowry and J. M. Unrine, Soil Sci. Soc. Am. J., 2011, 75, 365-377.

15. M. J. C. van der Ploeg, R. D. Handy, P. L. Waalewijn-Kool, J. H. J. van den Berg, Z. E. Herrera Rivera, J. Bovenschen, B. Molleman, J. M. Baveco, P. Tromp, R. J. B. Peters, G. F. Koopmans, I. M. C. M. Rietjens and N. W. van den Brink, Environmental Toxicology and Chemistry, 2014, 33, 743-752.

16. X. Yang, A. P. Gondikas, S. M. Marinakos, M. Auffan, J. Liu, H. Hsu-Kim and J. N. Meyer, Environ. Sci. Technol., 2011, 46, 1119-1127.

17. L. Yin, Y. Cheng, B. Espinasse, B. P. Colman, M. Auffan, M. Wiesner, J. Rose, J. Liu and E. S. Bernhardt, Environ. Sci. Technol., 2011, 45, 2360-2367.

18. H. C. Poynton, J. M. Lazorchak, C. A. Impellitteri, B. J. Blalock, K. Rogers, H. J. Allen, A. Loguinov, J. L. Heckman and S. Govindasmawy, Environ. Sci. Technol., 2012, 46, 62886296.

19. M. Yeo and M. Kang, Bulletin of the Korean Chemical Society, 2008, 29, 1179.

20. M. H. Shen, X. X. Zhou, X. Y. Yang, J. B. Chao, R. Liu and J. F. Liu, Scientific Reports, 2015, 5. 
21. Z. M. Xiu, Q. B. Zhang, H. L. Puppala, V. L. Colvin and P. J. J. Alvarez, Nano Letters, 2012, $12,4271-4275$.

22. J. Liu and R. H. Hurt, Environ. Sci. Technol., 2010, 44, 2169-2175.

23. K. Loza, J. Diendorf, C. Sengstock, L. Ruiz-Gonzalez, J. M. Gonzalez-Calbet, M. Vallet-Regi, M. Köller and M. Epple, Journal of Materials Chemistry B, 2014, 2, 1634-1643.

24. S. Kittler, C. Greulich, J. Diendorf, M. Köller and M. Epple, Chemistry of Materials, 2010, $22,4548-4554$.

25. J. Liu, D. A. Sonshine, S. Shervani and R. H. Hurt, ACS Nano, 2010, 4, 6903-6913.

26. T. S. Peretyazhko, Q. Zhang and V. L. Colvin, Environmental Science \& Technology, 2014, 48, 11954-11961.

27. G. A. Sotiriou, A. Meyer, J. T. N. Knijnenburg, S. Panke and S. E. Pratsinis, Langmuir, 2012, 28, 15929-15936.

28. W. Zhang, Y. Yao, N. Sullivan and Y. S. Chen, Environmental Science \& Technology, 2011, 45, 4422-4428.

29. R. Ma, C. m. Levard, S. M. Marinakos, Y. Cheng, J. Liu, F. M. Michel, G. E. Brown, Jr. and G. V. Lowry, Environmental Science \& Technology, 2011, 46, 752-759.

30. X. Li, J. J. Lenhart and H. W. Walker, Langmuir, 2011, 28, 1095-1104.

31. X. Li, J. J. Lenhart and H. W. Walker, Langmuir, 2010, 26, 16690-16698.

32. D. He, M. W. Bligh and T. D. Waite, Environmental Science \& Technology, 2013, 47, 9148 9156.

33. J. Dobias and R. Bernier-Latmani, Environ. Sci. Technol., 2013, 47, 4140-4146.

34. C. M. Ho, S. K. W. Yau, C. N. Lok, M. H. So and C. M. Che, Chemistry - An Asian journal, 2010, 5, 285.

35. C. M. Ho, C. K. Wong, S. K. W. Yau, C. N. Lok and C. M. Che, Chem. Asian J., 2011, 6, 25062511.

36. N. M. Martin, S. Klacar, H. Grönbeck, J. Knudsen, J. Schnadt, S. Blomberg, J. Gustafson and E. Lundgren, The Journal of Physical Chemistry C, 2014, 118, 15324-15331.

37. P. S. Yen and R. Datta, Journal of Colloid and Interface Science, 2014, 426, 314-323.

38. C. Levard, E. M. Hotze, G. V. Lowry and G. E. Brown, Jr., Environmental Science \& Technology, 2012, 46, 6900-6914.

39. A. M. Mittelman, A. Taghavy, Y. Wang, L. M. Abriola and K. D. Pennell, Journal of Nanoparticle Research, 2013, 15, 1-13.

40. W. P. Davey, Physical Review, 1925, 25, 753-761.

41. E. R. Jette and F. Foote, The Journal of Chemical Physics, 1935, 3, 605-616.

42. I. K. Suh, H. Ohta and Y. Waseda, Journal of Materials Science, 1988, 23, 757-760.

43. J. C. Azcárate, G. Corthey, E. Pensa, C. Vericat, M. H. Fonticelli, R. C. Salvarezza and P. Carro, The Journal of Physical Chemistry Letters, 2013, 4, 3127-3138.

44. A. Henglein and M. Giersig, The Journal of Physical Chemistry B, 1999, 103, 9533-9539.

45. H. Hofmeister, Encyclopedia of Nanoscience and Nanotechnology, 2004, 3, 431.

46. P. Niggli, Zeitschrift für Kristallographie - Crystalline Materials, 1922, 57, 253.

47. R. W. G. Wyckoff, American Journal of Science, 1922, 5, 184.

48. L. Pauling, Journal of the American Chemical Society, 1929, 51, 1010-1026.

49. S. S. Kabalkina, S. V. Popova, N. R. Serebrjanaja and L. F. Vereshchagin, Doklady Akademii Nauk SSSR, 1963, 152, 853-855.

50. W. Beesk, P. G. Jones, H. Rumpel, E. Schwarzmann and G. M. Sheldrick, Journal of the Chemical Society, Chemical Communications, 1981, DOI: 10.1039/C39810000664, 664665. 
51. R. Birkenberg and E. Schwarzmann, Zeitschrift für Naturforschung B, 1974, 29, 113-114.

52. H. Müller-Buschbaum, Zeitschrift für anorganische und allgemeine Chemie, 2004, 630, 2125-2175.

53. I. D. Brown and D. Altermatt, Acta Crystallographica Section B, 1985, 41, 244-247.

54. H. Ott and H. Seyfarth, Zeitschrift für Kristallographie - Crystalline Materials, 1928, 67, 430-433.

55. U. Wedig, P. Adler, J. Nuss, H. Modrow and M. Jansen, Solid State Sciences, 2006, 8, 753763.

56. M. D. Johannes, S. Streltsov, I. I. Mazin and D. I. Khomskii, Physical Review B, 2007, 75, 180404(R).

57. S. Ahlert, W. Klein, O. Jepsen, O. Gunnarsson, O. K. Andersen and M. Jansen, Angewandte Chemie International Edition, 2003, 42, 4321.

58. A. Henglein, Chemistry of Materials, 1998, 10, 444-450.

59. T. Hiemstra, P. Venema and W. H. van Riemsdijk, Journal of Colloid and Interface Science, $1996,184,680-692$.

60. T. Hiemstra, Langmuir, 2012, 28, 15614-15623.

61. M. Pereiro, D. Baldomir and J. E. Arias, Physical Review A, 2007, 75.

62. C. Batchelor-McAuley, K. Tschulik, C. C. M. Neumann, E. Laborda and R. G. Compton, International Journal of Electrochemical Science, 2014, 9, 1132-1138.

63. A. U. Nilekar and M. Mavrikakis, Surface Science, 2008, 602, L89-L94.

64. J. Sun, L. He, Y.-C. Lo, T. Xu, H. Bi, L. Sun, Z. Zhang, S. X. Mao and J. Li, Nature Materials, 2014, 13, 1007-1012.

65. J. A. Keith and T. Jacob, Angewandte Chemie International Edition, 2010, 49, 9521-9525.

66. M. Shi, H. S. Kwon, Z. Peng, A. Elder and H. Yang, ACS Nano, 2012, 6, 2157-2164.

67. L. Demarconnay, C. Coutanceau and J. M. Léger, Electrochimica Acta, 2004, 49, 45134521.

68. Y. Li, W. Zhang, J. Niu and Y. Chen, Environ. Sci. Technol., 2013, 47, 10293-10301.

69. M. G. Keizer and W. H. van Riemsdijk, Manual Program, Agricultural University, Wageningen, 1994

70. O. Stern, Zeitschrift für Elektrochemie und angewandte physikalische Chemie, 1924, 30, 508-516.

71. T. Hiemstra and W. H. van Riemsdijk, Journal of Colloid and Interface Science, 1996, 179, 488-508.

72. A. M. El Badawy, T. P. Luxton, R. G. Silva, K. G. Scheckel, M. T. Suidan and T. M. Tolaymat, Environ. Sci. Technol., 2010, 44, 1260-1266.

73. J. Hedberg, M. Lundin, T. Lowe, E. Blomberg, S. Wold and I. O. Wallinder, Journal of Colloid and Interface Science, 2012, 369, 193-201.

74. J. Lützenkirchen, T. Preočanin and N. Kallay, Physical Chemistry Chemical Physics, 2008, 10, 4946-4955.

75. R. Zangi and J. B. Engberts, Journal of the American Chemical Society, 2005, 127, 22722276. 



\section{Chapter 3}

Time, $\mathrm{pH}$, and size dependency of silver nanoparticle dissolution: the road to equilibrium

Bastiaan Molleman and Tjisse Hiemstra

Published in Environmental Science: Nano

Volume 4, Issue 6, Pages 1314-1327, 12 April 2017 


\section{Abstract}

Oxidative dissolution has large implications for the environmental fate and toxicity of silver nanoparticles (AgNPs). In this study, we quantify the kinetics, $\mathrm{pH}$, and size dependency of silver ion $\left(\mathrm{Ag}^{+}\right)$release from $\mathrm{AgNPs}$ and explain our results in a consistent manner with a mechanistic view. Pristine AgNPs are covered by partially oxidized silver present in a single layer of subvalent $\equiv \mathrm{Ag}_{3} \mathrm{OH}$ groups that will be released by oxidative dissolution via two different pathways. Undersaturation of a solution created by acidification will initiate a fast oxidative dissolution process in which a pristine surface can be opened at particular points that grow laterally until a full layer of $\mathrm{Ag}$ is stripped off. At the newly exposed surface, $\equiv \mathrm{Ag}_{3} \mathrm{OH}$ is reformed. The opening of new spots stops due to increasing $\mathrm{Ag}^{+}$concentrations. Via another pathway, the initial $\equiv \mathrm{Ag}_{3} \mathrm{OH}$ can be released by oxidative dissolution while simultaneously a new stable surface state is built with subvalent silver in two layers. This process is initiated by dilution and active around neutral $\mathrm{pH}$ values and may release a maximum of $30 \pm 1 \mu \mathrm{mol} \mathrm{Ag}^{+}$ $\mathrm{m}^{-2}$. Its equilibration can be well described with a formulated thermodynamic model. The equilibrium constant $(\log K)$ is linearly related to the specific surface area of the AgNPs used, but can be shifted by the type of capping agent. The particle size dependency of the $\log K$ can be attributed to a surface Gibbs free energy contribution of $0.7 \pm 0.1 \mathrm{~J} \mathrm{~m}^{-2}$. $\mathrm{Ag}^{+}$release by stripping is relatively fast ( 1 day) in contrast to the process that leads to equilibration of two types of surface species that differ in the amount of subvalent silver. For this process, a kinetic Langmuir model has been developed in which the rate of $\mathrm{Ag}^{+}$release is governed by adsorbed molecular oxygen that can be activated via a proton, while adsorption of molecular oxygen by itself can become rate limiting in the initial stage of dissolution with high rates of release. In our study with data of different kinds, the overall release and equilibration by AgNPs has been interpreted successfully with a coherent, overarching mechanistic view. 


\subsection{Introduction}

Silver nanoparticles (AgNPs) have a diverse range of applications, including catalysis, ${ }^{1-4}$ spectroscopy, ${ }^{5,6}$ cancer treatment, ${ }^{7,8}$ and preventing infection in e.g. surgical implants. ${ }^{9,10}$ However, AgNPs are most prominently used as an antimicrobial agent in consumer products such as cosmetics, clothing, and household items. ${ }^{11}$ The large availability of consumer products containing AgNPs may lead to an enhanced flux of these particles into the environment.

Environmental release of AgNPs may have serious consequences as AgNPs have been shown to be harmful to various bacteria, ${ }^{12-14}$ soil fauna, ${ }^{15-17}$ and aquatic organisms. ${ }^{18-21}$ Agricultural soils are especially at risk, as high AgNP retention in waste water treatment plants ${ }^{22}$ and use of sewage sludge as a soil conditioner may lead to accumulation of AgNPs. ${ }^{23}$ It is vital, therefore, to gain insight into the behavior of AgNPs in soils and other environmental systems.

Silver ions $\left(\mathrm{Ag}^{+}\right)$are the primary reason for AgNP toxicity. ${ }^{17,} 21,24$ In the environment, interactions with organic matter ${ }^{25,26}$ and inorganic ligands, such as sulfide ${ }^{27}$ and chloride, ${ }^{28}$ may influence $\mathrm{Ag}^{+}$release. However, as oxidation of AgNPs is not well understood, rationales behind these factors remain speculative. To improve our insight in the environmental fate and toxicity of AgNPs, it is necessary to elucidate the mechanisms controlling $\mathrm{Ag}^{+}$release. For this reason, we will focus on release of silver ions under well-defined conditions.

When a concentrated AgNP suspension is diluted in a solution containing dissolved oxygen, release of silver ions is observed. ${ }^{26,29-34}$ Dissolution may continue for a considerable time, but eventually, the $\mathrm{Ag}^{+}$concentration stabilizes and remains constant. Remarkably, this occurs well before either oxygen or nanoparticles have been used up. Once the system has stabilized, AgNPs may persists for months, ${ }^{33,} 35$ even in open systems with free exchange of atmospheric oxygen. $^{33}$

In the past, the remarkable long-term stability of AgNPs has been attributed to stabilization by a layer of silver oxide, generally assumed to consist of $\mathrm{Ag}_{2} \mathrm{O}$. Indeed, when oxygen is introduced to AgNPs, a red-shift of the surface plasmon resonance (SPR) band is observed which could imply oxidation of $\mathrm{Ag}^{36,}{ }^{37}$ However, $\mathrm{Ag}_{2} \mathrm{O}$ (s) is highly soluble $\left(K_{\mathrm{S}}=\left(\mathrm{Ag}^{+}\right)\left(\mathrm{OH}^{-}\right)=10^{-7.7}\right)^{38,39}$ and will generally not be stable under aqueous conditions. In pure water, the reaction $1 / 2 \mathrm{Ag}_{2} \mathrm{O}(\mathrm{s})+1 / 2 \mathrm{H}_{2} \mathrm{O}(\mathrm{I}) \Leftrightarrow \mathrm{Ag}^{+}(\mathrm{aq})+\mathrm{OH}^{-}(\mathrm{aq})$ results in a strong $\mathrm{pH}$ increase (to above $\mathrm{pH} 10$ ), strongly limiting $\mathrm{Ag}_{2} \mathrm{O}$ solubility (to around $25 \mathrm{mg} \mathrm{L}^{-1}$ ). However, at neutral $\mathrm{pH}$, the solubility is 1000 times higher and a $\mathrm{Ag}^{+}$concentration of $1 \mathrm{~mol} \mathrm{~L}^{-1}$ can be reached at $\mathrm{pH} \sim 6.5$ (see Figure $\mathrm{B} 1$ of Appendix $\mathrm{B}$ ). Thus, unless very high $\mathrm{pH}$ values are reported, formation or persistence of $\mathrm{Ag}_{2} \mathrm{O}$ coating is highly unlikely.

A layer of $\mathrm{Ag}_{2} \mathrm{O}$ can nevertheless occur on silver surfaces under certain conditions, e.g. in absence of water. Density functional theory (DFT) calculations, corroborated with X-ray photoelectron spectroscopy and scanning tunneling microscopy, strongly suggest that $\mathrm{Ag}_{2} \mathrm{O}-$ like structures form at prolonged exposure to atomic oxygen. ${ }^{40}$ Similar structures may be 
found on AgNPs if they are annealed or produced under dry conditions. ${ }^{41}$ Upon dispersion in solution, oxide layers initially present on such "dry" AgNPs dissolve exceptionally fast (within minutes $)^{41}$ which is never seen for AgNPs diluted from stock suspensions. ${ }^{29}$, $31-34$ It demonstrates that this type of $\mathrm{Ag}_{2} \mathrm{O}$-like oxide is highly prone to dissolution and cannot be expected to form a stable surface coating.

Recently, it has been proposed that a stable surface oxide may be formed by subvalent $\mathrm{Ag} .{ }^{42}$ Subvalent silver is found in a specific class of $\mathrm{Ag}$ minerals as discussed in detail in Molleman and Hiemstra. ${ }^{42}$ At the AgNP surface, subvalent Ag may be present in two forms. The primary surface species can be written as $\equiv \mathrm{Ag}_{3} \mathrm{OH}$ in which each $\mathrm{Ag}$ has a subvalency of $+1 / 3 \mathrm{~V}$.u. This is in agreement with the SPR red-shift observed by Henglein ${ }^{36}$ upon absorption of added silver ions. The unorthodox valence of $+1 / 3$ is also found in surface atoms of semi-metallic $\mathrm{Ag}_{13}$ clusters ${ }^{43}$ and is supported by recent MO-DFT calculations. ${ }^{44} \mathrm{The} \mathrm{Ag}_{3} \mathrm{OH}$ species is dominantly present at high $\mathrm{pH}$ and is organized in a single layer. Dissolution of $\equiv \mathrm{Ag}_{3} \mathrm{OH}$ initiates the formation of a second, more resistant surface species. This secondary surface structure has subvalent Ag present in the first two atomic layers. The presence of these subvalent surface species stabilizes the interface. In conclusion, AgNPs are not stabilized by a coating of $\mathrm{Ag}_{2} \mathrm{O}$, but by a surface layer of partially oxidized silver.

The above surface species are part of a chemical equilibrium that is established upon oxidative $\mathrm{Ag}^{+}$release. The $\mathrm{Ag}^{+}$concentration is a ruling factor suppressing $\mathrm{Ag}$ release when added intentionally. ${ }^{26}$ Peretyazhko et al. ${ }^{33}$ show that a decrease in released $\mathrm{Ag}^{+}$concentrations is also possible can be understood within the model framework that we develop here. However, a surface chemical equilibrium does not imply full thermodynamic equilibration, since the combination $\mathrm{O}_{2}$ and $\mathrm{Ag}$ is not stable under ambient conditions, i.e. all $\mathrm{Ag}$ will be oxidized in the end. Therefore, the chemical stabilization of AgNPs must be seen as a partial equilibrium, in a similar way as found for aluminum.

An important consequence of subvalency is that oxygen is essential for the dissolution of the $\equiv \mathrm{Ag}_{3} \mathrm{OH}$ species and consecutive formation of a new, more oxidized surface species. This is agreement with the observation that $\mathrm{Ag}^{+}$release is strongly reduced in deoxygenated solutions. ${ }^{24,26,45}$

Our surface structural model ${ }^{42}$ also suggests that $\mathrm{pH}$ is a controlling factors influencing $\mathrm{Ag}^{+}$ release, as literature confirms. On the short term, $\mathrm{Ag}^{+}$release strongly increases with decreasing $\mathrm{pH}^{26,29,32,46,47}$ Long term data show the same trend: much higher equilibrium concentrations are attained at a lower $\mathrm{pH} .{ }^{33}$ Unfortunately, the effect of $\mathrm{pH}$ on release kinetics and the final equilibrium concentrations have not been studied in a systematic manner. The objective of the present study is to measure the $\mathrm{pH}$-dependence of equilibrium $\mathrm{Ag}^{+}$ concentrations in an environmentally relevant $\mathrm{pH}$ range $(\mathrm{pH} \sim 3-9)$. This information will be used to quantify and further develop the surface structural model and to enhance our understanding of the environmental fate of AgNPs. 
The kinetics of $\mathrm{Ag}^{+}$release is another essential but poorly understood aspect of $\mathrm{AgNP}$ dissolution. $\mathrm{Ag}^{+}$is released in two phases: a short, initial phase with a high release rate, and a longer, second phase with more gradual release. ${ }^{29,31,32}$ First order kinetics, assuming a single release process, are commonly used to describe $\mathrm{Ag}^{+}$release, ${ }^{33-35}$ but this view does not capture the two-phase release behavior which is observed. In a recent effort, two different processes are assumed to describe the two kinetic phases of $\mathrm{Ag}^{+}$release, ${ }^{29}$ but a process of equilibration is not considered in their work. To gain insight in the complex nature of $\mathrm{Ag}^{+}$ release, we will study release kinetics as a function of $\mathrm{pH}$. It will be a great challenge to integrate release kinetics and surface equilibration into a single mechanistic model.

Particle size also strongly affects $\mathrm{Ag}^{+}$release: smaller particles, release more $\mathrm{Ag}^{+} .{ }^{30,33,34}$ This has been attributed to surface tension, ${ }^{30}$ but that rationale requires an equilibrium reaction, which has not yet been specified. The present study will investigate how particle size affects equilibrium $\mathrm{Ag}^{+}$concentrations and how this can be implemented in our model. The $\mathrm{pH}$ dependence of the equilibrium condition will be studied for AgNPs with a size of 5, 10, and $20 \mathrm{~nm}$.

In summary, the aim of the present study is to provide a large set of experimental data on the release of $\mathrm{Ag}^{+}$ions from AgNPs as a function of the $\mathrm{pH}$, time, and particle size as these are highly relevant for model development. ${ }^{42}$ The collected data will be used to increase our insight in the processes that ultimately lead to equilibration of AgNPs with a protective surface layer of subvalent silver under aqueous conditions.

\subsection{Material and Methods}

\subsubsection{Nanoparticles}

Four different batches of citrate coated silver nanoparticles were used: $\mathrm{AgNP}_{5}, \mathrm{AgNP}_{6}, \mathrm{AgNP}_{10}$ and $\mathrm{AgNP}_{20}$, having approximate diameters of 5, 6, 10, and 20 nanometers, respectively. The AgNPs were purchased from NanoComposix and stored unopened in the fridge until used. The nanoparticles are supplied suspended in $2 \mathrm{mM}$ trisodium citrate at a mass concentration of $\sim 1.0 \mathrm{~g} \mathrm{~L}^{-1}$. A number of relevant characteristics of the nanoparticles used are given in Table 3.1. 
Table 3.1 Characteristics of purchased AgNPs used, as provided by NanoComposix

\begin{tabular}{lllllllll}
\hline & Lot $\mathrm{n}^{\circ}$ & $\mathrm{pH}^{\mathrm{a}}$ & $\begin{array}{l}\rho_{\mathrm{c}}{ }^{\mathrm{a}} \\
\left(\mathrm{g} \mathrm{L}^{-1}\right)\end{array}$ & $\begin{array}{l}\mathrm{d}_{\text {TEM }}{ }^{\mathrm{b}} \\
(\mathrm{nm})\end{array}$ & $\begin{array}{l}\mathrm{d}_{\mathrm{DLS}}{ }^{\mathrm{c}} \\
(\mathrm{nm})\end{array}$ & $\begin{array}{l}A_{\mathrm{p}}{ }^{\mathrm{d}} \\
\left(\mathrm{m}^{2} \mathrm{~g}^{-1}\right)\end{array}$ & $\begin{array}{l}\zeta-\text { pot }^{\mathrm{e}} \\
(\mathrm{mV})\end{array}$ & $\begin{array}{l}\lambda_{\max }{ }^{\mathrm{f}} \\
(\mathrm{nm})\end{array}$ \\
\hline $\mathrm{AgNP}_{5}$ & DMW0375 & 7.8 & 0.95 & $4.9 \pm 0.7$ & $\mathrm{ND}$ & 111.8 & $\mathrm{ND}$ & 403 \\
$\mathrm{AgNP}_{6}$ & DMW0009 & 7.9 & 1.03 & $5.7 \pm 1.0$ & 9.5 & 94.1 & -26.5 & 401 \\
$\mathrm{AgNP}_{10}$ & WNB0064 & 7.4 & 1.04 & $9.5 \pm 1.9$ & 13.9 & 56.3 & -34.1 & 390 \\
$\mathrm{AgNP}_{20}$ & DMW0293 & 7.0 & 1.06 & $19.8 \pm 3.1$ & 24.4 & 27.5 & -43.3 & 393 \\
\hline
\end{tabular}

a $\mathrm{pH}$ and mass concentrations $\left(\rho_{\mathrm{c}}\right)$ for as-bought AgNP suspensions

b Mean and standard deviation of the diameter in the particle size distribution observed with Transmission Electron Microscopy (see Figure B2 of Appendix B)

c Hydrodynamic diameter measured with Dynamic Light Scattering

d Specific surface area as calculated from the relative contribution of particle sizes in the particle size distribution and standard deviation assuming a deviation from perfect spheres of no more than $20 \%$ (see Section B2 of Appendix B)

e Zeta potential measured using Laser Doppler Micro-electrophoresis

$f$ Wavelength of maximum absorption of the plasmon resonance band

\subsubsection{Dissolution experiments}

Stock solutions of $\sim 1.2 \mathrm{mM}$ nitric acid, $1.2 \mathrm{mM}$ sodium nitrate, and $1.2 \mathrm{mM}$ sodium bicarbonate were mixed in various ratios to achieve an environmentally relevant $\mathrm{pH}$ range $(\mathrm{pH}$ 3-9). These $\mathrm{pH}$ stocks were allowed to equilibrate with ambient air overnight. The as-bought AgNP suspensions were diluted to $\sim 50 \mathrm{mg} \mathrm{L}^{-1}$ with ultra-pure water and immediately mixed with the different electrolyte solutions, obtaining samples with an initial AgNP concentration of $\sim 10 \mathrm{mg} \mathrm{L}^{-1}$ and an ionic strength of $1 \mathrm{mM}$. As literature reports critical coagulation concentrations of 30-40 mM for uncoated and citrate coated AgNPs in monovalent electrolytes, ${ }^{48,49}$ and we do not expect aggregation to occur in our experiments.

$\mathrm{Ag}^{+}$release from $\mathrm{AgNP}_{5}$ was measured after 1, 7, 14, and 35 days, and two different experimental setups were used. In the first setup, a single batch was prepared for each $\mathrm{pH}$. Within 15 minutes of preparation, each batch was divided into several subsamples of $12 \mathrm{~mL}$. At every measuring time, two subsamples were sampled and analyzed. In the second setup, individual $50 \mathrm{~mL}$ batches were prepared for each $\mathrm{pH}$ without splitting into subsamples. Each batch was prepared in duplicate and batches were repetitively sampled over time. Results between both methods show little difference (see Figure B3 of Appendix B), and values were averaged for use in our modelling efforts. The second method described above was also used to prepare smaller $(15 \mathrm{~mL})$ samples with $\mathrm{AgNP}_{10}$ and $\mathrm{AgNP}_{20}, \mathrm{Ag}^{+}$release from these samples was determined only after 35 days.

The reaction containers were wrapped in aluminum foil, to prevent any possibility of photooxidation ${ }^{50}$ or photo-reduction. ${ }^{51}$ During preliminary experiments, it was found that agitation of suspensions promotes the formation of a silver-colored film on the container wall at low $\mathrm{pH}$. We have chosen, therefore, to keep suspensions stationary during equilibration, preventing this. Comparison between agitated and standing samples showed there are no indications that this approach results in a lower $\mathrm{Ag}^{+}$release (see Figure $\mathrm{B} 4$ of Appendix B). 


\subsubsection{Ultrafiltration}

To measure the free $\mathrm{Ag}^{+}$concentrations, Microsep ${ }^{\mathrm{TM}}$ Advance Centrifugal Devices ( $3 \mathrm{kDa}$ ) were used for phase separation. Prior to use, 3 centrifugal filtration steps were performed with ultrapure water to rinse the filter unit. Two separate volumes of sampled suspension were then filtrated over the filter units: the first to equilibrate the filter units with $\mathrm{Ag}^{+}$ concentrations in the sample, the second to obtain the filtrate for chemical analyses. Tests with $\mathrm{AgNO}_{3}$ solutions at various concentrations and $\mathrm{pH}$ values showed that this method yields adequately accurate results (see Figure B5 of Appendix B). On rare occasions, AgNPs were present in the filtrate, suggesting loss of filter membrane integrity. All samples were monitored for such events; contaminated samples have been removed from the dataset.

\subsubsection{Chemical analyses}

The final filtrates were diluted in $0.14 \mathrm{M} \mathrm{HNO}_{3}$ and analyzed with high resolution inductively coupled plasma mass spectrometry (HR-ICP-MS). For each individual batch prepared in the second setup, the total $\mathrm{Ag}$-content was determined separately. The $\mathrm{AgNP}_{5}$ stock was diluted to $\sim 50 \mathrm{mg} \mathrm{L}^{-1}$ and immediately analyzed in duplicate for dissolved $\mathrm{Ag}^{+}$. The total $\mathrm{Ag}$-content of diluted stock solutions was verified in triplicate by overnight destruction of $0.5 \mathrm{~mL}$ in $1 \mathrm{~mL}$ concentrated $\mathrm{HNO}_{3}$ (65\%), which was then diluted and analyzed using HR-ICP-MS.

\subsection{Results and discussion}

\subsubsection{Surface area dependency of $\mathrm{Ag}^{+}$release}

In a preliminary experiment, we measured the relation between released $\mathrm{Ag}^{+}$and initial $\mathrm{AgNP}$ concentrations $\left(\mathrm{g} \mathrm{L}^{-1}\right.$ ) for $\mathrm{AgNP}_{6}$ after 14 days of equilibration. In this experiment, the total available surface area $\left(A_{T}, \mathrm{~m}^{2} \mathrm{~L}^{-1}\right)$ is proportional with the specific surface area of the particles $\left(A_{\mathrm{p}}, \mathrm{m}^{2} \mathrm{~g}^{-1}\right)$ and the AgNP mass concentration $\left(\rho_{\mathrm{c}}, \mathrm{g} \mathrm{L}^{-1}\right)$. In Figure 3.1a, the $\mathrm{Ag}^{+}$concentrations are plotted as a function of $A_{T}$. The data show that the released amount of $\mathrm{Ag}^{+}$increases proportionally with the initial AgNP concentration. This is contradictory to the idea that concentrations are regulated by the dissolution of a solid phase, which would lead to a constant $\mathrm{Ag}^{+}$concentration, independent of the initial AgNP concentration. At $\mathrm{pH} \sim 3$, dissolution comprises a significant fraction ( $60 \%$ ) of initially added AgNPs; this will affect the slope of the relation, but not the linearity. The linearity in Figure 3.1a suggests an approximately constant release of $\mathrm{Ag}^{+}$both per unit mass of AgNP and per unit of AgNP surface area. 

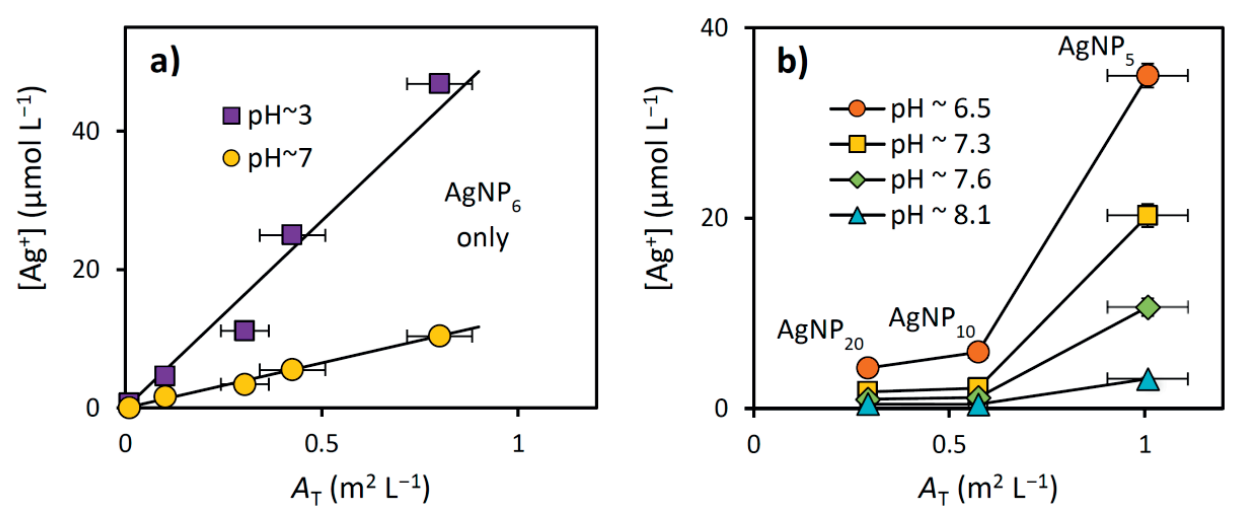

Figure 3.1 (a) $\mathrm{Ag}^{+}$release from $\mathrm{AgNP}_{6}$ after reacting for 14 days as a function of the amount of initially surface area added to $1 \mathrm{mM} \mathrm{HNO}_{3}$ ( $\mathrm{pH} \sim 3$, squares) and $1 \mathrm{mM} \mathrm{NaNO}{ }_{3} / \mathrm{NaHCO}_{3}$ (pH 7, circles); $A_{\mathrm{T}}\left(\mathrm{m}^{2}\right.$ $\left.\mathrm{L}^{-1}\right)=\rho_{\mathrm{c}}\left(\mathrm{g} \mathrm{L}^{-1}\right) \times A_{\mathrm{p}}\left(\mathrm{m}^{2} \mathrm{~g}^{-1}\right)$. (b) $\mathrm{Ag}^{+}$release after 35 days of equilibration at 4 different $\mathrm{pH}$ values from three different $\mathrm{AgNP}_{5}, \mathrm{AgNP}_{10}$, and $\mathrm{AgNP}_{20}$ at initial mass concentrations of $\mathrm{AgNP}$ being respectively $9.8 \pm 0.8,10.5 \pm 0.7$, and $10.4 \pm 0.9 \mathrm{mg} \mathrm{L}^{-1}$ (see Table 1 ).

The total available surface area $\left(A_{T}, \mathrm{~m}^{2} \mathrm{~L}^{-1}\right)$ can also be varied in an experiment by using AgNPs that differ in size. Figure 3.1b shows the silver ion concentrations for differently sized AgNPs $(5,10$, and $20 \mathrm{~nm})$, added at a similar mass concentration $\left(10 \pm 1 \mathrm{mg} \mathrm{L}^{-1}\right)$ and equilibrated for 35 days at various circum-neutral $\mathrm{pH}$ values. No linear relationship with $A_{T}$ is found, in contrast to the results of Figure 3.1a. More $\mathrm{Ag}^{+}$is released per unit surface area if the particles decrease in size, suggesting that the particles vary in surface properties. The possible relation with the surface structure will be discussed in more detail later.

\subsubsection{Equilibrium $\mathrm{Ag}^{+}$concentrations}

In Figure 3.2, we present the $\mathrm{pH}$ dependency of equilibrium $\mathrm{Ag}^{+}$concentrations for AgNPs of different size that have reacted for 35 days. The measured equilibrium concentrations are equivalent to $\mathrm{Ag}^{+}$release since the $\mathrm{Ag}^{+}$concentrations in the AgNP stocks were very low, (approximately $50 \mu \mathrm{g} \mathrm{\textrm {L } ^ { - 1 }}$ or $0.1 \%$ of the total silver).

The data of Figure 3.2 show that two $\mathrm{pH}$ regimes can be distinguished. For all three AgNP materials studied, a strong $\mathrm{pH}$ dependency is found in the neutral to high $\mathrm{pH}$ range while under acid conditions, the $\mathrm{pH}$ trend is less pronounced. The low incline below $\mathrm{pH} \sim 6-7$ indicates that, at those conditions, the influence of $\mathrm{pH}$ on the $\mathrm{Ag}^{+}$release is small. Note, however, that high amounts of $\mathrm{Ag}^{+}$are released at these low $\mathrm{pH}$ values, being equivalent to between 2 to 9 monolayers of $\mathrm{Ag}$ (see Figure B6 of Appendix B). 


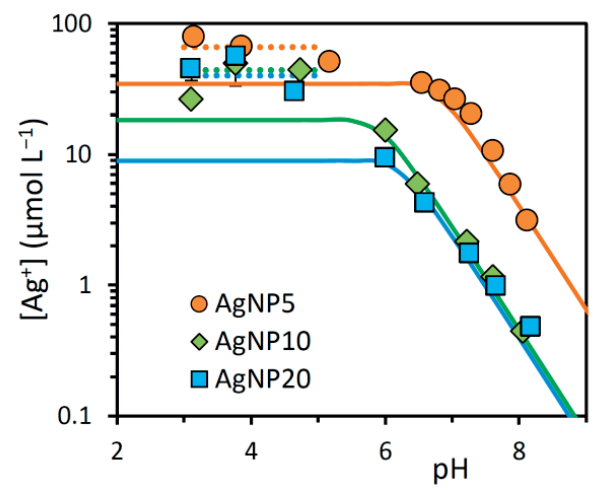

Figure 3.2 $\mathrm{Ag}^{+}$equilibrium concentrations for $\mathrm{AgNP}_{5}, \mathrm{AgNP}_{10}$, and $\mathrm{AgNP}_{20}$ as a function of $\mathrm{pH}$ at an ionic strength of $1 \mathrm{mM}$. AgNPs were equilibrated for 35 days at mass concentrations of, respectively, $9.8 \pm 0.8,10.5 \pm 0.7,10.4 \pm 0.9 \mathrm{mg} \mathrm{Ag} / \mathrm{L}$. The full lines have been calculated with the two-species model of Table 2, using $x+z=4$ and $\log K_{\mathrm{H} / \mathrm{Ag}}=14.5,9.7$, and 10.0, respectively.

Above $\mathrm{pH} \sim 6-7$, all three AgNPs show a strong linearity between the logarithm of the $\mathrm{Ag}^{+}$ concentration and $\mathrm{pH}$, having a mean slope, $\Delta \log \left[\mathrm{Ag}^{+}\right] / \Delta \mathrm{pH}$, of $-0.7 \pm 0.1$. This implies that we cannot explain these data with equilibration by dissolution of any bulk $\mathrm{Ag}$ (hydr)oxide material. For the reaction, $\mathrm{Ag}_{2} \mathrm{O}(\mathrm{s})+2 \mathrm{H}^{+}(\mathrm{aq}) \Leftrightarrow 2 \mathrm{Ag}^{+}(\mathrm{aq})+\mathrm{H}_{2} \mathrm{O}(\mathrm{I})$, the activities of water and $\mathrm{Ag}_{2} \mathrm{O}$ are set to unity, resulting in $\Delta \log \left[\mathrm{Ag}^{+}\right] / \Delta \mathrm{pH}=-1$, by definition. As discussed below, the observed slope is characteristic for a surface controlled $\mathrm{Ag}^{+}$release mechanism.

\subsubsection{General thermodynamic approach}

The above data can be described with a surface based equilibrium model. In this model, we assume that the surface is initially covered by a single type of subvalent silver species having a low oxidation state. Upon oxidation, this primary species will be released as $\mathrm{Ag}^{+}$, and the oxygen will react with the underlying metal. Part of the metal may become fully oxidized and dissolve, whereas the remaining metal is partially oxidized, leading to the formation of a second species with a higher oxidation state. ${ }^{42}$ For this view, we may formulate an equilibrium reaction as follows:

$$
\begin{aligned}
\equiv \mathrm{Ag}_{x}(\mathrm{OH})_{m}+ & (y+z) \mathrm{Ag}^{0}(\mathrm{np})+(x+z) \mathrm{H}^{+}(\mathrm{aq})+\frac{x+z+n}{4} \mathrm{O}_{2}(\mathrm{aq}) \Leftrightarrow \equiv \operatorname{Ag}_{y}(\mathrm{OH})_{m+n} \\
& +(x+z) \mathrm{Ag}^{+}(\mathrm{aq})+\frac{x+z-n}{2} \mathrm{H}_{2} \mathrm{O}(\mathrm{l})
\end{aligned}
$$

In this reaction, the primary surface site, $\equiv \mathrm{Ag}_{x}(\mathrm{OH})_{m}$, has $x$ subvalent silver ions with a mean valence, $z_{\mathrm{Ag}}=m / x$ valence units (v.u.). Additionally, $y+z$ metallic atoms are involved that are part of the AgNP core. During the reaction, $x$ subvalent ions and $z$ metallic atoms become fully oxidized and dissolve as $\mathrm{Ag}^{+}$. The remaining $y \mathrm{Ag}^{0}$ atoms are partially oxidized to form a more resistant surface site that can be defined as $\equiv \mathrm{Ag}_{y}(\mathrm{OH})_{m+n}$ with $Z_{\mathrm{Ag}}=(m+n) / y$ v.u. 
The equilibrium condition of eq 3.1 can be formulated as:

$$
\mathrm{K}_{\mathrm{H} / \mathrm{Ag}}=\frac{\left(\equiv \mathrm{Ag}_{y}(\mathrm{OH})_{m+n}\right)}{\left(\equiv \mathrm{Ag}_{x}(\mathrm{OH})_{m}\right)} \cdot \frac{\left(\mathrm{Ag}^{+}\right)^{x+z}}{\left(\mathrm{H}^{+}\right)^{x+z}} \cdot \frac{1}{\left(\mathrm{O}_{2}\right)^{\frac{x+z+n}{4}}}
$$

where $K_{\mathrm{H} / \mathrm{Ag}}$ is the equilibrium constant.

In eq 3.1, the consumption of protons is equal to the release of $\mathrm{Ag}^{+}$ions, which implies electroneutrality. Despite this 1:1 stoichiometry, the equilibrium condition (eq 3.2) yields a $\Delta \log \left[\mathrm{Ag}^{+}\right] / \Delta \mathrm{pH}$ ratio smaller than one. The reason is that the activity ratio of the surface species, i.e. $\left(\equiv \mathrm{Ag}_{y}(\mathrm{OH})_{m+n}\right) /\left(\equiv \mathrm{Ag}_{x}(\mathrm{OH})_{m}\right)$, changes with $\mathrm{Ag}^{+}$release and, since $K_{\mathrm{H} / \mathrm{Ag}}$ is a constant, this will affect the activity ratio of the species in solution. In case of an infinite amount of surface sites, the activities of the surface species will become constant, yielding $\Delta \log \left[\mathrm{Ag}^{+}\right] / \Delta \mathrm{pH}=1$. Our thermodynamic analysis thus strongly suggests that the equilibration of AgNP is governed by a surface reaction that involves mixing entropy of surface species and is not due to the dissolution of a bulk phase present on the surface.

\subsubsection{Relation with surface structure}

The values of the stoichiometry coefficients in eqs 3.1 and 3.2 are related to a molecular view on the surface structure of AgNPs. The surface structure of the aqueous interface of solid silver is relatively unknown and has not been established spectroscopically, as far as we know. However, basing ourselves on related structures, we have recently proposed a surface structure with subvalent silver organized in $\equiv \mathrm{Ag}_{3} \mathrm{OH}$ surface species, with a site density of 4.6 $\mathrm{nm}^{-2}$ or $7.6 \mu \mathrm{mol} \mathrm{m}{ }^{-2}{ }^{42}$

Taking $\equiv \mathrm{Ag}_{3} \mathrm{OH}$ as a starting point, we have fixed the values for $x$ and $m$, being 3 and 1 , respectively. Using this information, we are able to derive the value for $z$ from the experimental data. The combined value of $x+z$ represents the number of $\mathrm{Ag}^{+}$released per surface site, and thus determines both the slope of the line above $\mathrm{pH} \sim 6-7$ (Figure 3.2) and the maximum theoretical desorption. Our surface structural model ${ }^{42}$ suggests a site density, $N_{\mathrm{s}}$, of $4.6 \mathrm{~nm}^{-2}$ or $7.6 \mu \mathrm{mol} \mathrm{m}{ }^{-2}$ for the [111] face. If this site density is used, the release of 3 or $4 \mathrm{Ag}^{+}$per site will lead to a maximum release of respectively 23 or $31 \mu \mathrm{mol} \mathrm{m}{ }^{-2}$. Our experimental data for $\mathrm{AgNP}_{5}$ show that the $\mathrm{pH}$ dependency of the $\mathrm{Ag}^{+}$release changes when about $30 \mu \mathrm{mol} \mathrm{m}{ }^{-2}$ has been released, suggesting a release of about $4 \mathrm{Ag}^{+}$per site. As shown in Figure 3.2, the resulting slope with this value for $x+z$ is in good agreement with the data.

The values for $y$ and $n$ in eqs 3.1 and 3.2 are related to the molecular view on the surface structure that forms upon oxidative dissolution of $\mathrm{a} \equiv \mathrm{Ag}_{3} \mathrm{OH}$ site. In the present study, we propose the formation of a more oxidized surface species with subvalent silver present in the first two layers. Possible surface structures are presented in Appendix B, from which we have chosen a reasonable candidate. This molecular species leads to $y=5$ and $n=1$ i.e. $\equiv \operatorname{Ag}_{5}(\mathrm{OH})_{2}$. In principle, the value of $n$ might also be discerned from e.g. the oxygen consumption, but this 
has not been studied yet. With these choices, the reaction stoichiometry is fixed, but without spectroscopic confirmation of the surface structure, they are our current best guess.

With the formulated model (Table 3.2), the equilibrium concentration above $\mathrm{pH}^{\sim 6-7}$ can be well-described for the various AgNPs as illustrated with the lines in Figure 3.2.

Table 3.2 Tableau specifying the surface reaction for $\mathrm{Ag}^{+}$release (eq 1 ), as used for our two-species model. In Figure 3.2, $x+z$ has been set to 4 ions per site, yielding a theoretical maximum release of 31 $\mu \mathrm{mol} \mathrm{m}{ }^{-2}$ and a slope, $\Delta \log \left[\mathrm{Ag}^{+}\right] / \Delta \mathrm{pH}$, of -0.79 . The $\log K_{\mathrm{H} / \mathrm{Ag}}$ values are size-dependent, as discussed in the text. The $\log K_{\mathrm{H} / \mathrm{Ag}}$ values have been fitted assuming monodispersity as discussed in Appendix B.

\begin{tabular}{llllll}
\hline & Site & $\mathrm{Ag}^{+}$ & $\mathrm{H}^{+}$ & $\mathrm{O}_{2}$ & $\log K$ \\
\hline$\equiv \mathrm{Ag}_{x}(\mathrm{OH})_{m}$ & 1 & 0 & 0 & 0 & 0 \\
$\equiv \mathrm{Ag}_{y}(\mathrm{OH})_{m+n}$ & 1 & $-(x+z)$ & $\mathrm{x}+\mathrm{z}$ & $(x+z+n) / 4$ & $\log K_{\mathrm{H} / \mathrm{Ag}}$ \\
\hline
\end{tabular}

\subsubsection{The effect of particle size}

Our data suggest that in the neutral to high $\mathrm{pH}$ range, $\mathrm{AgNP}_{5}$ releases more $\mathrm{Ag}^{+}$per unit surface area than $\mathrm{AgNP}_{10}$ and $\mathrm{AgNP}_{20}$ (see also Figure 3.1b). Evidence for a higher reactivity of smaller particles is also found in literature, ${ }^{33}$ as exemplified in Figure $3.3 \mathrm{a}$, showing the $\mathrm{Ag}^{+}$release as a function of particle size at a fixed AgNP mass concentration. The dashed line represents the $\mathrm{Ag}^{+}$release calculated with the above model using a single $\log K_{\mathrm{H} / \mathrm{Ag}}$ value, i.e. a non-variable surface stability. With fixed surface stability, the model predicts a lower $\mathrm{Ag}^{+}$release (in $\mu \mathrm{mol} \mathrm{m}^{-2}$ ) for smaller particles. However, the data show that smaller particles release proportionally more silver ions, suggesting a relation between size and surface stability. 

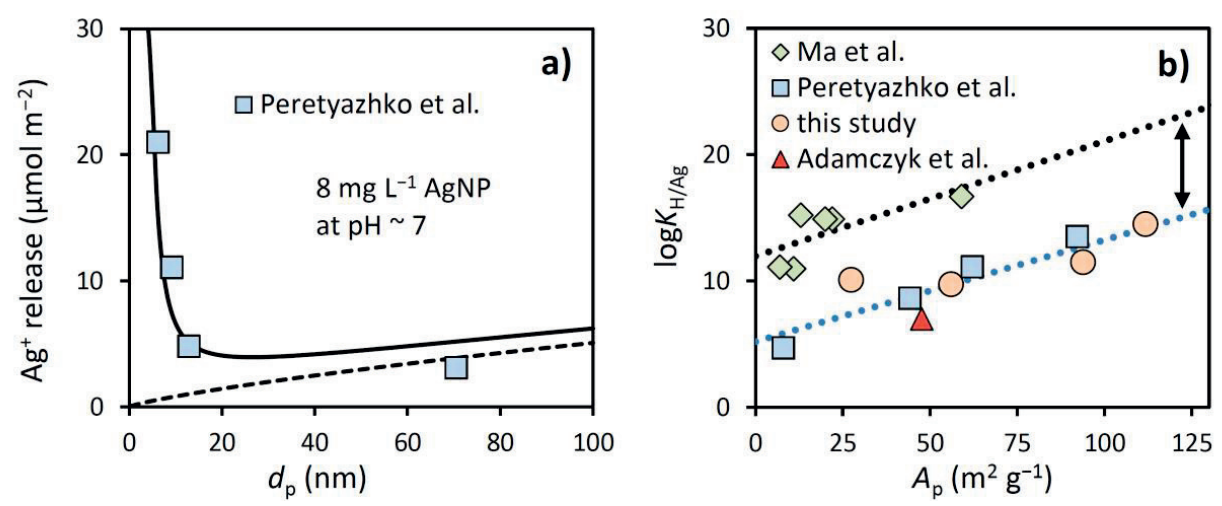

Figure 3.3 (a) Equilibrium $\mathrm{Ag}^{+}$concentrations at neutral $\mathrm{pH}$ as a function the particle diameter at the same AgNP concentration..$^{33}$ The dashed line is calculated using a single $\log K_{\mathrm{H} / \mathrm{Ag}}$ value, whereas the full line is predicted by including in our model the contribution of surface Gibbs free energy; (b) Influence of the specific surface area $\left(A_{p}\right)$ on the equilibrium constants of various AgNPs fitted using our own data (circles), data from Peretyazhko et al. ${ }^{33}$ (squares), Adamczyk et al. ${ }^{29}$ (triangle), and Ma et al. ${ }^{30}$ (diamonds). Two data points from Ma et al. ${ }^{30}$, have been omitted as surface equilibration cannot fully account for the observed $\mathrm{Ag}^{+}$release. Linear regression of the fitted $\log K_{\mathrm{H} / \mathrm{Ag}}$ values yields the very similar slopes of $0.08 \pm 0.01$ (circles, squares and triangle) and $0.09 \pm 0.04$ (diamonds). The slopes can be calculated back to surface Gibbs free energies, resulting in $y=0.7 \pm 0.1 \mathrm{~J} \mathrm{~m}^{-2}$ in case of $y+z=6$ (eq 6). The shift of the $A_{\mathrm{p}}-\log K_{\mathrm{H} / \mathrm{Ag}}$ relation (arrow) is attributed to capping agents (see text).

The reactivity of AgNPs has been evaluated by fitting the reaction constant, $\log K_{\mathrm{H} / \mathrm{Ag}}$, for the various AgNP materials studied here and given in literature. Figure $3.3 \mathrm{~b}$ shows that the $\log K_{\mathrm{H} / \mathrm{Ag}}$ values obtained correlate well with the specific surface area, $A_{\mathrm{p}}$. A very similar relation is found for both data sets, having a slope, $\log K_{\mathrm{H} / \mathrm{Ag}} / \Delta A_{\mathrm{p}}$, of $0.08 \pm 0.01$ for data from this study and Peretyazhko et al., ${ }^{33}$ and $0.09 \pm 0.04$ for data from Ma et al. ${ }^{30}$ As we will show in the next section, the slope of this correlation can be used to derive the surface tension. The similar slope suggests a similar surface tension for AgNPs used in the different studies.

\subsubsection{Surface Gibbs free energy}

The standard Gibbs free energy change of a reaction, $\Delta G^{0}$, is equal to the sum of standard chemical potentials, $\mu^{0}{ }_{k}$, of the reacting components, $k$, multiplied by a stoichiometric weighing factor, $r_{k}$, i.e. $\Delta G_{r}^{0}=\sum r_{k} \mu_{k}^{0}$. For the surface reaction with two surface species (eq 3.1), this translates to:

$$
\begin{gathered}
\Delta G_{\mathrm{r}}^{0}=\mu_{\equiv \mathrm{Ag}_{y} \mathrm{OH}_{m+n}}^{0}+(x+z) \mu_{\mathrm{Ag}^{+}(\mathrm{aq})}^{0}+\frac{x+z-n}{2} \cdot \mu_{\mathrm{H}_{2} \mathrm{O}(\mathrm{l})}^{0}-\mu_{\equiv \mathrm{Ag}_{x} \mathrm{OH}_{m}}^{0}-(y+z) \mu_{\mathrm{Ag}(\mathrm{np})}^{0} \\
-(x+z) \cdot \mu_{\mathrm{H}^{+}(\mathrm{aq})}^{0}-\frac{x+z+n}{4} \cdot \mu_{\mathrm{O}_{2}(\mathrm{~g})}^{0}
\end{gathered}
$$

The value of $\Delta G^{0}$ r can be linked to the equilibrium constant, $\log K_{H / A g}$, defined in eq 3.2 , according to: 
$\Delta G_{\mathrm{r}}^{0}=-2.3 \mathrm{RT} \log K_{\mathrm{H} / \mathrm{Ag}}$

in which $\mathrm{R}$ is the gas constant and $T$ is the absolute temperature.

According to our surface model, the surface is covered by two types of species that represent the two different states of oxidation. This surface layer covers the underlying metallic Aglattice. An essential difference with a classical adsorption mechanism is that in the present process, the new equilibrium state is attained by consumption of additional $\mathrm{Ag}$ from the underlying metallic lattice. It implies that two different forms of solid silver are involved in the reaction: subvalent silver, present as a surface species, and metallic silver, as a solid phase.

Oxidation of metallic $\mathrm{Ag}$ is a key process in the equilibration between the two surface groups. The Ag atoms of a AgNP have a variable stability that will depend on particle size. At a high surface curvature, the underlying metal will be less stable, allowing easier oxidation. It implies that the chemical potential of metallic silver in the AgNP core, $\mu_{\mathrm{Ag}(\mathrm{np})}^{0}$ in eq 3.3 , will have a surface Gibbs free energy contribution:

$\mu_{\mathrm{Ag}(\mathrm{np})}^{0}=\mu_{\mathrm{Ag}(\mathrm{s})}^{0}+\gamma A_{\mathrm{p}}$

where $\mu_{\mathrm{Ag}(\mathrm{s})}^{0}\left(\mathrm{~J} \mathrm{~mol}^{-1}\right)$ is the standard chemical potential of the bulk solid. In eq 3.5 , the specific surface area, $A_{p}$, is expressed in $\mathrm{m}^{2} \mathrm{~mol}^{-1} \mathrm{Ag}^{0}$ of the core; $\gamma$ (in $\mathrm{J} \mathrm{m}^{-2}$ ), is the Gibbs free energy of surface formation of metallic silver covered by subvalent silver. The $\Delta G^{0}{ }_{r}$ of the transformation reaction (eq 3.1) thus has an intrinsic part, defined as $\sum r_{k} \mu_{k}^{0}$, and a variable part, determined by a surface Gibbs free energy contribution, resulting in:

$$
2.3 R T \log K_{\mathrm{H} / \mathrm{Ag}}^{0}=2.3 R T \log K_{\mathrm{H} / \mathrm{Ag}}^{\mathrm{intr}}+(y+z) \gamma A_{\mathrm{p}}
$$

Using eq 3.6, one may derive the surface Gibbs free energy of the AgNP from the data in Figure 3.3b. The slope of the linear relation can be converted into the value of $\gamma$ by expressing both 2.3RT $\log K_{\mathrm{H} / \mathrm{Ag}}$ and the specific surface area per mole of consumed $\mathrm{Ag}^{0}(\mathrm{np})$. For the chosen surface structure, $\equiv \mathrm{Ag}_{5}(\mathrm{OH})_{2}$, the value of $y+z$ equals $6 \mathrm{Ag}^{0}$ atoms, resulting in $y=0.7 \pm 0.1 \mathrm{~J} \mathrm{~m}^{-2}$.

The surface Gibbs free energy calculated here is valid for metallic silver covered by subvalent silver. The formation of surface groups can be considered as an interaction of metallic silver with oxygen, which may lower the surface free energy. For liquid metallic silver, adsorption of oxygen is reported to lower the surface Gibbs free energy from $\sim 0.9 \mathrm{~J} \mathrm{~m}^{-2}$ in absence of oxygen, to $\sim 0.7 \mathrm{~J} \mathrm{~m}^{-2}$ at atmospheric oxygen pressure. ${ }^{52}$ This implies that the surface Gibbs free energy derived above (Figure 3.3b), cannot be directly compared with $\gamma$-values for bare metallic silver surfaces, which are reported to be in the range of $1 \mathrm{~J} \mathrm{~m}^{-2} .52-54$ 


\subsubsection{Effect of capping agents}

Added ligands and capping agents have been reported to influence the $\mathrm{Ag}^{+}$release. $\mathrm{The}^{\mathrm{Ag}}$ release may be enhanced as reported for chloride, ${ }^{55,56}$ and cysteine ${ }^{57}$ whereas the release can also be inhibited as found for e.g. $\mathrm{DOC}^{25,26,46}$. High affinity $\mathrm{Cl}-, \mathrm{N}-$, and S-ligands may displace $\mathrm{OH}$ groups when binding to the AgNP surface, changing the stability and potentially altering its structure. Ligands with a lower affinity, e.g. carboxylic groups, may also bind to the AgNP surface as found by spectroscopy, ${ }^{58}$ but we expect little change in the surface structure. In case of AgNPs coated with a high affinity coating (PVP), a much higher $\mathrm{Ag}^{+}$release is seen than with citrate. ${ }^{35}$ It suggests that PVP lowers the chemical stability, despite an improved colloidal stability. According to Figure 3.3b, the AgNPs studied by Ma et al. systematically have higher $\log K_{\mathrm{H} / \mathrm{Ag}}$ values and therefore, higher solubilities. This, we attribute to their use of capping agents that contain soft ligands (PVP and gum arabic). The effect of citrate on the chemical stability is probably small because the $\log K_{\mathrm{H} / \mathrm{Ag}}$ value derived from the data of Adamczyk et al. ${ }^{29}$ are in line with our results while they did not use citrate in contrast to us.

\subsection{8 $\mathrm{Ag}^{+}$release kinetics}

Figure 3.4a shows the release of $\mathrm{Ag}^{+}$from $\mathrm{AgNP}_{5}$ as a function of $\mathrm{pH}$ after reacting for $1,7,14$, and 35 day(s). The data show a good reproducibility, with generally low variations between the replicates. Exceptions are found at low $\mathrm{pH}$, where the $\mathrm{Ag}^{+}$release data at day 1 show a relatively large variability, but the $\mathrm{Ag}^{+}$release at low $\mathrm{pH}$ becomes highly reproducible when approaching equilibrium. After 14 days, the systems are close to equilibrium, in agreement with previous observations. ${ }^{33-35}$
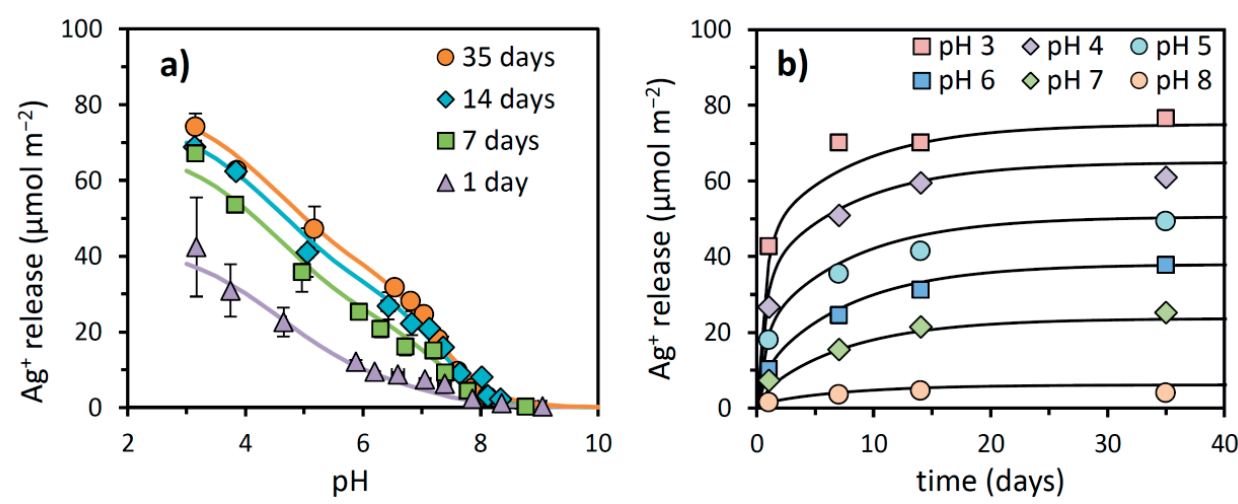

Figure 3.4 (a) pH-dependent $\mathrm{Ag}^{+}$release for $\mathrm{AgNP}_{5}$ after 1, 7, 14, and 35 day(s), experimental data and model lines; (b) time dependent $\mathrm{Ag}^{+}$release for different $\mathrm{pH}$ values, interpolated data and model lines. All data were collected in a medium at an ionic strength of $1 \mathrm{mM}$, made by mixing $\mathrm{NaNO}_{3}$ and $\mathrm{HNO}_{3}$ or $\mathrm{NaHCO}_{3}$ in various ratios. $\mathrm{Ag}^{+}$release for the specific $\mathrm{pH}$ values were obtained by interpolation of the experimental data. The lines have been calculated with an empirical kinetic model with two pools of $\mathrm{Ag}$ that are $\mathrm{pH}$-dependent in size. The chosen parameters for the fast and slow pool are, respectively, $k_{\mathrm{d}}=1.5 \mathrm{day}^{-1}, S_{\max }=51 \mu \mathrm{mol} \mathrm{m}{ }^{-2}, \log K_{\mathrm{H}}=4.6$ with $p=0.5$, and $k_{\mathrm{d}}=0.13$ day $^{-1}, S_{\max }=31 \mu \mathrm{mol} \mathrm{m} \mathrm{m}^{-2}$, $\log K_{\mathrm{H}}=7.3$, with $p=1$ (see text). 
The data of Figure 3.4a can be used to construct the time dependence of the $\mathrm{Ag}^{+}$release for various $\mathrm{pH}$ values as shown in Figure 3.4b. As the figure shows, two different regimes of dissolution can be distinguished. There is a fast initial release particularly for systems with $\mathrm{pH}$ values below $\mathrm{pH} \sim 6$, followed by a much slower release which is seen at all $\mathrm{pH}$ values. Indeed, a two-step release profile is often seen in AgNP dissolution. ${ }^{29,} 31,32$ In the next sections, we will quantify the time and $\mathrm{pH}$ dependency of both release processes.

\subsubsection{Dual first order kinetics}

To gain insight in the processes of $\mathrm{Ag}^{+}$release, we will start the evaluation of our data using first order kinetics. This approach has been used on several occasions in literature. ${ }^{32-35}$ In a first order rate equation, the rate of release is proportional to the size of a pool of silver that is available for dissolution, $S_{\mathrm{Ag}}$ :

$-\frac{d S_{\mathrm{Ag}}}{d t}=k S_{\mathrm{Ag}}$

in which $k$ is the rate constant of $\mathrm{Ag}^{+}$release. Integration of eq 3.7 leads to:

$S_{\mathrm{Ag}}(t)=S_{\text {ini }} e^{-k t}$

in which $S_{\text {ini }}$ represents the initial pool size at $t=0$. The amount of $\mathrm{Ag}^{+}$that is released as a function of time, $\Gamma_{\mathrm{Ag}}(t)$, can be given as:

$\Gamma_{\mathrm{Ag}}(t)=S_{\mathrm{ini}}-S_{\mathrm{Ag}}(t)=S_{\mathrm{ini}}\left(1-e^{-k t}\right)$

When using eq 3.9, which describes release from a single pool, $\mathrm{Ag}^{+}$release cannot be described satisfactorily. The use of a high $k$ reproduces the high initial release, but shows no release at longer time scales, while a low rate constant, leads to a more gradual release, but underestimates the high initial release. The time dependency of release apparently has characteristics of both fast and slow release.

The overall release can be well described with dual kinetics, in which two separate pools are defined: one with a high $k$ to describe the fast initial release, and one with a low $k$, describing the slower release at prolonged times. In this approach, the total $\mathrm{Ag}^{+}$release is equal to the sum of two independent first order release reactions. We were able to obtain a good description of our data using pool sizes that are $\mathrm{pH}$ dependent according to the expression:

$S_{\mathrm{ini}}=S_{\max } \frac{\left(K_{\mathrm{H}}\left(\mathrm{H}^{+}\right)\right)^{p}}{1+\left(K_{\mathrm{H}}\left(\mathrm{H}^{+}\right)\right)^{p}}$

in which $S_{\max }$ is the maximum pool size. The values for the parameters, $k, S_{\max }$, and $K_{\mathrm{H}}$, were optimized manually for both pools; optimized parameters are given in the caption to Figure 
3.4. For the slow pool, we have used $p=1$, but for the fast pool a much better fit was obtained if we used $p=0.5$. The expression for the pool sizes (eq 3.10) is strongly reminiscent of surface complexation with $(p=0.5)$ and without $(p=1)$ surface heterogeneity. ${ }^{59}$

Based on the above model, with fitted parameters, we can analyze the $\mathrm{pH}$ and time dependency of the contributions of the two Ag-pools (Figure 3.5). A fast pool dominates the dissolution below pH 6, releasing most of its silver within 1 day (Figure 3.5a). A second, slow pool releases $\mathrm{Ag}^{+}$ions much more gradually for weeks, and is active over the entire $\mathrm{pH}$ range, as is illustrated in Figure 3.5b. With this analysis, an important observation is done with respect to the slow pool: the total release of this pool is nearly perfectly equal to what is predicted using our thermodynamic model given in Table 3.2 (see Figure B9 of the Appendix). This convincingly suggests that the slow release is due to oxidative transformation of $\equiv \mathrm{Ag}_{3} \mathrm{OH}$ surface species.

The above analysis also indicates that the fast release reaction is completed well ahead of the slow reaction. Therefore, if the slow release is due to surface equilibration, we must conclude that the preceding fast release, apparently has not affected the equilibration. How this can be understood structurally will be discussed in the next section, where the goal is to develop a comprehensive mechanistic framework.
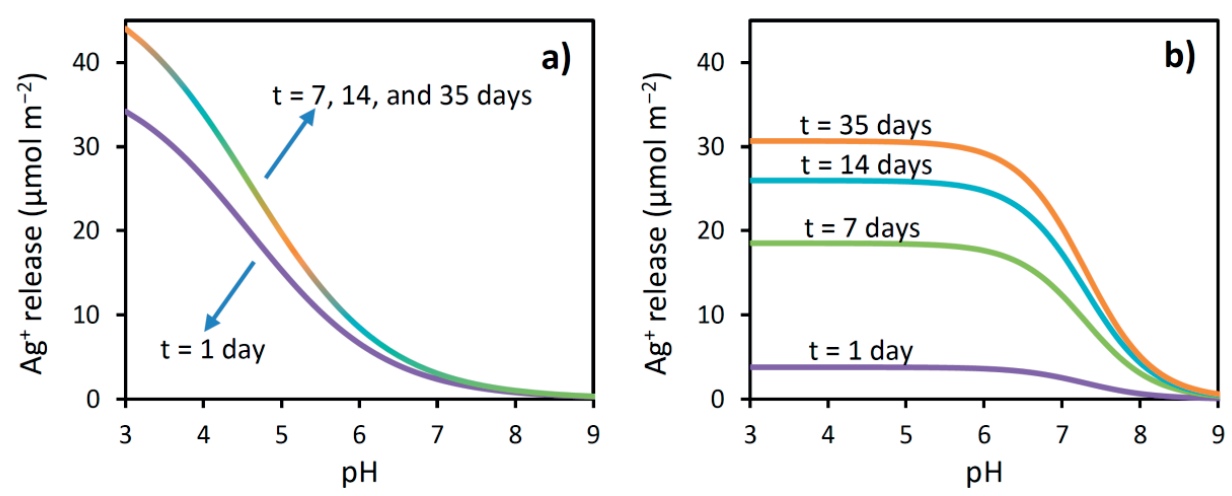

Figure 3.5 $\mathrm{Ag}^{+}$release according to the two-pool model with a fast (a) and slow $\mathrm{Ag}$ pool (b) as a function of $\mathrm{pH}$, using the parameters as disclosed in the caption of Figure 3.4. The lines illustrate that the slow pool releases $\mathrm{Ag}^{+}$over the entire natural $\mathrm{pH}$ range, most of it after the first day. The fast pool mainly releases $\mathrm{Ag}^{+}$below $\mathrm{pH} 6$, and almost all of it within 1 day, as is evident from the overlapping model lines for 7,14 , and 35 days.

\subsubsection{Fast $\mathrm{Ag}^{+}$release}

As illustrated in Figure 3.5, the fast $\mathrm{Ag}^{+}$release at low $\mathrm{pH}$ occurs prior to surface equilibration, but apparently without influencing it. This suggests that the surface structure is not affected, which is remarkable, as up to a two monolayers of silver can be dissolved by this process for $\mathrm{AgNP}_{5}$. These observations appear to be at odds and require explanation. 
Under conditions where dissolution of $\equiv \mathrm{Ag}_{3} \mathrm{OH}$ is much faster than the formation of $\equiv \mathrm{Ag}_{5}(\mathrm{OH})_{2}$, the equilibration process will be disrupted and oxidative dissolution may instead initiate opening of the surface. An opening can grow laterally to form shallow islands of depletion. In this process, dissolution of bulk material leads to decrease in Gibbs free energy $\left(\Delta \bar{G}_{\text {bulk }}\right)$, but simultaneously, an investment of Gibbs free energy is needed for creating surface $\left(\left(\Delta \bar{G}_{\text {surface }}\right)\right)$. If a patch is simplified to a disk-like shape (Figure 3.6), with newly formed $\equiv \mathrm{Ag}_{3} \mathrm{OH}$ at the bottom, we have to account solely for investment of surface energy to create the edge. With this simplification, the surface area of the edge with atomic height $h$ is proportional with the diameter $(\pi h d)$ and its volume is proportional with the square of the diameter $\left(1 / 4 \pi h d^{2}\right)$. The relation with size $(d)$ can be then described with:

$\Delta \bar{G}_{\mathrm{P}}=\Delta \bar{G}_{\mathrm{bulk}}+\Delta \bar{G}_{\text {surface }}=\frac{1}{4} \pi h d^{2} \frac{\rho_{\mathrm{d}}}{M} R T \ln \left(\frac{Q}{K}\right)+\pi h d \gamma$

in which $\left(\Delta \bar{G}_{\mathrm{P}}(\mathrm{J})\right.$ is the overall Gibbs free energy of patch formation. The Gibbs free energy change due to dissolution of the bulk is related to the undersaturation of the equilibrium, which is expressed in the ratio of the activity product and reaction constant, $Q / K{ }^{60}$ In eq 3.11 , $\gamma$ is the surface tension of the edge, $\rho_{\mathrm{d}}$ is the mass density $\left(\mathrm{g} \mathrm{m}^{-3}\right) \mathrm{M}$, is molar mass $\left(\mathrm{g} \mathrm{mol}^{-1}\right)$, and $R$ and $T$ are respectively the gas constant $\left(\mathrm{J} \mathrm{mol}^{-1} \mathrm{~K}^{-1}\right)$ and the absolute temperature (K).

A calculated example of nucleation of a disk-like patch, applying eq 3.11, is shown in Figure 3.6. At very strong undersaturation $(Q / K \cong 0)$, the Gibbs free energy curve has no maximum and the homogeneous surface may open spontaneously. Release of $\mathrm{Ag}^{+}$will decrease the degree of undersaturation, or increase $Q / K$. At decreasing undersaturation, less energy is gained from bulk dissolution and patches must reach a critical size before spontaneous dissolution is possible. ${ }^{61}$ The critical size corresponds to the top of the Gibbs free energy curve in Figure 3.6. At a surface tension of $0.7 \mathrm{~J} \mathrm{~m}^{-2}$, a patch with a depth of two monolayers $(h \cong 0.6)$ will have a critical diameter of about $1.3 \mathrm{~nm}$ for $Q / K=10^{-2}$ (Figure 3.6). The formation of a patch of this size approximately corresponds to the removal of a central $\equiv \mathrm{Ag}_{3} \mathrm{OH}$ group surrounded by six additional $\equiv \mathrm{Ag}_{3} \mathrm{OH}$ groups. 


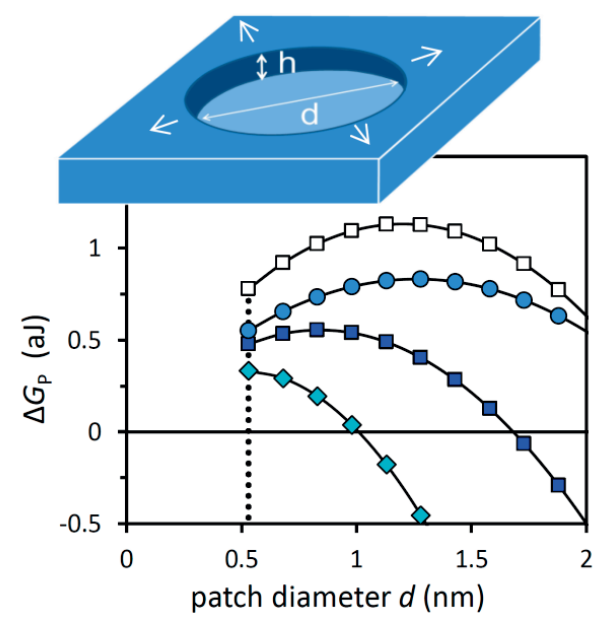

Figure 3.6 The Gibbs free energy change $\Delta \bar{G}_{\mathrm{p}}$ in aJ $\left(10^{-18} \mathrm{~J}\right)$ at formation of a flat 2D-patch on a homogeneous surface as function of size for a surface tension of $\gamma=0.7 \mathrm{~J} \mathrm{~m}^{-2}$ at three values of undersaturation of the solution namely: $Q / K=10^{-5}$ (diamonds), $10^{-3}$ (squares), and $10^{-2}$ (circles); in addition, the upper line (open squares) is for $Q / K=10^{-3}$ at $y=1.0 \mathrm{~J} \mathrm{~m}^{-2}$. The top of each curve corresponds to the critical size of nucleation. Patches are only formed spontaneously at strong undersaturation. The vertical dotted line represents the diameter of a single $\equiv \mathrm{Ag}_{3} \mathrm{OH}$ surface site $(\sim 0.5$ $\mathrm{nm})$. In the calculation, $h=0.6 \mathrm{~nm}, \rho_{\mathrm{d}}=10.5 \mathrm{~g} \mathrm{~cm}^{-3}$, and $M=108 \mathrm{~g} \mathrm{Ag} \mathrm{mol}^{-1}$.

If nucleation is a stochastic process, patches of different sizes will form that grow laterally by step retreat until a facet is fully stripped off. At low $\mathrm{pH}$, patch formation may occur on almost every facet. At higher $\mathrm{pH}$, undersaturation is lower, i.e. the critical size is higher (Figure 3.6), leading to a lower probability of patch formation and fewer affected crystal facets.

At a given $\mathrm{pH}$, undersaturation will decrease as a result of $\mathrm{Ag}^{+}$release. This will similarly increase the critical size of a patch, lowering the probability of nucleation and as a result no new patches can be formed. According to our kinetic analysis, most of the release by this mechanism will occur within the first day. The process ends due to failure to open new patches. A complicating factor is that there is no model that can describe the corresponding kinetics in an adequate manner. Therefore, we rely on an empirical approach.

\subsubsection{Kinetic Langmuir model}

Above, we have used a dual model, comprising two rate equations, as a first approach for gaining insight in the kinetics of $\mathrm{Ag}^{+}$release. Our results suggest the involvement of two release mechanisms. Our next challenge is to develop a single coherent mechanistic model that integrates both processes of $\mathrm{Ag}$ release and couples the description of kinetics to surface equilibration.

In general, an equilibrium can be split in a forward and a backward reaction with reaction rates, $R_{\mathrm{f}}$ and $R_{\mathrm{b}}$, respectively. The net reaction rate is equal to the difference between the forward and backward reaction rate: 
$\frac{d C}{d t}=R_{\mathrm{f}}-R_{\mathrm{b}}$

At equilibrium, the forward and backward reaction proceed at the same rate, i.e. $R_{\mathrm{f}}=R_{\mathrm{b}}$ or $d C / d t=0$.

Our data analysis of $\mathrm{Ag}^{+}$release suggests a first order dependency of the release rate on the proton activity, i.e. $\left(\mathrm{H}^{+}\right)^{1}$, restricting the rate of $\mathrm{Ag}^{+}$release in the high $\mathrm{pH}$ range. At lower $\mathrm{pH}$, below $\mathrm{pH} \sim 7$, our data suggest an additional rate limitation of $\mathrm{Ag}^{+}$release. We attribute to this to adsorption of molecular oxygen to $\mathrm{a} \equiv \mathrm{Ag} \mathrm{g}_{3} \mathrm{OH}$ group, forming $\equiv \mathrm{Ag}_{3} \mathrm{OH}-\mathrm{O}_{2}$ :

$\equiv \mathrm{Ag}_{3} \mathrm{OH}+\mathrm{O}_{2} \underset{k_{\text {des }}}{\stackrel{k_{\text {ads }}}{\rightleftarrows}} \equiv \mathrm{Ag}_{3} \mathrm{OH}-\mathrm{O}_{2}$

in which $k_{\text {ads }}$ and $k_{\text {des }}$ are the respective rate constants of oxygen adsorption and desorption. The suggestion is in line with Raman spectroscopy, distinguishing on a solid silver catalyst molecular, atomic, and subsurface oxygen species. ${ }^{62}$ The adsorption of molecular oxygen to silver surfaces is supported by DFT calculations. ${ }^{63}$ Moreover, adsorption of $\mathrm{O}_{2}$ is promoted in presence of water. ${ }^{63}$

Using the reaction in eq 3.13, we can formulate the expressions for the forward and backward reaction rates for the rate of $\equiv \mathrm{Ag}_{3} \mathrm{OH}-\mathrm{O}_{2}$ formation, i.e. the oxygen adsorption rate, we write:

$R_{\text {ads }}=k_{\text {ads }} \theta_{1}\left(\mathrm{O}_{2}\right)$

in which $k_{\text {ads }}$ is the rate constant, $\theta_{1}$ is the relative surface loading of $\equiv A g_{3} \mathrm{OH}$, and $\left(\mathrm{O}_{2}\right)$ is the concentration of dissolved oxygen (in $\mathrm{mol} \mathrm{L}^{-1}$ ). For the backward reaction, desorption of oxygen, the rate can be given as $R_{\text {des }}=k_{\text {des }} \theta_{2}$ in which $k_{\text {des }}$ is the rate constant of desorption and $\theta_{2}$ represents the relative surface loading of $\equiv \mathrm{Ag}_{3} \mathrm{OH}-\mathrm{O}_{2}$.

At equilibrium, $R_{\text {ads }}=R_{\text {des, }}$ leading to:

$K_{\mathrm{O}_{2}}=\frac{k_{\mathrm{ads}}}{k_{\mathrm{des}}}=\frac{\theta_{2}}{\theta_{1}\left(\mathrm{O}_{2}\right)}$

in which $K_{\mathrm{O}_{2}}$ is the equilibrium constant for the oxygen adsorption reaction (eq 3.13).

If oxygen has been adsorbed, the $\equiv \mathrm{Ag}_{3} \mathrm{OH}-\mathrm{O}_{2}$ species can become activated by a single proton. Upon activation, oxidative dissolution occurs instantaneously with the adsorbed oxygen as terminal electron acceptor. Additional oxygen $\left(1 / 4 \mathrm{O}_{2}\right)$ is required to oxidize the exposed surface into stable $\equiv \mathrm{Ag}_{5}(\mathrm{OH})_{2}$. These steps are treated as a single oxidation reaction $\equiv \mathrm{Ag}_{3} \mathrm{OH}-\mathrm{O}_{2}+4 \mathrm{H}^{+}(\mathrm{aq})+1 / 4 \mathrm{O}_{2}(\mathrm{aq}) \Leftrightarrow \equiv \mathrm{Ag}_{5}(\mathrm{OH})_{2}+4 \mathrm{Ag}^{+}(\mathrm{aq})$ for which we define a rate:

$R_{\mathrm{ox}}=k_{\mathrm{ox}} \theta_{2}\left(\mathrm{H}^{+}\right)\left(\mathrm{O}_{2}\right)^{1 / 4}$ 
in which $k_{\mathrm{ox}}$ is the rate constant of oxidation, and $\theta_{2}$ is the relative surface loading of $\equiv \mathrm{Ag}_{3} \mathrm{OH}-\mathrm{O}_{2}$, as before. The coefficient $1 / 4$ for oxygen follows from the overall stoichiometry of the transformation of $\equiv \mathrm{Ag}_{3} \mathrm{OH}$ into $\equiv \mathrm{Ag}_{5}(\mathrm{OH})_{2}$. The corresponding backward rate of reduction can be given as $R_{\text {red }}=\left(1-\theta_{1}-\theta_{2}\right)\left(\mathrm{Ag}^{+}\right)^{4}\left(\mathrm{H}^{+}\right)^{-3}$ in which $k_{\text {red }}$ is the rate constant of reduction, $1-\theta_{1}-\theta_{2}$ the relative surface loading of $\equiv \mathrm{Ag}_{5}(\mathrm{OH})_{2}$. The expressions for the rates of oxidation and reduction can be combined with the general equilibrium condition $R_{\mathrm{f}}=R_{\mathrm{b}}$, leading to:

$$
K_{\mathrm{H} / \mathrm{Ag}}^{*}=\frac{k_{\mathrm{ox}}}{k_{\mathrm{red}}}=\frac{1-\theta_{1}-\theta_{2}}{\theta_{2}} \frac{\left(\mathrm{Ag}^{+}\right)^{4}}{\left(\mathrm{H}^{+}\right)^{4}} \frac{1}{\left(\mathrm{O}_{2}\right)^{1 / 4}}
$$

We thus obtain an extended model with three surface species and two surface equilibria, which is summarized in Table 3.3. As follows from the above, the availability of $\equiv \mathrm{Ag}_{3} \mathrm{OH}-\mathrm{O}_{2}$ plays a central role in determining the kinetics of $\mathrm{Ag}^{+}$release. As illustrated in Figure 3.7, its formation (eq 3.14) as well as its release (eq 3.16) can be rate limiting, depending on the solution conditions.

Table 3.3 Tableau specifying the surface equilibria of $\mathrm{Ag}^{+}$release in a 3-species model. Note that $\log K_{\mathrm{H} / \mathrm{Ag}}^{*}+\log K_{\mathrm{O}_{2}}$ has almost the same value as $\log K_{\mathrm{H} / \mathrm{Ag}}$ in the two species model (Table 2) since the surface concentration of the $\equiv \mathrm{Ag}_{3} \mathrm{OH}-\mathrm{O}_{2}$ species is relatively low.

\begin{tabular}{llllll}
\hline & Site & $\mathrm{Ag}^{+}$ & $\mathrm{H}^{+}$ & $\mathrm{O}_{2}$ & $\log K$ \\
\hline$\equiv \mathrm{Ag}_{3} \mathrm{OH}$ & 1 & 0 & 0 & 0 & 0 \\
$\equiv \mathrm{Ag}_{3} \mathrm{OH}-\mathrm{O}_{2}$ & 1 & 0 & 0 & 1 & $\log K_{\mathrm{O}_{2}}$ \\
$\equiv \mathrm{Ag}_{5}(\mathrm{OH})_{2}$ & 1 & -4 & 4 & $11 / 4$ & $\log K^{*}{ }_{\mathrm{H} / \mathrm{Ag}}+\log K_{\mathrm{O}_{2}}$ \\
\hline
\end{tabular}




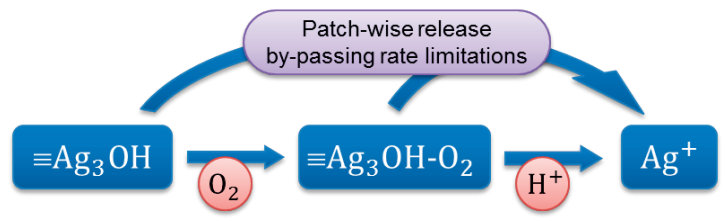

Figure 3.7 Schematic representation of mechanisms of kinetic $\mathrm{Ag}^{+}$release from $\mathrm{AgNPs}$. At high $\mathrm{pH}$, the $\mathrm{H}^{+}$concentration is rate limiting for the oxidative dissolution of $\equiv \mathrm{Ag}_{3} \mathrm{OH}-\mathrm{O}_{2}$ (eq 3.16). At increasing $\mathrm{H}^{+}$ concentrations, the oxidation rate is increased and adsorption of $\mathrm{O}_{2}$ becomes rate limiting; this typically occurs in the early stages of dissolution. At initial conditions of strong undersaturation, these processes can be by-passed via a reaction pathway (eq 3.18) in which surface opening leads to subsequent lateral stripping rather than to formation of a protective surface structure.

In our modeling, $K_{\mathrm{O}_{2}}$ is an adjustable parameter which specifies the amount of adsorbed oxygen present at equilibration with dissolved oxygen. The latter remains present in excess but the former will temporarily decrease if the rate of dissolution is relatively high. In our modelling, we assume that the system is at equilibrium with atmospheric oxygen prior to dilution. In an additional experiment, we derived the $\mathrm{Ag}^{+}$concentrations in the AgNP stock solutions, showing results in line with model predictions for a concentrated $\left(1 \mathrm{~g} \mathrm{~L}^{-1}\right) \mathrm{AgNP}$ suspension in contact with air.

If the oxidation rate of $\equiv \mathrm{Ag}_{3} \mathrm{OH}-\mathrm{O}_{2}\left(R_{\mathrm{ox}}\right)$ exceeds the rate of formation of $\equiv \mathrm{Ag}_{3} \mathrm{OH}-\mathrm{O}_{2}$ by oxygen adsorption $\left(R_{\text {ads }}\right)$, the initial concentration of $\equiv \mathrm{Ag}_{3} \mathrm{OH}-\mathrm{O}_{2}\left(\theta_{2}\right)$ will decrease and oxygen adsorption may become rate limiting. If, under these conditions, $\theta_{2}$ approaches zero, the net oxidation rate becomes equal to the rate of $\equiv \mathrm{Ag}_{3} \mathrm{OH}-\mathrm{O}_{2}$ formation, i.e. $R_{\mathrm{ox}}-R_{\text {red }}=R_{\text {ads }}$. In our systems, this will occur at increase of the proton concentration, according to $\left(\mathrm{H}^{+}\right)^{1}$, resulting in the observed rate limitation below $\mathrm{pH} \sim 7$.

The rates of oxidation and reduction formulated above are proportional to the forward and backward rates of $\mathrm{Ag}^{+}$release, $R_{\mathrm{f}}$ and $R_{\mathrm{b}}$. Transformation is achieved by multiplying with the specific surface area, $A_{\mathrm{p}}\left(\mathrm{m}^{2} \mathrm{~g}^{-1}\right)$, the AgNP concentration, $\rho_{\mathrm{c}}\left(\mathrm{g} \mathrm{L}^{-1}\right)$, the total site density $\left(N_{\mathrm{s}}\right)$, and the number of $\mathrm{Ag}^{+}$that are released per transformed site $(x+z)$, leading to:

$R_{\mathrm{f}}=\rho_{\mathrm{c}} A_{\mathrm{p}}(x+z) N_{\mathrm{S}} R_{\mathrm{ox}}$

and

$R_{\mathrm{b}}=\rho_{\mathrm{c}} A_{\mathrm{p}}(x+z) N_{\mathrm{S}} R_{\text {red }}$

\subsubsection{Kinetics of patch-wise release}

As we have discussed, patch-wise release of $\mathrm{Ag}^{+}$is the second pathway. The complexity of this process is reduced to a first order rate equation which we integrate into the mechanistic model that we develop here. The concept of the formation of shallow pits suggests that $\mathrm{Ag}^{+}$ release will start with removal of subvalent surface sites. The number of sites from which $\mathrm{Ag}^{+}$ 
is released will be approach by calculating the difference between the total amount of sites and the sites still occupied by $\equiv \mathrm{Ag}_{3} \mathrm{OH}$ and $\equiv \mathrm{Ag}_{5}(\mathrm{OH})_{2}$, expressed as a relative surface concentration, leading to a forward rate of patch wise release, $R_{\mathrm{P}}$, defined as:

$R_{\mathrm{P}}=k_{\mathrm{P}}\left(1-\theta_{1}-\theta_{2}\right) S_{\mathrm{P}}$

in which $k_{\mathrm{P}}$ is the rate constant of patch-wise release. The total amount that is released through patch formation, $S_{p}$, is a complex function of the $\mathrm{pH}$, that we describe with eq 3.10, using the values for $S_{\max }$ and $K_{\mathrm{H}}$ as previously optimized for $\operatorname{AgNP}_{5}$ using $p=0.5$. Note that no backward reaction is required, as patch-wise release is irreversible.

\subsubsection{Final modelling}

The kinetic Langmuir approach, in combination with the kinetics of patch-wise release, as detailed above, yields an excellent description of time dependency of $\mathrm{Ag}^{+}$release (see Figure 3.8). Essential for this success is the introduction of $\mathrm{O}_{2}$ adsorption as a rate-limiting step This effect is most pronounced at the shortest time-scales (in the order of hours), where release rates are highest. Although we have not studied these very short time-scales, the effect is nevertheless clearly visible in our results. Moreover, our model is supported by data collected in a recent study of short-term $\mathrm{Ag}^{+}$release by Adamczyk et al., ${ }^{29}$ to be discussed next.

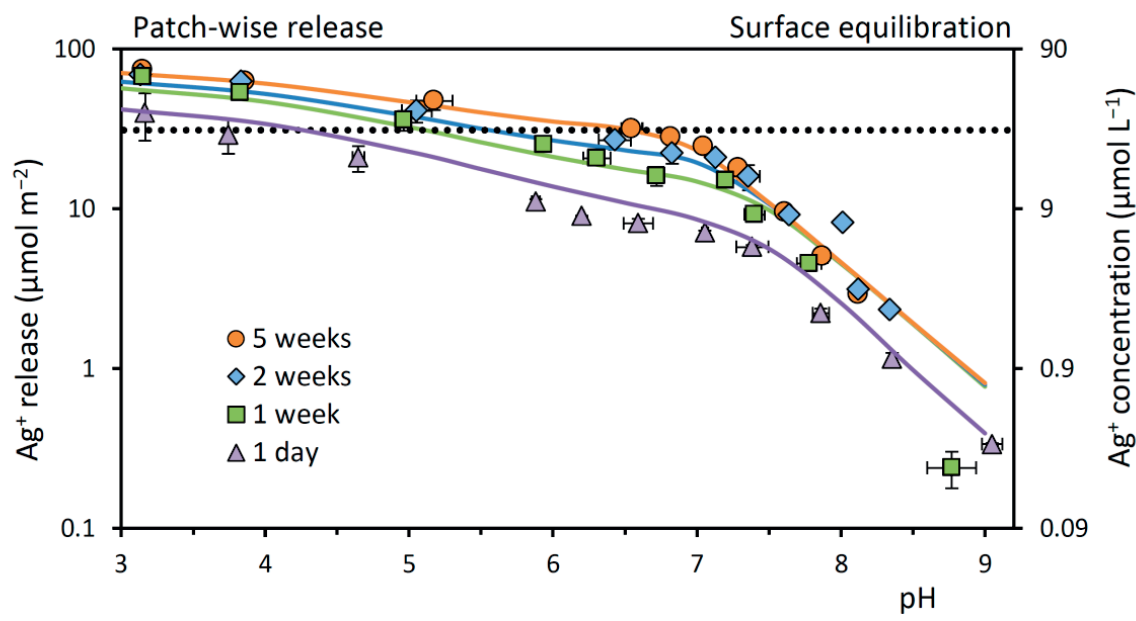

Figure 3.8 Time and $\mathrm{pH}$ dependent $\mathrm{Ag}^{+}$release for $\mathrm{AgNP}_{5}$ (symbols). Model lines (final model) have been calculated for an initial AgNP concentration of $10 \mathrm{mg} \mathrm{L}^{-1}$, with $A_{\mathrm{p}}=112 \mathrm{~m}^{2} \mathrm{~g}^{-1}$, and $N_{\mathrm{s}}=7.6 \mu \mathrm{mol} \mathrm{m}{ }^{-2}$. For reversible oxidative $\mathrm{Ag}^{+}$release, we used $k_{\mathrm{ox}}=4 \cdot 10^{8} \mathrm{day}^{-1}$ in combination with the equilibrium constant $\log K^{*}{ }_{\mathrm{H} / \mathrm{Ag}}=11.7$ with $x+z=4$ and $x+z+n=5$ (Table 3.3). For oxygen adsorption, we used $k_{\text {ads }}=0.2 \cdot 10^{3} \mathrm{day}^{-1}$, and $\log K_{\mathrm{O}_{2}}=2.8$, assuming initially $\left(\mathrm{O}_{2}\right)=0.27 \mathrm{mmol} \mathrm{L}^{-1}$ at $\mathrm{pO}_{2}=0.2$ bar (Henry's Law). For patch-wise $\mathrm{Ag}^{+}$release, we used $k_{\mathrm{p}}=6$, and a $\mathrm{pH}$-dependent value for $S_{\mathrm{p}}$, calculated using $S_{\max }=57 \mu \mathrm{mol} \mathrm{L}{ }^{-1}, \log K_{\mathrm{H}}=4.6$, and $p=0.5$ in eq 3.10 . 
For $12 \mathrm{~nm}$ AgNPs, without a capping agent, Adamczyk et al. ${ }^{29}$ have studied short term $\mathrm{Ag}^{+}$ release at $\mathrm{pH} 3.5$ for three AgNP concentrations (Figure 3.9a). They also measured $\mathrm{Ag}^{+}$release on the longer time scale at $\mathrm{pH} 3.5$ and at $\mathrm{pH} 6.2$ (Figure 3.9b). Interestingly, our model can successfully describe their short-term release data, even though we have not studied explicitly this short time scale. Using our model, only a single set of parameters is needed to describe the dynamic release of $\mathrm{Ag}^{+}$as a function of $\mathrm{pH}$ and $\mathrm{AgNP}$ concentration. Moreover, equilibration is part of our model, whereas the approach of Adamczyk et al. ${ }^{29}$ assumes oxidation will continue until full dissolution has occurred. Most of the parameter values remained unchanged, despite the larger size $(d=12 \mathrm{~nm})$ of their home-made AgNP particles and the absence of a capping agent. Some parameters were adjusted as discussed in the electronic supplementary information.
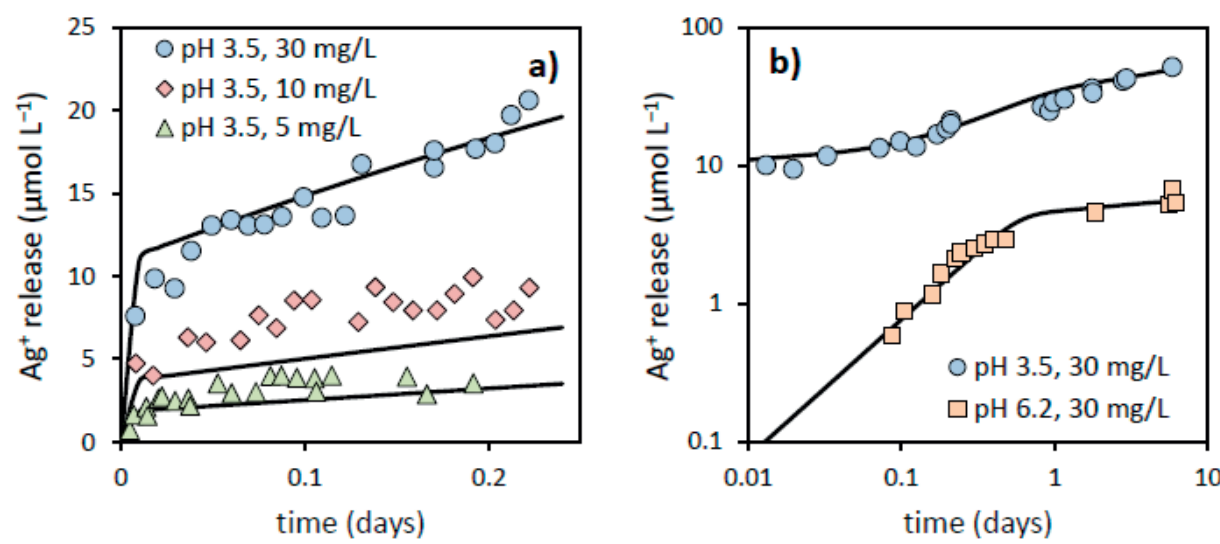

Figure 3.9 Kinetics of Ag+ release for systems with different AgNP concentrations at $\mathrm{pH} 3.5$ (a) and for a single AgNP concentration for two different $\mathrm{pH}$ values, as measured by Adamczyk et al. ${ }^{29}$ The lines have been calculated with our model for kinetic Langmuir release and shallow pit formation. Note that we have not fitted individual datasets in contrast to Adamczyk et al. ${ }^{29}$ (see Figure B10 of the Appendix)

\subsection{Conclusions}

This work reports the $\mathrm{pH}$, time, and size dependency of $\mathrm{Ag}^{+}$release from $\mathrm{AgNPs}$. The $\mathrm{Ag}^{+}$ release has been measured in a $\mathrm{pH}$ range of about 3-9, for reaction times of 1 to 35 days, using AgNPs with a diameter of 5,10 , and $20 \mathrm{~nm}$. Through careful study of both the equilibrium conditions and progression of AgNP dissolution process, a unique dataset has been collected allowing formulation of mechanistic framework for $\mathrm{Ag}^{+}$dissolution with refinement of our early ideas. ${ }^{42}$

Our results corroborate that dilution of a AgNP suspension as well as a decrease of $\mathrm{pH}$ will initiate $\mathrm{Ag}^{+}$release by an oxidative dissolution reaction of $\equiv \mathrm{Ag}_{3} \mathrm{OH}$ surface species. Upon dissolution, new surface groups with higher partial oxidation state are formed from the 
underlying metallic silver until a new equilibrium between both surface oxidation states is established. Our data suggest a maximum release of $\mathrm{Ag}^{+}$of around $31 \mu \mathrm{mol} \mathrm{m}{ }^{-2}$ by this surface equilibration process.

The present work improves our earlier attempt ${ }^{42}$ in which scarce data, available in literature, were interpreted with a single process, active over the entire $\mathrm{pH}$ range. With our current extensive dataset with a much better resolution, the contribution of two processes could be elucidated, greatly simplifying the equilibrium model.

Our study of the particle size dependency of the $\mathrm{Ag}^{+}$release allows us to generalize the model and allocate the contribution of surface Gibbs free energy in a consistent manner based on a mechanistic view. These insights suggest that particle growth upon ageing will lead to lower $\mathrm{Ag}^{+}$equilibrium concentrations, in agreement with observations by Peretyazhko et al. ${ }^{33}$ It also reveals the possible role of capping agents which may simultaneously decrease the chemical stability and increase the colloidal stability of AgNP.

Our study of the dissolution kinetics shows that the rate of $\mathrm{Ag}^{+}$release can be limited by a proton that activates molecular oxygen adsorbed by the surface. In addition, we show that the process of adsorption of this molecular oxygen can also be rate limiting in itself. The latter rate limitation is found to be relevant in the early stage of $\mathrm{Ag}^{+}$release in agreement with literature data.

Another major result of our work is the identification of a mechanism that explains why more $\mathrm{Ag}^{+}$can be released than can be accounted for by the surface equilibrium and explains initially high rates of release as frequently reported in literature. ${ }^{31,64}$ Formation and lateral growth of shallow pits at the surface is proposed as a mechanism that is activated by low solution concentrations of $\mathrm{Ag}^{+}$and high proton activity. Such conditions can be expected in the natural environment in particular when AgNPs are present in low numbers and $\mathrm{Ag}^{+}$ions are removed by complexation and adsorption to natural colloids. On the other hand, our model also predicts that the process of fast release can be suppressed by high $\mathrm{Ag}^{+}$concentrations but this has not yet been tested experimentally. ${ }^{29}$ Insight in the relation between equilibration, surface oxidation state and structure, as well as the process of release at low $\mathrm{pH}$ may further benefit from applying in future e.g. in-situ spectroscopy, high resolution TEM, and quantum mechanical computations.

Possibly the most important contribution of this work is that, for the first time, results of different kinds are interpreted within a coherent, overarching molecular view. All data are explained using a single, unifying paradigm, which describes equilibration and its kinetics based on experimental conditions and particle size. 


\subsection{References}

1. G. Merga, R. Wilson, G. Lynn, B. H. Milosavljevic and D. Meisel, The Journal of Physical Chemistry C, 2007, 111, 12220-12226.

2. N. Pradhan, A. Pal and T. Pal, Langmuir, 2001, 17, 1800-1802.

3. S. Saha, A. Pal, S. Kundu, S. Basu and T. Pal, Langmuir, 2010, 26, 2885-2893.

4. A. M. Signori, K. d. O. Santos, R. Eising, B. L. Albuquerque, F. C. Giacomelli and J. B. Domingos, Langmuir, 2010, 26, 17772-17779.

5. M. J. Mulvihill, X. Y. Ling, J. Henzie and P. Yang, Journal of the American Chemical Society, 2009, 132, 268-274.

6. Y. Yang, S. Matsubara, L. Xiong, T. Hayakawa and M. Nogami, The Journal of Physical Chemistry C, 2007, 111, 9095-9104.

7. M. Jeyaraj, G. Sathishkumar, G. Sivanandhan, D. MubarakAli, M. Rajesh, R. Arun, G. Kapildev, M. Manickavasagam, N. Thajuddin, K. Premkumar and A. Ganapathi, Colloids and Surfaces B: Biointerfaces, 2013, 106, 86-92.

8. M. I. Sriram, S. B. M. Kanth, K. Kalishwaralal and S. Gurunathan, International Journal of Nanomedicine, 2010, 5, 753-762.

9. E. I. Alarcon, B. Vulesevic, A. Argawal, A. Ross, P. Bejjani, J. Podrebarac, R. Ravichandran, J. Phopase, E. J. Suuronen and M. Griffith, Nanoscale, 2016, 8, 6484-6489.

10. J. Gallo, A. Panacek, R. Prucek, E. Kriegova, S. Hradilova, M. Hobza and M. Holinka, Materials, 2016, 9, 337.

11. M. E. Vance, T. Kuiken, E. P. Vejerano, S. P. McGinnis, M. F. Hochella Jr, D. Rejeski and M. S. Hull, Beilstein Journal of Nanotechnology, 2015, 6, 1769-1780.

12. O. Choi and Z. Hu, Environ. Sci. Technol., 2008, 42, 4583-4588.

13. J. Fabrega, J. C. Renshaw and J. R. Lead, Environ. Sci. Technol., 2009, 43, 9004-9009.

14. C. N. Lok, C. M. Ho, R. Chen, Q. Y. He, W. Y. Yu, H. Sun, P. K. H. Tam, J. F. Chiu and C. M. Che, Journal of Proteome Research, 2006, 5, 916-924.

15. W. A. Shoults-Wilson, B. C. Reinsch, O. V. Tsyusko, P. M. Bertsch, G. V. Lowry and J. M. Unrine, Soil Sci. Soc. Am. J., 2011, 75, 365-377.

16. M. J. C. van der Ploeg, R. D. Handy, P. L. Waalewijn-Kool, J. H. J. van den Berg, Z. E. Herrera Rivera, J. Bovenschen, B. Molleman, J. M. Baveco, P. Tromp, R. J. B. Peters, G. F. Koopmans, I. M. C. M. Rietjens and N. W. van den Brink, Environmental Toxicology and Chemistry, 2014, 33, 743-752.

17. X. Yang, A. P. Gondikas, S. M. Marinakos, M. Auffan, J. Liu, H. Hsu-Kim and J. N. Meyer, Environ. Sci. Technol., 2011, 46, 1119-1127.

18. S. Böhme, H. J. Stärk, T. Reemtsma and D. Kühnel, Environmental Science: Nano, 2015, 2, 603-614.

19. C. Kataoka, T. Ariyoshi, H. Kawaguchi, S. Nagasaka and S. Kashiwada, Environmental Science: Nano, 2015, 2, 94-103.

20. H. C. Poynton, J. M. Lazorchak, C. A. Impellitteri, B. J. Blalock, K. Rogers, H. J. Allen, A. Loguinov, J. L. Heckman and S. Govindasmawy, Environ. Sci. Technol., 2012, 46, 62886296.

21. M. H. Shen, X. X. Zhou, X. Y. Yang, J. B. Chao, R. Liu and J. F. Liu, Scientific Reports, 2015, 5, 9674.

22. R. Kaegi, A. Voegelin, C. Ort, B. Sinnet, B. Thalmann, J. Krismer, H. Hagendorfer, M. Elumelu and E. Mueller, Water Research, 2013, 47, 3866-3877.

23. K. Schlich, T. Klawonn, K. Terytze and K. Hund-Rinke, Environmental Sciences Europe, 2013, 25, 17. 
24. Z. M. Xiu, Q. B. Zhang, H. L. Puppala, V. L. Colvin and P. J. J. Alvarez, Nano Letters, 2012, $12,4271-4275$.

25. S. Klitzke, G. Metreveli, A. Peters, G. E. Schaumann and F. Lang, Science of the Total Environment, 2015, 535, 54-60.

26. J. Liu and R. H. Hurt, Environ. Sci. Technol., 2010, 44, 2169-2175.

27. C. Levard, B. C. Reinsch, F. M. Michel, C. Oumahi, G. V. Lowry and G. E. Brown Jr., Environ. Sci. Technol., 2011, 45, 5260-5266.

28. C. M. Ho, C. K. Wong, S. K. W. Yau, C. N. Lok and C. M. Che, Chem. Asian J., 2011, 6, 25062511.

29. Z. Adamczyk, M. Oćwieja, H. Mrowiec, S. Walas and D. Lupa, Journal of Colloid and Interface Science, 2016, 469, 355-364.

30. R. Ma, C. m. Levard, S. M. Marinakos, Y. Cheng, J. Liu, F. M. Michel, G. E. Brown Jr. and G. V. Lowry, Environ. Sci. Technol., 2012, 46, 752-759.

31. D. M. Mitrano, J. F. Ranville, A. Bednar, K. Kazor, A. S. Hering and C. P. Higgins, Environmental Science: Nano, 2014, 1, 248-259.

32. A. M. Mittelman, A. Taghavy, Y. Wang, L. M. Abriola and K. D. Pennell, Journal of Nanoparticle Research, 2013, 15, 1765.

33. T. S. Peretyazhko, Q. Zhang and V. L. Colvin, Environ. Sci. Technol., 2014, 48, 1195411961.

34. W. Zhang, Y. Yao, N. Sullivan and Y. Chen, Environ. Sci. Technol., 2011, 45, 4422-4428.

35. S. Kittler, C. Greulich, J. Diendorf, M. Köller and M. Epple, Chemistry of Materials, 2010, 22, 4548-4554.

36. A. Henglein, Chemistry of Materials, 1998, 10, 444-450.

37. Y. Yin, Z.-Y. Li, Z. Zhong, B. Gates, Y. Xia and S. Venkateswaran, Journal of Materials Chemistry, 2002, 12, 522-527.

38. G. Biedermann and L. G. Sillén, Acta Chemica Scandinavica, 1960, 14, 717-725.

39. L. Duro, M. Grivé, E. Cera, C. Domènech and J. Bruno, Update of a thermodynamic database for radionuclides to assist solubility limits calculation for performance assessment, 2006.

40. N. M. Martin, S. Klacar, H. Grönbeck, J. Knudsen, J. Schnadt, S. Blomberg, J. Gustafson and E. Lundgren, The Journal of Physical Chemistry C, 2014, 118, 15324-15331.

41. G. A. Sotiriou, A. Meyer, J. T. Knijnenburg, S. Panke and S. E. Pratsinis, Langmuir, 2012, 28, 15929-15936.

42. B. Molleman and T. Hiemstra, Langmuir, 2015, 31, 13361-13372.

43. S. Ahlert, W. Klein, O. Jepsen, O. Gunnarsson, O. K. Andersen and M. Jansen, Angew. Chem., 2003, 115, 4458-4461.

44. M. D. Johannes, S. Streltsov, I. I. Mazin and D. I. Khomskii, Physical Review B, 2007, 75, 180404(R).

45. K. Loza, J. Diendorf, C. Sengstock, L. Ruiz-Gonzalez, J. M. Gonzalez-Calbet, M. Vallet-Regi, M. Köller and M. Epple, Journal of Materials Chemistry B, 2014, 2, 1634-1643.

46. L. R. Pokhrel, B. Dubey and P. R. Scheuerman, Environmental Science: Nano, 2014, 1, 4554.

47. S. Yu, Y. Yin, X. Zhou, L. Dong and J. Liu, Environmental Science: Nano, 2016, 3, 883-893.

48. X. Li, J. J. Lenhart and H. W. Walker, Langmuir, 2010, 26, 16690-16698.

49. X. Li, J. J. Lenhart and H. W. Walker, Langmuir, 2011, 28, 1095-1104.

50. A. M. Mittelman, J. D. Fortner and K. D. Pennell, Environmental Science: Nano, 2015, 2, 683-691. 
51. J. M. Gorham, A. B. Rohlfing, K. A. Lippa, R. I. MacCuspie, A. Hemmati and R. D. Holbrook, Journal of Nanoparticle Research, 2014, 16, 2339.

52. P. S. Yen and R. Datta, Journal of Colloid and Interface Science, 2014, 426, 314-323.

53. B. Medasani, Y. H. Park and I. Vasiliev, Physical Review B, 2007, 75, 235436.

54. W. R. Tyson and W. A. Miller, Surface Science, 1977, 62, 267-276.

55. B. M. Angel, G. E. Batley, C. V. Jarolimek and N. J. Rogers, Chemosphere, 2013, 93, 359365.

56. R. D. Kent and P. J. Vikesland, Environ. Sci. Technol., 2012, 46, 6977-6984.

57. A. P. Gondikas, A. Morris, B. C. Reinsch, S. M. Marinakos, G. V. Lowry and H. Hsu-Kim, Environ. Sci. Technol., 2012, 46, 7037-7045.

58. R. Janardhanan, M. Karuppaiah, N. Hebalkar and T. N. Rao, Polyhedron, 2009, 28, 25222530.

59. R. Sips, J. Chem. Phys., 1948, 16, 490-495.

60. P. M. Dove and N. Han, AIP Conference Proceedings, 2007, 916, 215-234.

61. T. Hiemstra, Geochimica et Cosmochimica Acta, 2015, 158, 179-198.

62. G. I. Waterhouse, G. A. Bowmaker and J. B. Metson, Applied Surface Science, 2003, 214, 36-51.

63. H. Y. Su, M. M. Yang, X. H. Bao and W. X. Li, The Journal of Physical Chemistry C, 2008, $112,17303-17310$.

64. J. Liu, D. A. Sonshine, S. Shervani and R. H. Hurt, ACS Nano, 2010, 4, 6903-6913. 



\section{Chapter 4}

Size and shape dependency of surface energy of metallic nanoparticles: Unifying the atomic and thermodynamic approach

Bastiaan Molleman and Tjisse Hiemstra

Published in Physical Chemistry Chemical Physics

Volume 20, issue 31, Pages 20575-20587, 13 July 2018 


\section{Abstract}

Surface energy is a fundamental property of metallic nanoparticles (MeNPs), which plays a crucial role in nucleation and growth. Moreover, by affecting particle shape and chemical stability, it has strong implications for the application and environmental impact of MeNPs. Surface energy $\left(\mathrm{J} \mathrm{m}^{-2}\right)$ can be size dependent, but experimental data on surface energy trends for MeNPs are inconclusive. Computational chemistry may resolve the issue, but the surface used for scaling, which dramatically influences outcome and interpretation, has not been properly investigated. The size dependency of surface energy can only be determined by scaling to the thermodynamic surface of tension. To identify it, we have derived a generalized Tolman approach for non-spherical particles, which is used to analyze the thermodynamic consistency of various surface definitions. Only the physical surface, defined here, is consistent as the surface of tension. Scaling recent computational data for faceted MeNPs to this surface yields a low size dependency of surface energy, in good agreement to the Tolman lengths corresponding to its interfacial position. We find Tolman lengths of $-0.03 \mathrm{~nm}$ for icosahedra and $-0.04 \mathrm{~nm}$ for cuboctahedra of gold or silver. Our approach is used to quantify twinning energy for icosahedral nanoparticles, being $0.06 \mathrm{~J}$ per $\mathrm{m}^{2}$ twin area. To understand the unorthodox negative Tolman lengths, we have analyzed the surface energetics of the solid-gas interface of metals in relation to the liquid-vapor interface of water. Surface entropy is found to be imperative in determining the size dependence of surface free energy. At room temperature, the influence of surface entropy on surface enthalpy is much smaller for metals than for water. It explains why these two interfaces have an opposite size dependency of the surface Gibbs free energy and an opposite sign of the Tolman length. For water, forming nanodroplets or nanobubbles, the Tolman length is negative $(\sim-0.014 \mathrm{~nm})$ for the surface enthalpy but positive ( $\sim 0.06 \pm 0.02 \mathrm{~nm}$ ) for the surface Gibbs free energy. For MeNPs at room temperature, both entities are negative, but at high temperature, the increased surface entropy term may cause the size dependency of surface Gibb free energy to become reversed. 


\subsection{Introduction}

Metallic nanoparticles (MeNPs) are important in science and technology, being widely studied and applied. Having unique optical properties ${ }^{1}$ and a high specific surface area, MeNPs can be used in a range of innovative applications, such as three-dimensional tissue imaging, ${ }^{2}$ real time monitoring of surface processes, ${ }^{3}$ surface enhanced Raman scattering, ${ }^{4}$ and biosensors. ${ }^{5}$ In addition, MeNPs are used in catalysis ${ }^{6,7}$ and photocatalysis. ${ }^{8-10}$ Metallic nanoparticles offer many promising perspectives, but despite many technological and scientific advances, our understanding of and control over MeNPs can be much improved.

One of the most powerful and versatile parameters for understanding MeNP behavior is the surface energy. Creating surfaces requires energy, which adds to the chemical potential of a material; this has major consequences for crucial processes such as nucleation ${ }^{11,12}$ and growth. ${ }^{13,14}$ It may also affect magnetic behavior of materials as shown recently. ${ }^{15}$ Moreover, surface energy controls size dependent characteristics of MeNPs such as the crystal structure ${ }^{16,17}$ and the chemical stability, as reflected in e.g. the melting temperature ${ }^{18}$ and the solubility of silver nanoparticles (AgNPs). ${ }^{19}$ The latter aspect is relevant from the environmental perspective. Detailed knowledge of the surface energy can be used to understand the stability of different particle shapes ${ }^{20}$ or even to chart the stability as a function of size, shape, crystal structure, and temperature. ${ }^{21}$ It is clear that the study of the surface energy of MeNPs is pivotal for deepening our understanding of nanoparticle behavior. An important aspect of the topic is that surface energy may become size-dependent if particles get small. This will be studied.

The concept of size dependency of surface energy has its origin in the famous work of Tolman. ${ }^{22-24}$ Through a rigorous thermodynamic treatment of Gibbs' theory of surface tension, ${ }^{25}$ Tolman inferred how the surface tension may change with particle size. For water and organic liquids, it decreases for smaller particles ${ }^{24}$ as confirmed in a number of studies. ${ }^{26-}$ 28 In various models, the same behavior for $\mathrm{MeNPs}^{29,30}$ is assumed a priori, but no experimental data support this trend and therefore, the validity of this assumption may be questioned. We know that the energy of MeNPs expressed per mole atoms $\left(\mathrm{J} \mathrm{mol}^{-1}\right)$ is much higher if the particles are smaller. The general believe is that those small nanoparticles also have a higher surface energy value $\left(\mathrm{J} \mathrm{m}^{-2}\right)$, implying that the size dependency of surface energy of MeNPs is opposite to that for liquids. The question arises why and how much.

To date, experimental evidence has not provided an unambiguous answer to these questions concerning the size dependency of the surface energy of MeNPs. Experimentally, surface energies determined for MeNPs by a variety of methods have proven highly variable. While some sources report for MeNPs surface energy values ${ }^{19,31}$ or surface stresses ${ }^{32,33}$ to be very close to those of the bulk metal, strongly elevated values ${ }^{34-37}$ have also been reported, however without any size dependency and, remarkably, without any drop to bulk values even though the particles are already as large as $48 \mathrm{~nm}$. The multiple uncertainties make that direct 
experimental methods are to date not sensitive enough to resolve the issue. Instead, computational chemistry may be valuable.

To elucidate the size dependency of surface tension, a number of computational approaches can be used. With advanced quantum chemical computational methods, it is possible to calculate the surface energy of crystal faces using slabs. ${ }^{20,38,39}$ These surface energy values for a flat face include energy effects that occur in the interior of the material (e.g. relaxation) due to surface formation and therefore, these contributions can be considered by definition as part of the surface energy in a broad sense. Such computations may lead to an estimate of the surface energy of a particle of a given shape, and can be used to understand the most stable geometry for large particles. ${ }^{20}$ However, it does not answer the question of any particle size dependency, as particles of different size with the same geometry have a fixed ratio of crystal faces and the energy contributions of edges and corners are not quantified with this approach. The appropriate method to include that contribution involves the calculation of the total energy of nanoparticles $\left(E_{\mathrm{np}}\right)$ having face, edge, and corner contributions. The calculated total energies $\left(E_{\mathrm{np}}\right)$, expressed per mole of atoms, can be compared to the energy of atoms present in the bulk material $\left(E_{\mathrm{b}}\right)$ and the difference, or excess particle energy, is interpreted as a surface energy contribution, i.e. $\Delta E_{\mathrm{s}} \equiv E_{\mathrm{np}}-E_{\mathrm{b}}\left(\mathrm{J} \mathrm{mol}^{-1}\right) \cdot{ }^{40-42}$ When these surface energy contributions for particles of given shape are scaled to the specific surface area of the various nanoparticles $A_{p}\left(\mathrm{~m}^{2} \mathrm{~mol}^{-1}\right)$, the surface energy $\left(\mathrm{J} \mathrm{m}^{-2}\right)$ and its size dependency is obtained.

For a correct value of the surface energy of small particles, an accurate calculation of the surface area is as important as the calculation of the energy with advanced computational modelling, as will follow from the present paper. For our analysis, particles of various but regular shapes will be chosen, as we want to test the principles of our approach. Different geometries will be used because their shapes differ in contributions of faces, edges, and corners. Moreover, icosahedra are included as these particles have internal stress due to crystal twinning. ${ }^{43,44}$ The various types of particles were also used in recent modelling studies from which it has been concluded that smaller nanoparticles have a higher surface energy. ${ }^{40-}$ ${ }^{42}$ The focus in these modeling efforts has been on calculating particle energies $\left(\mathrm{J} \mathrm{mol}^{-1}\right)$, which was done with great care, but little or no attention was paid to how one should calculate the surface area $\left(\mathrm{m}^{2} \mathrm{~mol}^{-1}\right)$. The latter seems rather trivial, but it is not, as will be shown in the present work. We will demonstrate the far-reaching implications of the method that is used to calculate the surface area and show that only with help of thermodynamics can the appropriate scaling be done.

Different approaches are in use to derive the surface area of metal clusters and nanoparticles of various shapes. One approach has been the use of the spherical approximation, ${ }^{41,42}$ but particles often have a faceted nature ${ }^{40}$ for which one may account in the calculation of the surface area. In case of small facetted particles, atoms at corners and edges will also contribute considerably to the surface area. In the model for the calculation of the surface area to be developed, this will be quantified. 
Obviously, the surface area used for energy scaling of a particle will depend on the chosen location of the surface in the interface. However, this position cannot be chosen freely, but is restricted by thermodynamics. To identify the position of the surface in the interface required for the scaling of the calculated particle energies, we will return to the classical treatises of Tolman ${ }^{22,} 23$ on the consequences of Gibbs' work for interfaces. ${ }^{25}$ In thermodynamics, surface energy is attributed to a specific plane in the interface, known as the surface of tension. The corresponding surface area must also be chosen in the above-mentioned scaling of the particle energy. Importantly, this surface may differ from the so-called equimolar surface. The equimolar surface marks the interface position that is equivalent to an infinitely sharp transition of material between two constituting phases. Therefore, that location can be defined unambiguously. If the surface for scaling of the calculated energy is equal to the welldefined equimolar surface, there will be no size dependency of the surface energy according to thermodynamics. If it has a different position than the equimolar surface, size dependency will follow.

The above indicates that both the surface used for scaling of the calculated particle energy and the surface of tension used in the thermodynamic treatment lead to a certain size dependency. As only one size dependency exists physically, this implies that both treatments are fully coupled and as a result, the location of the surface and its corresponding surface area cannot be chosen arbitrarily. This coupling allows identification of the location of the surface plane in the interface to be used for a correct scaling of the particle energy. The location should be chosen such that consistency exists between the quantum chemical and thermodynamic approach. It will be a major conclusion of the present study.

Consistent scaling will be used to evaluate a range of factors that may contribute to the observed size dependency of the surface energy of various MeNPs, for instance geometry with different corner and edge contributions and the presence of twin planes in icosahedra and decahedra. The insights gained will be used to contribute to a more general understanding of the differences between the size dependencies of surface enthalpy, surface entropy, and surface Gibbs free energy in both solid-gas and liquid-gas interfaces.

\subsection{Theory}

In this section, we will first briefly review the approaches commonly used in literature for estimating the surface area of polyhedral MeNPs, before we present our new, more realistic method. Next, we will describe the thermodynamic concepts of surface energy that are related to the allocation of the surface in the interface. Both aspects will later be applied in Results and Discussion.

\subsubsection{Spherical approximations}

In a spherical approximation of the surface area, the nanocluster is simplified to a perfect sphere with radius $r$. Medasani et al. ${ }^{41}$ obtained the radius $r$ by averaging the distances from 
the center of the cluster to the outer atoms. A more general method is to estimate it from the number of atoms $(N)$ of a particle with a bulk density $(\rho)$ and molar mass $(M)^{11}$ :

$r=\left(\frac{3 N M}{4 \pi N_{A} \rho}\right)^{1 / 3}$

in which $N_{\mathrm{A}}$ is Avogrado's number; the corresponding surface area is found using $A=4 \pi r^{2}$.

The spherical approach may be seen as reasonable for large MeNP but for small, faceted particles with well-defined shapes (Figure 4.1), it will lead to underestimation of the surface area, and thus overestimation of the surface energy.
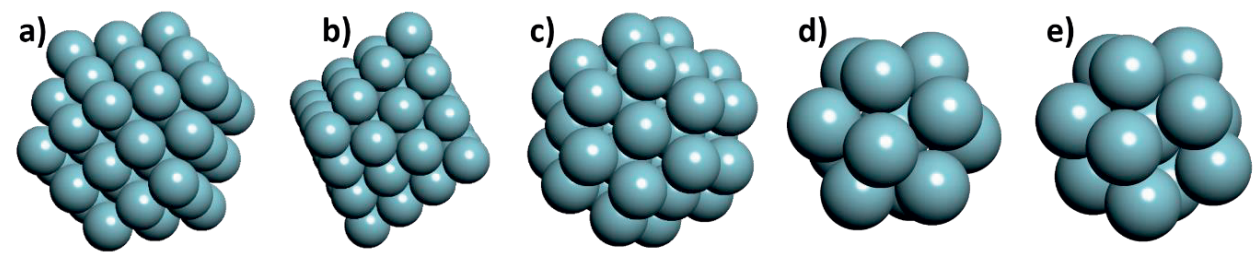

Figure 4.1 Five commonly used geometrical clusters with $s$ atoms along the edge and $N_{T}$ atoms per particle: a cuboctahedron with $s=3$ and $N_{\mathrm{T}}=55$ atoms (a); an octahedron with $s=4$ and $N_{\mathrm{T}}=44$ atoms (b); a regular truncated octahedron with $s=2$ and $N_{T}=38$ atoms (c); a regular icosahedron with $s=2$ and $N_{\mathrm{T}}=13$ atoms (d); a regular truncated decahedron with $s=2$ and $N_{\mathrm{T}}=13$ atoms (e).

\subsubsection{Polyhedral approximations}

In literature, a general approach for calculating the surface area of small facetted particles (Figure 4.1) is simplifying the shape to geometrically perfect polyhedra with 1-dimensional edges. In this view, the surface area of a particle $(A)$ is equal to the total facet surface area $\left(A_{\mathrm{f}, \mathrm{T}}\right)$ :

$$
A=A_{\mathrm{f}, \mathrm{T}}=\sum x_{h} A_{\mathrm{f}, h}
$$

where $A_{\mathrm{f}, h}$ is the surface area of a facet $h$, and $x_{h}$ is the number of facets of type $h$ present on the particle. This approach ignores the presence of rounded edges and corners, greatly simplifying the calculation.

For a perfect polyhedron, the surface area of the facets follows readily from the lengths of its edges. In literature, two methods are used to derive the edge-length of a polyhedron from the number of atoms $s$ along an edge (Figure 4.2) and the interatomic distance $d_{\mathrm{a}}$. However, both methods lead to very different surface areas if the particles become very small. 


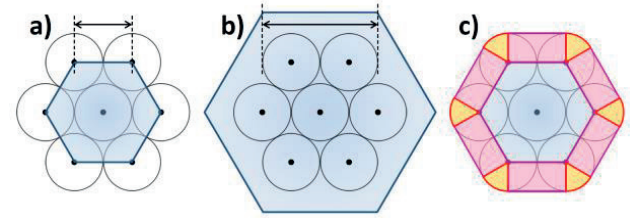

Figure 4.2 Three ways of assessing the surface area of metallic nanoparticles illustrated with a 2D representation of a particle having $s$ atoms with a diameter $d_{\mathrm{a}}$. In methods A and B, particle shape is simplified to a perfect polyhedron, using the edge-lengths as the sole parameter to calculate surface area. In method $A$, edges stretch between the centers of corner atoms, leading to a length equal to $I=$ $d_{\mathrm{a}}(s-1)$. In method $\mathrm{B}$, the edge-length is equal to the sum of the diameters of edge atoms $I=d_{\mathrm{a}} s$. Method A underestimates the surface area while method B overestimates it for most particle shapes, as visualized by the blue surfaces. For the physical surface area (c), we supplement the facet surface area of method A (blue), with a 3D contribution of rounded edges (pink) and corners (orange), calculated using cylindrical and spherical geometry, respectively.

In crystallography, atoms are reduced to points in space defining crystal faces. From that perspective, the edge-length $(I)$ is equal to the distance between the cores of corner atoms, which is equal to $I=d_{\mathrm{a}}(s-1)$, as illustrated in Figure 4.2 (method A). Alternatively, one may treat atoms as hard spheres with a diameter equal to the interatomic distance $d_{\mathrm{a}}$. In that model, an edge-length equal to $I=d_{\mathrm{a}} s$ is taken, ${ }^{30}$ as shown in Figure 4.2 (method B).

In method B, edge-lengths are longer by exactly one time the interatomic distance than in method A. Although this difference may seem small, it leads to significantly different surface areas. For the icosahedral cluster of Figure $4.1 \mathrm{~d}$ with 13 atoms, method A yields a $75 \%$ (!) smaller surface area than method B. In case of a $5 \mathrm{~nm}$ icosahedral AgNP, the difference is still $15 \%$. At scaling of excess particle energy $\left(\Delta E=E_{\mathrm{NP}}-E_{\text {bulk }}\right)$, these differences will lead to very different conclusions with respect to the size dependency of the surface energy, as we will show.

\subsubsection{Physical surface area}

In the above approaches, edges and corners are 1-dimensional and 0-dimensional objects, respectively. However, in an atomic view as shown in Figure 4.1, edges and corners are rounded. In the model that we will formulate below, we will explicitly assign a surface area to these curved sections of the particle surface.

In our approach, we will use a planar geometry for the facets, in accordance with the definition of macroscopic surface energy values. For the edge and corner atoms, we will account for the physical space that they occupy, using an atomic radius $\left(r_{\mathrm{a}}\right)$ set to half the interatomic distance $\left(d_{\mathrm{a}}\right)$. For the edges (I) and the corners (II), cylindrical and spherical geometry will be used, respectively, to calculate the surface area contribution. The thus defined surface is close to the van der Waals contact area and will be referred to as the physical surface.

1) The edge contribution follows from the geometry of a cylinder with a diameter equal to that of the edge atoms, i.e. $d_{\mathrm{a}}$. With this choice, there is a seamless transition from one facet to 
the next. As corners atoms are treated separately, the cylinder has a length equal to $d_{\mathrm{a}}(s-1)$, as shown in Figure 4.2. If two facets intersect at a dihedral angle $\alpha$, the cylindrical section forming the surface is $\pi-\alpha$ rad (see Appendix C, Figure C1). The sum of the surface area of the edges can then be expressed as:

$$
A_{e, T}=\sum y_{i} A_{e, i}=0.5 d_{a}^{2} \sum y_{i}\left(\pi-\alpha_{i}\right)\left(s_{i}-1\right)
$$

where $\alpha_{i}$ is the dihedral angle (rad) of an edge $i$, and $y_{i}$ is the number of edges of type $i$ present on a particle. Although we presently consider only particle geometries with equal edges, equation 4.3 can be applied to any particle geometry as long as the number of atoms along an edge, $s_{i}$, is well documented. An overview of intersecting planes and corresponding dihedral angles is given in Table 1 for the particle geometries (Figure 4.1) that we treat in this work.

II) The contribution of corner atoms is found by considering corner atoms as spheres with a radius equal to the atomic radius, $r=r_{\text {a }}$. Part of a corner is covered by the edge cylinders, with only a small section left uncovered. This spherical polygon, enclosed by the ends of the cylinders forming great circles on corner atoms, forms the surface area of a corner. The total surface of the corners $A_{c, T}$ is equal to:

$$
A_{c, T}=\sum z_{j} A_{c, j}=r_{a}^{2} \sum z_{j} \Delta_{j}
$$

where $A_{c, j}$ is the surface area of a corner $j$, and $z_{j}$ is the number of corners of type $j$ on a given particle. The surface area of a spherical polygon follows from the spherical excess multiplied by the radius squared. ${ }^{45}$ The spherical excess is equal to $\Delta=\sum \theta_{k}-\pi(p-2)$, in which $\sum \theta_{k}$ is the sum of the internal angles and $p$ is the number of angles (see Appendix C, Figure C1). Interestingly, $\sum z_{j} A_{c, j}$ always equals to $\pi$, for the chosen shapes, implying that combined corner atoms contribute exactly the surface area of a single hard-sphere atom. Internal angles follow from the particle geometry and the crystal structure (see Table C1); an overview of the equations is given in Table 1 for regular particle geometries. 


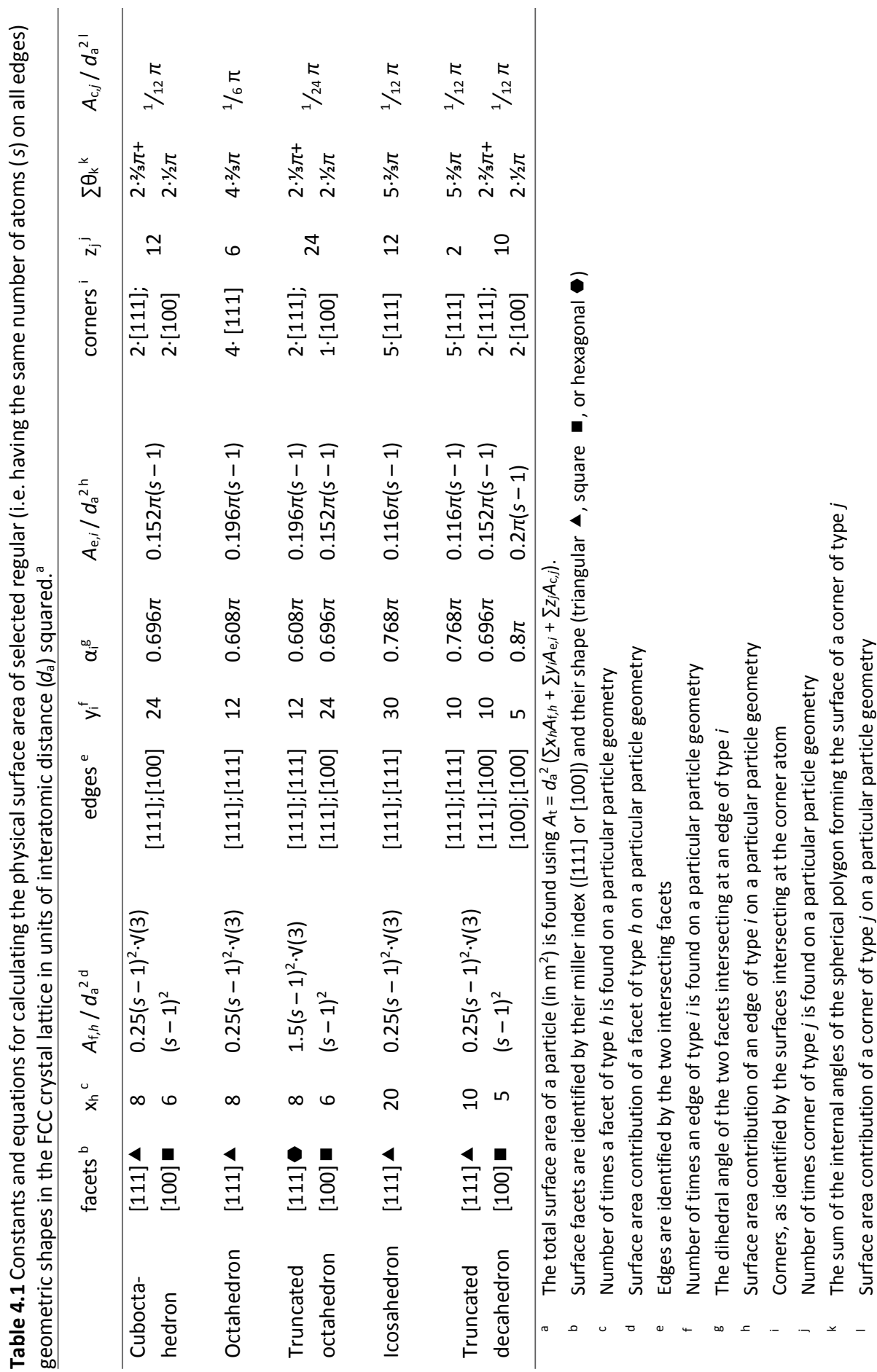




\subsubsection{Thermodynamics of surfaces}

The theoretical work of Tolman on surface tension ${ }^{23}$ is often referred to in relation to the surface energy. The thermodynamic treatment of Tolman describes the size dependence of surface tension. It is particularly important for small nanoparticles and metal clusters.

Two essential concepts for understanding the theoretical background of the Tolman equation are the equimolar surface and the surface of tension. These concepts will be introduced using the sphere as example, but they apply regardless of geometry.

The equimolar surface is a theoretical plane in the interface, with a position equivalent to an infinitely sharp transition between two phases. As illustrated in Figure 4.3a, the actual transition between two phases may be smooth; in a symmetrical interface, the equimolar surface would be located in the middle. The surface of tension is a plane, parallel to the equimolar surface, where the surface tension is allocated by definition; consequently, the excess energy of a particle should consequently be scaled to this surface.
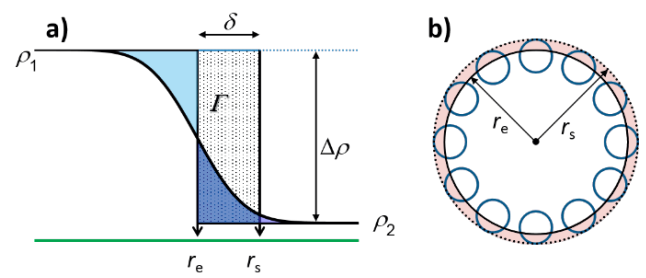

Figure 4.3 Left side (a), mass density profile of an interface with a gradual change of the mass density from phase $1\left(\rho_{1}\right)$ to that of phase $2\left(\rho_{2}\right)$. The equimolar particle radius $\left(r_{\mathrm{e}}\right)$ is at a point in the interface where the amount of mass at side 2 (dark blue area) is equal to the amount of mass missing at side 1 (light blue area). The dotted rectangle represents the excess amount of mass $\Gamma$ relative to the surface of tension of the particle with the radius $r_{\mathrm{s}}$. This excess is the product of the distance $\delta$ and the difference in mass density $\Delta \rho$ of both phases, i.e. $\Gamma=\delta\left(\rho_{1}-\rho_{2}\right)$. Note that $\delta \equiv r_{\mathrm{e}}-r_{\mathrm{s}}$, implying that $\Gamma$ has a negative sign in the above case. Right side (b), a spherical particle with excess adsorption shown in red. The full and dotted circles respectively represent the equimolar surface and the surface of tension with the arrows for the radii $r_{\mathrm{e}}$ and $r_{\mathrm{s}}$.

The equimolar surface and the surface of tension may have a different position in the interface, and in case of curved surfaces, their surface areas may differ. The distance between the two surfaces is known as the Tolman length $\delta$ (Figure 4.3a). For a spherical particle (Figure $4.3 \mathrm{~b})$, the Tolman length is equal to the difference $\delta$ between the radii of the equimolar surface $r_{\mathrm{e}}$ and the surface of tension $r_{\mathrm{s}}$, according to:

$\delta \equiv r_{\mathrm{e}}-r_{\mathrm{s}}$

The Tolman length $\delta$ can thus be either positive or a negative, depending on the position of the surface of tension with respect to the equimolar surface. 
The Tolman length can be seen as the thickness of a layer of material, adsorbed to the surface of tension. This layer is referred to as the interfacial excess adsorption $\Gamma=\delta\left(\rho_{1}-\rho_{2}\right)$. A negative excess adsorption represents an absence of mass with respect to the surface of tension.

Excess adsorption influences the size dependency of surface tension according to $d \nu=-\Gamma d \mu .^{22}$ The equation expresses that a change in chemical potential results in a change in surface tension if the surface of tension and the equimolar surface have a different location in the interface. If the surface of tension is located outside of the equimolar surface, as shown in Figure 4.3, the Tolman length $\delta$ and the excess adsorption $\Gamma$ will be negative. In that case, at a decrease in size, the resulting increase in the chemical potential $d \mu$ will cause an increase in the surface tension $d \gamma$.

The change in chemical potential with particle size can be expressed in terms of surface tension and size, which is used to derive the classical Tolman equation. As shown in Appendix C (Section 2), we use the central role of the Laplace equation in the derivation to arrive at a generalized expression for the size-dependent surface tension $\gamma_{r}$ :

$$
\gamma_{r}=\frac{\gamma_{\infty}}{1+2 c \delta / r_{\mathrm{s}}}=\gamma_{\infty}\left(1+\frac{2 c \delta}{r_{\mathrm{s}}}\right)^{-1}=\gamma_{\infty}\left(1+\frac{2 c \delta}{r_{\mathrm{e}}-\delta}\right)^{-1}
$$

in which $\gamma_{\infty}$ is the surface tension of a planar surface at $r_{\mathrm{e}} \rightarrow \infty$. The factor $c$ represents a correction that accounts for the higher surface to volume ratio of faceted or spheroidal particles. For a sphere, the shape factor $c$ is equal to unity, in which case equation 4.6 reduces to the classical Tolman equation for spherical particles. ${ }^{23}$ An overview of $c$ values for selected shapes is given in Table 4.2; the derivation of these shape factors is given in Appendix $C$ (Section 2). The shape factor for oblate and prolate spheroids is not constant but rather a function of the aspect ratio, this is treated in detail in Appendix C (Section 2).

Table 4.2 Particle shape factor $c$ (eq 4.6) for a selection of faceted particles (see Appendix C, Section 2)

\begin{tabular}{ll}
\hline Particle geometry & $c$ \\
\hline Cuboctahedra & 1.105 \\
Octahedra & 1.183 \\
Truncated octahedra & 1.099 \\
Icosahedra & 1.065 \\
Truncated decahedra & 1.100 \\
\hline
\end{tabular}

According to the above equation, surface tension decreases if the surface of tension is located within the equimolar surface, i.e. if $r_{\mathrm{e}}>r_{\mathrm{s}}$, and vice versa; at zero excess adsorption, the surface of tension coincides with the equimolar surface, i.e. $\delta=0$, in which case the surface tension is size independent (eq 4.6). We note that equation 4.6 is the analytical solution of the relationship between $d \nu$ and $d \mu$ for $r_{\mathrm{e}} \gg \delta$. For extremely small spherical particles, the Tolman 
size dependency can be evaluated accurately with mathematical solutions available in literature. $^{46}$

\subsubsection{Thermodynamic consistency}

For a spherical particle, the location of the equimolar surface is well defined with the radius $r_{\mathrm{e}}$ in equation 4.1. For the surface of tension, the interfacial position is less obvious. In Thermodynamics, the surface of tension is a mathematical construct, which does not necessarily have a structural meaning; nevertheless, its position is not arbitrary. This is exemplified next.

Imagine a spherical particle with an equimolar radius $r_{\mathrm{e}}$ for which the chemical potential has been established, either computationally or experimentally. For this particle, any chosen radius for the surface of tension $r_{\mathrm{s}}$ will result in (I) a Tolman length $\delta\left(=r_{\mathrm{e}}-r_{\mathrm{s}}\right)$ and a corresponding surface energy for that particle according to equation 4.6, as well as (II) a surface area $\left(4 \pi r_{s}{ }^{2}\right)$ which also leads to a surface energy value after scaling the excess energy of the particle. The surface energies according to both methods depend on the chosen radius $r_{s}$, but in an opposite manner (see Appendix C, Figure (4). As a result, there is a single, unique value of $r_{\mathrm{s}}$ where both surface energy values are the same. Here, consistency exists.

The above principle can also be applied to facetted particles as we address in Appendix $C$ (Section C2). There, we derive an adapted Tolman equation for various facetted particles and show there is a negligible deviation $(<1 \%)$ from the classical equation for particles as small as $\sim 1 \mathrm{~nm}$.

\subsubsection{Sign and value of the Tolman length}

Analysis of the liquid-vapor interface of water by Tolman ${ }^{24}$ suggested a positive value for the Tolman length of about $\delta \sim+0.1 \mathrm{~nm}$. More recently, a molecular dynamics simulation of vapor pressures of water nanodroplets is in accordance with a positive value for the Tolman length, being in the range of about $0.04-0.08 \mathrm{~nm} .{ }^{27}$ In another very recent contribution, ${ }^{28}$ the formation of nanocavities in water has been studied with state-of-the-art molecular dynamics. From the generated data, the authors derived a higher value for the Tolman length of $\delta \sim+0.2$ $\mathrm{nm}$. However, in their approach the planar surface tension $\gamma_{\infty}$ was used as a fitting parameter resulting in an incorrect value for $\gamma_{\infty}$; moreover, the surface tension was scaled to the equimolar surface rather than to the surface of tension. In our reinterpretation of these data (see Appendix C, Section C4), we find a Tolman length of $\delta \sim+0.07 \mathrm{~nm}$, in line with the other data. Literature thus suggests a positive value for Tolman length for the liquid-vapor interface of water, being likely about $+0.06 \pm 0.02 \mathrm{~nm}$. Positive numbers are also found for other liquids. ${ }^{24,} 26$

A positive value for the Tolman length implies that the surface tension for nanodroplets $\left(\nu_{r}\right)$ is lower than for bulk liquids $\left(\gamma_{\infty}\right)$. It also indicates that the surface of tension is located within 
the equimolar surface as given in Figure 4.3a. The question arises where the surface of tension is located in the solid-gas interface of MeNPs.

In Figure 4.2, we have presented a number of options for calculating the surface area, each corresponding to a unique interfacial position of the surface of tension. Importantly, each of these surfaces is located at some distance from the equimolar surface, either inside or outside, as shown in Figure 4.4 for the [100] face of metallic FCC particles. As a result, the surface definitions correspond to different Tolman lengths and therefore, to different sizedependencies of surface energy according to equation 4.6.

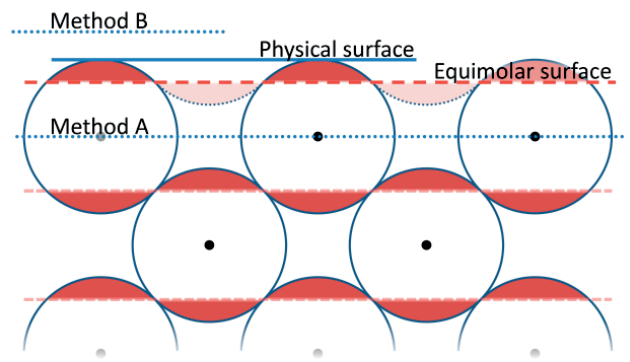

Figure 4.4 Positions of the surface of tension according to different definitions and the equimolar surface in solid metallic surfaces. The figure shows a to-scale cross-section, perpendicular to the [100] face. The centers of atoms are represented as black dots, the atomic shells as blue circles; the shaded sections of atoms have the same volume. The physical surface area is placed on top of the outer shells of the surface atoms. The surface according to method A (see Figure 4.2) runs through the centers of surface atoms. The surface according to method B (see Figure 4.2) is located above the physical surface. The overlap of atoms implies that a higher atomic density is found in the bulk of the crystal there then at the physical surface. The equimolar surface is located where the overlapping portion of the surface atom, is equal to the missing overlapping section. For more detail, we refer to Appendix $C$ (Section C5).

The location of the equimolar surface in Figure 4.4 (bold dashed line) follows from the crystal structure and is different for different crystal faces. In the FCC crystal structure with atoms of radius $r_{\mathrm{a}}=1 / 2 d_{\mathrm{a}}$, the position can be expressed as the distance to the cores of surface atoms, being $\sqrt{ } 1 / 2 r_{a}$ for the [100] face and $\sqrt{2} / 3 r_{a}$ for the [111] face (see Appendix C, Section C5). Since the physical surface as defined above is positioned at a distance of $r_{\mathrm{a}}$ from the cores of surface atoms, the resulting Tolman lengths are $\delta_{[100]}=(\mathrm{V} 1 / 2-1) r_{\mathrm{a}}=-0.146 d_{\mathrm{a}}$ and $\delta_{[111]}=\left(\mathrm{V}^{2} / 3-1\right) r_{\mathrm{a}}=$ $-0.093 d_{\mathrm{a}}$.

For the surface according to method $A$, the [100] and [111] faces have Tolman lengths of $\delta_{[100]}$ $=\sqrt{ } 1 / 2 r_{\mathrm{a}}$ and $\delta_{[111]}=\mathrm{V}^{2} / 3 r_{\mathrm{a}}$. For the surface of Method $\mathrm{B}$, the Tolman length depends on particle geometry; in case of cuboctahedra, the Tolman lengths for the [100] and the [111] face are $\delta_{[100]}=-\sqrt{1} 1 / 2 r_{\mathrm{a}}$ and $\delta_{[111]}=-\mathrm{V}^{2} / 3 r_{\mathrm{a}}$ (see Appendix C, Section C5). 
For faceted particles, an average Tolman length can be calculated using the two Tolman lengths, $\delta_{[100]}$ and $\delta_{[111]}$ and the ratio between the total surface areas the facets, $A_{[100]} / A_{[111]}$. Surface area ratios for selected shapes are presented in Table 3, together with the corresponding overall Tolman lengths for the physical surface. Note that according to our analysis, the Tolman length will depend on the interatomic distance $d_{\mathrm{a}}$ and therefore, on the metal involved.

Table 4.3 Ratio between surface area contribution of the [100] and [111] face for particles of various shapes and the corresponding overall Tolman lengths related to the physical surface.

\begin{tabular}{lcc}
\hline Particle geometry & $A_{[100]} / A_{[111]}$ & $\delta$ \\
\hline Cuboctahedra & $\sqrt{ } 3 / 1$ & $-0.126 d_{\mathrm{a}}$ \\
Octahedra & $0 / 1$ & $-0.092 d_{\mathrm{a}}$ \\
Truncated octahedra & $1 / \sqrt{ } 12$ & $-0.104 d_{\mathrm{a}}$ \\
Icosahedra & $0 / 1$ & $-0.092 d_{\mathrm{a}}$ \\
Truncated decahedra & $1 / \sqrt{ } 3 / 4$ & $-0.121 d_{\mathrm{a}}$ \\
\hline
\end{tabular}

\subsection{Results and Discussion}

In this section, the thermodynamic consistency of the three surface area models will be evaluated first, showing that the physical surface is the only valid choice. Next, we will show that this finding has major implications for the size dependency of surface energy and that this improved understanding of size-dependency can be used to reveal other contributions to surface energy due to for instance crystal twinning. In the last part, we will analyze the size dependent surface thermochemistry in terms of enthalpy, Gibbs free energy, and entropy in order to broaden and deepen our insight into the differences between solid-gas and liquidvapor interfaces in general.

\subsubsection{Microscopic and Thermodynamic consistency}

In Theory, we have explained that the location of the surface of tension, although without physical meaning per se, cannot be freely chosen. We will use the data for gold cuboctahedra from Ali et al..$^{40}$ to evaluate which of the discussed surfaces is consistent as the location of the surface of tension, if any.

The size dependence of the surface energy of cuboctahedral AuNPs is plotted in Figure 4.5. The energy data were calculated with molecular dynamics using the embedded atom method. ${ }^{40}$ The symbols give the surface energy that is derived by scaling the calculated energies to the three surfaces. The dotted lines give the calculated size dependency according to the Tolman equation using the Tolman lengths corresponding to the respective surface definitions, using $d_{\mathrm{a}}=0.288 \mathrm{~nm}$ for gold. ${ }^{47} \mathrm{~A}$ surface energy of $\gamma_{\infty}=0.87 \mathrm{~J} \mathrm{~nm}^{-2}$ is used for macroscopic cuboctahedra, derived from the surface energies of $0.79 \mathrm{~J} \mathrm{~m}^{-2}$ for the [111] face and $0.92 \mathrm{~J} \mathrm{~m}^{-2}$ for the [100] face. ${ }^{40}$ 

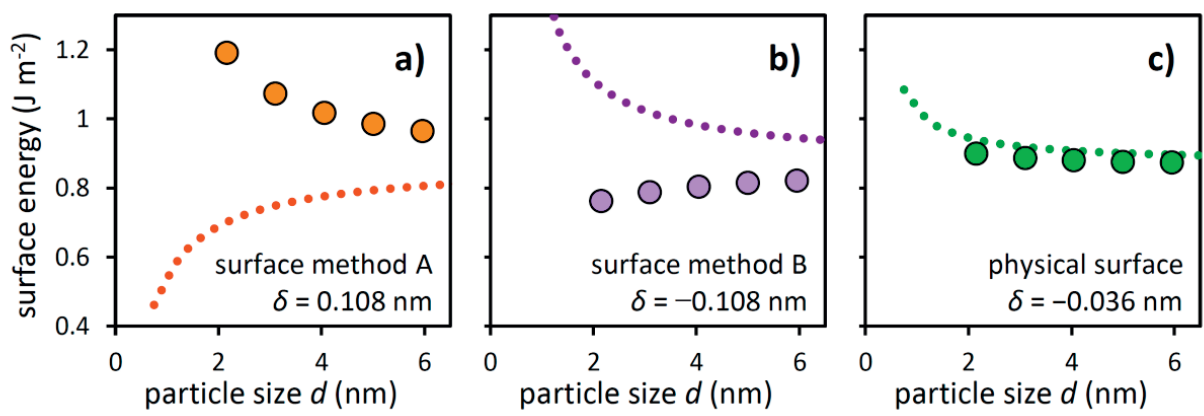

Figure 4.5 Size dependency of surface energy of gold cuboctahedral nanoparticles for three different surface definitions, each leading to a different surface area (see Figure 4.2) and a different position in the interface (see Figure 4.4). Symbols show the surface energy derived from scaling the excess particle energy $\Delta E_{\mathrm{s}}$ to the different surface areas; the dotted lines give the surface energies that are predicted by the thermodynamic approach (eq 4.6) using the Tolman lengths (given in the panels) that follow from the different interfacial positions. Only for the physical surface do symbols coincide with the lines, implying consistency.

As follows from Figure 4.5, the use of the physical surface leads to an excellent agreement between the atomically calculated surface energy and the thermodynamically calculated surface energy. Both other surface methods show a large discrepancy between atomic and thermodynamic scaling.

In case of option A of Figure 4.2, the surface for scaling lies within the equimolar surface of the particle. It leads to underestimation of the surface area and overestimation of surface energy (symbols of Figure 4.5a). Simultaneously, this choice is equivalent with a positive value for the Tolman length, which leads to a decrease of the surface energy with decrease of particle size (dotted line in Figure 4.5a). In case of option B, one gets the opposite. It must be concluded that only scaling to the physical surface (Figure $4.5 \mathrm{c}$ ) leads to internal consistency.

For our analysis, the data for gold cuboctahedra published by Ali et al. ${ }^{40}$ fulfilled all the necessary criteria for our consistency analysis. In addition, we have interpreted other particle energy data ${ }^{41,48-50}$ with the Tolman equation, as shown in Appendix C (Section C6). The results further support the physical surface as the thermodynamically consistent surface of tension.

\subsubsection{Surface energy and particle shape}

Based on the above conclusion, we may scale several data sets with particle energy data (J $\left.\mathrm{mol}^{-1}\right)$ to the physical surface area $\left(\mathrm{m}^{2} \mathrm{~mol}^{-1}\right)$ for nanoparticles of different size and shape. The particle size dependency of the surface energy $\left(\mathrm{J} \mathrm{m}^{-2}\right)$ resolved may be used to gain insight in the various surface energy contributions in relation to the geometry.

Figure 4.6 shows surface energies for very small, faceted silver nanoparticles. The open symbols have been calculated by Medasani et al. ${ }^{41}$ using density functional theory (DFT) in the generalized gradient approximation (GGA) for particle energy. Their way of energy scaling to 
surface area leads to both a significantly higher surface energy and a much stronger size dependency than found with the consistent physical surface area (colored symbols). More recent data of Oliveira et al. ${ }^{50}$ also point to a low size dependency of surface energy (see Appendix C, Figure (6). The data of Figure 4.6 are for particles of various shapes. However, the data set of Figure 4.6 is too limited to elucidate the role of particle geometry in relation to the size dependency of surface energy. This will be done using with the extensive data of Ali et al. ${ }^{40}$ (Figure 4.7).

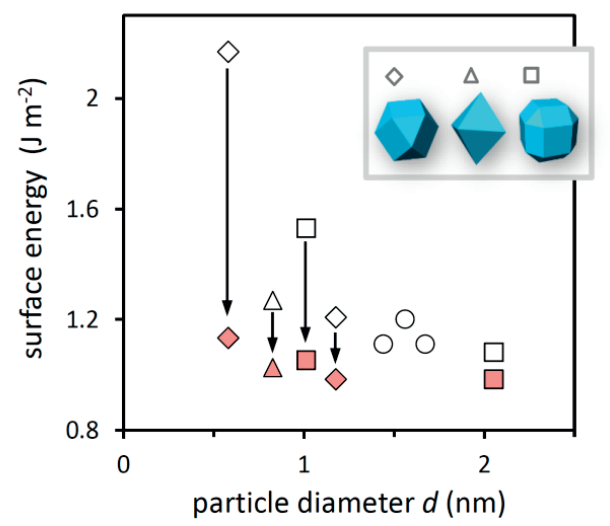

Figure 4.6 Surface energies for small silver nanoclusters as function of size. The strong size dependency calculated by Medasani et al. ${ }^{41}$ using a spherical approach (open symbols), drastically decreases after scaling to the consistent physical surface area (filled symbols). The physical surface area could be calculated for cuboctahedra (diamonds), an octahedron (triangle), and truncated cuboctahedra (squares). The structures of the open circles are insufficiently defined in the original publication to allow calculation of a surface area.

Figure 4.7 shows the surface energy for a range of gold nanoparticles calculated by Ali et al. ${ }^{40}$ Their surface energy values ${ }^{40}$ (open symbols) show a relatively steep rise towards the smaller particle sizes. This is the result of their use of method A for calculating the surface area. When scaled to the physical surface (colored symbols), most of the size dependency of surface energy disappears, as was also seen for their cuboctahedra (Figure 4.5).

Size dependency for the truncated octahedra of Figure 4.7 has also been interpreted with the Tolman equation. As these particles vary in the relative contribution of the constituent crystal faces, each particle has different values for $\delta$ and $\gamma_{\infty}$, as discussed in Appendix C (Section C7). It results in a different model line for each of the particles, of which the relevant sections are shown in Figure 4.7 with full lines. The surface energy values found by scaling to the physical surface area closely match with the surface energy found with the Tolman equation (eq 4.6), using the different $\delta$ and $\gamma_{\infty}$ values involved. 

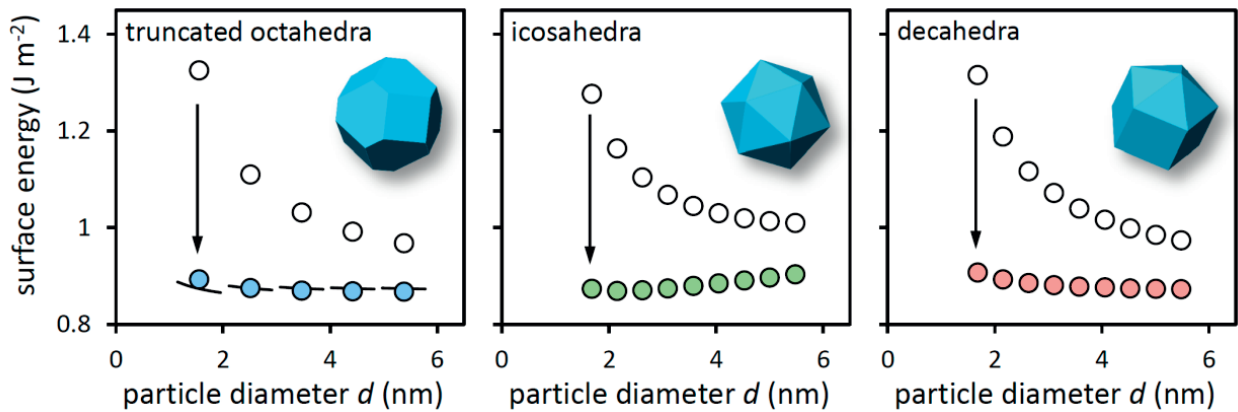

Figure 4.7 Size dependency of the surface energy of gold nanoparticles calculated by scaling the excess particle energy ${ }^{40}$ to the surface area for particles of different shape approximated with a simplified geometrical approach given in Figure 4.2a (open symbols) or using the presently formulated physical surface area model (filled symbols). The decrease in surface area with the new scaling is most significant for the smallest particles (arrows). For each of the truncated octahedra, we also present the corresponding size dependency of surface tension calculated using equation 4.6 (short full lines). The surface area for icosahedra and decahedra follows directly from the formulae presented in Table 4.1; formulae used for the (non-regular) truncated octahedra are given in Appendix C (Section C7).

For the icosahedral particles of Figure 4.7, the an increase rather than a decrease of the surface energy with particle size is found. This is likely related to the fivefold cyclic crystal twinning in the icosahedral structure, which leads to increasing internal strain with size. ${ }^{14}$

\subsubsection{Twinning energy}

Fivefold twinned icosahedral MeNPs consist of 20 tetrahedral subunits, and is bounded exclusively by [111] faces that contribute to a high particle stability due to their low surface energy. However, these subunits do not perfectly fit, ${ }^{51}$ which leads to an internal strain, ${ }^{14}$ particularly at increase of the particle size. In addition, stacking faults at the twin-planes may contribute. ${ }^{52}$

In the particle energy approach of Ali et al. ${ }^{40}$ the energy contribution of fivefold twinning in icosahedra and decahedra cannot be distinguished from surface energy sec. However, the latter contribution can be quantified separately with our approach by calculating the surface energy expected according to the Tolman equation using the Tolman lengths of the crystals faces involved. The results are shown in Figure 4.8. 

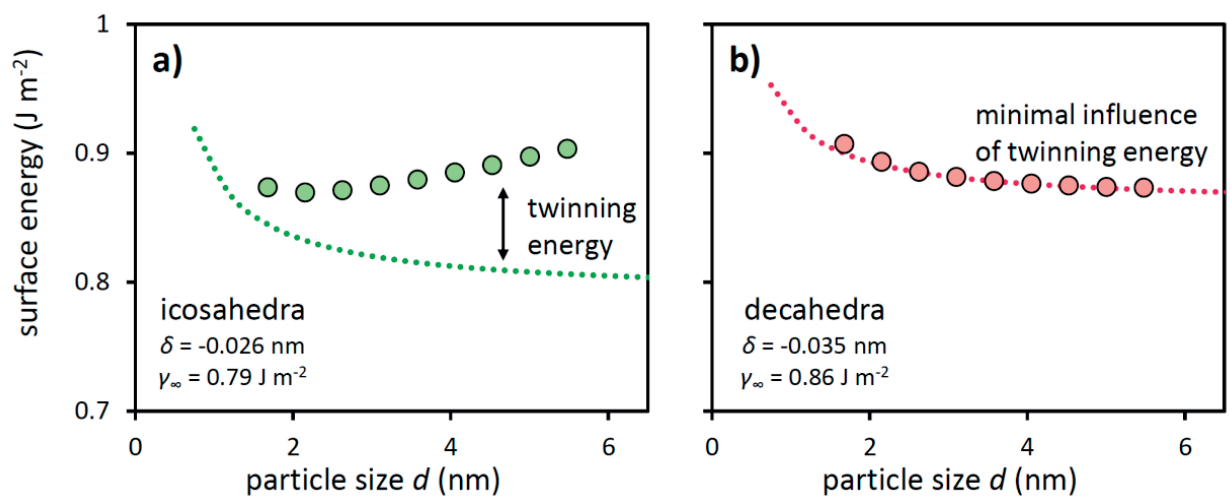

Figure 4.8 Twinning energy for icosahedra (a) and decahedra (b) of AuNP. The size dependent surface energies (dotted lines) were calculated with equation 4.6, using the Tolman length and bulk surface energy shown. The data points are the same as in Figure 4.7. The difference between line and data points is due to internal strain as result of twinning.

Figure 4.8 shows the surface energy of the facets according to Tolman (dotted line) and the total excess particle energy of AuNP ${ }^{40}$ scaled to the physical surface. If the difference is attributed to twinning it suggests that this has a large influence on particle energy in icosahedra, while for the decahedra, this influence appears to be very small or even absent. This may be related to the much smaller degree of twinning in decahedra, which have a single 5-fold twin axis, whereas icosahedra have twelve.

Using the data in Figure 4.8, a total energy contribution due to twinning (aJ) has been calculated; this has been plotted against the total twin-plane surface area in Figure 4.9. Twinplanes for icosahedra are defined as stretching between the cores of the central atom and two corner atoms, a visualized in Appendix C (Figure C7).

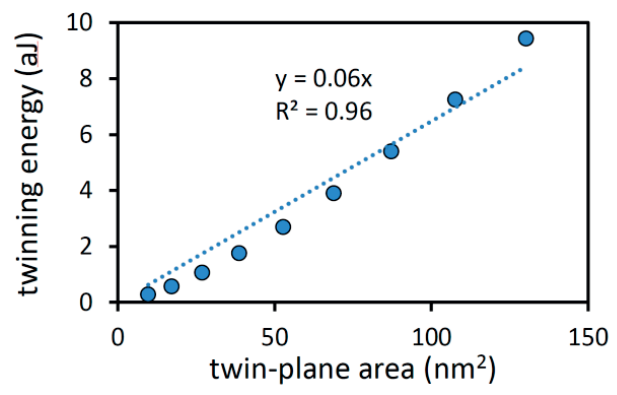

Figure 4.9 Twinning energy of gold icosahedral nanoparticles plotted against the twin-plane area. Twinning energy is calculated as the difference between excess particle energy as calculated by Ali et al. ${ }^{40}$ and the product of the surface energy $\nu_{r}$ (eq 4.6) and the physical surface area. The 30 identical twin-planes in an icosahedron are defined as stretching between the centers of the central atom and two corner atoms; this is visualized in Appendix C (Figure C7). 
In Figure 4.9 the slope of the relationship between twinning energy and twin-plane area represents the strain energy. It slightly increases with size suggesting more strain energy per surface area in larger particles. This might be due to the increasing stress that is created in the center of the particle as suggested by the work of Mottet et al. ${ }^{43}$ The slope of the trendline represents the mean twin-plane energy, being $\sim 0.06 \mathrm{~J} \mathrm{~m}^{-2}$. However, for the smallest icosahedral particles, a lower value $\left(\sim 0.03 \mathrm{~J} \mathrm{~m}^{-2}\right)$ is found. The latter is in good agreement with the value found by Barnard ${ }^{52}$ for twin-planes in bulk gold $\left(\sim 0.03 \mathrm{~J} \mathrm{~m}^{-2}\right)$, but our analysis suggests that it may be higher in larger icosahedral particles.

\subsubsection{Surface enthalpy}

Above, we have established that consistent scaling leads to a size dependency of surface energy that corresponds to a small, negative Tolman length. These results are very different than what has previously been found for water and other liquids. We not that as our analysis is based on data calculated for $0 \mathrm{~K}$, our results are effectively based on the surface enthalpy. The question arises whether the observed size-dependency is a general surface enthalpy effect. To answer that question, we return for a moment to the water-vapor interface.

For the water-vapor interface, Hiemstra ${ }^{11}$ recently noticed that surface enthalpy can be largely understood from enthalpy of evaporation. If surface formation of a droplet is considered as breaking an increasing number of bonds, the limit of the process is formation of a gaseous $\mathrm{H}_{2} \mathrm{O}$ molecule. The corresponding enthalpy of surface formation should then be equal to the enthalpy of evaporation. Indeed, the surface area of a single water molecule $\left(\mathrm{m}^{2} \mathrm{~mol}^{-1}\right)$ multiplied by the macroscopic surface enthalpy of water $\left(\mathrm{J} \mathrm{m}^{-2}\right)$ yields a value only slightly lower than the enthalpy of evaporation $\left(\mathrm{kJ} \mathrm{mol}^{-1}\right)$, as illustrated in Figure $\mathrm{C} 8$ of Appendix $\mathrm{C}$. If the Tolman equation is applied to the surface enthalpy, both values can be unified. Although uncertain, the estimated Tolman length for water (see Appendix C, Section C4) will be about $\delta=-0.014 \mathrm{~nm}$. The Tolman length is negative and the value is of the same order as the values found above for MeNPs $\left(\delta^{\sim}-0.12 d_{\mathrm{a}}=-0.034 \pm 0.01 \mathrm{~nm}\right)$.

\subsubsection{Surface entropy.}

According to the above, the surface enthalpy for water increases at the nanoscale as it does for MeNPs. It shows that surface enthalpy behaves differently than surface Gibbs free energy, revealing an intriguing role of surface entropy. When the above approach for surface enthalpy can is applied to the Gibbs free energy of evaporation of water, a Tolman length of $0.04 \mathrm{~nm}$ is found, which compares well with $\delta \sim 0.06 \pm 0.02 \mathrm{~nm}$, our estimate based on literature (see S4). The size dependent behavior of both energies is used to find the surface entropy term ( $\left.T \Delta S_{\text {surf }}\right)$.

The above approach reveals the size dependency of the the surface entropy value ( $\left.\Delta S_{\text {surf }}\right)$, which can be described with an empirical equation $\Delta S_{\text {surf, } r}=\Delta S_{\text {surf, } \infty}\left(1+0.18 / r_{\mathrm{e}}\right)$, where $r_{\mathrm{e}}$ is the equimolar radius in $\mathrm{nm}$. The absolute increase in surface entropy is higher than the increase in surface enthalpy. Although the surface enthalpy increases with decreasing particle 
size, the surface entropy increases more, resulting in in a decrease in surface Gibbs free energy, as shown for water in Figure 4.10a (dotted lines).
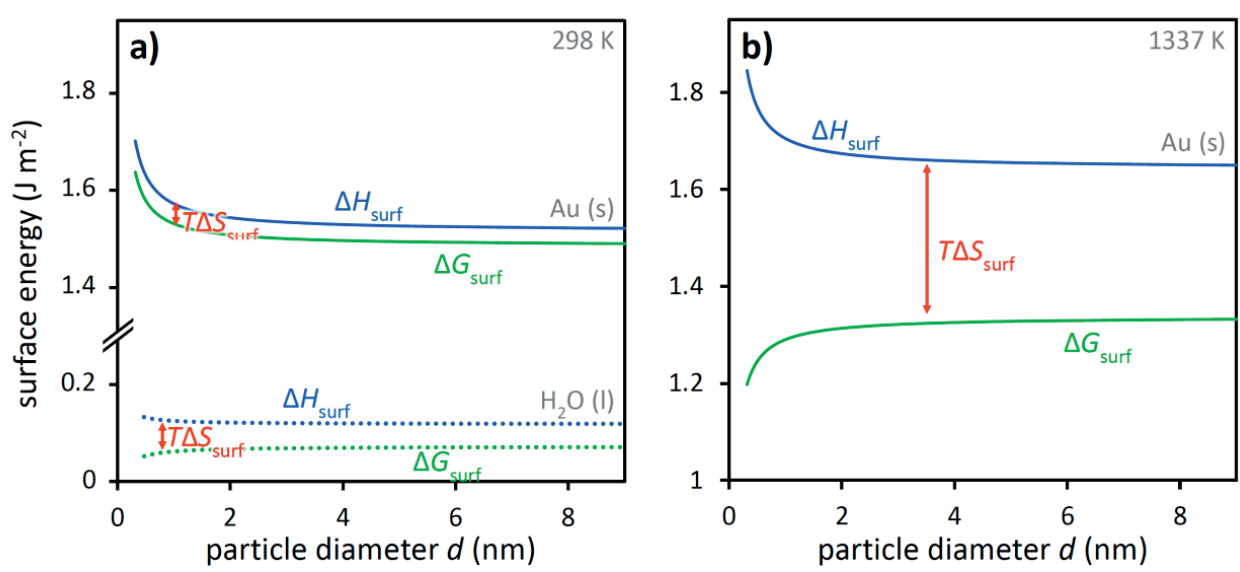

Figure 4.10 Size dependency of surface enthalpy $\left(\Delta H_{\text {surf }}\right)$ and surface free energy $\left(\Delta G_{\text {surf }}\right)$. Shown are (a) values at room temperature for the liquid-vapor interface of water and the solid-vapor interface of gold and (b) values for the solid-vapor interface of gold at its melting temperature. The difference between both energies is the surface entropy $\left(T \Delta S_{\text {surf }}\right)$. For water (a), surface entropy changes the size dependency of $\Delta G_{\text {surf }}$ because surface enthalpy is relatively low. For metals at room temperature (a), having a much ( $\sim 10$ times) higher surface enthalpy but a similar surface entropy (Table 4.4 ), the surface free energy trend remains upwards. However, as shown in the right panel, this changes at elevated temperatures, where the influence of surface entropy is much higher. In case of metal melting, this trend is enhanced.

To understand the size dependency of the surface Gibbs free energy of metals, we must therefore focus on the surface entropy of these materials. Based on general estimates for metals, ${ }^{53}$ a surface entropy for solid gold is $\sim 0.23 \mathrm{~mJ} \mathrm{~m}^{-2} \mathrm{~K}^{-1}$ at the temperature near melting. This value is nearly equal to the entropy of the ice-gas interface $\left(\sim 0.26 \mathrm{~mJ} \mathrm{~m}^{-2} \mathrm{~K}^{-1}\right)$ given by Hiemstra. ${ }^{11}$ In case of molten $\mathrm{Au}$, the surface entropy values are in the range of $\Delta S_{\text {surf }}=0.15 \pm$ $0.01 \mathrm{~mJ} \mathrm{~m}^{-2} \mathrm{~K}^{-154-56}$ and this value is equal to the entropy of the liquid-vapor interface of $\mathrm{H}_{2} \mathrm{O},{ }^{11}$ showing consistency. According to Tyson and Miller, ${ }^{53}$ surface entropy $S_{\text {surf }}$ at room temperature is expected to be around half of the value at the melting temperature (see Appendix C, Section C9). Taking the above value for surface entropy of solid gold near the melting temperature as our best guess, we obtain a value of $\Delta S_{\text {surf }} \sim 0.10 \mathrm{~mJ} \mathrm{~m}^{-2} \mathrm{~K}^{-1}$ at room temperature (Table 4.4). 
Table 4.4 Surface energy data for water, gold, and silver in the solid-gas and liquid-gas interface at absolute zero, room temperature, and melting temperature $\left(T_{\mathrm{M}}\right)^{53}$

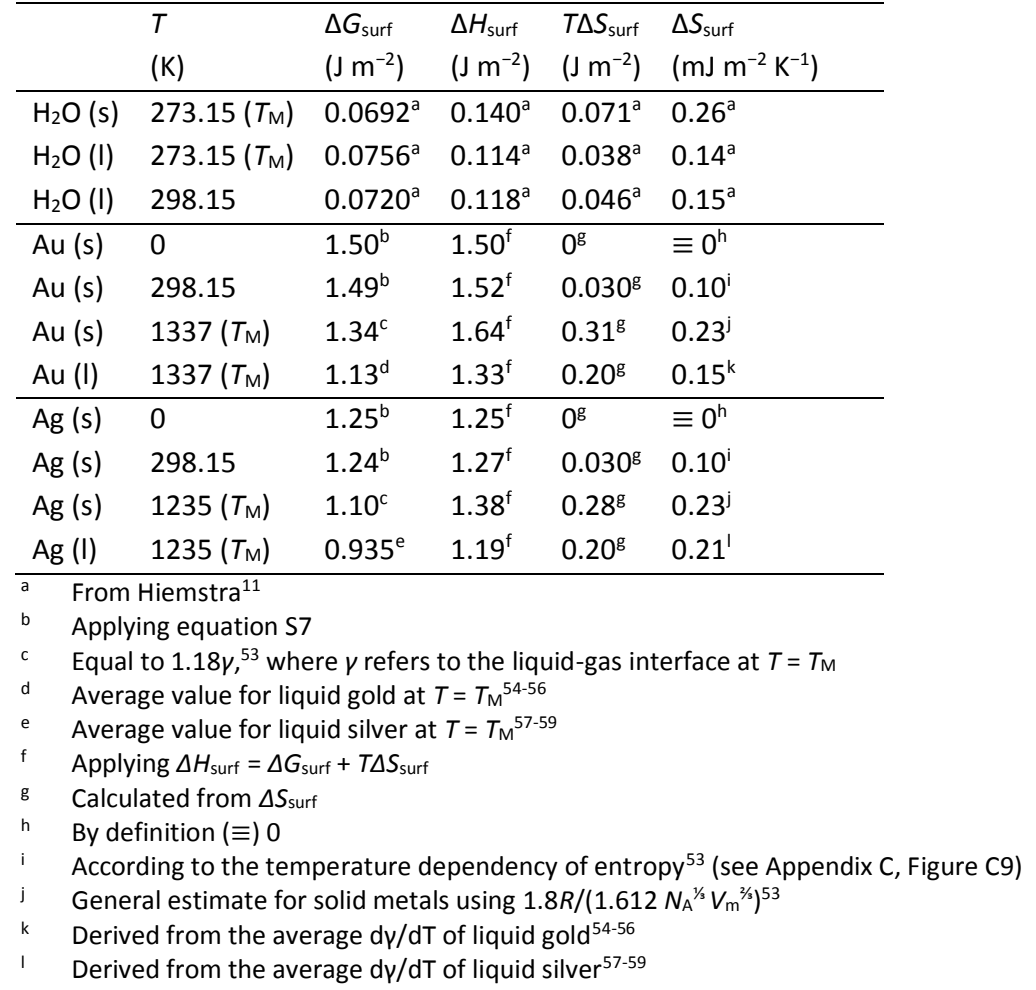

\subsubsection{Surface Gibbs free energy}

In contrast to the surface entropy, the surface enthalpy is much higher for gold than for water. Very little data are available on the precise value for the surface enthalpy of solid metals. In Appendix C (Section C9), we estimated the value for gold and silver using the work of Tyson and Miller. ${ }^{53}$ For gold, a value of $\Delta H_{\text {surf }}=1.52 \mathrm{~J} \mathrm{~m}^{-2}$ is expected at room temperature (Table 4). Following the same approach as used above for water, the surface enthalpy of gold can be unified with the enthalpy of atomization $\left(366 \mathrm{~kJ} \mathrm{~mol}^{-1}\right)$ if a Tolman length of $\delta=-0.009 \mathrm{~nm}$ is used (see Appendix C, Figure C8). If we assume a similar size dependency of surface entropy for water and gold, i.e. $\Delta S_{\text {surf }, r}=\Delta S_{\text {surf,o }}\left(1+0.18 / r_{\mathrm{e}}\right)$, one can calculate an estimated size dependency for the surface Gibbs free energy of solid gold nanoparticles, as given in Figure 4.10.

Figure 4.10a shows that, at room temperature, the surface entropy contribution for gold is very small compared to the surface enthalpy. Though still strongly size dependent, the absolute value of the increase in surface entropy at small particle size is insignificant compared to the increase in surface enthalpy. As a result, a similar trend is seen for size dependency of the surface enthalpy and surface Gibbs free energy and the corresponding Tolman length will thus be negative for AuNPs at room temperature. 
Figure 4.10b shows the completely different situation at strongly elevated temperature (1337 K). Here, the surface entropy term $T \Delta S_{\text {surf }}$ is much higher, due to increase of $T$ and as well $\Delta S_{\text {surf }}$ (Table 4). As a result, the absolute increase in surface entropy at small size exceeds the increase in surface enthalpy, and the surface Gibbs free energy decreases at smaller particle sizes. Experimentally, decreasing surface free energy values at smaller sizes have been found for silica nanoparticles at elevated temperature $(1100 \mathrm{~K}),{ }^{60}$ suggesting this principle may be extended to other materials.

For water nanodroplets and nanobubbles, the surface entropy has a relatively strong influence even at room temperature (Figure 4.10a) due to the much lower surface enthalpy. It results in a positive size dependency for the surface Gibbs free energy at room temperature, while for gold this is only seen at very high temperatures.

The above analysis has also been performed for silver with similar results as for gold (see Table 4). It implies that a similar size dependence of surface Gibbs free energy can be expected, which is supported by our interpretation of additional computational data in Figure $\mathrm{C6}$ of Appendix C. Note, however, that at ambient atmospheric conditions, surface energy values for AgNPs may be notably different from values for the pure solid-gas interface, as this metal is thought to be covered by a layer of subvalent silver at atmospheric conditions. ${ }^{61} \mathrm{~A}$ low surface energy value $\left(\sim 0.7 \mathrm{~J} \mathrm{~m}^{-2}\right)$ is found for this interface in water-AgNP systems when relating the equilibrium concentration of $\mathrm{Ag}^{+}(\mathrm{aq})$ to particle size. ${ }^{19}$ No data are currently available to quantify the size-dependency of surface Gibbs free energy if subvalent $\mathrm{Ag}$ is present in the interface.

In summary, the size dependency of the surface Gibbs free energy strongly depends on the magnitude of the surface entropy relative to the surface enthalpy. It explains the why the low enthalpy liquid-vapor interface of $\mathrm{H}_{2} \mathrm{O}$ behaves completely different from the high enthalpy solid-gas interface of MeNPs at room temperature, where their surface entropy values are similar. At high temperature, where the entropy contribution is much higher, the size dependency of the surface Gibbs free energy of metals may change towards a behavior with similarities to that of water at room temperature.

\subsection{Conclusions}

There is insufficient awareness in the literature of the importance and implications of the surface area in scaling particle energies. The interfacial position and the area of a surface are intrinsically linked, whatever method is used to approximate it. In this work, we investigate three methods for calculating the surface area of polyhedral nanoparticles (Figure 4.2). For a particle of a given size and shape, these surface area methods dictate a position of the surface in the interface (Figure 4.4). Its distance from the equimolar surface, a hypothetical, infinitely sharp boundary between phases, gives the Tolman length, which can be used for predicting 
the size dependency of the surface enthalpy thermodynamically. The Tolman lengths involved have been derived structurally for main crystal faces of FCC metals (Table C3).

In the present work, the Laplace equation is used to generalize the Tolman approach for particles of any shape. The shape factors involved have been derived for facetted nanoparticles (Table 4.2) as well as oblate and prolate spheroids (see Appendix C, Figure C2).

The size dependencies of surface enthalpy, as predicted by the Tolman lengths and by scaling of excess particle energy to the surface areas, are compared for the different surface definitions of Figure 4.2; Figure 4.5 shows that only scaling to the physical surface area, formulated in the present work (Table 4.1) leads to consistency between the thermodynamic and the atomic approach of surface energy.

Surface energy values for faceted nanoparticles found in literature have been reinterpreted using the thermodynamically consistent physical surface area (Figure 4.6, 4.7, and C6). It is found that surface energy increases only slightly with size for very small particles (typically $\sim 3$ $\mathrm{nm}$ ), which is in stark contrast to surface energy trends presented in literature. Scaled to the physical surface, surface energies can be as much as $100 \%$ lower than using other (inconsistent) surface area approaches. It clearly demonstrates that surface area is not a trivial parameter in scaling atomic energy. It is as important as the accurate calculation of excess particle energy itself.

Our scaling of the energy of AuNPs reveals that the size dependency of the surface energy may strongly vary with the crystal habit (Figure 4.7). In contrast to regular cuboctahedral and truncated octahedral shapes, a significant increase of the surface energy was found for icosahedral nanoparticles of increasing size. This can be attributed to an energy contribution due to crystal twinning, which increasingly creates internal strain. The internal strain due to twinning can be distinguished from the external surface energy by applying the physical surface and associated Tolman lengths (Figure 4.8). It elucidates and quantifies the large role of twinning in the energetics of icosahedra and the limited role in decahedra. For icosahedra, the mean twin energy is $\sim 0.06 \mathrm{~J} \mathrm{~m}^{-2}$.

The size dependency of the surface Gibbs free energy of MeNPs is equivalent with a negative Tolman length. This is very different in comparison to the liquid-vapor interface of water, for which the Tolman length has a positive sign $(\sim+0.06 \pm 0.02 \mathrm{~nm})$, meaning that the surface Gibbs free energy decreases at smaller size. However, the surface enthalpy of the liquid-vapor interface of water can be interpreted with a negative Tolman length ( -0.014 nm). By comparing both interfaces, we derive that these differences can be explained by the relative contribution of the surface entropy (Table 4.4), being large in the case of water and small in the case of metals such as Au and Ag (Figure 4.10a). At higher temperatures, surface entropy increases and becomes relatively more important, which can completely change the size dependency of surface Gibbs free energy (Figure 4.10b). 
Our work provides a theoretical framework that allows scaling of energy in a consistent manner, unifying the atomic and thermodynamic approach. The physical surface, as defined here, includes the surface area contribution of the edges and corners. Our work demonstrates that, at the nanoscale, atoms should be viewed as three-dimensional objects: the surface area contribution of a spherical atomic surface is crucial for understanding the size dependence of the surface energy of small MeNPs and metallic clusters.

\subsection{References}

1. K. L. Kelly, E. Coronado, L. L. Zhao and G. C. Schatz, The Journal of Physical Chemistry B, 2003, 107, 668-677.

2. A. M. Syed, S. Sindhwani, S. Wilhelm, B. R. Kingston, D. S. W. Lee, J. L. Gommerman and W. C. W. Chan, Journal of the American Chemical Society, 2017, 139, 9961-9971.

3. S. S. E. Collins, M. Cittadini, C. Pecharromán, A. Martucci and P. Mulvaney, ACS Nano, 2015, 9, 7846-7856.

4. K. E. Shafer-Peltier, C. L. Haynes, M. R. Glucksberg and R. P. Van Duyne, Journal of the American Chemical Society, 2003, 125, 588-593.

5. Y. Li, H. J. Schluesener and S. Xu, Gold Bulletin, 2010, 43, 29-41.

6. F. Lu, Y. Zhang, S. Liu, D. Lu, D. Su, M. Liu, Y. Zhang, P. Liu, J. X. Wang and R. R. Adzic, Journal of the American Chemical Society, 2017.

7. G. F. Wei and Z. P. Liu, Physical Chemistry Chemical Physics, 2013, 15, 18555-18561.

8. H. Yang, Z. H. Wang, Y. Y. Zheng, L. Q. He, C. Zhan, X. Lu, Z. Q. Tian, P. P. Fang and Y. Tong, Journal of the American Chemical Society, 2016, 138, 16204-16207.

9. A. Primo, A. Corma and H. Garcia, Physical Chemistry Chemical Physics, 2011, 13, 886910.

10. A. Kafizas, C. W. Dunnill and I. P. Parkin, Physical Chemistry Chemical Physics, 2011, 13, 13827-13838.

11. T. Hiemstra, Geochimica et Cosmochimica Acta, 2015, 158, 179-198.

12. Z. Wu, S. Yang and W. Wu, Nanoscale, 2016, 8, 1237-1259.

13. P. Liu, R. Qin, G. Fu and N. Zheng, Journal of the American Chemical Society, 2017, 139, 2122-2131.

14. W. Zhang, Y. Liu, R. Cao, Z. Li, Y. Zhang, Y. Tang and K. Fan, Journal of the American Chemical Society, 2008, 130, 15581-15588.

15. T. Hiemstra, Environmental Science: Nano, 2018, 5, 752-764.

16. J. L. Huang, Z. Li, H. H. Duan, Z. Y. Cheng, Y. D. Li, J. Zhu and R. Yu, Journal of the American Chemical Society, 2017, 139, 575-578.

17. B. Wiley, Y. Sun, B. Mayers and Y. Xia, Chem. Eur. J., 2005, 11, 454-463.

18. K. Nanda, S. Sahu and S. Behera, Physical review A, 2002, 66, 013208.

19. B. Molleman and T. Hiemstra, Environmental Science-Nano, 2017, 4, 1314-1327.

20. R. Tran, Z. Xu, D. W. Balachandran Radhakrishnan, W. Sun, K. A. Persson and S. P. Ong, Scientific data, 2016, 3.

21. A. S. Barnard, N. P. Young, A. I. Kirkland, M. A. Van Huis and H. Xu, ACS nano, 2009, 3, 1431-1436.

22. R. C. Tolman, The journal of chemical physics, 1948, 16, 758-774.

23. R. C. Tolman, The journal of chemical physics, 1949, 17, 333-337.

24. R. C. Tolman, The journal of chemical physics, 1949, 17, 118-127. 
25. G. Gibbs, Collected works. Thermodynamics, Longmans, 1928.

26. L. R. Fisher and J. N. Israelachvili, Journal of colloid and Interface Science, 1981, 80, 528541.

27. M. H. Factorovich, V. Molinero and D. A. Scherlis, Journal of the American Chemical Society, 2014, 136, 4508-4514.

28. G. Menzl, M. A. Gonzalez, P. Geiger, F. Caupin, J. L. Abascal, C. Valeriani and C. Dellago, Proceedings of the National Academy of Sciences, 2016, 113, 13582-13587.

29. H. Lu and Q. Jiang, The Journal of Physical Chemistry B, 2004, 108, 5617-5619.

30. S. Xiong, W. Qi, B. Huang, M. Wang, Y. Cheng and Y. Li, Journal of Computational and Theoretical Nanoscience, 2011, 8, 2477-2481.

31. M. Blackman, N. D. Lisgarten and L. M. Skinner, Nature, 1968, 217, 1245-1246.

32. C. Mays, J. Vermaak and D. Kuhlmann-Wilsdorf, Surface science, 1968, 12, 134-140.

33. H. Wasserman and J. Vermaak, Surface Science, 1970, 22, 164-172.

34. F. Piuz, Helv. Phys. Acta, 1964, 37, 620-622.

35. P. Montano, W. Schulze, B. Tesche, G. Shenoy and T. Morrison, Physical review B, 1984, 30,672 .

36. H. Hofmeister, S. Thiel, M. Dubiel and E. Schurig, Applied Physics Letters, 1997, 70, 16941696.

37. K. Nanda, A. Maisels, F. Kruis, H. Fissan and S. Stappert, Physical review letters, 2003, 91, 106102.

38. I. Galanakis, G. Bihlmayer, V. Bellini, N. Papanikolaou, R. Zeller, S. Blügel and P. Dederichs, EPL (Europhysics Letters), 2002, 58, 751.

39. N. E. Singh-Miller and N. Marzari, Physical Review B, 2009, 80, 235407.

40. S. Ali, V. S. Myasnichenko and E. C. Neyts, Physical Chemistry Chemical Physics, 2016, 18, 792-800.

41. B. Medasani, Y. H. Park and I. Vasiliev, Physical Review B, 2007, 75, 235436.

42. B. Medasani and I. Vasiliev, Surface Science, 2009, 603, 2042-2046.

43. C. Mottet, G. Tréglia and B. Legrand, Surface science, 1997, 383, L719-L727.

44. A. S. Barnard, X. Lin and L. A. Curtiss, The Journal of Physical Chemistry B, 2005, 109, 24465-24472.

45. I. Todhunter, Spherical Trigonometry: For the Use of Colleges and Schools, MacMillan and co., London, 1886.

46. J. Kalová and R. Mareš, International Journal of Thermophysics, 2015, 36, 2862-2868.

47. I. K. Suh, H. Ohta and Y. Waseda, Journal of Materials Science, 1988, 23, 757-760.

48. A. S. Barnard and L. A. Curtiss, ChemPhysChem, 2006, 7, 1544-1553.

49. D. Liu, J. Lian and Q. Jiang, The Journal of Physical Chemistry C, 2009, 113, 1168-1170.

50. L. F. Oliveira, N. Tarrat, J. Cuny, J. Morillo, D. Lemoine, F. Spiegelman and M. Rapacioli, The Journal of Physical Chemistry A, 2016, 120, 8469-8483.

51. H. Hofmeister, Encyclopedia of nanoscience and nanotechnology, 2004, 3, 431-452.

52. A. Barnard, The Journal of Physical Chemistry B, 2006, 110, 24498-24504.

53. W. R. Tyson and W. A. Miller, Surface Science, 1977, 62, 267-276.

54. T. Dubberstein and H. P. Heller, High Temperatures-High Pressures, 2015, 44, 393-406.

55. I. Egry, G. Lohoefer, E. Schwartz, J. Szekely and P. Neuhaus, Metallurgical and Materials Transactions B, 1998, 29, 1031-1035.

56. R. Novakovic, E. Ricci, F. Gnecco, D. Giuranno and G. Borzone, Surface science, 2005, 599, 230-247.

57. J. Lee, W. Shimoda and T. Tanaka, Materials transactions, 2004, 45, 2864-2870. 
Chapter 4

58. R. Novakovic, E. Ricci, D. Giuranno and A. Passerone, Surface science, 2005, 576, 175187.

59. S. Ozawa, K. Morohoshi, T. Hibiya and H. Fukuyama, Journal of Applied Physics, 2010, 107, 014910.

60. I. F. Crowe, M. P. Halsall, O. Hulko, A. P. Knights, R. M. Gwilliam, M. Wojdak and A. J. Kenyon, Journal of Applied Physics, 2011, 109, 083534.

61. B. Molleman and T. Hiemstra, Langmuir, 2015, 31, 13361-13372. 


\section{Chapter 5}

Structural approach to surface energy of nanoparticles: Role of corners, edges, faces, crystal twinning, and internal strain

Bastiaan Molleman and Tjisse Hiemstra

To be submitted to ACS Nano 


\section{Abstract}

In this work, we have studied the relationship between the coordination of surface atoms and their energy. A coordination (CN) model is formulated that excellently describes and predicts the energy of metallic nanoparticles as a function of size and shape, using coordination numbers of surface atoms in combination with the experimental energy of the uncoordinated atom (corrected cohesive energy). The $\mathrm{CN}$ model allocates surface energy contributions to specific surface atoms, revealing that corner atoms, despite their high energy, hardly contribute to surface energy due to their low abundance. Edge atoms, however, contribute significantly throughout the entire nanoscale $(1-100 \mathrm{~nm})$, emphasizing the importance of accounting for edge effects in thermodynamic surface models. We have applied the CN model to distinguish external from internal energy contributions found in e.g. decahedral and icosahedral particles due to crystal twinning. An energy contribution for the twin-plane is identified $\left(18 \mathrm{~mJ} \mathrm{~m}^{-2}\right.$ ), as well as a much higher contribution due to strain energy for icosahedra. The latter is the main contributor to low stability of icosahedra at larger size. The $\mathrm{CN}$ model can also be applied to predict the surface energy of macroscopic crystal faces of solid FCC metals using the experimental cohesive energy as the only input, showing excellent agreement with experimental data. Moreover, model calculations can contribute to the evaluation of MO/DFT derived surface energies of crystal faces. Based on the calculated energy contributions of all atoms of a nanoparticle, our model can predict the size and shape dependency of surface energy by applying scaling to the thermodynamically consistent surface area, revealing Tolman lengths between -0.015 to $-0.019 \mathrm{~nm}$ for variously shaped gold and silver nanoparticles. A negative value of the Tolman length illustrates that the surface enthalpy of non-twinned particles increases at smaller sizes due to the increased contributions of edges and corners. Finally, with our model for coordination and twinning energy, the stability of various particle geometries have been evaluated showing stability of icosahedra at small size and stability of Marks decahedra at larger sizes. The precise value of the crossover point is highly dependent on the energy contribution of internal strain. 


\subsection{Introduction}

Metallic nanoparticles (MeNPs) offer a wide range of technological and scientific applications including catalysis, ${ }^{1-3}$ photocatalysis, ${ }^{4,5}$ imaging, $^{6}$ sensing, ${ }^{7,8}$ and biosensing. ${ }^{9,}{ }^{10}$ However, concerns with regards to human health and environmental impact have also been raised. Silver nanoparticles (AgNPs) in particular are associated with inflammatory reactions, ${ }^{11,12}$ and negatively impact terrestrial ${ }^{13-15}$ and aquatic ${ }^{16-18}$ organisms.

Central to opportunities and threats of MeNPs are size, shape, and surface energy. The size and shape of MeNPs control catalytic selectivity ${ }^{19}$ and optical properties ${ }^{20}$ relevant for imaging and sensing, while surface energy controls the size dependence of toxicity of AgNPs. ${ }^{21}$ In addition, surface energy is a dominant energy term in particle formation, affecting nucleation, ${ }^{22}$ growth, ${ }^{23,}{ }^{24}$ and twinning. ${ }^{25}$ In the present work, we will focus on the different atomic contributions to surface energy, as these closely tie in to the size and shape of nanoparticles, as we will see.

The most obvious contributors to the surface energy of a nanoparticle are the various types of crystal faces. Due to the arrangement of atoms in a crystal lattice, a limited number of highly regular surface structures can be formed with different surface energies. The stability of a particle depends on the total surface energy contribution $\Delta E_{\mathrm{S}}(\mathrm{J})$, which is the product of surface energy $\gamma\left(\mathrm{J} \mathrm{m}^{-2}\right)$ and surface area $A\left(\mathrm{~m}^{2}\right)$. It leads to a drive for the formation of both low energy surfaces and low area shapes. Based on this concept, the lowest energy shape can be estimated for different metals, if accurate surface energy values are available for the major crystal faces. ${ }^{26}$ First principles calculations reveal that these crystal faces strongly differ in surface energy. ${ }^{26-34}$ The surface energy of different crystal faces can be largely understood based on their surface structure, as we will show with the coordination model that we will develop here.

In addition to the crystal faces, edge and corner atoms contribute to surface energy. This is particularly important at the small end of the nanoscale, as the fraction of edge and corner atoms increases at smaller size. Edge and corner atoms have a higher energy than other surface atoms, and it is often assumed that this leads to a higher overall surface energy in smaller MeNPs. To obtain the surface energy for very small particles, it is therefore essential to use a more sophisticated approach than accounting only for the crystal faces.

For small clusters of atoms, one may perform ab initio energy calculations to get the particle energy in excess to the energy of bulk material. By scaling this excess energy to the surface area, the surface energy can be derived. As we have very recently demonstrated, ${ }^{35}$ it is essential that the surface area used for scaling is thermodynamically consistent as the surface of tension. With consistent scaling, an increase in overall surface energy is found with decreasing size for regular, i.e. non-twinned, MeNPs. However, such a holistic approach does not yet explain and explicitly specify the relative contribution of atoms at the edges, corners, and faces. 
In the some thermodynamic models, energy contributions of edge and corner atoms have been formalized, ${ }^{36,37}$ but the importance of these contributions is largely unknown. This may be the reason that their energy contribution has not been included in the final chemical stability calculations with these models. ${ }^{36,37}$ One of the goals of the present work is to gain insight in the energy contributions of various types of surface atoms, edge and corner atoms included, and understand and quantify their role in the size dependency of the surface energy of MeNPs.

The energy contributions of crystal faces, edges, and corners are external, and may form an incomplete picture for MeNPs that also have internal energy contributions. The drive to minimize surface energy can lead to changes in the internal structure, which gives rise to a different class of energy contributions. Well-known examples are cyclic twinning as found in icosahedral and decahedral nanoparticles, ${ }^{38}$ and reconstruction to a different crystal lattice. ${ }^{39}$ While these structural changes lead to a higher internal energy of MeNPs, this is compensated by promoting low energy surfaces. Such effects are therefore typically observed in the smallest particles, where the influence of the surface on excess energy is greatest. While fivefold twinned particles are regularly observed, ${ }^{40-42}$ relatively little information is available about the energy contribution of twinning or restructuring. In this work, we will perform a quantitative analysis of to date available computational energy data of MeNPs with fivefold crystal twinning over a large range of particle sizes.

Computational modelling offers important insights in the energetics of metallic nanoclusters ${ }^{43-46}$ and crystal faces. ${ }^{26-34}$ However, computational methods do not yet provide undisputable results. For the same structures or surfaces, large differences exist in the energies calculated with different computational methods and even when using the same method. The agreement with experimental data, as far as these are available, is highly variable, limiting applicability of the results. ${ }^{33,} 34$ Moreover, the "true" energy of crystal faces is unknown, which hampers the development and testing of more advanced computational methods at a higher rung of the Jacobs ladder of quantum chemistry. ${ }^{47}$ Furthermore, insight in how material properties vary at the nanoscale is limited by the fact that the energy contributions for surfaces, edges, corners, and crystal twinning are not differentiated in current computational methods. To address these issues and gain valuable insight into the energetics of nanoparticles, we will develop here a model for surface and twin energy that specifies the various external and internal energy contributions of atoms to the overall excess energy of nanoparticles.

Our surface model approach is based on the notion that the energy of an atom is related to the coordination number and the cohesive energy of the bulk. ${ }^{48,} 49$ The role of surface coordination has been demonstrated in the analysis of the surface energy of different macroscopic crystal faces, ${ }^{28}$ and its application to assess the accuracy of DFT calculations. ${ }^{31}$ In the present study, the coordination concept will be extended to include edge and corner atoms. It will be combined with a surface structural analysis of a range of particle geometries 
to provide a mechanistic framework for elucidating the size and shape dependency of the surface energy of MeNPs. With our coordination (CN) model, we will evaluate data collected with advanced computational methods. The objective is to quantify high and low energy contributions of edges, corners, and faces. As will be shown, this will also allow us to differentiate explicitly between internal and external energy and derive contributions of crystal twinning and internal stress. Using the resulting model description for external surface energy contributions, twinning energy can be attributed to the various types of atoms in the interior.

Our treatment will start with formulating a model for quantifying surface energy contributions based on metal coordination and surface densities. The energy of atoms at corners, edges, and crystal faces will be quantified within a single framework. For understanding the limitations of the coordination ( $\mathrm{CN}$ ) model and for optimizing the parameters, the concept will be first applied to crystalline nanoparticles without an internal energy contribution. A further validation step will be to compare predictions of macroscopic surface energy values for several metals to values based on experiments.

Using the optimized model, the total energy of twinned nanoparticles can be compared to the external surface energy contribution. The difference will be systematically analyzed to understand how internal energy varies with particle size, morphology, and crystal structure, with the goal of identifying different energy contributions due to twinning energy. Together, the internal and external energy contributions can be used to build a complete model that specifies the energy contribution of the various atoms of metallic nanoparticles to the overall excess energy.

Once derived and calibrated, the full model will be applied to predict for various metals the external and internal excess energy contributions of nanoparticles of different size and shapes. The calculated excess energies will be scaled to the surface in a thermodynamically consistent manner, as established recently, ${ }^{35}$ providing realistic surface energy values and an overview of the size-dependency for particle of different shapes. Moreover, excess energies for different particles will be compared in order to assess how the stability of different shapes changes with particle size.

\subsection{Theory}

In this section, we will review the relation between the coordination of surface atoms and the surface energy. We will use this to construct a framework for predicting the surface energy of nanoparticles based solely on the coordination of surface atoms. For this, we start by analyzing the surface energy of crystal faces, leading up to an expression for the energy contribution of individual atoms, based on their coordination number. Our final model is obtained when the latter is combined with a model for the number of different types of atoms and their coordination in a geometrical particle of a given size. 


\subsubsection{Surface energy of crystal faces}

The surface energy of low index $[h k l]$ crystal faces is related to the coordination number of surface atoms. In the bulk, atoms are fully coordinated, having 12 nearest neighbors at identical distance in the case of the FCC metals. At the surface, up to half of these nearest neighbor bonds may be absent, increasing the energy of surface atoms with respect to bulk atoms. When this energy difference is scaled to the surface area, a surface energy $\gamma\left(\mathrm{J} \mathrm{m}^{-2}\right)$ is obtained.

For FCC metals, a variety of crystal faces can be defined, which may have atoms in multiple positions $i$, with coordination numbers $\mathrm{CN}_{i}$ between 6 and 11 (see Table D1). For a surface atom $i$, the decrease in the number of bonds, i.e. the change of its coordination number $\triangle C_{i}$, is equal to the difference between the coordination number of a bulk atom $\mathrm{CN}_{\mathrm{B}}$ and that surface atom $\mathrm{CN}_{i}$. By combining $\Delta \mathrm{CN}_{i}$ with the appropriate atomic surface densities $\Gamma_{i}$ (atoms $\mathrm{nm}^{-2}$ ), the total number of broken bonds per unit surface area $X$ can be found for the different crystal faces, according to:

$$
X=\sum \Gamma_{i} \Delta \mathrm{CN}_{i}=\sum \Gamma_{i}\left(\mathrm{CN}_{\mathrm{B}}-\mathrm{CN}_{i}\right)=\sum \Gamma_{i} \mathrm{CN}_{\mathrm{B}}\left(1-\frac{\mathrm{CN}_{i}}{\mathrm{CN}_{\mathrm{B}}}\right)
$$

An overview of atomic surface densities $\left(\Gamma_{i}\right)$ is given in Table D1.

When using the above scaling to unit of surface area, a remarkably strong correlation is found between surface density of broken first neighbor bonds $\left(\mathrm{nm}^{-2}\right)$ and the surface energy (aJ $\mathrm{nm}^{-2}$ ). This is illustrated in Figure 5.1 for data by Galanakis et al., ${ }^{28}$ but similar results are found for surface energy data of a variety of FCC metals (see supporting information, Section D1). 


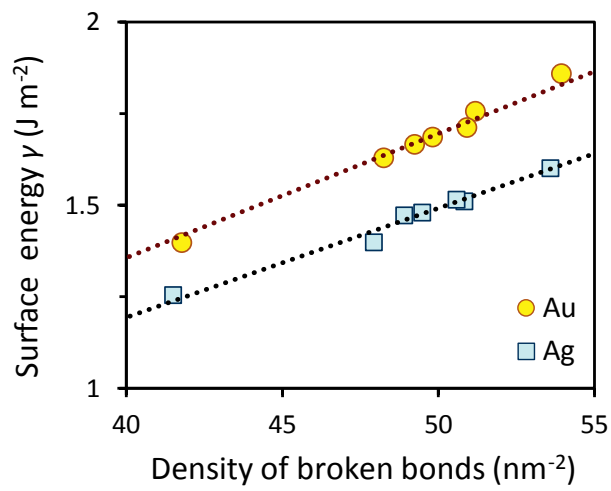

Figure 5.1 Surface energy $\left(\mathrm{J} \mathrm{m}^{-2}\right.$ or aJ $\left.\mathrm{nm}^{-2}\right)$ of metallic gold and silver, for various low index surfaces, plotted against the surface density of broken bonds, $\Sigma \Gamma_{i} \Delta \mathrm{CN}_{i}$ (eq 5.1). Surface energies were calculated $^{28}$ using molecular orbital density functional theory (MO/DFT). Note that the dotted lines pass through the origin (not visible), i.e. the slope of the model line represents an average energy per broken bond. A similar proportional relation is found for surface energies of a variety of other metals calculated using different first principles methods, as shown in the supporting information (Section D1).

In Figure 5.1, the data strongly suggest a proportional relationship exists between the surface density of broken bonds and the surface energy. Each line in Figure 5.1 passes through the origin and the corresponding slope gives information about the mean energy associated with the breaking of a single bond $E_{\mathrm{b}} \equiv \gamma / X$. It shows that surface energy can be very well understood based solely on the breaking first-neighbor bonds. Moreover, it implies that the surface energy of any crystal face of a metal can in principle be predicted with reasonable accuracy after calibration of the relationship using the surface energy of a single crystal face.

\subsubsection{The surface energy contribution of atoms}

Using the above definition of bond energy $E_{\mathrm{b}}$, one may calculate the excess energy of a surface atom with respect to a bulk atom. For different types of surface atoms $i$, the excess energy $\Delta E_{i}$ can be estimated using the number of broken bonds, i.e. $\Delta E_{i}=E_{\mathrm{b}}\left(\mathrm{CN}_{\mathrm{B}}-\mathrm{CN}_{i}\right)=E_{\mathrm{b}} \Delta C N_{i}$. This method, in which $E_{\mathrm{b}}$ is assumed to have a constant value, yields excellent estimates for surface atoms with coordination numbers between 6 and 11 .

At a constant bond energy, the energy of a completely uncoordinated atom $(\triangle C N=12)$, or cohesive energy, would be equal to $12 E_{\mathrm{b}}$. Using this hypothetical relationship, bond energies could be directly obtained from cohesive energy values that have been established experimentally for most metals. ${ }^{50,51}$ However, this method is flawed. The reason is that the remaining bonds increase in strength at a decrease of the coordination number of an atom. In other words, the bond energy is not constant, but increases slightly for each subsequent broken bond. This observation is in line with well-known concept of Pauling for the bond strength in ionic minerals, ${ }^{52}$ stating that it increases with decrease of the coordination. As a result, the proportional relationship found above is not valid at higher values of $\triangle C N$. 
The relationship between coordination number and atomic energy is visualized in Figure 5.2, where the dotted line represents the atomic energy for typical bond energy values obtained using $E_{\mathrm{b}}=\gamma / X$, while the full blue line gives a more realistic depiction of how atomic energy changes with coordination number. The surface atoms for common crystal faces have a coordination number between 6 and 11 (see Table D1). In this range, the atomic energy can be approached with a linear relationship, as indicated by the red area. However, at a lower coordination number, as found for corner atoms, the atomic energy will be higher, to be quantified next.

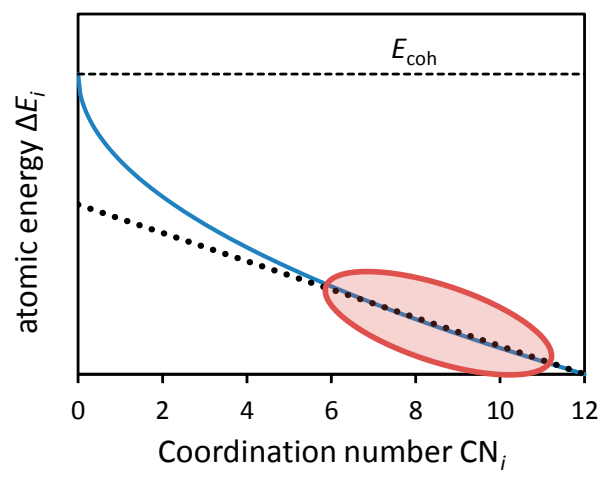

Figure 5.2 Conceptual relationships between the coordination number of an atom and the atomic energy $\Delta E_{\mathrm{i}}$. The dotted (black) line shows the atomic energy as a function of the coordination number assuming a constant energy per bond $\left(E_{\mathrm{b}}\right)$, irrespective of the coordination number. The full (blue) line represents the atomic energy in case of an increasing bond strength at lowering of coordination that follows from eq 5.2 assuming $E_{0}=E_{\text {coh. }}$. For low index crystal faces with $\mathrm{CN}_{i}=6-11$ (the shaded area), the value of $E_{\mathrm{b}}$ is more or less constant; it can be applied in eq 5.1 for calculating the surface energy of crystal faces as a function of the coordination density.

Methfessel et al. ${ }^{48}$ studied the relation between atomic energy and coordination number for metals in various $0,1,2$, and 3 dimensional structures using DFT in the full potential linear muffin-tin orbital approximation. The energies for these structures with $\mathrm{CN}=2-12$ suggested the following relationship between the energy of atoms and their coordination number:

$\Delta E_{i}=E_{0}\left(1-\sqrt{\frac{\mathrm{CN}_{i}}{\mathrm{CN}_{\mathrm{B}}}}\right)$

In the above equation, $E_{0}$ represents the energy of an uncoordinated atom $(\mathrm{CN}=0)$ without spin-polarization, which is about $10-20 \%$ higher than the cohesive energy $\left(E_{\text {coh }}\right)$ that does include spin-polarization. ${ }^{48}$

In literature, some varieties to the very basic equation for atomic energy (eq 5.2) have been proposed. Methfessel et al. ${ }^{48}$ suggested the addition of a linear term with a fitted coefficient 
to account for a repulsive term, which leads to a slightly improved fit for their data. Alternatively, Xiong et al. ${ }^{53}$ have suggested that a cube root function may be more suitable for corner atoms, while a combination of a cube and a square root is appropriate for edges, though no rationale is given for this choice. In the present work, we restrict ourselves to the square root function, as it leads to very good results in our model.

\subsubsection{Coordination model: Excess energy of nanoparticles}

For a MeNP, the presence of surface atoms will lead to an increased energy with respect to the bulk. This external excess energy $\Delta E_{S}$ can be approximated by the sum of the energy contributions of all surface atoms, i.e. $\Delta E_{S}=\Sigma \Delta E_{i}$. In combination with equation 2 , the excess energy of a regular nanoparticle can be found with:

$$
\Delta E_{\mathrm{S}}=\sum \Delta E_{i}=E_{0} \sum N_{i}\left(1-\sqrt{\frac{\mathrm{CN}_{i}}{\mathrm{CN}_{\mathrm{B}}}}\right)
$$

where $N_{i}$ is the number of times a surface atom of type $i$ is found on a cluster. For application of the above equation, we have analyzed the atomic structure of MeNPs of different shapes, i.e. icosahedral, truncated decahedral, cuboctahedral, octahedral, and truncated octahedral nanoclusters.

On a particle, we can distinguish between face atoms, edge atoms and corner atoms, as illustrated in Figure 5.3. Depending on the particle geometry, there may by more than one type of face, with a different structures and coordination numbers. More complex particles, such as the truncated decahedron, may also have multiple types of edges and corners. The different atom types and their coordination numbers are summarized in Table 5.1 for a set of selected geometries.

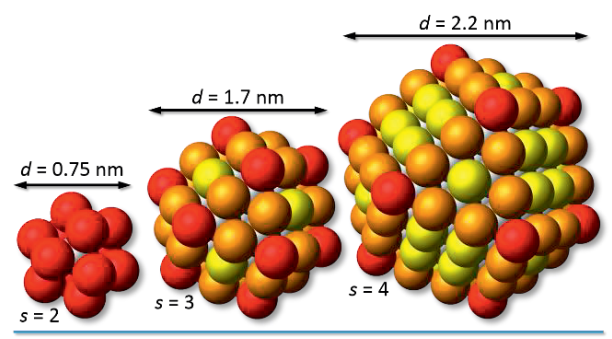

Figure 5.3 Graphic representation of three small nanoclusters with the cuboctahedral geometry that differ in edge-length $(s)$, expressed in a number of atoms. For smaller particles, the fraction of corner (red) and edge (orange) atoms increases at expense of face atoms (yellow). In the smallest cluster, all surface atoms are corner atoms, whereas in the largest cluster, corner atoms comprise only 12 out of 92 surface atoms. The given particle size is an equivalent diameter, calculated from the total number of atoms $N_{\mathrm{T}}$, using $d=\left(6 / \pi \cdot N_{\mathrm{T}} / N_{\mathrm{Av}} \cdot M / \rho\right)^{1 / 3}$ with $M$ as the molar mass and $\rho$ as the mass density. 
Figure 5.3 illustrates that, while the number of corner atoms is fixed, the number of face and edge atoms is size dependent. The varying number of atoms on the faces and edges can be expressed as a function of the number of atoms along the edges $s$, where $s$ includes the corner atoms. While icosahedra, cuboctahedra, and octahedra have only a single edge-length, truncated decahedra and truncated octahedra can have two different edge-lengths. In Table 1 , these are referred to as $s_{1}$ and $s_{2}$, respectively indicating the edges between two [111] faces and the edges between a [111] and a [100] face. Formulae to calculate the number of each atom type on the different particle geometries are given in Table 5.1. The total number of atoms $N_{T}$ in the various particles can also be expressed as a function of $s$ (or of $s_{1}$ and $s_{2}$ ); these equations are given in the supporting information (Section D2). The equations in Table 1 will be applied together with the coordination number to calculate the external excess particle energy $\Delta E_{\mathrm{S}}$, created by surface atoms as a result of a decrease of the metal coordination (eq 3 ). 


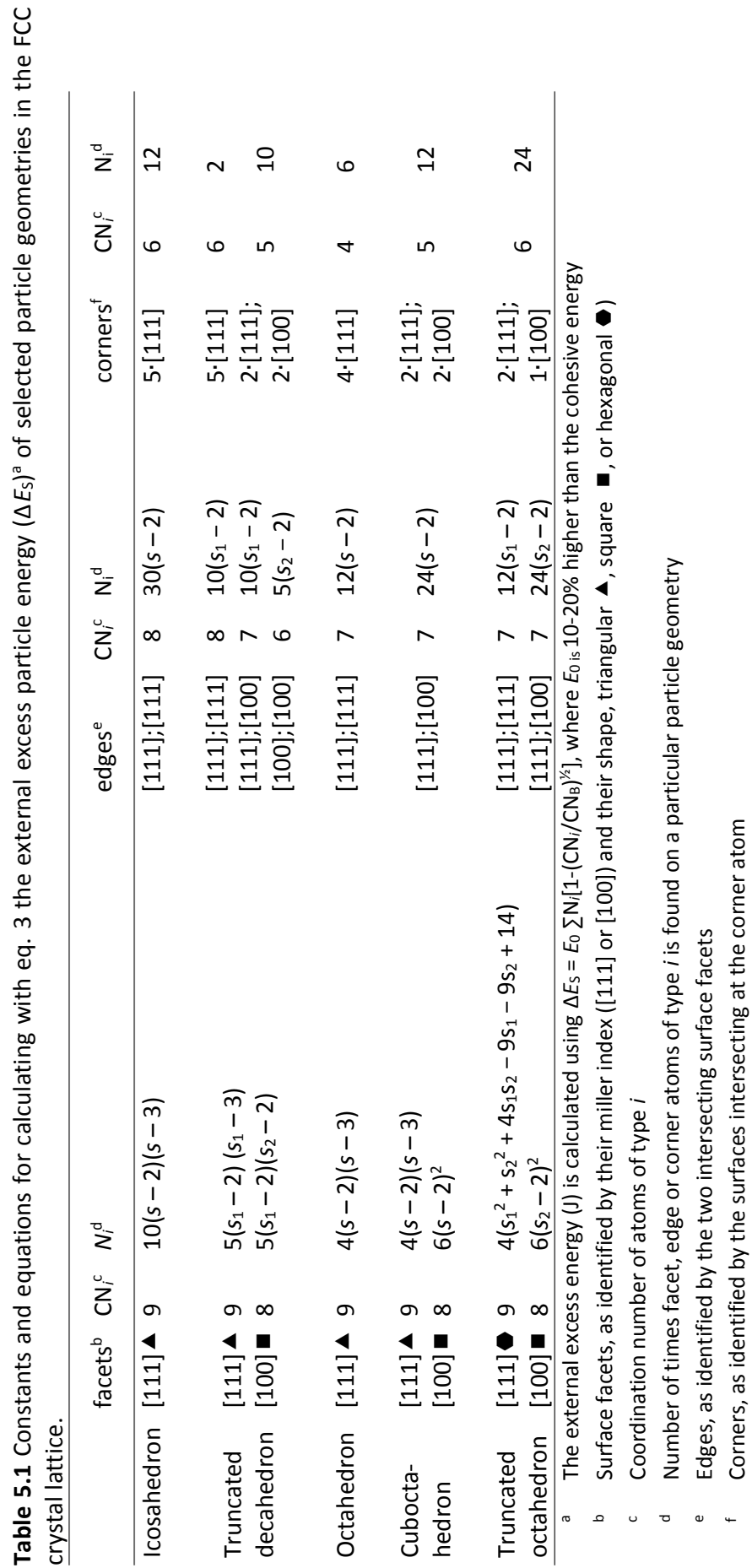




\subsection{Results and discussion}

\subsubsection{External excess energy of MeNPs}

With the above $C N$ model (eq 3), we can calculate the external excess energy $\Delta E_{S}$ of different shapes of nanoparticles as result of the presence of surface atoms having a lower coordination. The calculated value of $\Delta E_{\mathrm{S}}$ can be compared to the excess energy of particles derived in literature with advanced computational methods. This is shown in Figure 5.4 for a variety of regular, i.e. non-twinned, gold and silver nanoparticles; these particles are expected to have exclusively external excess energy contributions.
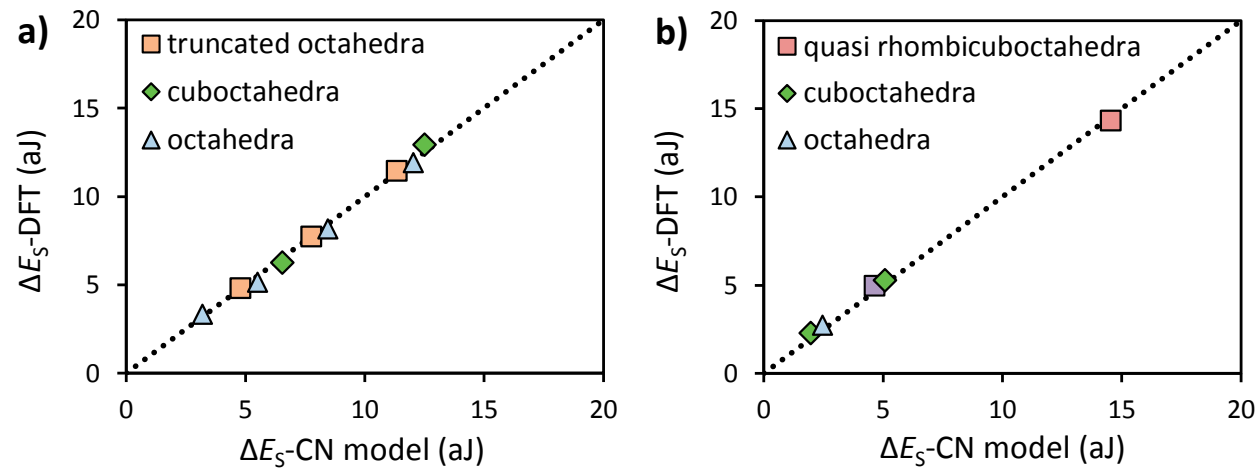

Figure 5.4 Comparison of excess energies $\Delta E_{\mathrm{s}}$ of clusters of gold (a) and silver (b), found by first principle calculations (vertical axis) and by application of the coordination (CN) model for surface atoms (horizontal axis), using the value of the zero coordination energy $E_{0}$ as adjustable parameter. Computational data refer to DFT-GGA ${ }^{43}$ (a) or DFT-GGA ${ }^{44}(b)$. The dotted line represents the 1:1 ratio.

In Figure 5.4a, we have plotted the excess energy data for gold nanoparticles of different shapes, calculated by Barnard and Curtis ${ }^{43}$ using DFT-GGA ( $\Delta E_{S}$-DFT) against our own model prediction. An excellent 1:1 relation is found with the excess particle energy calculated with the metal coordination model $\left(\Delta E_{\mathrm{S}}-\mathrm{CN}\right.$ model), when applying a zero-coordination energy of $E_{0}=0.59$ aJ per atom or $357 \mathrm{~kJ} \mathrm{~mol}^{-1}$ in eq 5.3. This value of the zero-coordination energy $E_{0}$ can be derived graphically by plotting $\Delta E_{s}$-DFT versus the $\Sigma$ factor of eq 5.3 , leading to a linear relationship with a slope $E_{0}$ as we illustrate and discuss in the supporting information (Section D3).

Figure $5.4 \mathrm{~b}$ shows the excess energy of silver nanoclusters, calculated by Medasani et al. ${ }^{44}$ using DFT-GGA. Our analysis of the data shows a near perfect 1:1 relation is obtained with $E_{0}=0.44 \mathrm{aJ}=265 \mathrm{~kJ} \mathrm{~mol}^{-1}$ if an additional constant energy contribution of $0.40 \mathrm{aJ}$ per cluster is included as discussed in more detail in the supporting information (Section D3). We note that the geometry for two quasi rhombicuboctahedral clusters of Figure 5.4b used by Medasani et al. ${ }^{44}$ are not defined in Table 1; these are described in detail in the supporting information (Section D4). 
Liu et al., ${ }^{46}$ have calculated excess energies of truncated octahedral AgNP as well as for crystal faces using DFT-LDA. Using $E_{0}=0.66 \mathrm{aJ}=396 \mathrm{~kJ} \mathrm{~mol}^{-1}$ used in eq 5.3, an almost perfect 1:1 relationship is found between the computational data and the $\mathrm{CN}$ model for the truncated octahedra and the [111] face (results not shown). Contrasting to this, for the [100] face, a value of $E_{0}=0.60 \mathrm{aJ}$ or $363 \mathrm{~kJ} \mathrm{~mol}^{-1}$ is found, for reasons unknown.

The zero-coordination energies $E_{0}$ established above for $\mathrm{Ag}$ and $\mathrm{Au}$ can be compared (Table 5.2 ) to the cohesive energy as calculated in the same works. Barnard and Curtis ${ }^{43}$ reported a cohesive energy of 0.51 aJ or $309 \mathrm{~kJ} \mathrm{~mol}^{-1}$ for bulk gold while Liu et al. ${ }^{46}$ calculate a value of 0.56 aJ or $339 \mathrm{~kJ} \mathrm{~mol}^{-1}$ for silver. Medasani et al. ${ }^{44}$ reported a value of $0.45 \mathrm{aJ}$ or $272 \mathrm{~kJ} \mathrm{~mol}^{-1}$ for silver using DFT-GGA, but express their concern that the small, localized basis set may lead to an overestimation of the cohesive energy; an alternate value of 0.39 aJ or $232 \mathrm{~kJ} \mathrm{~mol}^{-1}$ is obtained with first principles plane-wave GGA. The energy levels of MO computation may differ, but more importantly, the zero-coordination energies $E_{0}$ are systematically higher than the reported cohesive energies $E_{\text {coh, }}$ as shown in Table 5.2. This is in excellent agreement with the work of Methfessel et al., ${ }^{48}$ who expected a difference of $10-20 \%$ as a result of the lack of magnetic spin polarization in surface atoms. According to the $E_{0}$ values derived here (Table 5.2), the difference is $16 \pm 1 \%$.

Table 5.2 Zero-coordination energies $E_{0}$ derived by our analysis (Figure 5.3 and Figure D2) and cohesive energy values $E_{\text {coh }}$ derived by computational approaches.

\begin{tabular}{llll}
\hline & $E_{0}{ }^{\mathrm{a}}(\mathrm{aJ})$ & $E_{\text {coh }}(\mathrm{aJ})$ & $E_{0} / E_{\text {coh }}$ \\
\hline Gold $^{43}$ & 0.593 & 0.513 & 1.16 \\
Silver $^{44}$ & 0.441 & $0.385^{\mathrm{b}}$ & 1.15 \\
Silver $^{46}$ & 0.657 & 0.562 & 1.17 \\
\hline a & \multicolumn{3}{l}{ From the slopes in Figure D2 } \\
b According to plane-wave calculations
\end{tabular}

We have extended our analysis by also examining data for gold nanoparticles generated by Ali et al. ${ }^{54}$ with molecular dynamics using the embedded atom method. From the reported values for the surface energy $\left(\mathrm{J} \mathrm{m}^{-2}\right)$ and surface area $\left(\mathrm{m}^{2} \mathrm{~mol}^{-1}\right)$, the excess particle energies for truncated octahedra and cuboctahedra can be back calculated. In Figure 5.5, these excess energy data $\left(\Delta E_{S}-\mathrm{MD}\right)$ are compared to the external excess particle energy according to the $\mathrm{CN}$ model applying an appropriate value of the zero energy $E_{0}$ in eq 5.3 (0.42 aJ per atom = $253 \mathrm{~kJ} \mathrm{~mol}^{-1}$ ). The result of Figure 5.5 is impressive. 


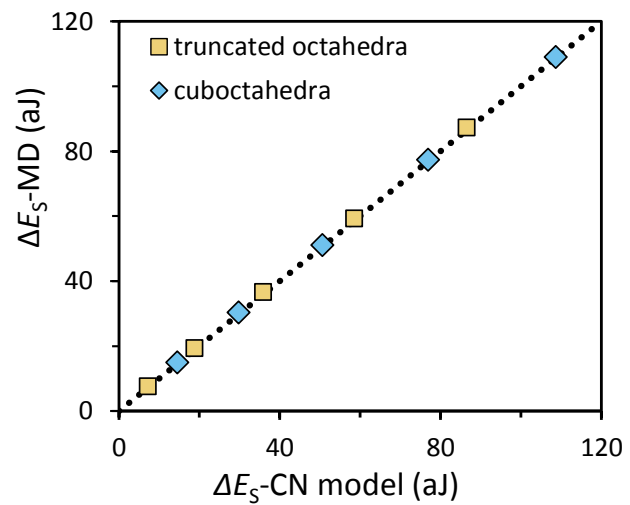

Figure 5.5 Comparison of excess particle energies $\Delta E_{S}$ of AuNP found by molecular dynamics calculations of Ali et al. ${ }^{54}$ (vertical axis) and by application of the metal coordination (CN) model (horizontal axis), using the value of a zero coordination energy of $E_{0}=0.42$ aJ or $253 \mathrm{~kJ} \mathrm{~mol}^{-1}$ as the sole adjustable parameter in the model (eq 5.3). The dotted line represents the 1:1 line.

As shown in the figure, a very good linear 1:1 relationship is found. As for the data by Medasani et al., ${ }^{44}$ a detailed analysis reveals a small systematic offset in the MD values compared to the $\mathrm{CN}$ model, equal to just 0.58 aJ as follows from our analysis presented in the supporting information (Section D3).

In addition to the energy for clusters, Ali et al. ${ }^{54}$ perform slab-calculations to find the surface energy of the [111] and the [100] face. The respective surface energies are 0.79 and $0.92 \mathrm{~J} \mathrm{~m}^{-2}$, which is equivalent to 0.056 aJ per surface atom for the [111] face and 0.076 aJ for the [100] face. These atomic energies $\Delta E_{i}$ can be described with equation 2 using a zero coordination energy $\left(E_{0}\right)$ of $0.42 \mathrm{aJ}$, in agreement with the description of the clusters. Coordination numbers and surface densities for the above calculations are given in Table D1.

The above demonstrates that by taking the sum of the individual contributions of the different types of surface atoms, the $\mathrm{CN}$ model successfully reproduces the total surface energy term found by advanced computational methods. Next, the model can be applied to elucidate the energy contributions of the various types of surface atoms.

In Figure 5.6, the individual contributions for silver cuboctahedra have been plotted against particle size. It demonstrates how the contribution of atoms on faces, edges, and corners changes with particle size. The figure shows that the influence of high-energy corner atoms decreases very rapidly, being responsible for less than $3 \%$ of the total surface energy in particles of $5 \mathrm{~nm}$ and larger. Edge atoms, on the other hand, still cause around $30 \%$ of the total surface energy term for a $5 \mathrm{~nm}$ particle (Figure 5.6 insert). The reason for this difference is that the number of corner atoms is constant irrespective of size, while the number of edge atoms increases with particle size (see Figure 5.3). For that reason, the contribution of edge atoms remains relatively large, even for large nanoparticles. It demonstrates the importance of understanding the surface structure and composition when considering MeNPs. 


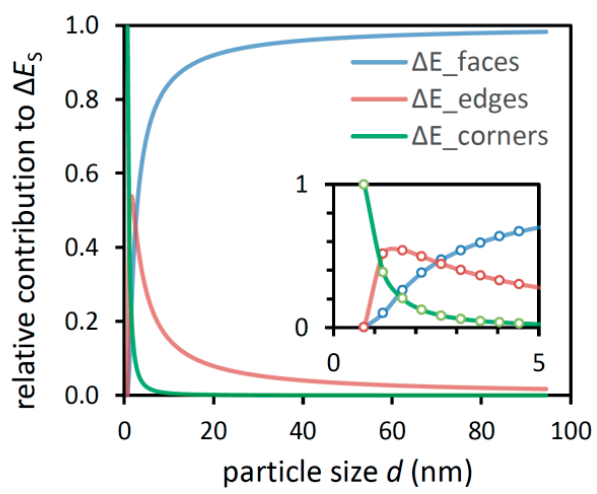

Figure 5.6 Relative contribution of face atoms (blue line), edge atoms (red line), and corner atoms (green line) to the external excess energy as a function of particle size. Data are calculated for cuboctahedral silver nanoparticles using the $\mathrm{CN}$ model, but almost identical data are found for gold nanoparticles. The insert shows a more detailed picture of the very small size range, data points represent cuboctahedra with side-lengths of $s=2,3$, or more atoms (Figure 5.3). Particle size is given as the mass based particle diameter $d=\left(6 / \pi \cdot M / \rho \cdot N_{\mathrm{T}} / N_{\mathrm{A}}\right)^{1 / 3}$.

In conclusion, our surface coordination model performs remarkably well for noble metal nanoclusters. It demonstrates that the external excess energy $\Delta E_{\mathrm{S}}$ can be almost completely understood from the variation in coordination and total number of surface atoms. The $\mathrm{CN}$ model has the great advantage that it can make the energy contributions to the excess particle energy $\Delta E_{\mathrm{S}}$ explicit for the various types of surface atoms as shown above. Since the $C N$ model can accurately calculate energy contributions of surface atoms, the model can also be used to reveal additional energy contributions that are related to internal structural changes such as crystal twinning.

\subsubsection{Energy of twinning}

The surface coordination model calculates the energy as a result of a lowering of the coordination of atoms at the surface. However, additional factors may affect the particle energy. Notably, fivefold twinning, found in icosahedra and decahedra, will increase the particle energy. Fivefold twinning is associated with internal strain and stacking faults at the twin-plane, which both may lead to an increased particle energy. Internal strain is the result of a misalignment in the crystal structure because the sum of angles $\left(70.53^{\circ}\right)$ of the five sections is less than $360^{\circ} .{ }^{38}$ It leads to stretching of the outer layers and/or compression of the inner layers, which results in an additional contribution to the excess energy term of particles. This contribution will be analyzed using our $\mathrm{CN}$ model and interpreted with a twinning energy model that we will develop here.

Ali et al. ${ }^{54}$ have calculated particle energies for a large number of icosahedra and truncated (Ino) decahedra. The energy due to twinning can be calculated as the difference between reported excess particle energy values $(\triangle E-M D)$ and the energy contribution of surface atoms $\left(\Delta E_{\mathrm{S}}\right)$ according to the $\mathrm{CN}$ model using $E_{0}=253 \mathrm{~kJ} \mathrm{~mol}^{-1}$ in eq 5.3. This residual excess energy 
is plotted in Figure 5.7 for icosahedra and decahedra. For comparison, the values for cuboctahedra and truncated octahedra are given. The figure shows a small deviation for cuboctahedra and truncated octahedra, averaging $0.58 \mathrm{aJ}$. This deviation is also apparent from the relationship between the computed energies and the $\mathrm{CN}$ model (Figure 5.5), showing the same off-set value (see Section D3 of Appendix D for more detail). Despite this complication, it is evident that the energy difference of icosahedra as well as decahedra increases hugely with the particle size. The grey baseline has been used to isolate the contribution of the twinning energy.

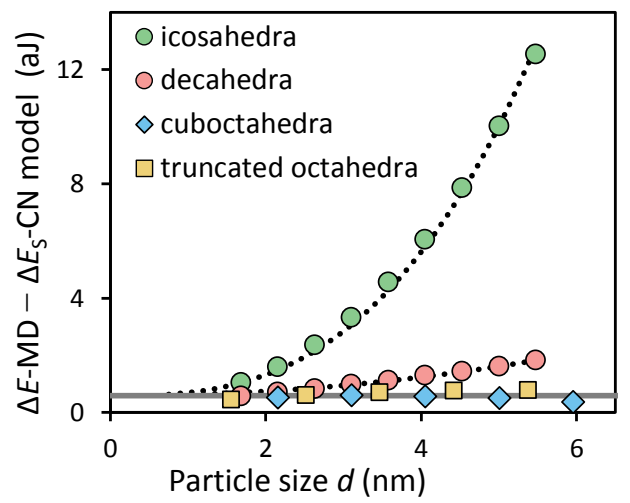

Figure 5.7 Difference between the reported excess particle energy ${ }^{54}$ and the external excess energy found using the $\mathrm{CN}$ model for gold icosahedra and decahedra (spheres). The dotted lines are predictions of total twinning energy with a structural model, using the data for truncated octahedra (squares) and cuboctahedra (diamonds) to establish the baseline (grey). In the model, two types of atoms are distinguished that contribute differently to the overall twinning energy (see text). Particle size is given as the mass based particle diameter $d=\left(6 / \pi \cdot N_{\mathrm{T}} / N_{\mathrm{A}} \cdot M / \rho\right)^{1 / 3}$.

As shown in Figure 5.7, the twinning energy for icosahedra is significantly higher than for decahedra. This is expected as icosahedral particles have twice as much twin-plane area as the latter. However, the twinning energy is up to almost 10 times higher. It suggests that the icosahedra have an additional energy contribution, which is absent or much lower in the decahedra. A logical reason may be internal strain as a result of the distorted crystal structure which is caused by five-fold twinning ${ }^{38}$ as icosahedra have 30 twin-planes and 12 twin-axis (see supporting information, Section D5), compared to 5 twin planes around a single twin-axis in decahedra.

To improve our understanding, we have developed a twinning energy model in which we distinguish two types of energy contributions. The first type is due to the atoms present in the twin-plane. Here, the normal FCC stacking is interrupted and reversed, leading to a slightly 
higher energy. In addition, the five sections around a twin axis need to be slightly deformed in order to fit together, leading to an internal strain that is present throughout the particle.

The number of atoms related to the above factors, being the amount of twin plane atoms $N_{\text {tp }}$ for the twin-plane energy and the total amount of atoms $N_{T}$ for the internal strain energy, follow logically from the structure of icosahedra and decahedra. Formulae for the calculation of the number of atoms involved $\left(N_{\mathrm{T}}\right.$ and $\left.N_{\mathrm{tp}}\right)$ are presented in the supporting information (Section D5). The twinning energy model can be formulated as:

$$
\Delta E_{\text {twin }}=\Delta E_{\text {tp }} N_{\text {tp }}+\Delta E_{\mathrm{T}} N_{\mathrm{T}}
$$

The values for the energy contributions $\Delta E_{\mathrm{tp}}$ and $\Delta E_{\mathrm{T}}$ have been derived by parameter optimization using the twinning energy data of Figure 5.7. For a good description, the contribution of $\Delta E_{\mathrm{T}}$ for decahedral atoms of AuNP can be set to zero, resulting in a twining energy of $\Delta E_{\mathrm{tp}}=1.3 \cdot 10^{-3}$ aJ $\left(0.78 \mathrm{~kJ} \mathrm{~mol}^{-1}\right)$ for Au atoms in the twin plane. Applying this same energy to the atoms of twin-planes in icosahedra, the data can be described applying an overall strain contribution of $\Delta E_{\mathrm{T}}=2.0 \cdot 10^{-3}$ aJ $\left(1.2 \mathrm{~kJ} \mathrm{~mol}^{-1}\right)$ for the Au atoms in the icosahedra. It leads to an excellent description of twinning energy, as shown in Figure 5.7 with the dotted lines. As demonstrated in the supporting information (Fig. S5), the model also works reasonably well for small icosahedral and decahedral clusters for which the energy was calculated using DFT. ${ }^{43,46}$

The above data description can be slightly improved for icosahedral particles by differentiating between atoms at the ordinary twin-planes and atoms at twin-axis. According to this more detailed analysis (Section D5 of Appendix D), the latter have a strongly increased energy as a result of compression by the outer layers, as was also found by Mottet et al. ${ }^{55}$ However, the present data do not yet allow definite conclusions.

The above-derived twin-plane energy of $1.3 \cdot 10^{-3}$ aJ per atom $\left(0.78 \mathrm{~kJ} \mathrm{~mol}^{-1}\right)$ is equivalent to $18 \mathrm{~mJ} \mathrm{~m}^{-2}$. The value can be compared to the twin-plane energy in bulk gold, which is $27 \mathrm{~mJ}$ $\mathrm{m}^{-2}$ according to Barnard. ${ }^{36}$ Both values are of the same order, although the latter value is slightly higher. We note that surface energies reported in the work of Barnard ${ }^{36}$ are also higher than those found by Ali et al. ${ }^{54}$ As the tendency for twinning is determined by the tradeoff between having a higher internal energy and a lower external energy, twin-plane energy should be seen relative to surface energy. From this perspective, our results are in excellent agreement: while we find a twin-plane energy to $2.2 \%$ of the surface energy of the [111] plane, this is $2.0 \%$ for the data reported by Barnard. ${ }^{36}$ Thus, while the absolute twin-plane energies are different, they are equivalent in terms of their effect on particle structure, giving good credibility to our model approach.

With the above model (eq 5.4), the overall twining energy as well as the both contributions can be quantified as a function of the particle size, using values of $N_{T}$ and $N_{\text {tp }}$ that follow from the structure. This is given in Figure 5.8, showing that for icosahedral particles the strongest 
contribution comes from internal strain $\left(\Delta E_{\mathrm{T}}\right)$. The contribution by the twin planes is relatively small. In absence of internal strain, the twinning energy for icosahedra would be only around two times higher than for decahedra. The additional strain energy strongly raises the energy of icosahedral nanoparticles as indicated with the arrow in Figure 5.8.

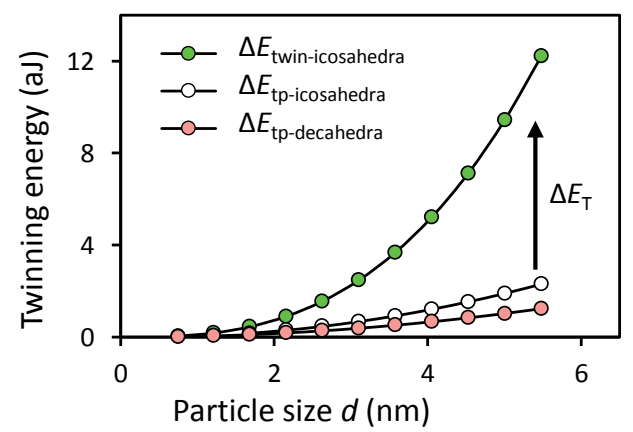

Figure 5.8 Twinning energy of icosahedra and decahedra according to the twinning energy model (eq 5.4). For icosahedra, shown are the full-twinning energy ( $\left.\Delta E_{\text {twin }}\right)$ including strain (green symbols) and the twinning energy due to the twin-plane $\left(\Delta E_{\mathrm{tp}}\right)$ only (open symbols), demonstrating the strong contribution of internal strain.

\subsubsection{Prediction of surface energy of crystal faces}

Surface enthalpy of the various crystal faces of the FCC metals are notoriously difficult to measure while concurrently computational surface energy data ${ }^{26-34}$ are strongly method dependent. Therefore, we will describe in this section how our coordination model (eq 5.3) can be used to make realistic predictions that are based on well-established experimental information about the enthalpy of atomization $\Delta H_{\mathrm{a}}$.

Surface energy $\gamma$ of a surface can be found from the surface densities $\left(\Gamma_{i}\right)$ and energies $\left(\Delta E_{i}\right)$ of the various surface atoms $i$, using:

$\gamma=\sum \Gamma_{i} \Delta E_{i}=E_{0} \sum \Gamma_{i}\left(1-\sqrt{\frac{\mathrm{CN}_{i}}{\mathrm{CN}_{\mathrm{B}}}}\right)$

where $\Gamma_{i}$ (Table D1) follows from the surface structure and the closest interatomic distance $d_{a}$ (given in Table 5.3). The calculation requires the zero-coordination energy $E_{0}$, which we estimate from the enthalpy of atomization $\Delta H_{\mathrm{a}}$, for which values are well established (Table 3)..$^{50,51}$ The zero-coordination energy $E_{0}$ can be taken as $16 \pm 1 \%$ higher than the enthalpy of atomization $\Delta H_{\mathrm{a}}$, as we derived in the previous section (Table 5.2). However, for application to a wider range of metals than investigated in Section 5.3.1, we take a more conservative 
estimate of $15 \pm 5 \%$. For the [111] and the [100] face, the resulting surface enthalpies $\Delta H_{\mathrm{s}}$ are presented in Table 5.3.

Table 5.3 Surface enthalpies (in $\left.\mathrm{J} \mathrm{m}^{-2}\right)$ for the [111] and [100] face $\left(\Delta H_{\mathrm{s},[111]}\right.$ and $\left.\Delta H_{\mathrm{s},[100]}\right)$ of selected metals at standard conditions calculated using the standard enthalpy of atomization $\left(\Delta H_{a}\right)$ and the surface densities $\left(\Gamma_{[111]}\right.$ and $\left.\Gamma_{[100]}, \mu \mathrm{mol} \mathrm{\textrm {m } ^ { - 2 }}\right)$ of both faces (eq. 5). Experimental surface enthalpies $\left(\Delta H_{\mathrm{s}, \mathrm{exp}}\right)$ are given for comparison. Also shown is the atomic diameter $d_{\mathrm{a}}(\mathrm{nm})$ used to find the surface densities.

\begin{tabular}{llllllll}
\hline & $\Delta H_{\mathrm{s},[111]^{\mathrm{a}}}$ & $\Delta H_{\mathrm{s},[100]^{\mathrm{a}}}$ & $\Delta H_{\mathrm{s}, \mathrm{exp}}{ }^{\mathrm{b}}$ & $\Delta H_{\mathrm{a}}{ }^{\mathrm{c}}$ & $\Gamma_{[111]}{ }^{\mathrm{d}}$ & $\Gamma_{[100]}{ }^{\mathrm{d}}$ & $d_{\mathrm{a}}{ }^{\mathrm{e}}$ \\
\hline $\mathrm{Ni}$ & $2.05 \pm 0.09$ & $2.43 \pm 0.11$ & $2.40 \pm 0.01$ & 453.8 & 30.9 & 26.7 & 0.249 \\
$\mathrm{Cu}$ & $1.53 \pm 0.07$ & $1.81 \pm 0.08$ & $1.72 \pm 0.06$ & 337.4 & 29.4 & 25.4 & 0.255 \\
$\mathrm{Ag}$ & $1.01 \pm 0.04$ & $1.20 \pm 0.05$ & $1.27 \pm 0.07$ & 284.9 & 23.0 & 19.9 & 0.289 \\
$\mathrm{Au}$ & $1.30 \pm 0.06$ & $1.55 \pm 0.07$ & $1.47 \pm 0.01$ & 366.0 & 23.1 & 20.0 & 0.288
\end{tabular}

a The uncertainties of the predicted surface enthalpy of the [111] and the [100] face are based on the uncertainty in the zero-coordination energy $E_{0}=1.15 \Delta H_{a} \pm 0.05 \Delta H_{a}$

b Experimental surface enthalpy $\left(\mathrm{J} \mathrm{m}^{-2}\right)$, extrapolated from collected surface energy data of liquid metals (see Section D6 of Appendix D). Uncertainty margins refer to the standard deviation of collected data.

c Standard enthalpy of atomization $\left(\mathrm{kJ} \mathrm{mol}^{-1}\right)$ from Cox et al. ${ }^{50}\left(\mathrm{Cu}\right.$ and $\mathrm{Ag}$ ) and Schumm et al. ${ }^{51}(\mathrm{Ni}$ and $\mathrm{Au})$; these values were used to calculate the zero-coordination energy $E_{0}$ in equation 2 , according to $E_{0}=1.15 \Delta H_{\mathrm{a}} \pm 0.05 \Delta H_{\mathrm{a}}$

d Surface density of atoms on the [111] and [100] face $\left(\mu \mathrm{mol} \mathrm{m} \mathrm{m}^{-2}\right)$, calculated using the general surface properties given in Table D1 and the closest interatomic distance $d_{a}$

e Closest interatomic distance $(\mathrm{nm})$ from crystallographic data by and Suh et al. ${ }^{56}$

The surface enthalpy values $\left(\Delta H_{s}\right)$ predicted for the [111] and [100] faces (Table 5.3) are in good agreement with the experimental surface enthalpies $\left(\Delta H_{\mathrm{s}, \mathrm{exp}}\right)$. The latter values have been extrapolated from the experimental surface tension data of liquid nickel, ${ }^{57,}{ }^{58}$ copper, $^{58-}$ ${ }^{63}$ silver, ${ }^{61-66}$ and gold ${ }^{66-68}$ collected at high temperature. The relations described by Tyson and Miller ${ }^{69}$ were used to estimate the surface free energy values for the solid phase at room temperature. The good agreement of these values with the predicted surface enthalpy of the [111] and the [100] face suggests that realistic surface enthalpy values can be derived using the enthalpy of atomization as experimental input.

Importantly, the above approach does not lead to good results for surface Gibbs free energy, as we discuss in the supporting information (Section D6). In short, using the Gibbs free energy of atomization leads to an underestimation of surface Gibbs free energy. This discrepancy is due a high entropic energy contribution in the free atom, even at room temperature, whereas surface entropy for metals is relatively small, as we have shown recently. ${ }^{35}$ The low surface entropy values suggest that the surface enthalpy value in Table 5.3 can be used as a good approximation for the surface Gibbs free energy.

\subsubsection{First principles methods for surface energy of crystal faces}

As mentioned in the introduction, first principle calculations of the surface energy of the crystal faces of metals show a large variation. The approach of predicting the surface energy using the $\mathrm{CN}$ model calibrated with well-established experimental information (Section 5.3.3) 
can be applied to evaluate the results obtained for the same surfaces with different computational methods.

In these methods, electron exchange and correlation energies are usually obtained with the local density approximation (LDA) or the generalized gradient approximation (GGA). The LDA generally leads to higher surface energy values than the GGA as is illustrated in Figure 5.9 for three major low index crystal faces of Au. Taking the surface energy values obtained with the surface coordination model (eq 5.5) as the best estimates, we can assess which of these two MO/DFT methods gives a realistic result.

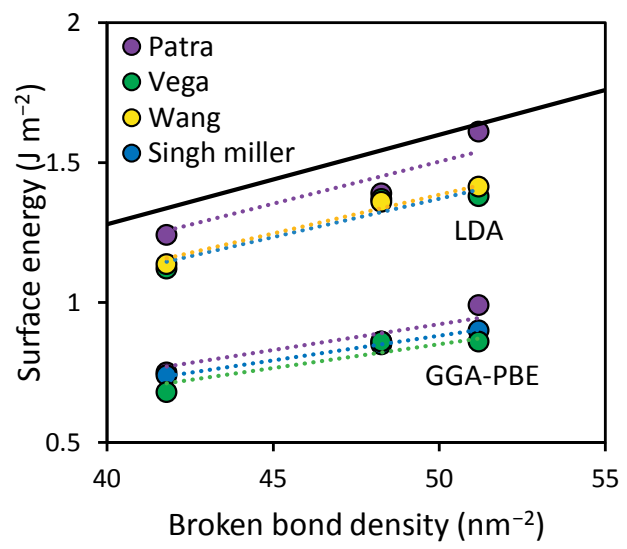

Figure 5.9 Relationship between the MO/DFT calculated surface energy of the [111], [100], and [110] face crystal face of Au and the surface density of broken bonds (symbols). Use of the GGA applying the PBE functional leads systematically to lower surface energy values compared to the use of LDA. The dotted linear lines pass the origin (not visible) and the corresponding slopes represent the average bond energy, as discussed at Figure 5.2. The full line represents the surface energy predicted using the cohesive energy and interatomic distance of $\mathrm{Au}$ as the sole input parameters (eq. 5.5).

In Figure 5.9, the surface energies are plotted against the surface density of broken bonds and the slope of the linear relations passing the origin (dotted lines) represents the average energy per broken bond $E_{\mathrm{b}}$ as discussed previously at Figures 5.2 and 5.3. For Au, the bond energy value is $E_{\mathrm{b}}=10.6 \pm 0.5 \mathrm{~kJ} \mathrm{~mol}^{-1}$ when calculated using the data found by GGA, and $E_{\mathrm{b}}=17.1 \pm 0.9 \mathrm{~kJ} \mathrm{~mol}^{-1}$ if generated by LDA. The latter value of $E_{\mathrm{b}}$ is much closer to the average bond energy of $E_{\mathrm{b}}=19.2 \pm 0.4 \mathrm{~kJ} \mathrm{~mol}^{-1}$ that we find with eq 5.5 , using a zero-coordination energy $E_{0}$ derived from the well-established enthalpy of atomization $\Delta H_{\mathrm{a}}\left(E_{0}=1.15 \Delta H_{\mathrm{a}}\right)$. For comparison with DFT data, $\Delta H_{\mathrm{a}}$ values for $0 \mathrm{~K}$ were taken. ${ }^{50,51}$ The model results strongly suggest that the values obtained by LDA are likely to be better.

Computational surface energies are commonly compared to experimental numbers extrapolated from data for molten metals. Patra et al. ${ }^{33}$ consider the mean value of the three low index crystal faces shown above (Figure 5.9) as representative for liquid metals. This best 
guess was also suggested in the recent work of Vega et al., ${ }^{34}$ but it can only be considered as provisional and uncertain since the equal weighing of the surface energy of the three chosen crystal faces is arbitrary in light of the relatively large variation between crystal faces. From this perspective, calculations with our independently calibrated coordination model will be useful as to date no experimental information exists for surface energy that allows direct comparison to values for crystal faces. Our metal coordination model provides data for individual crystal faces.

Our result (full line) suggests that the values derived by the simple LDA approach are significantly closer to reality than found with the more advanced GGA method. ${ }^{34}$ The relative success of the use of LDA has been attributed to good cancellation of errors. ${ }^{33}$ Recently, new theories of higher hierarchy have been developed. ${ }^{33}$ Compared to GGA, these state-of-the-art approaches significantly decrease the energy gap between the computational values and the values obtained independently calibrated $\mathrm{CN}$ model. However, their performance in terms of surface energy is not markedly better or worse than the LDA (see Section D7 of Appendix D).

\subsubsection{Particle size and shape dependency of surface energy}

Besides application to crystal faces (Section 5.3.4), our energy model can also be used to predict the surface energy of nanoparticles as a whole. We will extend our approach to evaluate the surface energetics of metallic nanoparticles of various size and shape. An essential difference with planar crystal faces is the surface curvature, which has far-reaching implications for scaling, as we have addressed very recently. ${ }^{35}$ To obtain thermodynamically consistent surface energy values, the excess energy must be scaled to the surface of tension. In curved surfaces, the position of the surface in the interface determines the exact value of the surface and thus the calculated surface energy. As a result, the size dependency of the surface energy is highly dependent on the interfacial position of the surface of tension.

The size dependency of the surface energy $y_{r}$ can be calculated with the generalized Tolman equation: ${ }^{35}$

$$
\gamma_{r}=\gamma_{\infty}\left(1+\frac{2 c \delta}{r_{\mathrm{e}}-\delta}\right)^{-1}
$$

in which $\gamma_{\infty}$ is the macroscopic surface tension and $c$ is a shape factor representing a correction that accounts for the higher surface to volume ratio of faceted shape compared to a sphere. ${ }^{35}$ In eq 5.6, $r_{\mathrm{e}}$ is the effective or equimolar radius of a particle and $\delta$ is the Tolman length. The latter characterizes the interfacial position of the surface of tension relative to the welldefined equimolar radius ${ }^{35}$ and can be assessed through a consistency analysis ${ }^{35}$ as described in detail in the supporting information (Section D8).

The surface enthalpy values for silver nanoparticles, calculated using the parameterized surface coordination and twinning model (eqs 5.3 and 5.4), are given in Figure 5.10 as a function of the particle size for cuboctahedra, truncated decahedra, icosahedra, truncated 
octahedra, and octahedra. The surface enthalpy values are for the pristine solid-gas interface at room temperature ( $298.15 \mathrm{~K}$ ) and atmospheric pressure (1 bar). These values will be very close to the surface Gibbs free energy values, because the surface entropy at room temperature will be relatively small, ${ }^{35}$ as discussed at the end of Section 5.3.3.

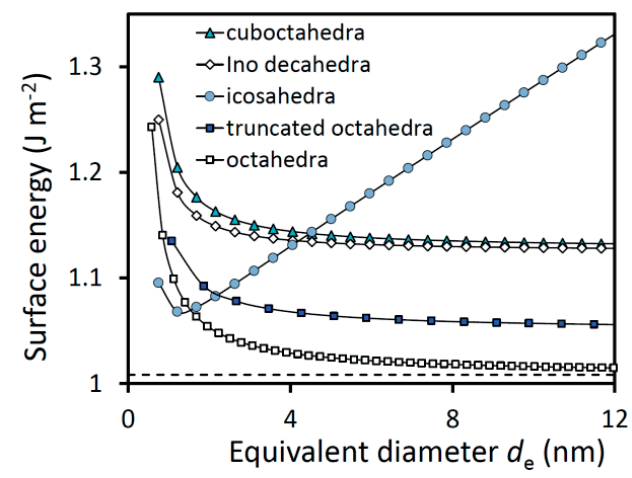

Figure 5.10 Size dependent surface enthalpy values at standard conditions for silver nanoparticles of different regular geometrical shapes. Surface enthalpy values are calculated from the excess enthalpy, having contributions from undercoordinated surface atoms (eq 5.3) and, where applicable, twinning effects (eq 5.4). These energies have been scaled to the surface area at a distance of $\sim 0.12 \mathrm{~nm}$ from the cores of surface atoms, equivalent with the use of a Tolman length of $\delta \cong 0.02 \mathrm{~nm}$ (eq 5.6), which leads to thermodynamically consistent surface energy values as shown in the supporting information (Figure D7). To illustrate the effect of corners and edges, we have indicated for octahedra, the surface energy of only the faces (dashed line).

Figure 5.10 shows that the surface energies increase as particles get smaller. This is the result of the increasing contribution of edge and corner atoms (see Figure 5.6). If only faces would contribute, a constant surface energy would be found, as is indicated for octahedra with the dashed line. Edge and corner atoms have a higher number of broken bonds, leading to a higher atomic energy and thus a higher surface energy.

At a first glance, it may be tempting to attribute the largest chemical stability to the particle with the lowest surface energy of Figure 5.10. However, the lowest surface energy does not translate directly to the highest stability. The reason is that particles with the same mass and number of atoms do not necessarily have the same surface area. What counts is the excess energy $\left(\mathrm{J} \mathrm{mol}^{-1}\right)$, which is found by multiplying surface energy $\left(\mathrm{J} \mathrm{m}^{-2}\right)$ with surface area $\left(\mathrm{m}^{2}\right.$ $\left.\mathrm{mol}^{-1}\right)$. This will be evaluated in the next section.

\subsubsection{Stability diagram}

Using the excess enthalpy values found with the model for energy contributions of surface atoms (eq 5.3) and twinning (eq 5.4), the stability of the various particle shapes can be calculated as a function of size, as shown in Figure 5.11. To facilitate a neat representation, 
the stability of all particles is given as a function of the stability of a hypothetical spherical particle with a low surface energy, as defined in the legend of Figure 5.11. The stabilities presented in Figure 5.11 are calculated as the quotient of the total excess particle energy and the reference energy. By chosen the most stable particle as reference, the relative stability value of the faceted particles will be larger than 1 .

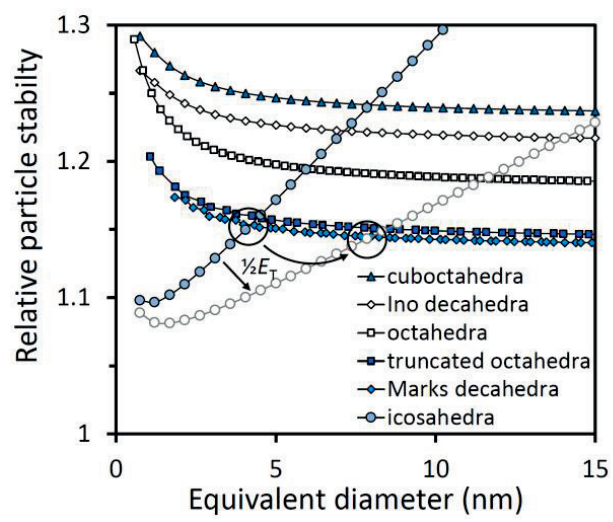

Figure 5.11 Particle stability of gold nanoparticles, calculated with the surface coordination and twinning energy model. The highest stability and lowest energy is for icosahedra when the particles are small, while Marks decahedra become the most stable nanoparticles for large particle sizes. The location of the crossover point is strongly determined by the value of the internal strain $\left(E_{T}\right)$, which contributes strongly to the energy of icosahedra particles at increasing particle size. In case of a $50 \%$ lower internal strain (open spheres), the crossover point of icosahedra with Marks decahedra may easily shift from about $\sim 4 \mathrm{~nm}$ to $\sim 8 \mathrm{~nm}$, as indicated by the arrow. The relative stability is defined as a relative energy, using as reference a spherical particle of equal mass $m$, mass density $\rho$, and number of atoms $N_{\mathrm{T}}\left(m=M \cdot N_{\mathrm{T}} / N_{\mathrm{A}}\right)$ and having a surface area $\left.A=(6 / \pi \cdot m / \rho)^{2 / 3}\right)$ and a surface energy $\gamma_{[111]}\left(\mathrm{J} \mathrm{\textrm {m } ^ { - 2 } )}\right.$ contributing an energy $\gamma_{[111]} A$.

In Figure 5.11, we present, in addition to the particle geometries given in Table 1, also Marks decahedra (defined in Section D5 of Appendix D). The latter have a lower excess energy than standard truncated (Ino) decahedra due to selective removal of the high-energy edge atoms. For these Marks decahedra, the edge-lengths were optimized for obtaining the highest stability; edge-lengths of the optimized geometries are given in the supporting information (Table D5). A similar optimization was done for the truncated octahedra of Figure 5.11.

Figure 5.11 reveals that the icosahedron is the most stable shape up to a particle size of $\sim 4 \mathrm{~nm}$. This can be attributed to the presence of a surface with only [111] faces, having the highest stability (Figure 5.1). The contribution of internal energy is initially still small but it increases with size exponentially, mainly due to the internal stress $\Delta E_{\mathrm{T}}$ as discussed at Figure 5.8. That energy contribution has been parameterized for relatively small gold nanoparticles $(<6 \mathrm{~nm})$ using only one dataset. If the internal stress is actually smaller, icosahedra will remain the stable geometry over a larger size range, as illustrated in Figure 5.11 by the light grey open 
spheres. It illustrates the importance of the energy contribution of stress in the stability of icosahedra.

The crossover point at $\sim 4 \mathrm{~nm}$ between icosahedra and Marks decahedra is in excellent agreement with the results of the quantitative phase map developed by Barnard et al. ${ }^{37}$ These results are supported by observations of structural transition in gold nanoparticles between 7 and $12 \mathrm{~nm}$, from icosahedral and single-crystalline to a decahedral structure. ${ }^{37}$ Barnard et al. ${ }^{37}$ additionally predict a second crossover point between Marks decahedra and truncated octahedra at around $15 \mathrm{~nm}$. This is not seen in our approach. As the twinning energy model was calibrated for nanoparticles at sizes below $6 \mathrm{~nm}$, a strain energy which becomes significant at larger sizes may be found in decahedra, leading to lower stabilities at larger size. Computational data of larger particles are needed to confirm this.

\subsection{Conclusions}

In this work, we have studied the relationship between the coordination of surface atoms and their energy. It is shown that the surface density of broken first-neighbor bonds is proportional to the energy of surface atoms (Figure 5.1) with a relatively high coordination at the low index crystal faces. However, at lower coordination, the relationship is no longer linear due to an increase in bond-strength with decreasing coordination (Figure 5.2). A root function can be used to predict atomic energies using only the coordination number and the energy of an uncoordinated atom $E_{0}$ (eq 5.2).

By summing the atomic energies for the surface atoms of a particle (eq 5.3), the energy of nanoparticles can be found. This coordination (CN) model explains the surface energy for monocrystalline noble metal nanoparticles very well (Figures 5.4 and 5.5). Our analysis reveals that the zero-coordination energy $E_{0}$ is approximately $15 \%$ higher than the cohesive energy, as previously found by Methfessel et al. ${ }^{48}$ The excellent agreement between the coordination model and computational data implies that the breaking of first-neighbor bonds is the dominant contributing factor for surface energy.

The $\mathrm{CN}$ model can be used to allocate surface energy contributions to specific surface atoms (Figure 5.6). While corner atoms have a much higher energy than the other atoms, their overall contribution to surface energy is limited due to their low abundance. However, edge atoms contribute significantly throughout the entire nanoscale $(1-100 \mathrm{~nm})$. This finding emphasizes the importance of accounting for edge effects in thermodynamic models.

The $\mathrm{CN}$ model can be used to distinguish external from internal energy contributions (Figure 5.7). Application reveals a clear size dependency of twinning energy when particles increase in size. For truncated decahedra, these trends are well-explained by assigning energy contributions to the twin-plane atoms, while for icosahedra all atoms participate in an additional strain energy contribution. The latter is much higher in icosahedra than that of the 
twin-planes (Figure 5.8), and is the main contributor to low stability of icosahedra at larger size.

The surface coordination model can also be applied to predict the surface energy of macroscopic crystal faces of solid FCC metals. This prediction uses the experimental enthalpy of atomization as solely input. Thus calculated values are in excellent agreement with surface tension data for solid-gas interface extrapolated from literature data for the liquid-gas interface. Moreover, our model calculations can contribute to the evaluation of MO/DFT derived surface energies. According to our model, surface energies for a range of low-index faces calculated in literature with DFT-LDA are significantly better than those found with DFTGGA (Figure 5.9), in agreement with existing opinions in literature.

Besides predictions for crystal faces, our model can also predict overall surface energies for nanoparticles with a range of shapes and sizes (Figure 5.10). This calculation additionally requires consistent thermodynamic scaling, ${ }^{35}$ revealing a Tolman length of about -0.015 to $-0.019 \mathrm{~nm}$ for gold and silver nanoparticles. A negative value of Tolman length illustrates our finding that surface enthalpy of non-twinned particles increases at smaller sizes.

Finally, with our model for coordination and twinning energy, the stability of various particle geometries can be evaluated (Figure 5.11). The results show stability of icosahedra at sizes below $4 \mathrm{~nm}$, and stability of Marks decahedra at larger sizes. The precise value of the crossover point is highly dependent on the energy contribution of internal strain.

By using a mechanistic understanding of surface energy and excess particle energy, the surface coordination and twinning model is demonstrated to be a powerful tool to interpret the data obtained with computational methods. It allows a comparison between results obtained by different first principle and empirical methods, with a high level of detail. Data such as the energy contribution of corner, edge, and face atoms, as well as twinning and internal strain can be calculated with a fair amount of certainty, and may be used to understand where differences between the various methods arise. In conclusion, our approach significantly improves the broad understanding of the energetics of nanoparticles in general. 


\subsection{References}

1. T. Zhang, H. Zhao, S. He, K. Liu, H. Liu, Y. Yin and C. Gao, ACS Nano, 2014, 8, 7297-7304.

2. J. Watt, S. Cheong, M. F. Toney, B. Ingham, J. Cookson, P. T. Bishop and R. D. Tilley, ACS Nano, 2009, 4, 396-402.

3. S. Wang, N. Omidvar, E. Marx and H. Xin, Physical Chemistry Chemical Physics, 2018, 20, 6055-6059.

4. J. R. Adleman, D. A. Boyd, D. G. Goodwin and D. Psaltis, Nano letters, 2009, 9, 4417-4423.

5. W. H. Hung, M. Aykol, D. Valley, W. Hou and S. B. Cronin, Nano letters, 2010, 10, 13141318.

6. J. W. Kang, P. T. So, R. R. Dasari and D. K. Lim, Nano letters, 2015, 15, 1766-1772.

7. G. H. Chen, W. Y. Chen, Y. C. Yen, C. W. Wang, H. T. Chang and C. F. Chen, Analytical chemistry, 2014, 86, 6843-6849.

8. W. T. Koo, S. Qiao, A. F. Ogata, G. Jha, J. S. Jang, V. T. Chen, I. D. Kim and R. M. Penner, ACS Nano, 2017, 11, 9276-9285.

9. P. Chen, M. T. Chung, W. McHugh, R. Nidetz, Y. Li, J. Fu, T. T. Cornell, T. P. Shanley and K. Kurabayashi, ACS Nano, 2015, 9, 4173-4181.

10. A. Belushkin, F. Yesilkoy and H. Altug, ACS Nano, 2018, DOI: 10.1021/acsnano.8b00519.

11. C. L. Huang, I. L. Hsiao, H. C. Lin, C. F. Wang, Y. J. Huang and C. Y. Chuang, Environmental research, 2015, 136, 253-263.

12. E. J. Park, E. Bae, J. Yi, Y. Kim, K. Choi, S. H. Lee, J. Yoon, B. C. Lee and K. Park, Environmental Toxicology and Pharmacology, 2010, 30, 162-168.

13. K. Schlich, T. Klawonn, K. Terytze and K. Hund-Rinke, Environmental Sciences Europe, 2013, 25, 17.

14. M. J. C. van der Ploeg, R. D. Handy, P. L. Waalewijn-Kool, J. H. J. van den Berg, Z. E. Herrera Rivera, J. Bovenschen, B. Molleman, J. M. Baveco, P. Tromp, R. J. B. Peters, G. F. Koopmans, I. M. C. M. Rietjens and N. W. van den Brink, Environmental Toxicology and Chemistry, 2014, 33, 743-752.

15. X. Yang, A. P. Gondikas, S. M. Marinakos, M. Auffan, J. Liu, H. Hsu-Kim and J. N. Meyer, Environ. Sci. Technol., 2011, 46, 1119-1127.

16. S. Böhme, H. J. Stärk, T. Reemtsma and D. Kühnel, Environmental Science: Nano, 2015, 2, 603-614.

17. C. Kataoka, T. Ariyoshi, H. Kawaguchi, S. Nagasaka and S. Kashiwada, Environmental Science: Nano, 2015, 2, 94-103.

18. H. C. Poynton, J. M. Lazorchak, C. A. Impellitteri, B. J. Blalock, K. Rogers, H. J. Allen, A. Loguinov, J. L. Heckman and S. Govindasmawy, Environ. Sci. Technol., 2012, 46, 62886296.

19. K. An and G. A. Somorjai, ChemCatChem, 2012, 4, 1512-1524.

20. K. L. Kelly, E. Coronado, L. L. Zhao and G. C. Schatz, The Journal of Physical Chemistry B, 2003, 107, 668-677.

21. B. Molleman and T. Hiemstra, Environmental Science: Nano, 2017, 4, 1314-1327.

22. T. Hiemstra, Geochimica et Cosmochimica Acta, 2015, 158, 179-198.

23. P. Liu, R. Qin, G. Fu and N. Zheng, Journal of the American Chemical Society, 2017, 139, 2122-2131.

24. W. Zhang, Y. Liu, R. Cao, Z. Li, Y. Zhang, Y. Tang and K. Fan, Journal of the American Chemical Society, 2008, 130, 15581-15588.

25. B. Wiley, Y. Sun, B. Mayers and Y. Xia, Chem. Eur. J., 2005, 11, 454-463. 
26. R. Tran, Z. Xu, D. W. Balachandran Radhakrishnan, W. Sun, K. A. Persson and S. P. Ong, Scientific Data, 2016, 3.

27. L. Vitos, A. Ruban, H. L. Skriver and J. Kollar, Surface Science, 1998, 411, 186-202.

28. I. Galanakis, G. Bihlmayer, V. Bellini, N. Papanikolaou, R. Zeller, S. Blügel and P. Dederichs, EPL (Europhysics Letters), 2002, 58, 751.

29. I. Galanakis, N. Papanikolaou and P. Dederichs, Surface science, 2002, 511, 1-12.

30. N. E. Singh-Miller and N. Marzari, Physical Review B, 2009, 80, 235407.

31. M. Fishman, H. L. Zhuang, K. Mathew, W. Dirschka and R. G. Hennig, Physical Review B, 2013, 87, 245402.

32. J. Wang and S.-Q. Wang, Surface Science, 2014, 630, 216-224.

33. A. Patra, J. E. Bates, J. Sun and J. P. Perdew, Proceedings of the National Academy of Sciences, 2017, 201713320.

34. L. Vega, J. Ruvireta, F. Viñes and F. Illas, Journal of chemical theory and computation, 2018, 14, 395-403.

35. B. Molleman and T. Hiemstra, Physical Chemistry Chemical Physics, 2018, 20, 2057520587.

36. A. Barnard, The Journal of Physical Chemistry B, 2006, 110, 24498-24504.

37. A. S. Barnard, N. P. Young, A. I. Kirkland, M. A. Van Huis and H. Xu, ACS Nano, 2009, 3, 1431-1436.

38. H. Hofmeister, Encyclopedia of nanoscience and nanotechnology, 2004, 3, 431-452.

39. J. L. Huang, Z. Li, H. H. Duan, Z. Y. Cheng, Y. D. Li, J. Zhu and R. Yu, Journal of the American Chemical Society, 2017, 139, 575-578.

40. Q. Zhang, J. Xie, J. Yang and J. Y. Lee, ACS Nano, 2009, 3, 139-148.

41. F. Silly and M. R. Castell, ACS Nano, 2009, 3, 901-906.

42. T. Liu, P. Jiang, Q. You and S. Ye, CrystEngComm, 2013, 15, 2350-2353.

43. A. S. Barnard and L. A. Curtiss, ChemPhysChem, 2006, 7, 1544-1553.

44. B. Medasani, Y. H. Park and I. Vasiliev, Physical Review B, 2007, 75, 235436.

45. B. Medasani and I. Vasiliev, Surface Science, 2009, 603, 2042-2046.

46. D. Liu, J. Lian and Q. Jiang, The Journal of Physical Chemistry C, 2009, 113, 1168-1170.

47. N. Mardirossian and M. Head-Gordon, Molecular Physics, 2017, 115, 2315-2372.

48. M. Methfessel, D. Hennig and M. Scheffler, Applied Physics A, 1992, 55, 442-448.

49. M. Methfessel, D. Hennig and M. Scheffler, Physical Review B, 1992, 46, 4816.

50. J. Cox, D. D. Wagman and V. A. Medvedev, CODATA key values for thermodynamics, Hemisphere Publishing Corp., New York, 1989.

51. R. Schumm, D. Wagman, S. Bailey, W. Evans and V. Parker, National Bureau of Standards, USA, 1973.

52. L. Pauling, Journal of the American Chemical Society, 1929, 51, 1010-1026.

53. S. Xiong, W. Qi, B. Huang, M. Wang, Y. Cheng and Y. Li, Journal of Computational and Theoretical Nanoscience, 2011, 8, 2477-2481.

54. S. Ali, V. S. Myasnichenko and E. C. Neyts, Physical Chemistry Chemical Physics, 2016, 18, 792-800.

55. C. Mottet, G. Tréglia and B. Legrand, Surface science, 1997, 383, L719-L727.

56. I. K. Suh, H. Ohta and Y. Waseda, Journal of Materials Science, 1988, 23, 757-760.

57. S. Sauerland, K. Eckler and I. Egry, Journal of materials science letters, 1992, 11, 330-333.

58. J. Brillo and I. Egry, Journal of materials science, 2005, 40, 2213-2216.

59. M. Abbasi, J. Lee, M. Shin, Y. Kim and Y. Kang, Applied Surface Science, 2014, 313, 116122. 
60. T. Matsumoto, H. Fujii, T. Ueda, M. Kamai and K. Nogi, Measurement Science and Technology, 2005, 16, 432.

61. J. Brillo, G. Lauletta, L. Vaianella, E. Arato, D. Giuranno, R. Novakovic and E. Ricci, Isij International, 2014, 54, 2115-2119.

62. J. Lee, W. Shimoda and T. Tanaka, Materials transactions, 2004, 45, 2864-2870.

63. R. Novakovic, E. Ricci, D. Giuranno and A. Passerone, Surface science, 2005, 576, 175187.

64. R. Sangiorgi, M. Muolo and A. Passerone, Acta Metallurgica, 1982, 30, 1597-1604.

65. S. Ozawa, K. Morohoshi, T. Hibiya and H. Fukuyama, Journal of Applied Physics, 2010, 107, 014910.

66. T. Dubberstein and H. P. Heller, High Temperatures-High Pressures, 2015, 44, 393-406.

67. I. Egry, G. Lohoefer, E. Schwartz, J. Szekely and P. Neuhaus, Metallurgical and Materials Transactions B, 1998, 29, 1031-1035.

68. R. Novakovic, E. Ricci, F. Gnecco, D. Giuranno and G. Borzone, Surface science, 2005, 599, 230-247.

69. W. R. Tyson and W. A. Miller, Surface Science, 1977, 62, 267-276. 


\section{Chapter 6}

General discussion

Bastiaan Molleman 


\subsection{Preface}

The premise of this thesis has been to understand the fate of engineered inorganic nanoparticles in the environment. Within this premise, I selected silver nanoparticles (AgNPs) as a topic of study, as they appeared to represent the most clear environmental risk, due to their general application in consumer products, ${ }^{1}$ relative stability, and proven toxicity to a variety of organisms across the food chain..$^{2-7}$ Moreover, AgNPs are a metallic material and therefore have chemical and physical properties that are different from the general class of minerals in soils. This, in combination with the fascinating redox properties of silver, being capable of switching between a metallic and an ionic state within environmentally relevant redox-conditions (see Figure 6.1), immediately captured my scientific interest.

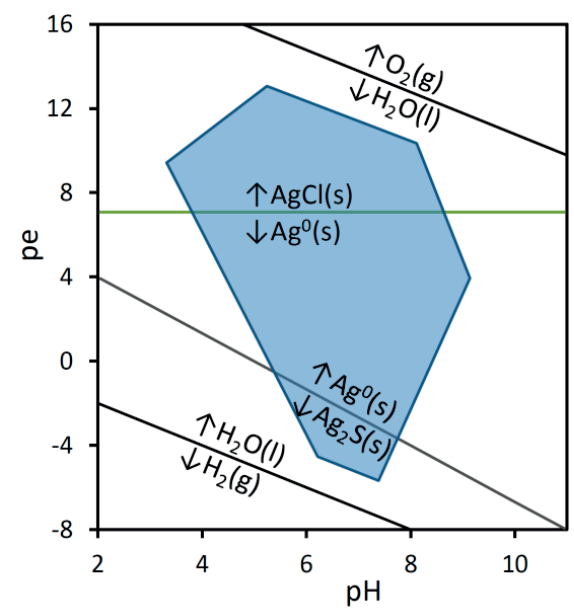

Figure 6.1 Redox diagram showing the stability of metallic (bulk) silver as a function of $\mathrm{pH}$ and pe. The green line shows the phase change of metallic silver to silver chloride, according to $\mathrm{Ag}^{0}(\mathrm{~s})+\mathrm{Cl}^{-} \leftrightarrow$ $\mathrm{AgCl}(\mathrm{s})+\mathrm{e}^{-}$, calculated for a chloride concentration of $0.5 \mathrm{mM}$; the grey line shows the phase change of metallic silver to silver sulfide, according to $2 \mathrm{Ag}^{0}(\mathrm{~s})+\mathrm{SO}_{4}{ }^{2-}(\mathrm{aq})+8 \mathrm{H}^{+} \leftrightarrow \mathrm{Ag}_{2} \mathrm{~S}(\mathrm{~s})+4 \mathrm{H}_{2} \mathrm{O}(\mathrm{l})+6 \mathrm{e}^{-}$, calculated for a sulfate concentration of $1 \mathrm{mM}$. Gibbs free energy values were taken from Haynes et al. ${ }^{8}$ The blue area represents the most predominant redox conditions in the environment.

It is evident that the environmental fate of nanoparticles is strongly affected by a variety of interactions with particulates and solutes found in environmental matrices. These interactions will exclusively take place, where a particle and its surrounding environment come into contact with each other: the interface. This is a somewhat ambiguous term, which we here take to mean the combined surfaces the solid nanoparticle and the surrounding aquatic phase, where material properties are unlike those in the bulk. In the early phases of my research, it became clear to me that if I was to make a relevant contribution to our understanding of the fate of nanoparticles in the environment, it would be inevitable to focus on the interface, and interpret results from that perspective. 
Even within the few atomic layers that comprise the interface, there is a wide array of topics to be studied, such as adsorption of organic matter and capping agents, complexation of organic and inorganic ligands, surface structure, water ordering, surface charge, and in the case of silver nanoparticles, oxidation and dissolution and potentially reduction and surfaceprecipitation. All of these phenomena significantly influence the environmental fate of silver nanoparticles and deserve further attention, for that reason as well as for a broader scientific interest, applied and fundamental. Two topics, however, are particularly relevant.

Firstly, the surface structure of silver nanoparticles, which will have a dominant role in the interface, being the only rigid factor. Adsorption and complexation, surface charge and water ordering are all under direct influence of the structural arrangement of surface atoms. Secondly, from the perspective of environmental health, oxidation and dissolution are pivotal processes, as the release of silver ions is the primary reason for silver nanoparticle toxicity. ${ }^{9,} 10$

The above two topics are intrinsically linked, as oxidation is an interface process, and will therefore be controlled, to a large degree, by the surface structure. On the other hand, oxidation may lead to dissolution or the formation of oxides, and is certain to affect the surface structure. A mechanistic approach to either of these topics will be incomplete if the other is not included.

A third essential factor to take into account is size dependence of the chemical properties of nanoparticles, such as chemical stability. AgNPs have a higher energy per atom than bulk silver. Therefore, small particles are expected to be more soluble and this fundamental property is attributed to surface (Gibbs free) energy. The energy contribution of the surface will be approximately proportional with the specific surface area, leading to a size dependent Gibbs free energy change of the dissolution reaction.

The surface Gibbs free energy of AgNPs is strongly dependent on the contributions of crystal faces, edges, and corners. In addition, the particle energy may have internal energy contributions that are related to the atomic arrangements. The shape of AgNPs determines the types of faces, edges and corners as well as the internal structure. Conversely, the combined energetic effects of these characteristics determine the equilibrium shape. There is thus a complex interplay between shape, size, and surface energy; a crucial step in understanding this is interpreting the various contributions to the overall energy of AgNPs. Doing so will elucidate the impact of size, shape, and internal structure on AgNP stability, and will thus be pivotal for our understanding of AgNP behavior.

In this thesis, the above topics have been studied in great detail, both experimentally and theoretically, and from many different perspectives. The result is a consistent, overarching theoretical framework with relevance that transcends the environmental sciences and silver nanoparticle research alone. Nevertheless, the ultimate objective is to understand the environmental fate of silver nanoparticles. In this chapter, we will briefly revisit our most 
important findings and subject them to critical reflection. The significance for behavior of AgNPs in the environment will be discussed.

\subsection{Surface structure}

One of the biggest unanswered questions in the study of silver nanoparticles has been their long-term stability under aqueous conditions in the presence of oxygen. Thermodynamically, up to around $1 \mathrm{~mol} \mathrm{~L}^{-1}$ of silver can dissolve from silver nanoparticles at circumneutral $\mathrm{pH}$ upon reaction with oxygen. However, literature data ${ }^{11-16}$ consistently show that, after a period of fast initial dissolution, the release of $\mathrm{Ag}^{+}$ions slows down and eventually stops. The silver nanoparticles can then be seen to remain stable for periods up to several months. ${ }^{15,17}$ The most obvious explanation for this peculiar behavior is the presence of a surface layer of Agoxide ${ }^{13}$ that regulates the $\mathrm{Ag}^{+}$concentration and prevents oxygen from reacting with the metallic core of AgNPs, analogous to how metallic aluminum is stabilized.

\subsubsection{How certain can we be that there is a layer of oxide on the surface?}

The idea of the presence of a surface oxide on silver nanoparticles in aqueous suspension has been around for some time. Surface charge ${ }^{18}$ ion relase, ${ }^{19}$ and oxidation resistance ${ }^{13}$ have all been attributed to the presence of a layer of silver oxide on the AgNP surface. Such a surface oxide layer may be extremely thin and potentially strongly influenced by the presence of water. Therefore, direct observation of such a layer requires dedicated in-situ spectroscopy or in-situ imaging techniques. X-ray spectroscopy to grasp the structure of AgNP did not provide evidence for the presence of a surface oxide layer. ${ }^{20}$ Others ${ }^{21}$ have observed structural changes at the surface of metallic Ag when targeted with oxygen in vacuum. However, these results remain inconclusive for AgNPs in suspensions, as these measurements were taken in absence of an aqueous phase.

The most important argument for presence of a layer of silver oxide is, to me, the long-term stability of silver nanoparticles, which can only be understood if oxygen is prevented from reacting with metallic silver. Although capping agents are sometimes thought to seal off the surface from oxygen, ${ }^{15}, 22$ stabilization is also observed in experiments where capping agents are not present. ${ }^{19}$ The latter also negates reduction by organics as an explanation for particle persistence. A surface oxide is formed from the metallic silver and can thus be universally present. However, it is likely to be of an extraordinary nature, as classical $\mathrm{Ag}_{2} \mathrm{O}$ is highly soluble.

More direct evidence of the formation of an oxidized surface at aqueous conditions is provided by spectroscopic measurements by Henglein. ${ }^{23} \mathrm{~A}$ redshift of the plasmon resonance band is observed when highly reduced, i.e. fully metallic, silver nanoparticles are oxidized with added $\mathrm{Ag}^{+}$ions or by exposure to air. The limited level of oxidation indicated by the redshift is in agreement with oxidation confined to the AgNP surface. 


\subsubsection{Subvalent surface layer}

If it is indeed an oxidized layer that stabilizes the surface of silver nanoparticles against further oxidation, it must have an extraordinary structure. While only a limited amount of $\mathrm{Ag}_{2} \mathrm{O}$ can be dissolved in water, this limitation is due to the strong increase of the $\mathrm{pH}$ when the oxide is added to water. If the $\mathrm{pH}$ is maintained at circumneutral conditions, it is relatively soluble $\left(\log K_{\mathrm{AgOH}}=-7.7\right)^{24}$ and not stable at the experimental conditions where AgNP dissolution reaches its maximum. ${ }^{17}$ Moreover, release of $\mathrm{Ag}^{+}$ions from AgNP requires the presence of oxygen, $, 13,14$ excluding $\mathrm{Ag}_{2} \mathrm{O}$ as the source of $\mathrm{Ag}^{+}$release. In Chapter 2, we propose the presence of subvalent, i.e. partially oxidized, $\mathrm{Ag}$ at the surface as a stable (semi-)oxidized layer.

Subvalency is a property found in particular silver compounds, where the silver has a valence between 0 and 1 as a result of delocalized electrons. This characteristic is observed in a number of silver compounds with a doubly layered Ag structure, as discussed in Chapter 2. Subvalent silver or semi-metallic silver has a non-integer value for the valence, typically between $+1 / 3$ and $2 / 3$, whereas the classical oxidation states of silver are $0,{ }^{25} 1,{ }^{26} 2,{ }^{27}$ or $3 .{ }^{28,} 29$ The full continuum of bond valences can be described with a relationship to bond length, which shows a single trend in which subvalent and fully oxidized Ag minerals seamlessly fit together (see Figure 2.2).

In subvalent silver structures such as $\mathrm{Ag}_{3} \mathrm{O}(\mathrm{s}),{ }^{30} \mathrm{Ag}_{2} \mathrm{NiO}_{2}(\mathrm{~s}),{ }^{31}$ and $\mathrm{Ag}_{2} \mathrm{~F}(\mathrm{~s}),{ }^{32}$ a hexagonal arrangement of silver is invariably seen, with three subvalent silver atoms that coordinate to a central anion $\left(\mathrm{O}^{2-}, \mathrm{F}^{-}\right) \cdot{ }^{30-32} \mathrm{~A}$ similar hexagonal $\mathrm{Ag}$ arrangement is also seen in the crystal structure of metallic silver and at the [111] faces. The latter have the highest stability, as discussed in Chapter 5, and will be the prominent surface of small AgNPs. It suggests that subvalency could occur in the upper layers of this surface. The formation of a surface with semi-metallic Ag properties allows a smooth transition of the oxidation state in the AgNPwater interface from metallic in the mineral bulk to ionic in the solution.

Subvalent silver appears to be the only viable candidate for the presence of an oxidized surface structure. As mentioned, ordinary $\mathrm{Ag}_{2} \mathrm{O}$ is far too soluble, and higher oxidation states, will not be formed at ambient oxygen concentrations. A subvalent silver oxide can only dissolve after reaction with oxygen, which is in agreement with the observation that AgNP dissolution is nearly nonexistent in the absence of dissolved oxygen. ${ }^{9,13}$ No detailed structures have been reported for silver surfaces under aqueous conditions. There are indications of subvalency, even in absence of water. In oxide structures formed at reaction with atomic oxygen, reported by Martin et al., ${ }^{21}$ oxygen appears to be coordinated not only to silver atoms in the reconstructed outer layer, but also to atoms in the underlying hexagonal layer. It leads to a high coordination for the oxide anion $\left(\mathrm{O}^{2-}\right)$, suggesting low bond valence and presence of subvalent silver ions in these structures. Thus, while no subvalent surface structure has been explicitly reported for suspended silver nanoparticles, there is evidence to support subvalency in an oxidic surface layer on metallic silver. 


\subsubsection{Two Ag oxidation states: two surface structures}

The spectroscopic measurements by Henglein ${ }^{23}$ mentioned earlier suggest the existence two possible oxidation states on the AgNP surface. A mild surface oxidation can occur in contact with added $\mathrm{Ag}^{+}(\mathrm{aq})$, oxidation with $\mathrm{O}_{2}$ may lead to a higher oxidation state.

The change in the wavelength of maximum absorbance $\lambda_{\max }$ of the plasmon resonance band can be interpreted in terms of decreased electron density. At mild oxidation by addition of $\mathrm{Ag}^{+}$, the electron density indicated by the red-shift of $\lambda_{\max }$ observed by Henglein ${ }^{33}$ suggests a surface charge close to $\sim 1 / 3$ per $\mathrm{Ag}$, when scaled to the surface area. This can be interpreted as the presence of subvalent $\mathrm{Ag}_{3}{ }^{+}$surface sites. These sites may bind a hydroxyl ion as ligand to compensate the surface charge, leading to the surface structure with $\equiv \mathrm{Ag}_{3} \mathrm{OH}$ groups proposed in Chapter 2.

$\mathrm{MO} / \mathrm{DFT}$ simulations presented in Chapter 2 show that an $\mathrm{Ag}_{13}$ nanocluster with $\equiv \mathrm{Ag}_{3} \mathrm{OH}$ groups and a Ag subvalency of $+1 / 3$ is strongly stabilized with respect to a fully metallic $\mathrm{Ag}_{13}{ }^{0}$ cluster. The same cluster with a higher subvalency of $+2 / 3$ and the presence of $O$ ligands to compensate this charge, is far less stable. It suggests that a higher subvalent oxidation state is not simply reached while keeping the same structure. Therefore, restructuring of the $\equiv \mathrm{Ag}_{3} \mathrm{OH}$ surface layer and incorporation of oxygen ions has been proposed for AgNP with a higher oxidation state.

The second oxidation state is obtained under more strongly oxidative conditions and correspondingly has roughly the double surface charge density. The structure of this second oxidation state is, as of yet, not well-understood. The higher surface charge density may point to surface atoms with a higher valence, or presence of subvalent silver in both the surface and subsurface layers. A number of possible structures can thus be envisioned which could explain the high surface oxidation state. In Chapter 2, a structure with subsurface oxygen and subvalent silver in two layers is presented, consisting of the species $\equiv \mathrm{Ag}_{6} \mathrm{O}$ (see Figure $2.1 \mathrm{c}$ ); similar species are thought to form during heating of macroscopic silver surfaces in presence of oxygen. ${ }^{34}$ In Chapter 3, that view is amended to a surface structure with $\equiv \mathrm{Ag}_{3} \mathrm{OH}$ groups at two different layers in the interface. The formation of this species leads to steps at the surface comparable to the surface oxides found on metallic $\mathrm{Ag}$ at water free conditions. ${ }^{15}$

The presence of $\mathrm{OH}$ groups at the AgNP surface under aqueous conditions with dissolved oxygen has not yet been confirmed by spectroscopy or imaging techniques. Such information is also lacking for the proposed restructuring upon stronger oxidation that may occur when the surface is exposed to oxygen under aqueous conditions at low $\mathrm{pH}$. The observation of a surface oxide layer on AgNPs under aqueous conditions requires highly sensitive in-situ techniques. The identification of the precise surface structure will be a future challenge, before a more definite description of the AgNP-water interface can be given. Nevertheless, the present view developed in Chapter 2 is already of great value to interpret the dissolution behavior of AgNP under various solution conditions in a consistent manner that includes a suite of information collected in literature for this process, as further discussed in Section 6.3. 


\subsubsection{Oxide structures on other surfaces}

The structural analysis of Chapter 2 has used the [111] face as model to develop an atomic view for the AgNP water interface and both oxidation states. The [111] surface has the lowest surface energy and is the most important crystal facet on the most stable particle geometries for AgNPs without subvalency. However, other faces may also be found on AgNPs, especially in the higher size range where the surface energy contributes less to overall stability.

I have not presented any specific surface structure for a potential subvalent surface layer on the other crystal faces. However, the stabilization of $\mathrm{Ag}^{+}$concentrations is also found for larger AgNPs, where such surfaces are expected to occur. It seems highly probable that these, too, are passivated by an oxidized surface layer.

A possibility may be restructuring of certain crystal faces to more stable structures. It has been observed that clean [100] surfaces of e.g. platinum reconstruct to form an overlayer with the hexagonal arrangement found on the [111] face. ${ }^{35}$ The lower surface energy of the [111] face is seen as the driving force for this construction. ${ }^{36}$ Rearrangement of the position of surface atoms upon oxide formation was also observed by Martin et al. ${ }^{21}$ These observations suggest that it would be possible that the [100] face is covered by a hexagonally arranged $\equiv \mathrm{Ag}_{3} \mathrm{OH}$ layer. In other words, the same surface oxide structure could be formed on e.g. the [100] face as on the [111] face. However, there would be considerable misalignment between a metallic [100] face and a hexagonally arranged subvalent overlayer, leading to a higher surface energy.

In Chapter 5, the relative stability of different shapes of metallic nanoparticles is assessed using surface energy of the different faces as one of the main contributors. The predictions may not be valid for AgNPs with subvalent surface structures. Predictions of stable geometries having a surface with subvalent silver cannot yet be done as the change of surface Gibbs free energy due to formation of subvalent $\mathrm{Ag}$ is presently unknown, and may be different for the different surfaces due to e.g. the presence of a reconstructed overlayer, as discussed above. In other words, the interaction energy between the subvalent surface layer and the underlying metal may be different for the different crystal faces. In case of a hexagonal subvalent surface structure on all faces, the stability of the [111] face, relative to the other faces, could be increased even further.

In my description of the surface structure (Chapters 2 and 3), I assert that icosahedral particles may be the dominant shape, due to a low surface energy of the [111] face. However, in the stability diagram of Chapter 5 (Figure 5.11), the stable size range for icosahedra is limited to sizes of $5 \mathrm{~nm}$ and lower. At larger size, the internal strain due to twinning leads to higher excess energy levels than found for other geometries. If the relative stability of the [111] face is increased with respect to other surfaces due to a more favorable interaction with the subvalent surface layer, the stability size-range of icosahedral AgNPs could be extended. One might speculate that this explains why icosahedral AgNPs can be $10 \mathrm{~nm}$ in diameter, while gold and palladium nanoparticles are usually smaller. ${ }^{37}$ 
The above synthesis indicates that analysis of the surface structures of AgNP needs more attention in further work, e.g. by studying single crystal faces with spectroscopy or imaging techniques at ambient conditions or by optimizing surface structures on flat surfaces using $\mathrm{MO} / \mathrm{DFT}$, as done for the $\mathrm{Ag}_{13}(\mathrm{OH})_{4}$ cluster in Chapter 2. The advantage of the latter is that, in addition to a detailed molecular structure, the surface energy of surface structures can be calculated. This could be used to interpret the surface energy change upon formation of a subvalent surface layer and integrate that knowledge into the coordination model developed in Chapter 5.

\subsection{Silver ion release}

As discussed in the general introduction (Chapter 1 ), the release of silver ions is likely the most important mechanism of AgNP toxicity. It is thus absolutely vital for environmental risk assessment to be able to estimate the release of $\mathrm{Ag}^{+}$. The mechanism of $\mathrm{Ag}^{+}$release is a question that has long confounded researchers.

In Chapter 3, a reaction mechanism for $\mathrm{Ag}^{+}$release is presented that is based on the oxidative transformation of the primary subvalent surface oxide $\equiv \mathrm{Ag}_{3} \mathrm{OH}$ groups into a secondary subvalent surface oxide. In the non-equilibrium state, reaction with dissolved oxygen and protons leads to full oxidation of the $\equiv \mathrm{Ag}_{3} \mathrm{OH}$ surface group, which is then released as $\mathrm{Ag}^{+}$ions. This exposes the underlying layer of metallic silver atoms, which, too, reacts with oxygen and protons. The proposed reaction leads to a partial dissolution of this metallic layer, and the formation of a stable secondary structure. The latter has subvalent silver present in two layers, with oxidation of the deeper-lying metallic atoms being possible after partial dissolution of the upper Ag-layer. A schematic representation of this process is given in Figure 6.2. Dissolution will continue until equilibrium is attained between both surface structures and the solution. The major reaction components, i.e. protons, oxygen, silver ions, and the two surface structures, play a major role in determining the total amount of released ionic silver. 


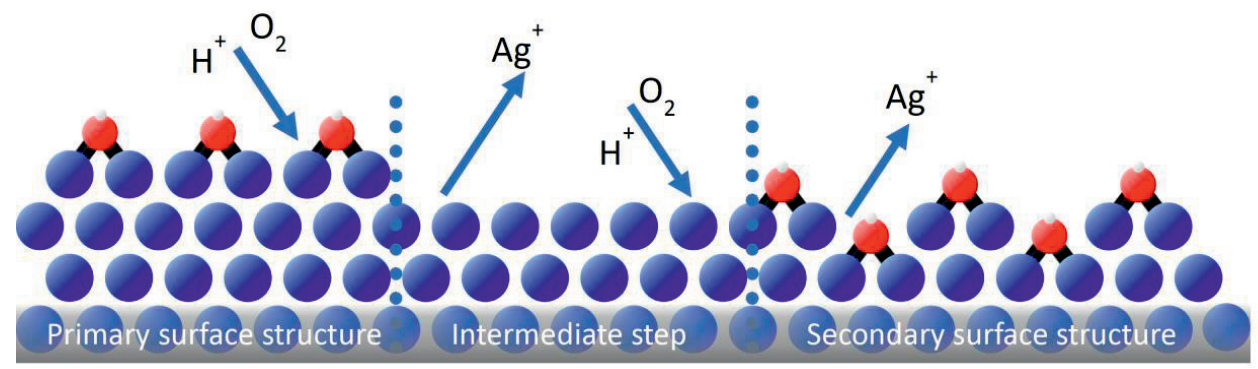

Figure 6.2 Schematic representation of the transformation of the primary surface structure into the secondary. Interaction with oxygen and protons may lead to oxidation of the subvalent $\equiv \mathrm{Ag}_{3} \mathrm{OH}$ groups of the primary surface structure, which is released as $\mathrm{Ag}^{+}$ions. The exposed metallic layer further reacts with oxygen and protons, leading to partial dissolution and the formation of subvalent surface groups over two metallic layers.

\subsubsection{Influence of $\mathrm{pH}$ on $\mathrm{Ag}^{+}$release}

The effect of $\mathrm{pH}$ on the release of $\mathrm{Ag}^{+}$has been known for a long time, and the negative relationship between $\mathrm{pH}$ and AgNP dissolution has been shown on multiple occasions. ${ }^{13,15,16,22}$ However, the relationship between equilibrium $\mathrm{Ag}^{+}$concentrations and $\mathrm{pH}$, which is presented in Chapter 3, had not been established before. At circumneutral $\mathrm{pH}$, where the amount of $\mathrm{Ag}^{+}$released is relatively small, the slope of the relationship is $\log \left[\mathrm{Ag}^{+}\right] / \mathrm{pH}=0.7 \pm 0.1$. This is in agreement with a surface-controlled equilibrium with a stoichiometric exchange ratio of $\mathrm{Ag}^{+} / \mathrm{H}^{+}=1$, typically for the reaction mechanisms proposed in Chapters 2 and 3 . The slope $\log \left[\mathrm{Ag}^{+}\right] / \mathrm{pH}$ is lower than unity due to the influence of the surface species in the chemical equilibrium, as explained in Chapter 3 . The dissolution of a surface site can be written as:

$$
\left.\equiv \mathrm{Ag}: \mathrm{Ag}_{3} \mathrm{OH}^{0}+4 \mathrm{H}^{+}(\mathrm{aq})+a \mathrm{O}_{2}(\mathrm{aq}) \Leftrightarrow\right]^{0}+4 \mathrm{Ag}^{+}(\mathrm{aq})+b \mathrm{H}_{2} \mathrm{O}(\mathrm{l})
$$

In the dissolution, $\equiv \mathrm{Ag}_{3} \mathrm{OH}^{0}$ is removed from the surface and the other $\mathrm{Ag}$ is released from the underlying $\mathrm{Ag}$ of the bulk. The equation, as formulated above, does not take into account the oxidative formation of the secondary surface structure. This requires additional oxygen, as well as water to form the hydroxides.

Despite 4 protons being involved in the reaction, the kinetics of $\mathrm{Ag}^{+}$release are only first order dependent on the proton concentration. The rate limiting step may originate from the protonation of an adsorbed oxygen molecule $\left(\mathrm{O}_{2}\right)$, which is a suggested pathway for the oxygen reduction reaction. ${ }^{38}$ The resulting reactive oxygen species $\mathrm{HO}_{2}$ is a radical and may react at much higher rates.

At low $\mathrm{pH}$, the dissolution is less regular: more scattering in the data is observed for all particle sizes investigated. In Chapter 3, we hypothesize that at low $\mathrm{pH}$, the first release is due to a very fast, irreversible process that only occurs at conditions of strong undersaturation. In this process, large surface cavities are formed which can grow laterally, stripping off a complete 
layer of the particular facet affected. The surface stripping process is rather uncontrolled under the experimental conditions leading to more scattering of the data in the first hours.

The formation of surface cavities involves an energy cost due to an increased surface area, and an energy gain from the dissolution process (see eq 3.11). As shown in Figure 3.6, the balance between both energy contributions shifts with the size of the cavity. There is a critical size after which the energy gain with growth is higher than the energy cost. If initially formed cavities have a distribution of sizes, those of critical size or larger, will spontaneously grow leading to surface stripping, while smaller cavities will tend to close up.

The energy gain of dissolution is related to the saturation of the solution with respect to the dissolution reaction $(Q / K)$, leading to a smaller critical cavity size at conditions of strong undersaturation. Release of $\mathrm{Ag}^{+}$decreases the undersaturation, while a lower $\mathrm{pH}$ increases the undersaturation. As a result, the critical cavity size is smaller at low $\mathrm{pH}$, and there is thus a higher chance for formation of critical cavities. Upon dissolution, $\mathrm{Ag}^{+}$concentrations increase, reducing the probability of formation of additional cavities. As a result, critical cavities will mainly be formed in the initial stages of dissolution. In other words, the release of $\mathrm{Ag}^{+}$may prevent further stripping, which could explain why full dissolution was never observed, even at $\mathrm{pH}<3.5$.

In Chapter 3, the above conceptual model has been approached using an idealized cylindrical cavity with a surface energy of $0.7 \mathrm{~J} \mathrm{~m}^{-2}$ that we estimated from our size dependency of the equilibrium constant of the transformation reaction shown in Figure 3.3b. While the formation of critical cavities can be used for a qualitative understanding of the experimental observations in Chapter 3, this concept has not yet been fully developed or tested in a more comprehensive way. Estimations of the energy changes involved at the formation might be improved along two lines of thoughts, i.e. a thermodynamic or an atomic approach.

From Chapter 4, it has become evident that the value of surface Gibbs free energy that we derived will depend of the position of the thermodynamic surface in the interface. This location is also vital for determining the surface energy contribution in small cavities. In the calculation, the geometry is important and additional model development is probably needed before the physical surface model that we developed in Chapter 4 can be correctly applied to cavities. Alternative to this approach is the direct calculation of the change of energy as a function of the shape and size of the cavity. The $\mathrm{CN}$ model developed in Chapter 5 may be a good tool to derive the energy contribution of the atoms at the edges and corners. In the approach, experimental information about the shape is required. It may lead to a model that describes the Gibbs free energy as a function of cavity size and shape, contributing to a more realistic picture of surface cavitation at the surface of AgNP.

The conceptual model for surface stripping predicts that high release at low $\mathrm{pH}$ can be mitigated by changing the reaction quotient $\left(\mathrm{Ag}^{+}\right) /\left(\mathrm{H}^{+}\right)$. This can be verified experimentally by studying the early release kinetics for systems in which ionic silver is added prior to the onset 
of dissolution. The results can be compared with predictions made by the model, after it is improved by incorporating a more sophisticated description of the energy and geometry of cavities.

\subsubsection{Influence of oxygen on $\mathrm{Ag}^{+}$release}

As mentioned above, at eq 6.1, the total number of oxygen molecules consumed by the dissolution reaction will depend on the secondary structure that is formed. The precise relationship between oxygen consumed and the secondary surface structure is formulated in the general reaction in Chapter 3 (eq 3.1). The low energy of the $\operatorname{Ag}_{13}(\mathrm{OH})_{4}$ nanocluster (Figure 2.5) suggests that a primary structure consisting of a monolayer of $\equiv \mathrm{Ag}_{3} \mathrm{OH}$ groups could be highly stable. However, due to the complexity, similar calculations could not be performed for a potential secondary structure with subvalent silver present in two atomic layers. As a result, the secondary is poorly understood High precision data on the relation between the oxygen consumption and released $\mathrm{Ag}^{+}$may lead to a better understanding of the secondary surface structure. Such data may be obtained by performing additional dissolution experiments at a range of oxygen concentrations, or by measuring the decrease in oxygen concentration during dissolution in airtight sample containers. A complication in such an experimental approach may be the formation of reactive oxygen species (ROS), which may need to be monitored in addition to the oxygen concentration. The influence of oxygen on the final $\mathrm{Ag}^{+}$concentrations was not investigated in this thesis, but various publications have shown that at exclusion of oxygen, $\mathrm{Ag}^{+}$release is strongly inhibited. ${ }^{9,14,22}$ This confirms that oxygen is required for the release of $\mathrm{Ag}^{+}$, but the observations made in literature reveal very little about the mechanism of dissolution.

In the kinetic analyses of the dissolution process (Chapter 3), I proposed that the adsorption of molecular oxygen is a rate-limiting step and that initially a certain amount of oxygen is already adsorbed. These assumptions are needed to describe the $\mathrm{pH}$ dependency of the $\mathrm{Ag}^{+}$ release rate, particularly at the short reaction times, as is discussed in Chapter 3. It explains why the dissolution rate constant is much higher in the first days than in the later stages, as is repeatedly reported in literature. ${ }^{16,39}$ According to the model, the amount of adsorbed oxygen determines the initial rate of dissolution, not the free concentration of molecular oxygen in solution. Of course, both are initially related by an adsorption equilibrium in the stock AgNP suspension, which becomes disturbed at a fast consumption due to dissolution upon dilution and acidification.

Mittelman et al. ${ }^{13}$ present data on the $\mathrm{Ag}^{+}$release rate at three different $\mathrm{O}_{2}$ concentrations, but their data is quite irregular, showing a poor correlation between time and $\mathrm{Ag}^{+}$ concentration in the initial stages, and little difference between the different $\mathrm{O}_{2}$ concentrations. The rate constants for adsorption of oxygen in Chapter 3 suggest that the six hours of reaction in solutions with lower oxygen concentrations are insufficient to equilibrate surface bound oxygen with the lower solution concentrations. Ho et al. ${ }^{40}$ found that the rate of release is first order dependent on the oxygen level in presence of a catalytic amine, but a 
different $\mathrm{O}_{2}$-dependency may apply to non-catalyzed dissolution. The above indicates that there is a need for additional experimental work on the role of oxygen in AgNP dissolution. AgNP dissolution experiments at variable oxygen pressures, in combinations with a detailed kinetic analysis as performed in Chapter 3, can be used to verify the adsorption of oxygen to the AgNP surface as a rate limiting step. Moreover, it would likely reveal an equilibrium constant and an adsorption maximum for the adsorption of molecular oxygen to the AgNP surface. My results indicate that the concentrated AgNP stocks must be allowed to equilibrate to the conditions at which the experiment is to be conducted. Moreover, the $\mathrm{pH}$ range of the experiment must be carefully chosen, as the proton availability was rate limiting at a high $\mathrm{pH}$, obscuring the rate limitation by oxygen adsorption. Experimental findings could be supplemented by investigating the interaction between the silver surface and molecular oxygen using computational methods. It would be an important step in unraveling the mechanism of oxidative dissolution of AgNPs.

\subsubsection{Influence of the surface area on $\mathrm{Ag}^{+}$release}

Since $\mathrm{Ag}^{+}$release is a surface controlled process, it is strongly connected to the total concentration $\left(\mathrm{g} \mathrm{L}^{-1}\right)$ and the specific surface area $\left(\mathrm{m}^{2} \mathrm{~g}^{-1}\right)$ of the AgNPs. The product of these two, i.e. the total AgNP surface area in $\mathrm{m}^{2} \mathrm{~L}^{-1}$, is demonstrated to have a strong correlation with the total amount of $\mathrm{Ag}^{+}$released for collected literature data as shown in Chapter 2 (Figure 2.7). Our own experiments, discussed in Chapter 3 (Figure 3.3b), confirm this fact. My finding that the released $\mathrm{Ag}^{+}$concentrations are coupled to the total AgNP surface area $\left(\mathrm{m}^{2} \mathrm{~L}^{-1}\right)$ is of major importance for the general application of AgNPs and their environmental impact in particular.

Around four $\mathrm{Ag}^{+}$ions can be released for every oxidized $\equiv \mathrm{Ag}_{3} \mathrm{OH}$ group; the precise number depends on the secondary structure formed. This number may have an influence on the total amount of $\mathrm{Ag}^{+}$that can be released through surface equilibration, as well as on the $\mathrm{pH}$ dependency of $\mathrm{Ag}^{+}$release. As shown in Figure 3.2, the experimental equilibrium ratio at high $\mathrm{pH}, \log \left[\mathrm{Ag}^{+}\right] / \mathrm{pH}=-0.7 \pm 0.1$ is in good agreement with calculations for a surface group releasing four $\mathrm{Ag}^{+}$ions. Moreover, the $\mathrm{pH}$ dependency of $\mathrm{Ag}^{+}$release changes, indicating a maximum release through equilibration, when $\sim 30 \mu \mathrm{mol} \mathrm{m}{ }^{-2}$ of $\mathrm{Ag}^{+}$has been released (Figure 3.8), which also corresponds to roughly four $\mathrm{Ag}^{+}$ions per surface site.

The relationship between $\mathrm{pH}$, concentrations of $\mathrm{Ag}^{+}$and reaction time, determined in our own experiments, strongly points to regulation by an equilibrium condition. This implies that a high concentration of $\mathrm{Ag}^{+}$will suppress the oxidation reaction, or promote the backward reaction. Conversely, once equilibrium has been attained, lowering of the $\mathrm{Ag}^{+}$concentration would lead to additional ion release, e.g. by diluting the equilibrium system. It means that, expressed per unit surface area, the release is higher at lower AgNP concentrations, and vice versa.

Evidence for a feedback mechanism of the $\mathrm{Ag}^{+}$concentration on the $\mathrm{Ag}^{+}$release is found in literature. Loza et al. ${ }^{14}$ observed that intermediate removal of $\mathrm{Ag}^{+}$ions during the dissolution 
process increases the $\mathrm{Ag}^{+}$release. They refreshed the medium after stabilization of the $\mathrm{Ag}^{+}$ concentrations, and found that dissolution resumes. Less $\mathrm{Ag}^{+}$ions were released in the second phase, which is expected as part of the surface had already reacted (see Figure 6.2), meaning less $\equiv \mathrm{Ag}_{3} \mathrm{OH}$ groups were available for oxidation and $\mathrm{Ag}^{+}$release at the beginning of the second dissolution step. Liu and Hurt, ${ }^{22}$ on the other hand, observed a decreased $\mathrm{Ag}^{+}$release when $\mathrm{Ag}^{+}$is present before onset of the AgNP oxidation. They diluted a AgNP suspension in a $\sim 3 \mu \mathrm{M}$ $\mathrm{AgClO}_{4}$ solution and found that the dissolved silver concentrations initially dropped to $\sim 2 \mu \mathrm{M}$, suggesting the dissolution reaction (eq 6.1) may be reversible. The total $\mathrm{Ag}^{+}$release at the end of the experiment was much lower than when the same particles were diluted in deionized water. The runtime of these experiments was unfortunately only 1 day, and equilibrium was clearly not yet attained.

The above indicates that there are several good possibilities to extend our study of the release of $\mathrm{Ag}^{+}$ions. If a surface equilibrium exists, it will be shifted and this can be verified quantitatively. If successful, it will be a great support for the model developed.

\subsubsection{Influence of particle size on silver ion release}

In studies with AgNP, experimental design and results can be expressed on a mass basis. By doing so, particle size has a very large influence. The reason is that $\mathrm{Ag}^{+}$release is determined by surface sites in the equilibrium controlled dissolution reaction, meaning the specific surface area $A_{p}$ is of great importance for $\mathrm{Ag}^{+}$release. The latter is determined by both size and shape as discussed in Chapter 4. As a result, small particles will release much more silver ions when release is expressed as a fraction of the mass concentration of added AgNPs. It suggests that much of this variation may disappear when scaled per unit surface area. However, reality is more complex.

In Figure 3.3a, I show that smaller particles have a higher $\mathrm{Ag}^{+}$release, when expressed per unit surface area. This manner of scaling illustrates the general feeling in literature that smaller particles are more reactive and negates the obscuring effect of scaling data on mass basis. The reason for this observation is the lower stability of the AgNP at small size due to the larger surface energy contribution $\gamma A_{p}$ to the Gibbs free energy change of the reaction, as expressed in eq 3.6. The equation expresses that the Gibbs free energy of the metallic silver is modified by a contribution due to the presence of surface atoms. The smaller the particle, the higher the specific surface area, and the higher the energy of the metallic silver in the particle, shifting the equilibrium towards higher dissolution.

Using the reaction constants of variously sized particles, the surface energy contribution can be resolved (Figure 3.3b), revealing a surface energy of $\sim 0.7 \mathrm{~J} \mathrm{~m}^{-2}$ for metallic silver, covered with a monolayer of $\equiv \mathrm{Ag}_{3} \mathrm{OH}$ groups. Ma et al. ${ }^{20}$ calculated a higher estimate of $\sim 1 \mathrm{~J} \mathrm{~m}^{-2}$ for the surface energy of silver in aqueous conditions, applying the Ostwald-Freundlich equation to their data. The reason for the different surface energies is that these authors, without specifying a reaction, implicitly assumed the consumption of 1 metallic silver atom for every 
$\mathrm{Ag}^{+}$released. However, most of the $\mathrm{Ag}^{+}$is released from the surface structure, which is not part of the metallic silver. A major part of the metallic silver consumed in the reaction does not dissolve but instead is transformed into a subvalent surface structure. The formulation of a dissolution reaction is a critical factor in obtaining the correct surface energy value from equilibrium data.

Using our coordination model (Chapter 5), we calculate a value of $1 \mathrm{~J} \mathrm{~m}^{-2}$ for the low energy [111] surface of AgNP from the cohesive energy. This is in agreement with MO/DFT generated particle energies, ${ }^{41}$ scaled to the physical surface (Chapter 4 ), which also yield an overall surface energy of around $1 \mathrm{~J} \mathrm{~m}^{-2}$. These values, which are for the solid-gas interface, are expected to be higher than the value determined from our dissolution experiments, which apply to an interface between a metal and a subvalent oxide with a matching structure.

The effect of particle size may also influence the process of Ag stripping according to the model developed. The formation of surface cavities, leading to stripping of the surface, is dependent on the amount of energy released in the dissolution reaction. This implies that critical undersaturation levels, at which cavitation can take place, will occur at a higher $\mathrm{pH}$ for small particles with a high surface energy contribution. Smaller particles will thus have a higher release $\left(\mathrm{mol} \mathrm{m}^{-2}\right)$ at neutral to alkaline condition, and a higher $\mathrm{pH}$ of destabilization, which can be tested.

In Chapter 4 and 5, we investigate the size dependency of surface energy using two different approaches. Both point to a small increase in surface energy at small size. This typically becomes relevant only at sizes below $5 \mathrm{~nm}$. Even in ultra-small nanoparticles $(\leq 1 \mathrm{~nm})$, the surface energy is generally less than $10 \%$ higher than that of a macroscopic particle. In contrast, strongly enhanced surface energies of $6 \mathrm{~J} \mathrm{~m}^{-2}$ and $8 \mathrm{~J} \mathrm{~m}^{-2}$ have been reported, respectively, for silver and gold nanoparticles in the size range $8-40 \mathrm{~nm} .{ }^{42}$, 43 The impressive elevation of these values with respect to the surface energies of the bulk metal, being $1.2 \mathrm{~J}$ $\mathrm{m}^{-2}$ for silver and $1.5 \mathrm{~J} \mathrm{~m}^{-2}$ for gold (see Table 4.4), is attributed to size dependency of surface energy. However, this explanation may be questioned as, in these studies, the same high surface energy is found for all particles in the investigated size range, i.e. no size dependency is observed. Moreover, these exorbitantly high surface energy values have not been reproduced using alternate methods, casting doubt on the validity of these results. Surface energy values determined from the size-dependency of $\mathrm{Ag}^{+}$dissolution (Chapter 3 ), show no indication of size-dependence in the experimental size range $(d \geq 5 \mathrm{~nm})$. The size dependency of surface energy is thus of limited importance, compared to the effect of specific surface area, and will not affect the surface equilibrium in a noticeable manner.

\subsubsection{Influence of particle geometry on silver ion release}

The geometry of silver nanoparticles has a tremendous influence on the surface energy, as discussed in Chapter 5 (see Figure 5.10). Different geometries have different crystal faces, influencing the stability and ion release. For example, cube shaped nanoparticles, which have 
exclusively the [100] surface, would have a much higher surface energy than octahedral nanoparticles, which only have [111] surfaces. Both types of particles have a relatively low stability due to a high surface to volume ratio and a low coordination of the edge and corner atoms. At an equivalent particle size, a truncated octahedron would be much more stable due to its more rounded shape.

The optimal geometry of a particle is a balance between surface-to-volume ratio and surface energy. Intuitively, spherical particles are expected to be most stable due to their low surface to volume ratio, but this is not necessarily true since it ignores the faceted nature of crystalline particles. This is not only relevant for metal clusters of the very small scale, but remains noticeable at large sizes. A sphere-like particle, formed from a crystalline solid, can be seen as a collection of very small facets, many of which will have a high energy. Moreover, the presence of many facets will lead to many edges with a higher energy. Analyses of spherical particles, simulated using molecular dynamics by Medasani et al. ${ }^{41}$ show that they have a higher energy than perfect truncated octahedra and Marks decahedra of equivalent size (see Figure 6.3). This once again stresses that faceted particles are highly relevant, not just as idealized structures, but as highly stable geometries, which can be expected to occur up to relatively large sizes. It is clear that the development of dedicated theory to calculate the stability of such particles, as in Chapters 4 and 5 , is needed in connection to data collected in dissolution experiments with particles that have well-defined facetted shapes.

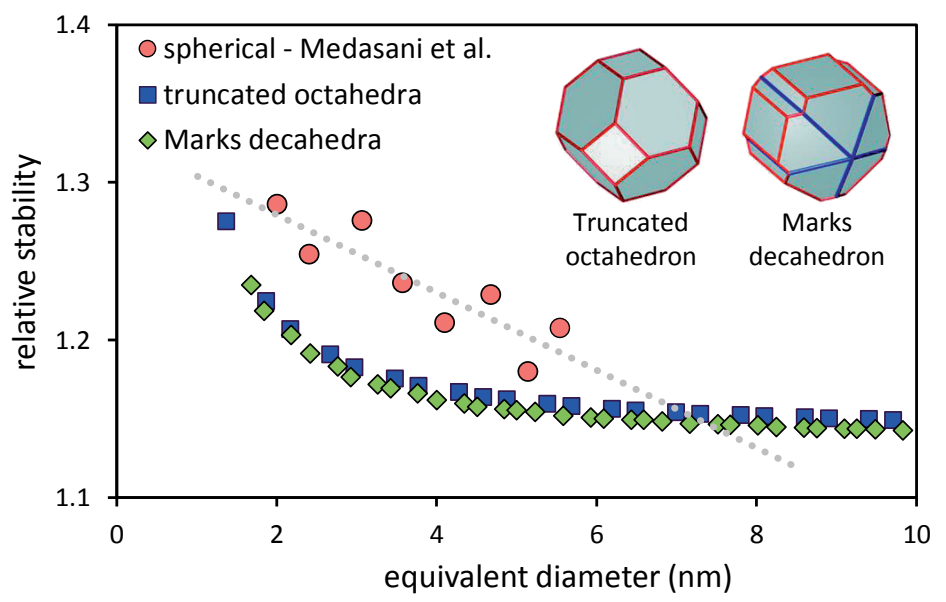

Figure 6.3 Relative stability of AgNP particles of different shape. The relative stability for the faceted particles has been calculated with the $\mathrm{CN}$ model (Chapter 5), using a zero-coordination energy $E_{0}=$ $0.44 \mathrm{aJ}=265 \mathrm{~kJ} \mathrm{~mol}^{-1}$. It enables comparison to the stability of near spherical particles calculated by Medasani et al. ${ }^{41}$ with molecular dynamics. Using a linear trendline (dotted line), it can be estimated that a sphere may be the stable geometry for particles with a diameter larger than $\sim 7 \mathrm{~nm}$. All data are presented at the relative scale using the approach explained in detail in Chapter 5 (see Figure 5.11). 
Besides surface energy, internal energy may also influence the stability of a particle and therefore its dissolution, as discussed in Chapter 5. This is of particular interest for icosahedral particles, which have a low surface energy, but a larger internal energy due to their strained five-fold twinned crystal structure. It leads to a higher apparent surface energy, where the apparent surface energy is defined as the sum of the internal and external energy contributions scaled to the surface area.

As is shown in Figure 5.7, the stability of icosahedral particles, relative to other geometries, dramatically decreases at sizes above 3-4 $\mathrm{nm}$. My data analysis with the $\mathrm{CN}$ and twinning energy model suggests that the reason for this is the development of internal strain, which imparts an increased energy on all atoms in the particle. It will lead to a higher $\mathrm{Ag}^{+}$release than expected based on the surface energy and the specific surface area alone. As the energy due to internal strain is roughly proportional to particle volume, its importance, relative to the external surface energy, increases with size. Therefore, the total excess energy, when scaled to the surface area, increases with particle size for icosahedra. If for example, the 5 and $10 \mathrm{~nm}$ particles in my dissolution experiments (Chapter 3 ) both would have an icosahedral geometry, the latter would have a higher apparent surface energy due to the internal energy contribution. At these sizes, our coordination and twinning model (Chapter 5) predicts a difference in apparent surface energy of $\sim 11 \%$. While this difference is relatively small, it is possible that it has influenced the relationship between specific surface area and stability of the surface groups that we presented in Figure 3.3b. In future dissolution experiments with the objective of gathering data with a higher accuracy, it would be prudent to establish the particle geometry, and especially twinning.

Summarizing, the $\mathrm{CN}$ and twinning energy model predicts that the most stable shape for silver nanoparticles will depend on particle size. For pure metallic particles, the current model predicts that icosahedra will be stable up to a size of approximately $4 \mathrm{~nm}$ (see Figure 5.11); above that size, truncated octahedra and marks decahedra are more stable. By extrapolating the data from Medasani et al.,41 as shown in Figure 6.3, it can be estimated that spherical particles will be more stable above approximately $7 \mathrm{~nm}$. As larger particles are more persistent, it can be expected that the spherical morphology will be the most prominent in the environment. It must be noted that the exact crossover sizes between these geometries may be different from the values presented above, due to the unknown influenced of the surface structure on the surface energy of the different crystal faces (see also Section 6.2.4).

\subsection{AgNPs in the natural environment}

The research that I have performed for this thesis has primarily focused on unravelling the behavior of AgNPs at the simplest conditions. This has given us a clear view on the core mechanism of oxidative dissolution. Nevertheless, the outlook of this thesis was to understand the environmental fate of silver nanoparticles. In this paragraph, I will discuss the possible 
effect of a number of major natural components on the dissolution and stability of silver nanoparticles.

\subsubsection{Effect of humic substances}

Humic substances, such as humic and fulvic acids, are omnipresent in the natural environment and are expected to strongly interact with AgNPs. However, there are many forms of interaction which have been reported, and the overall result of these interactions is hard to predict.

First of all, it is known that humic acids can adsorb silver ions, ${ }^{44}$ which will lead to a lower concentration of free $\mathrm{Ag}^{+}$, which will affect the surface equilibrium (eq 6.1). In case of soils, a high mass ratio between humics and AgNPs may occur relatively easily. In that case, complexation of $\mathrm{Ag}^{+}$by humic substances could lead to negligible concentrations of free $\mathrm{Ag}^{+}$, particularly at a relatively high $\mathrm{pH}(\sim 7)$ where dissolution is relatively low and adsorption is high. Under such circumstances, surface stripping can occur even at neutral $\mathrm{pH}$, leading to higher, or even complete dissolution of AgNPs.

On the other hand, humic substances are sometimes asserted to reduce AgNP oxidation. ${ }^{22}$ The suggested mechanism is that reactive oxygen species, e.g. hydrogen peroxide, are formed as critical intermediates in the reaction of oxygen with the AgNP. ${ }^{22}$ Natural organic matter may reduce these intermediates, partially preventing oxidation. In laboratory experiments, dissolved $\mathrm{Ag}^{+}$concentrations have been determined by using ultrafiltration, which mechanically separates the nanoparticles from the aqueous phase. In presence of humic acids (HA) or fulvic acids (FA), lower concentration of $\mathrm{Ag}^{+}$were found in the filtrate. ${ }^{22}$ However, $\mathrm{HA}$ -

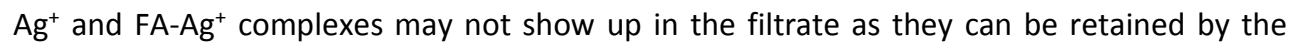
extremely small ( $3 \mathrm{kDa}$ ) filter size, leading to an underestimation of total AgNP dissolution. In other experiments, ${ }^{40}$ presence of oxygen radical scavengers has been shown to have little effect on AgNP dissolution rates, suggesting that this function may not be very important. In light of the above evidence, the negative effect of humic substances on AgNP dissolution may thus be questioned.

In a recent study, Zhou et al. ${ }^{45}$ used particle size measurements to study AgNP dissolution in presence of $\mathrm{HA}$, with highly variable results. In a $6 \mathrm{mM} \mathrm{NaNO}_{3}$ medium, dissolution was clearly less in presence of higher concentrations at $\mathrm{pH} 5$, but there was no effect at $\mathrm{pH} 9$. In a $2 \mathrm{mM}$ $\mathrm{NaCl}$ medium, on the other hand, there was no effect at $\mathrm{pH} 5$, while at $\mathrm{pH} 8.5$ a higher dissolution was found at higher $\mathrm{HA}$ concentrations. Moreover, dissolved $\mathrm{Ag}^{+}$concentrations showed large fluctuations throughout the experiment. The effect of HA on AgNPs is apparently more complicated than simply preventing or promoting oxidation.

The complicated influence of humic substances may be related to the reduction of $\mathrm{Ag}^{+}$by organic matter. AgNP formation has been observed in humic acid solutions containing ionic silver at ambient temperature and even in presence of oxygen. ${ }^{46}$ In addition, AgNP can be prepared in the lab with help of simple organic molecules like citrate or glucose that act as 
reducing agent. It suggests that $\mathrm{Ag}^{+}$in environmental systems could be reduced to form AgNPs, or even that subvalent silver at the surface could be reduced to the metallic form. However, experimental evidence also supports release of $\mathrm{Ag}^{+}$ions in aerobic soils. ${ }^{47}$ These results suggest that organic matter-induced reduction and oxidation may occur simultaneously, as I will shortly discuss.

According to the dynamic model developed in Chapter 3, molecular oxygen $\left(\mathrm{O}_{2}\right)$ can be a ratelimiting step in the oxidative dissolution of AgNPs. This idea fits very well with the concept of the formation of a mixed redox potential at the surfaces of metals such as Pt. It is a wellknown phenomenon from electrochemistry that despite ample dissolved oxygen, the redox couple $\mathrm{O}_{2} / \mathrm{H}_{2} \mathrm{O}$ is not able to establish a chemical equilibrium at the Pt electrode. Other redox couples in the system may react faster, leading to a mixed redox potential at the electrode. It is maintained by a continuous reaction between the reduction of oxygen and the oxidation of the reducing agent, which can be humic substances in case of soils. If AgNPs act similar to a Pt-electrode, a mixed potential with humic substances and oxygen can form on the particle. If low enough, $\mathrm{Ag}^{+}$ions can be reduced to $\mathrm{Ag}^{0}$ and the $\mathrm{AgNP}$ particle may grow. It is obvious that the stability of AgNP will then depend on the relative rates of redox reactions involved. AgNPs may be stabilized and become less toxic as the equilibrium $\mathrm{Ag}^{+}$concentration decreases to the value determined by the redox potential of the reaction $\mathrm{Ag}^{+}(\mathrm{aq})+\mathrm{e}^{-} \Leftrightarrow \mathrm{Ag}^{0}$. Potentially, AgNPs could be reformed under anaerobic conditions, although formation of silver sulfide may prevent this, as discussed later.

Whether the above-sketched process of stabilization occurs (or not) will depend on the $\mathrm{O}_{2}$ activity and the quality of the organic matter in the soil in the sense of how easily electroactive moieties are oxidized by $\mathrm{O}_{2}$ at the surface of AgNPs. In this respect, it is important to note that the AgNP surface may act as a catalyst for the oxidation of organic matter, as silver is widely used for catalysis of oxidation. ${ }^{48}$ In addition, it is obvious that adsorption of various substances to the AgNP surface may have a significant effect on the process sketched as it may be expected that the reactive molecules have to be close to the surface. Strongly binding (e.g. thiolated) capping agents or surface coatings by e.g. silver sulfide may prevent this. This complex balance between oxidation and reduction has many unanswered questions and allows for a great deal of fascinating research with high relevance for the environmental fate of AgNPs.

Adsorption of humics to the AgNP surface is frequently observed, ${ }^{49}$ but the mechanism of adsorption is not well understood. Results of computational chemistry suggest that citrate coordinates to the metallic AgNP surface with its carboxylic groups, ${ }^{50}$ humic and fulvic acids may bind in the same way. In case of a subvalent surface with $\equiv \mathrm{Ag}_{3} \mathrm{OH}$ groups, binding may occur through ligand exchange, according to $\equiv \mathrm{Ag}_{3} \mathrm{OH}+\mathrm{R}-\mathrm{C}(\mathrm{O}) \mathrm{OH} \rightleftarrows \equiv \mathrm{Ag}_{3} \mathrm{OC}(\mathrm{O})-\mathrm{R}+\mathrm{H}_{2} \mathrm{O}$. Such an interaction may result in similar competitive adsorption trends as found for various iron oxides, i.e. large structures with a large number of reactive groups that are resilient to 
competitive desorption. ${ }^{51,52}$ The binding of organic matter to the AgNP surface may facilitate catalyzed oxidation, as discussed above.

It is thought that the adsorption of humic acids, or capping agents in general, may reduce the surface tension of AgNPs, thereby stabilizing them, but this may not be the case. Although the presence of higher levels of PVP have been shown to decrease dissolution rates, ${ }^{40}$ we find a lower stability for AgNPs coated with PVP and gum arabic than for our own citrate-coated AgNPs (Figure 3.6b). However, similar slopes $\Delta G_{r} / A_{p}$ are found, indicating that the surface energy was not different. Instead, the subvalent surface structure may be destabilized as a result of the adsorption, leading to a higher $\mathrm{Ag}^{+}$release. The reasons for this apparent destabilization are not clear, nor is it known if other molecules including humic acids would have the same effect.

As discussed above, humic substances can affect AgNPs in many different ways. Both oxidation and reduction may be promoted, as a consequence of interaction of humic substances with the $\mathrm{Ag}^{+}$ion, or with the AgNP surface. The different interactions are still poorly documented and even less well understood. Dissolution experiments in presence of humic substances of different quality (size, types and amounts of reactive groups, aromaticity) could provide additional information on which organic matter properties can be linked to reduction and stabilization or destabilization of AgNPs. Adsorption of ionic silver is a major complication in this type of experiments, as it may influence dissolution as discussed above; it needs to be studied separately in titration experiments.

\subsubsection{Effect of sulfide and chloride}

It is well known that sulfide and chloride strongly interact with $\mathrm{Ag}^{+}$leading to insoluble solids, such as $\mathrm{Ag}_{2} \mathrm{~S}(\mathrm{~s})$ and $\mathrm{AgCl}(\mathrm{s})$. Therefore, these ions may be important for the environmental fate of AgNP.

Sulfide concentrations in the environment are highly variable, strongly depending on the redox state. High concentrations may be found in strongly reduced environments such as waterlogged soils, but sulfide is expected to be largely absent in e.g. aerobic top soils. Sulfide has a very high affinity for silver and will interact with the AgNP surface, potentially displacing surface hydroxide groups and facilitating oxidation of subvalent silver to $\mathrm{Ag}(\mathrm{I})$. In sulfide rich conditions, such as sewage sludge, complete transformation of metallic AgNPs to sulfide nanoparticle has been observed. ${ }^{53,54}$ The presence of humic acid has been shown to increase the rate of sulfidation, ${ }^{54}$ however, this effect may vary depending on the quality of the humic acid. In reduced soils and sediments, the reductive capacity of humic substances (see section 6.4.1) could potentially prevent sulfidation. The interaction with sulfide has been shown to strongly decrease the release of ionic silver from silver nanoparticles, ${ }^{55,56}$ and reduce toxicity. ${ }^{57}$ Nevertheless, there is evidence for long-term negative effects of sulfidized AgNPs on soil biota. ${ }^{58}$ This may be the result of $\mathrm{Ag}^{+}$release from the residual metallic core in case of incomplete sulfidation or, alternatively, due to oxidization of $\mathrm{Ag}_{2} \mathrm{~S}$ nanoparticles, which could 
potentially be mediated by bacteria. ${ }^{59}$ In summary, the effect of sulfide on the environmental fate of AgNPs will vary with sulfide concentrations and may further depend on organic matter and redox conditions. Moreover, sulfidation of AgNPs may not (permanently) prevent release of ionic silver. It is certain, however, that if soluble sulfide is present in any amount, it will precipitate with released silver ions as silver sulfide.

Chloride is present in concentrations around $0.5 \mathrm{mM}$ in Dutch, rain fed groundwaters. ${ }^{60} \mathrm{At}$ this concentration, a low solubility of around $0.5 \mu \mathrm{M} \mathrm{Ag}$ is expected in case of equilibrium with solid $\mathrm{AgCl}(\mathrm{s})$. However, predicted environmental concentrations of AgNPs do not exceed that value. ${ }^{61}$ In that respect, the influence of chloride is limited. However, it has been shown that chloride at low concentrations can decrease the dissolution rate of AgNPs. ${ }^{40,62,63}$ The reason for this may be ligand exchange leading to $\equiv \mathrm{Ag}_{3} \mathrm{Cl}$ groups, which are expected to be much more stable than $\equiv \mathrm{Ag}_{3} \mathrm{OH}$. At higher chloride concentrations, the dissolution rates increase, ${ }^{63}$ presumably because of the formation of $\mathrm{AgCl}_{x}{ }^{1-x}(\mathrm{aq})$ complexes in solution, which reduces the free $\mathrm{Ag}^{+}$activity that is relevant for the equilibrium with the surface. As hardly any dissolved $\mathrm{AgCl}_{x}{ }^{1-x}$ species will be present at the low chloride levels found in rain fed groundwaters, the interaction with chloride is likely to reduce dissolution of the AgNPs and increase particle persistence.

\subsubsection{AgNP stability in the environment}

Using the model for AgNPs dissolution, based on the proposed surface structures and the experimentally determined $\mathrm{pH}$ dependency of $\mathrm{Ag}^{+}$release, we can make predictions for stability of AgNPs in the environment. I have performed model calculations in ECOSAT ${ }^{64}$ using the surface model defined in Chapter 3. Silver is released according to the thermodynamic reaction:

$$
\equiv \mathrm{Ag}_{3} \mathrm{OH}^{0}+6 \mathrm{Ag}^{0}+4 \mathrm{H}^{+}+1.25 \mathrm{O}_{2} \Leftrightarrow \equiv \mathrm{Ag}_{5}(\mathrm{OH})_{2}^{0}+4 \mathrm{Ag}^{+}+1.5 \mathrm{H}_{2} \mathrm{O}
$$

In this equation, $\equiv \mathrm{Ag}_{5}(\mathrm{OH})_{2}$ represents a single site of the secondary surface structure, with subvalent silver present in two atomic layers. Initially, the AgNP surface has only primary $\equiv \mathrm{Ag}_{3} \mathrm{OH}$ sites. At release of $\mathrm{Ag}^{+}$, the ratio between the secondary and the primary surface sites increases.

The mechanism of surface stripping can in principle lead to full dissolution of the AgNP. Therefore, the conditions where stripping commences have been taken as the stability criterion. In the experiments, stripping is seen to take place at $\mathrm{pH}$ levels where full conversion of the surface has taken place. In the calculations leading up to Figure 6.4, an initial approximation of the stability is defined by a surface ratio $\equiv \mathrm{Ag}_{5}(\mathrm{OH})_{2} / \equiv \mathrm{Ag}_{3} \mathrm{OH}=10^{3}$, which constitutes practically full conversion of the surface. It must be noted that this choice is fairly arbitrary and a higher ratio may be associated with full dissolution of AgNPs. In other words, a conservative approach is taken; actual stability may be higher than presented here. 
Stability of a $20 \mathrm{~nm} \mathrm{AgNP}$ was calculated at a loading of $0.1 \mu \mathrm{g} \mathrm{kg}^{-1}$ in soil and a soil to water ratio of $10 \mathrm{~kg} \mathrm{~L}^{-1}$. The chosen loading is based on a high AgNP emission scenario by Mueller and Nowack. ${ }^{61}$ For the solubility of the AgNP, a value of $\log K_{\mathrm{H} / \mathrm{Ag}}$ of 7.5 was used, valid for a 20 $\mathrm{nm}$ particle according to the trend established in Chapter 3 (see Figure 3.6b).

Using the above system parameters, the stability condition $\equiv \mathrm{Ag}_{5}(\mathrm{OH})_{2} / \equiv \mathrm{Ag}_{3} \mathrm{OH}=10^{3}$ is reached at $\mathrm{pH} 9.6$ for an oxygen pressure of 1 bar. The amount of $\mathrm{Ag}^{+}$released is fixed the chosen surface ratio, therefore, at lowering of the $\mathrm{pH}$ by 1 unit, the same surface condition is found when the oxygen pressure is $4 / 1.25=3.2$ times lower. Using the relation between $\mathrm{pH}$, pe, and $\mathrm{P}-\mathrm{O}_{2}$, a slope for the stability line of $-0.2 \mathrm{pe} / \mathrm{pH}$ is found, as indicated by the light blue line in Figure 6.4. Above this line, complete dissolution of silver nanoparticles is expected, while below, silver nanoparticles are expected to be stabilized by the surface equilibrium. For every order of magnitude with which the stability criterion $\equiv \mathrm{Ag}_{5}(\mathrm{OH})_{2} / \equiv \mathrm{Ag}_{3} \mathrm{OH}$ is increased, the stability line is shifted up by 0.2 pe units.

Results are shown in Figure 6.4 in the form of a redox diagram in which we have indicated the stability of AgNPs in absence of organic matter (thick light blue line). Despite the low AgNP loading, it is seen that AgNPs may be stable in a large portion of $\mathrm{pH}$ soil conditions at a mild reduction in the absence of organic matter. 


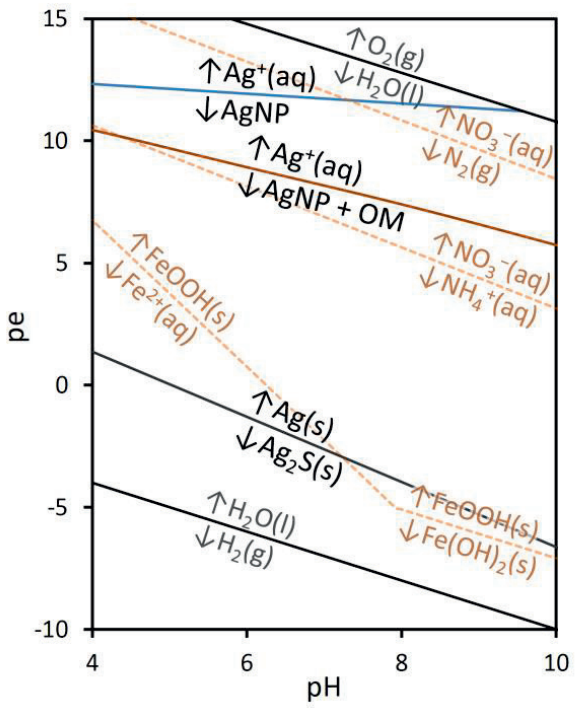

Figure 6.4 Redox diagram indicating the stability of $20 \mathrm{~nm} \mathrm{AgNP(s)}$ present a total concentration of 0.1 $\mu \mathrm{g} \mathrm{Ag} \mathrm{kg}{ }^{-1}$ soil at a SSR of $10 \mathrm{~kg} \mathrm{~L}^{-1}$ (or $1 \mu \mathrm{gg} \mathrm{L}^{-1}$ ) in the absence (blue line) and presence (brown line) of organic matter. For reference, the dotted lines indicate the pe-pH conditions for a number of relevant redox reactions known to occur in soil. The redox couples are indicated in the figure. In aerobic soils, the AgNPs may not be thermodynamically stable at the chosen AgNP loading of the system. It depends on the precise redox conditions. In soils with some denitrification due to rather mild redox conditions (dashed $\mathrm{NO}_{3}{ }^{-} / \mathrm{N}_{2}$ line), thermodynamic stability may occur at high $\mathrm{pH}$. However, at low $\mathrm{pH}$, AgNPs will dissolve. In presence of organic matter $\left(20 \mathrm{~g} \mathrm{~kg}^{-1}\right)$, the free $\mathrm{Ag}^{+}$concentration established by the surface equilibrium is much lower due to complexation. It leads to a lower AgNP stability, and consequently, a lower redox potential is needed to stabilize the particles. Model calculations point to stability at conditions where nitrification occurs $\left(\mathrm{NO}_{3}{ }^{-} / \mathrm{NH}_{4}{ }^{+}\right.$line $)$. At very strongly reducing conditions, silver sulfide is expected to form (grey line). Model calculations were performed for a system with 0.5 $\mathrm{mM}$ of chloride. Free $\mathrm{Ag}^{+}$concentrations are such that precipitation of $\mathrm{AgCl}(\mathrm{s})$ will not occur, however, $\mathrm{AgCl}(\mathrm{aq})$ is an important species, having roughly the same concentration as free $\mathrm{Ag}^{+}$. For redox calculations, I used $1 \mathrm{mM}$ of $\mathrm{NO}_{3}{ }^{-}, \mathrm{NH}_{4}{ }^{+}, \mathrm{Fe}^{2+}$, and $\mathrm{SO}_{4}{ }^{2-}$, and 1 bar of $\mathrm{N}_{2}$. Black lines indicate the stability limits of water, i.e. below the $\mathrm{H}_{2} / \mathrm{H}_{2} \mathrm{O}$ line water will lyse to generate hydrogen, above the $\mathrm{H}_{2} \mathrm{O} / \mathrm{O}_{2}$ line water will lyse to form oxygen.

Figure 6.4 also shows the calculated stability of AgNPs in presence of organic matter (thick dark blue line). The complexation of dissolved $\mathrm{Ag}^{+}$by organic matter leads to lower free $\mathrm{Ag}^{+}$ concentrations, which shifts the surface equilibrium towards higher dissolution. $\mathrm{Ag}^{+}$ adsorption by organic matter is modeled using the NICA-Donnan model, ${ }^{65}$ taking a generic humic acid ${ }^{66}$ as a proxy for soil organic matter. An organic matter content of $20 \mathrm{~g} \mathrm{~kg}^{-1}$ is used. Adsorption parameters for $\mathrm{Ag}^{+}$to organic matter have not yet been published and were obtained using the method reported by Milne et al. ${ }^{67}$ These authors noticed a strong correlation between freely fitted non-ideality parameters $\left(n_{1}\right.$ and $\left.n_{2}\right)$ for nine different metal ions $\left(\mathrm{Me}^{z+}\right)$ and the formation constant of their first hydrolysis product $\left(\mathrm{MeOH}^{\left({ }^{-1}\right)+}\right)$. In addition, the product of the non-ideality constants and the binding constants $\left(n_{1} \cdot \log K_{1}\right.$ and $n_{2} \cdot \log K_{2}$ ) was similarly correlated to the first hydrolysis constant. The reported correlations led 
to good descriptions for datasets too small for unconstrained fitting, demonstrating that it is a useful tool to obtain a first estimate for NICA-Donnan parameters. For $\mathrm{Ag}^{+}$, the reported correlations parameters lead to $\log K_{1}=-0.6$ and $\log K_{2}=0.1$ for the carboxylic type of sites and phenolic type of sites, respectively, in combination with $n_{1}=0.8$ and $n_{2}=0.6$.

Surface stripping leads to additional $\mathrm{Ag}^{+}$release which is not accounted for by the surface equilibrium model. At high stripping, the increased dissolution changes solution $\mathrm{Ag}^{+}$ concentrations, which affects the surface equilibrium, raising the stability. The presence of 10 $\mathrm{nmol} \mathrm{L} \mathrm{L}^{-1}$, equivalent to full dissolution of $1 \mu \mathrm{g} \mathrm{AgNP} \mathrm{L^{-1 }}$, increases the stability limit of AgNPs by approximately one pe unit, for systems with and without humic acid. This is not shown in the graph to keep the graph from becoming too complicated. The exact stability line will also be subject to the decreasing particle stability as particles shrink, but such considerations are beyond the scope of the figure.

As discussed in section 6.4.1, reduction by humic acids and binding of humic acids to the surface structure through ligand exchange, may be important processes in the environment. However, these processes cannot yet be quantitatively described, and they have therefore not been considered in Figure 6.4.

Partly due to the chosen low total AgNP concentrations, the model predictions for dissolved $\mathrm{Ag}^{+}$concentrations are very low. At the line of stability, the concentration of released $\mathrm{Ag}^{+}$is around the maximum $\mathrm{Ag}^{+}$release through surface equilibration, $\pm 1 \mathrm{nmol} \mathrm{L^{-1 }}$, is reached. At a chloride concentration of $0.5 \mathrm{mmol} \mathrm{L}^{-1}$, but in absence of $\mathrm{HAs}$, this leads to a free $\mathrm{Ag}^{+}$ concentration of roughly $0.5 \mathrm{nmol} \mathrm{L^{-1 }}$. In presence of $\mathrm{HAs}$, free $\mathrm{Ag}^{+}$concentrations are determined by a combination of adsorption and dissolution, leading to a variable $\mathrm{Ag}^{+}$level, which is predicted to range from concentrations in the order of $1 \cdot 10^{-12} \mathrm{M}$ at low $\mathrm{pH}$, to $1 \cdot 10^{-16}$ $\mathrm{M}$ at high $\mathrm{pH}$. These concentration levels are not expected to lead to acute toxicity. However, as the amount of long-term studies is very limited, we cannot be certain about the effects of chronic exposure, even to levels as low as these. Moreover, in environmental systems, part of the $\mathrm{Ag}^{+}$will be bound to dissolved organic matter, which could potentially be bioavailable.

In the model calculations, a background chloride concentration of $0.5 \mathrm{mmol} \mathrm{L}^{-1}$ was used, which is a representative value for Dutch groundwaters. At that level, the $\mathrm{AgCl}(\mathrm{aq})$ complex constitutes approximately half of the dissolved silver. The low $\mathrm{Ag}^{+}$concentrations predicted by the model suggest that solid silver chloride will not be formed under environmental conditions. However, chloride may become bound to the AgNP surface through ligand exchange (see section 6.4.2), forming a stable $\equiv \mathrm{Ag}_{3} \mathrm{Cl}$ surface group. In principle, this may shift the stability line towards higher redox conditions. The effect of the potential formation of a $\equiv \mathrm{Ag}_{3} \mathrm{Cl}$ surface group and on $\mathrm{AgNP}$ stability and equilibrium $\mathrm{Ag}^{+}$concentrations is thus an important topic for further research.

If sulfide is present, $\mathrm{Ag}_{2} \mathrm{~S}$ may precipitate, at the low concentrations predicted at the stability lines. However, at these redox conditions, hardly any sulfide is expected if the system is in 
equilibrium. In equilibrium with bulk silver, and sulfide forming from sulfate present at $1 \mathrm{mmol}$ $\mathrm{L}^{-1}, \mathrm{Ag}_{2} \mathrm{~S}$ is predicted to form at redox conditions below the thick black line in Figure 6.4, according to $\mathrm{Ag}^{0}+4 \mathrm{H}^{+}+3 \mathrm{e}^{-}+1 / 2 \mathrm{SO}_{4}{ }^{2-} \Leftrightarrow 1 / 2 \mathrm{Ag}_{2} \mathrm{~S}+2 \mathrm{H}_{2} \mathrm{O}$. However, in equilibrium with the surface structure, a lower concentration of $\mathrm{Ag}^{+}$is predicted, leading to a downward shift of the silver sulfide line.

The above predictions should be seen as preliminary results as these are heavily based on the hypothesized model parameters presented in Chapter 3. As has been discussed in this chapter, there are yet a large number of unknowns. Confirmation of the model in environmental matrices at environmentally relevant conditions is highly challenging due to low total AgNP concentrations and the different complexes that are formed with $\mathrm{Ag}^{+}$in soil or surface waters. Nevertheless, the notion that organic matter can enhance AgNP dissolution is powerfully demonstrated by Figure 6.4. This insight is the direct result of the mechanistic understanding of the stability and dissolution of silver nanoparticles I have developed in this thesis. The development of the theoretical framework (Chapter 2) and the refinement of parameters (Chapter 3) have been strongly dependent on experimental data from "clean" laboratory settings; I could not have achieved similar results by looking at media that are more complex. Nevertheless, important insights for the environment could be extrapolated from measurements in unrealistic conditions. Hopefully, the knowledge generated here can serve as a foothold for the future challenge of interpreting and understanding AgNP behavior in more complex media.

\subsection{References}

1. K. Kulinowski, in ICON Backgrounders, ICON, Houston, 2008, ch. November 2008.

2. O. Choi and Z. Hu, Environ. Sci. Technol., 2008, 42, 4583-4588.

3. J. Fabrega, J. C. Renshaw and J. R. Lead, Environ. Sci. Technol., 2009, 43, 9004-9009.

4. W. A. Shoults-Wilson, B. C. Reinsch, O. V. Tsyusko, P. M. Bertsch, G. V. Lowry and J. M. Unrine, Soil Sci. Soc. Am. J., 2011, 75, 365-377.

5. L. Yin, Y. Cheng, B. Espinasse, B. P. Colman, M. Auffan, M. Wiesner, J. Rose, J. Liu and E. S. Bernhardt, Environ. Sci. Technol., 2011, 45, 2360-2367.

6. H. C. Poynton, J. M. Lazorchak, C. A. Impellitteri, B. J. Blalock, K. Rogers, H. J. Allen, A. Loguinov, J. L. Heckman and S. Govindasmawy, Environ. Sci. Technol., 2012, 46, 62886296.

7. S. Böhme, H. J. Stärk, T. Reemtsma and D. Kühnel, Environmental Science: Nano, 2015, 2, 603-614.

8. W. M. Haynes, T. J. Bruno and D. R. Lide, CRC Handbook of chemistry and physics, CRC press, [Boca Raton, FL], 2014.

9. Z. M. Xiu, Q. B. Zhang, H. L. Puppala, V. L. Colvin and P. J. J. Alvarez, Nano Letters, 2012, $12,4271-4275$.

10. M. H. Shen, X. X. Zhou, X. Y. Yang, J. B. Chao, R. Liu and J. F. Liu, Scientific Reports, 2015, 5, 9674.

11. S. Kittler, C. Greulich, J. Diendorf, M. Köller and M. Epple, Chemistry of Materials, 2010, $22,4548-4554$. 
12. W. Zhang, Y. Yao, N. Sullivan and Y. Chen, Environ. Sci. Technol., 2011, 45, 4422-4428.

13. A. M. Mittelman, A. Taghavy, Y. Wang, L. M. Abriola and K. D. Pennell, Journal of Nanoparticle Research, 2013, 15, 1765.

14. K. Loza, J. Diendorf, C. Sengstock, L. Ruiz-Gonzalez, J. M. Gonzalez-Calbet, M. Vallet-Regi, M. Köller and M. Epple, Journal of Materials Chemistry B, 2014, 2, 1634-1643.

15. T. S. Peretyazhko, Q. Zhang and V. L. Colvin, Environ. Sci. Technol., 2014, 48, 1195411961.

16. Z. Adamczyk, M. Oćwieja, H. Mrowiec, S. Walas and D. Lupa, Journal of Colloid and Interface Science, 2016, 469, 355-364.

17. B. Molleman and T. Hiemstra, Environmental Science: Nano, 2017, 4, 1314-1327.

18. M. A. Chappell, L. F. Miller, A. J. George, B. A. Pettway, C. L. Price, B. E. Porter, A. J. Bednar, J. M. Seiter, A. J. Kennedy and J. A. Steevens, Chemosphere, 2011, 84, 11081116.

19. G. A. Sotiriou, A. Meyer, J. T. N. Knijnenburg, S. Panke and S. E. Pratsinis, Langmuir, 2012, 28, 15929-15936.

20. R. Ma, C. m. Levard, S. M. Marinakos, Y. Cheng, J. Liu, F. M. Michel, G. E. Brown Jr. and G. V. Lowry, Environ. Sci. Technol., 2012, 46, 752-759.

21. N. M. Martin, S. Klacar, H. Grönbeck, J. Knudsen, J. Schnadt, S. Blomberg, J. Gustafson and E. Lundgren, The Journal of Physical Chemistry C, 2014, 118, 15324-15331.

22. J. Liu and R. H. Hurt, Environ. Sci. Technol., 2010, 44, 2169-2175.

23. A. Henglein, Chemistry of Materials, 1998, 10, 444-450.

24. L. Duro, M. Grivé, E. Cera, C. Domènech and J. Bruno, Update of a thermodynamic database for radionuclides to assist solubility limits calculation for performance assessment, 2006.

25. I. K. Suh, H. Ohta and Y. Waseda, Journal of Materials Science, 1988, 23, 757-760.

26. R. Wyckoff, American Journal of Science, 1922, 5, 184.

27. A. Jesih, K. Lutar, B. Žemva, B. Bachmann, S. Becker, B. Müller and R. Hoppe, Zeitschrift für anorganische und allgemeine Chemie, 1990, 588, 77-83.

28. N. Brese, M. O'keeffe, B. Ramakrishna and R. Von Dreele, Journal of Solid State Chemistry, 1990, 89, 184-190.

29. B. Standke and M. Jansen, Zeitschrift für anorganische und allgemeine Chemie, 1986, 535, 39-46.

30. W. Beesk, P. G. Jones, H. Rumpel, E. Schwarzmann and G. M. Sheldrick, Journal of the Chemical Society, Chemical communications, 1981, 664-665.

31. M. D. Johannes, S. Streltsov, I. I. Mazin and D. I. Khomskii, Physical Review B, 2007, 75, 180404(R).

32. H. Ott and H. Seyfarth, Zeitschrift für Kristallographie-Crystalline Materials, 1928, 67, 430-433.

33. A. Henglein and M. Giersig, The Journal of Physical Chemistry B, 1999, 103, 9533-9539.

34. G. I. N. Waterhouse, G. A. Bowmaker and J. B. Metson, Applied Surface Science, 2003, 214, 36-51.

35. M. A. Vanhove, R. J. Koestner, P. C. Stair, J. P. Biberian, L. L. Kesmodel, I. Bartos and G.

A. Somorjai, Surface Science, 1981, 103, 218-238.

36. R. C. Cammarata, Progress in surface science, 1994, 46, 1-38.

37. Q. Zhang, J. Xie, J. Yang and J. Y. Lee, ACS Nano, 2009, 3, 139-148.

38. J. A. Keith and T. Jacob, Angewandte Chemie International Edition, 2010, 49, 9521-9525.

39. J. Liu, D. A. Sonshine, S. Shervani and R. H. Hurt, ACS Nano, 2010, 4, 6903-6913. 
40. C. M. Ho, C. K. Wong, S. K. W. Yau, C. N. Lok and C. M. Che, Chem. Asian J., 2011, 6, 25062511.

41. B. Medasani, Y. H. Park and I. Vasiliev, Physical Review B, 2007, 75, 235436.

42. K. Nanda, A. Maisels, F. Kruis, H. Fissan and S. Stappert, Physical Review Letters, 2003, 91, 106102.

43. K. Nanda, A. Maisels and F. Kruis, The Journal of Physical Chemistry C, 2008, 112, 1348813491.

44. F. J. Sikora and F. J. Stevenson, Geoderma, 1988, 42, 353-363.

45. W. Zhou, Y.-L. Liu, A. M. Stallworth, C. Ye and J. J. Lenhart, Environ. Sci. Technol., 2016, 50, 12214-12224.46. N. Akaighe, R. I. MacCuspie, D. A. Navarro, D. S. Aga, S. Banerjee, M. Sohn and V. K. Sharma, Environ. Sci. Technol., 2011, 45, 3895-3901.

47. Y. Hashimoto, S. Takeuchi, S. Mitsunobu and Y.-S. Ok, Journal of hazardous materials, 2017, 322, 318-324.

48. I. E. Wachs and R. J. Madix, Surface Science, 1978, 76, 531-558.

49. S. Klitzke, G. Metreveli, A. Peters, G. E. Schaumann and F. Lang, Science of the Total Environment, 2015, 535, 54-60.

50. D. S. Kilin, O. V. Prezhdo and Y. Xia, Chemical Physics Letters, 2008, 458, 113-116.

51. L. Weng, W. H. Van Riemsdijk and T. Hiemstra, Environ. Sci. Technol., 2008, 42, 87478752.

52. L. Weng, W. H. Van Riemsdijk and T. Hiemstra, Environ. Sci. Technol., 2009, 43, 71987204.

53. R. Kaegi, A. Voegelin, C. Ort, B. Sinnet, B. Thalmann, J. Krismer, H. Hagendorfer, M. Elumelu and E. Mueller, Water Research, 2013, 47, 3866-3877.

54. B. Thalmann, A. Voegelin, E. Morgenroth and R. Kaegi, Environmental Science: Nano, 2016, 3, 203-212.

55. C. Levard, B. C. Reinsch, F. M. Michel, C. Oumahi, G. V. Lowry and G. E. Brown Jr., Environ. Sci. Technol., 2011, 45, 5260-5266.

56. J. Liu, K. G. Pennell and R. H. Hurt, Environ. Sci. Technol., 2011, 45, 7345-7353.

57. O. Choi, T. E. Clevenger, B. Deng, R. Y. Surampalli, L. Ross Jr and Z. Hu, Water research, 2009, 43, 1879-1886.

58. M. Kraas, K. Schlich, B. Knopf, F. Wege, R. Kägi, K. Terytze and K. Hund-Rinke, Environmental Toxicology and Chemistry, 2017, 36, 3305-3313.

59. M. Vera, A. Schippers and W. Sand, Applied microbiology and biotechnology, 2013, 97, 7529-7541.

60. M. Van Vliet, A. Vrijhoef, L. Boumans and E. Wattel-Koekkoek, RIVM rapport 680721005, 2010.

61. N. C. Mueller and B. Nowack, Environ. Sci. Technol., 2008, 42, 4447-4453.

62. C.-M. Ho, S. K.-W. Yau, C.-N. Lok, M.-H. So and C.-M. Che, Chemistry, an Asian journal, 2010, 5, 285.

63. C. m. Levard, S. Mitra, T. Yang, A. D. Jew, A. R. Badireddy, G. V. Lowry and G. E. Brown Jr, Environ. Sci. Technol., 2013, 47, 5738-5745.

64. M. G. Keizer and W. H. Van Riemsdijk, Manual Program, Agricultural University, Wageningen, 1994.

65. D. G. Kinniburgh, C. J. Milne, M. F. Benedetti, J. P. Pinheiro, J. Filius, L. K. Koopal and W. H. Van Riemsdijk, Environ. Sci. Technol., 1996, 30, 1687-1698.

66. C. J. Milne, D. G. Kinniburgh and E. Tipping, Environ. Sci. Technol., 2001, 35, 2049-2059. 
General discussion

67. C. J. Milne, D. G. Kinniburgh, W. H. van Riemsdijk and E. Tipping, Environ. Sci. Technol., 2003, 37, 958-971. 



\section{Appendix A}

\section{Supporting information to Chapter 2}

Surface structure of silver nanoparticles as model for understanding oxidative release of silver ions

Bastiaan Molleman and Tjisse Hiemstra*

A1 Literature data of $\mathrm{Ag}^{+}$release. Kinetics and equilibrium

A2 Spheroidal nanoparticle morphologies

A3 Bond valence analyses

A4 Silver compounds with a layered crystal structure

A5 MO/DFT computation

A6 Collected literature data

A7 References 
Appendix A

\section{$\mathrm{A} 1 \mathrm{Ag}^{+}$release literature data}

$\mathrm{Ag}^{+}$release from AgNPs has been measured on several occasions in recent years. Figure $\mathrm{A} 1$ shows collected time dependent release data as could be distilled from published graphs. Note the quick initial release and the long-term stability of the concentrations that are eventually reached. Data by Sotiriou et al. ${ }^{1}$ distinguish themselves from the other datasets by the extremely short dissolution times ( $<2$ hours), this is possibly due to a different AgNP production method (flame spray pyrolysis and wet impregnation) which include a high temperature step under water-free conditions. 

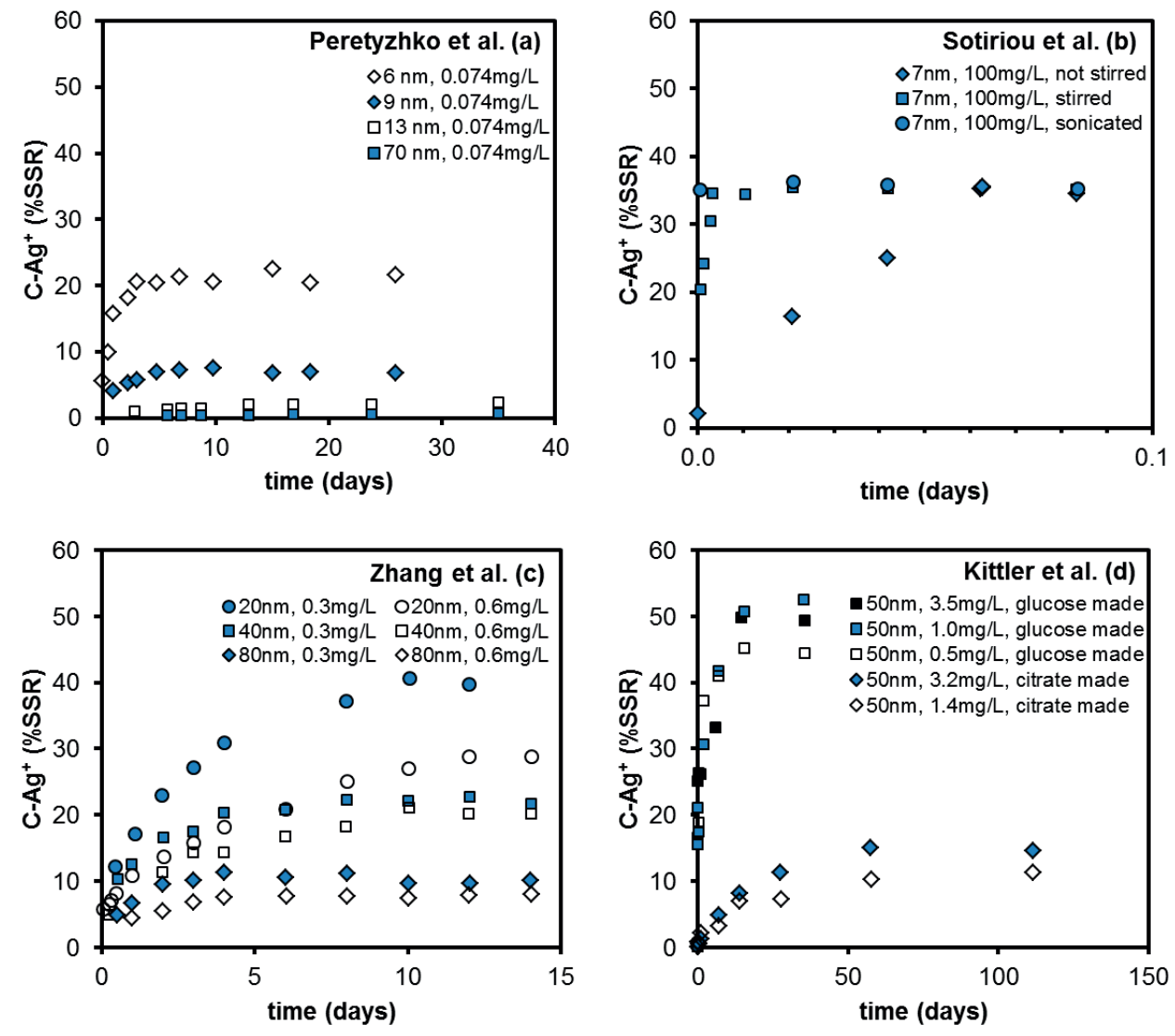

Figure A1. $\mathrm{Ag}^{+}$release data of several $\mathrm{AgNP}$ dissolution experiments from recent literature. Experimental parameters (e.g. particle size, preparation method, capping agent, solid solution ratio) are highly variable between datasets. a) Ion release data from Peretyazhko et al., ${ }^{2}$ using four different particle sizes at a single SSR. AgNPs were reduced using $\mathrm{NaBH}_{4}(6 \mathrm{~nm})$, citrate $(70 \mathrm{~nm})$, or both ( 9 and $13 \mathrm{~nm}$, seeded with $\mathrm{NaBH}_{4}$ and grown with citrate), and capped with thiolated PEG. $\mathrm{Ag}^{+}$concentrations are measured with an ion-selective electrode. In all figures $\mathrm{Ag}^{+}$release is expressed as a percentage of the SSR. b) Ion release taken from Sotiriou et al., ${ }^{1}$ using flame-made AgNPs at a high SSR. $\mathrm{Ag}^{+}$ concentrations are determined using ion selective electrode and ion meter. c) lon release taken from Zhang et al., ${ }^{3}$ citrate coated AgNPs of unknown production method (purchased) of different sizes were used at two different SSR. $\mathrm{Ag}^{+}$concentrations were determined by ultrafiltration and ICP-MS. d) Ion release taken from Kittler et al., ${ }^{4}$ AgNPs were placed in dialysis bags, which were placed in a 100 -fold excess of ultrapure water. Two types of particles were used, one was reduced by glucose and coated with PVP, the other had citrate as both the reductant and capping agent. Both particles had a size of $50 \mathrm{~nm}$. 


\section{A2 Spheroidal nanoparticle morphologies}

\section{Cuboctahedra}

In the fcc crystal structure, near spherical, single crystals can be made which are called cuboctahedra (Figure A2a). These structures are bounded by (111) and (100) faces. How much these faces contribute to the total surface area depends on the ratio between the distances between opposing crystal faces. The (111) face tends to be dominant $(75 \pm 11 \%)$.

\section{Icosahedra}

Surface tension greatly contributes to the total free energy of a nanoparticle. This may lead to different morphologies than are expected based on the crystal structure of a substance. In metal nanoparticles this often leads five-fold twinning, ${ }^{5}$ which may result in an icosahedral structure (Figure A2b). The outer surface has only (111) faces, minimizing surface tension; the internal crystal symmetry is only minimally distorted.

\section{Surface calculations for icosahedra}

A regular icosahedron consists of 20 triangular faces. The number of atoms in a single triangle is equal to:

$x_{n}=\frac{n^{2}+n}{2}$

where $n$ is the number of atoms at the base of a triangle. As edge and corner atoms (shown in Figure A3) are shared between faces, the number of surface atoms is less than $20 x$. We can calculate the effective number of atoms per triangle, $x_{\text {eff, }}$ by subtracting the shared atoms from $x$. Corner atoms in the structure are shared between five faces, and edge atoms are shared between two faces, as is shown in Figure A3, there are three corner atoms and $3(n-2)$ edge atoms in each triangle, leading to:

$$
x_{\text {eff, } \mathrm{n}}=x-3 \frac{(n-2)}{2}-3 \frac{4}{5}
$$

The number of surface atoms is equal to $20 x_{\text {eff, } n}$, number of total atoms may be calculated by taking the sum of the successive surface layers. With these equations one may find the relationship between, specific surface area and the effective diameter $d_{\text {eff, }}$ taking for the diameter the distance between the middle of opposing ribs of the icosahedron, which is given by:

$$
d_{\mathrm{eff}}=2 r_{\mathrm{eff}} \approx 2 \cdot 0.809 \cdot n \cdot d_{\mathrm{Ag}-\mathrm{Ag}}
$$

where $d_{\mathrm{Ag}-\mathrm{Ag}}$ is the bond length between silver atoms in the metallic silver crystal lattice. 


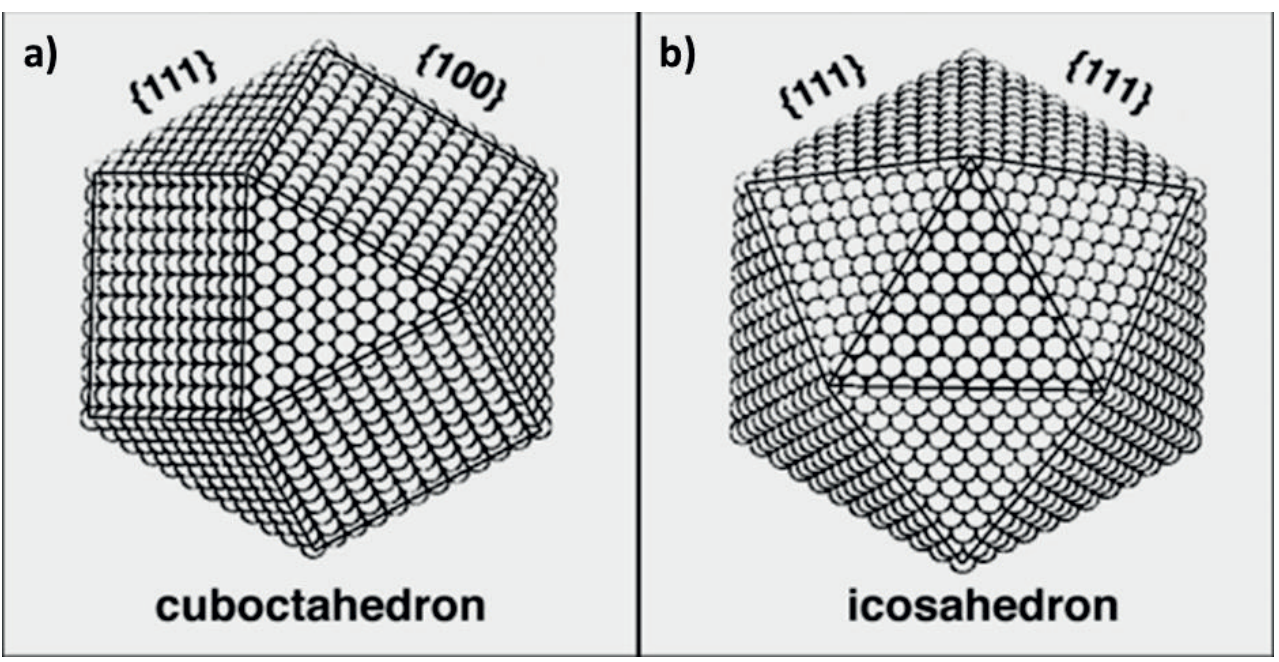

Figure A2. Two types of spheroidal nanoparticles which may occur in the fcc crystal lattice, taken from Hofmeister ${ }^{5}$, showing: a) a singly crystalline cuboctahedron having both the(111) and the (100) plane at the surface; b) a fivefold twinned icosahedron with exclusively (111) plane surfaces
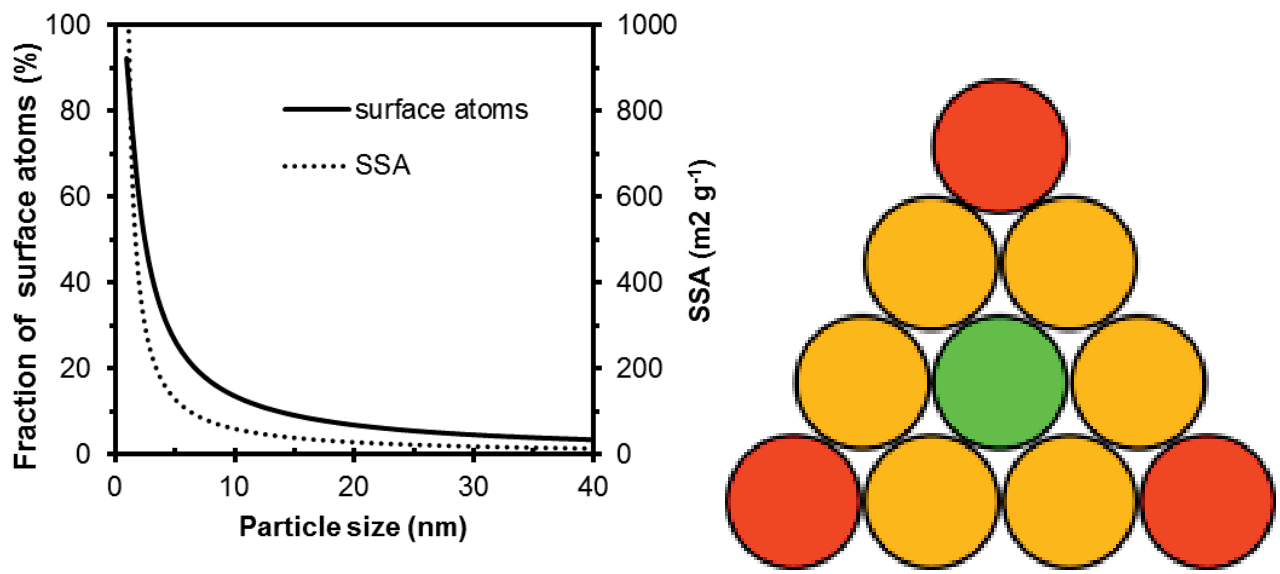

Figure A3. The relationship between particle diameter and specific surface area and percentage of surface atoms. Also shown is a triangular (111) face with base $n=4$, with corner atoms (shared between 5 faces) shown in red, and edge atoms (shared between two faces) shown in orange. 


\section{A3 Bond valence analyses}

An empirical relationship between bond length, $R$, and bond valence, $v$, is found to exist in minerals of the same cation. ${ }^{6}$ We have studied the crystal structures of various silver oxides in order to analyze this relationship for this class of minerals.

\section{Calculating the bond valence}

Bond valences were calculated according to the empirical relationship between bond length, $R$, and bond valence, $v^{6}$

$$
v=\mathrm{e}^{-\left(R-\mathrm{R}_{0}\right) / \mathrm{B}}
$$

where $R_{0}$ is the reference bond length (184.2 pm), which is cation specific, and $B$ is a chosen constant $(37 \mathrm{pm})$, which is traditionally kept constant for all compounds 6 . From crystallographic data (see Table A1 for references) the coordination numbers bond lengths were extracted. In most crystal structures, more than one bond length can be found. Bond lengths were grouped together if differences were very small, otherwise they were treated separately. The coordination number refers to the number of bonds of the given bond length that were attached to the cation.

Varying the reference bond length

If the reference bond length, $R_{0}$, is kept constant at its reference value of $184.2 \mathrm{pm},{ }^{6}$ the sum of the bond valences may be larger or smaller than the charge of the cation. Therefore, $R_{0}$ was varied by trial and error until the sum of the bond valences was equal to the charge of the cation. $\mathrm{R}_{0}$ of a given element, may vary with oxidation state; ${ }^{6}$ therefore, in the case of AgO, or more correctly $\mathrm{Ag}(\mathrm{I}) \mathrm{Ag}(\mathrm{III}) \mathrm{O}_{2}$, a different value was used to the two types of $\mathrm{Ag}$ found in its crystal structure.

\section{Soft bond valence}

It is known that the empirical bond valence-bond strength relationship cannot be solved for all crystal structures. In the case of $\mathrm{Ag}_{2} \mathrm{O}_{3}$, the optimization approach described above led to a sum of bond valences around the oxygen anion which was not equal to 2 . This problem can be overcome by choosing a different value $(29 \mathrm{pm})$ for the constant $B$ To keep things comparable, we have chosen to maintain the standard value for $B(37 \mathrm{pm})$. 
Table A1. Overview of bond valences calculated by adjusting the reference bond strength, $R_{0}$, so that the sum of the bond valences, $v$, equals the charge of the silver cation, $z_{\mathrm{Ag}}$. References concern the crystallographic data from which bond lengths, $R$, and coordination numbers, $\mathrm{CN}$, were taken.

\begin{tabular}{lllllll}
\hline & $Z_{\mathrm{Ag}}$ & $R 0$ & $\mathrm{CN}$ & $\mathrm{R}$ & $v$ & Reference \\
\hline $\mathrm{Ag}_{3} \mathrm{O}$ & $+2 / 3$ & 188.5 & 2 & 229.2 & 0.33 & 7 \\
$\mathrm{Ag}_{2} \mathrm{O}$ & +1 & 180.5 & 2 & 206.1 & 0.50 & 8 \\
$\mathrm{Ag}^{+}(\mathrm{aq})$ & +1 & 187.9 & 2 & 232 & 0.30 & 9 \\
& & & 2 & 248 & 0.20 & \\
$\mathrm{AgO}$ & +3 & 189.2 & 4 & 202.0 & 0.71 & 10 \\
& & & 2 & 279.6 & 0.09 & \\
& +1 & 182.8 & 2 & 216.7 & 0.40 & \\
& & & 2 & 267.8 & 0.10 & \\
$\mathrm{Ag}_{2} \mathrm{O}_{3}$ & +3 & 187.0 & 1 & 191.6 & 0.88 & 11 \\
& & & 2 & 202.5 & 0.66 & \\
& & & 1 & 204.6 & 0.62 & \\
& & & 1 & 269.9 & 0.11 & \\
$\mathrm{Ag}_{2} \mathrm{~F}$ & $+1 / 2$ & 180.4 & 3 & 246.7 & 0.17 & 12 \\
$\mathrm{Ag}_{2} \mathrm{NiO}_{2}$ & $+1 / 2$ & 184.8 & 2 & 252.7 & 0.16 & 13 \\
& & & 1 & 248.1 & 0.18 & \\
$\mathrm{AgNiO}_{2}$ & 1 & 186.6 & 2 & 212.2 & 0.50 & 14 \\
$\mathrm{Ag}_{13} \mathrm{OsO}_{6}$ & $+1 / 3$ & 179.2 & 2 & 245.5 & 0.17 & 15 \\
\hline
\end{tabular}

\section{A4 Silver compounds with a layered crystal structure}

Several silver compounds can be found with a layered structure. When silver is present in a bilayer, it may assume a subvalent oxidation state, as in $\mathrm{Ag}_{2} \mathrm{~F}, \mathrm{Ag}_{6} \mathrm{O}_{2}$, and $\mathrm{Ag}_{2} \mathrm{NiO}_{2}$. When only a single layer of $\mathrm{Ag}$ is present, as in $\mathrm{AgNiO}_{2}$, subvalence is not observed. The crystal structures of $\mathrm{Ag}_{2} \mathrm{~F}, \mathrm{Ag}_{6} \mathrm{O}_{2}, \mathrm{Ag}_{2} \mathrm{NiO}_{2}$, and $\mathrm{AgNiO}_{2}$ are given in Figure $\mathrm{A} 4$.

The view presented in Figure A4 focusses on the presence of silver bilayers in the structure and may therefore appear at odds with the bond valence analyses of $\mathrm{Ag}_{6} \mathrm{O}_{2}$ and $\mathrm{Ag}_{2} \mathrm{~F}$ in the main text, which focusses on the octahedra. To clarify this matter, we point out that the $\mathrm{Ag}-$ $\mathrm{O}-\mathrm{Ag}$ and $\mathrm{Ag}-\mathrm{F}-\mathrm{Ag}$ slabs, in which said octahedra can be identified, form Ag-bilayers when stacked together. 

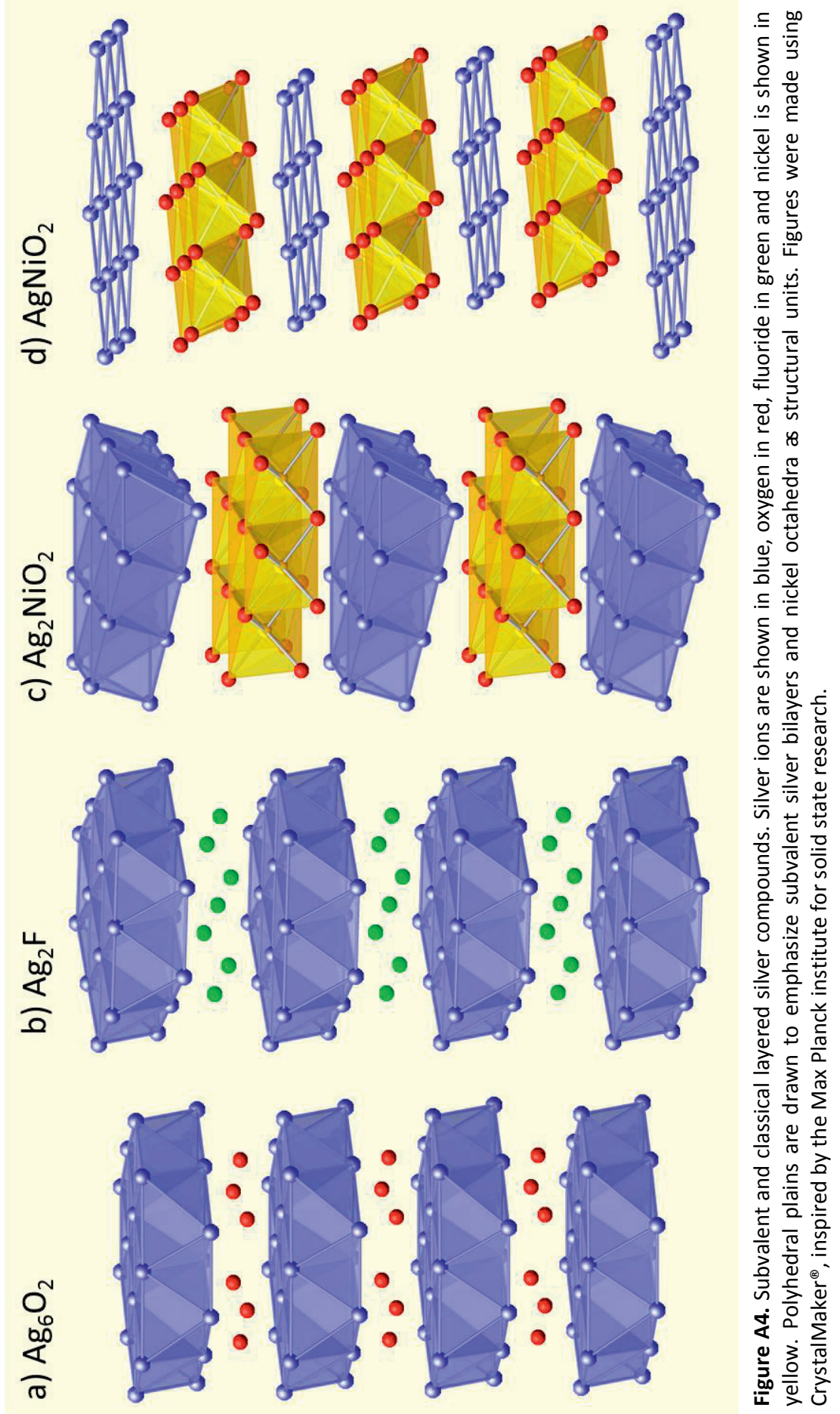


\section{A5 MO/DFT computation}

The quantum mechanical optimization program Spartan 06 was used to evaluate the energies and molecular configurations of $\mathrm{Ag}_{13}$ clusters with various states of subvalency.

\section{Geometrical optimization}

As is discussed in the main text, the metallic $\mathrm{Ag}_{13}$-cluster has a regular icosahedral shape, which becomes slightly distorted if $4-\mathrm{OH}$ groups are placed on its surface. If the structure is further oxidized, and 4 -O groups are placed on the surface, the icosahedral structure becomes severely distorted, as is shown below (Figure A5).

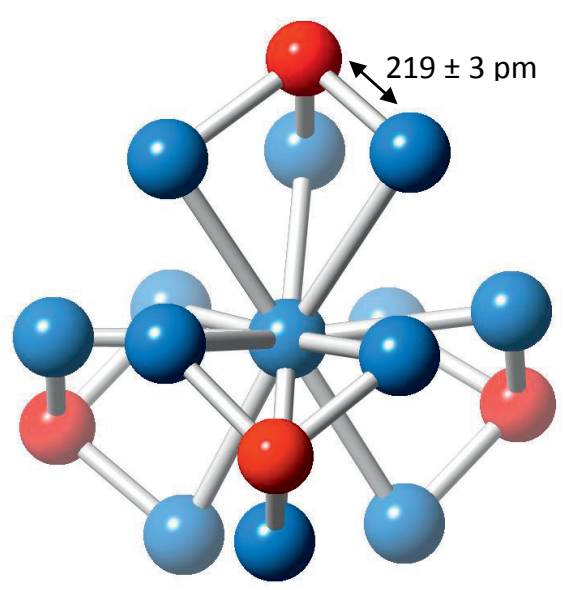

Figure A5. The optimized structures of a $\mathrm{Ag}_{13} \mathrm{O}_{4}$ cluster. Distortion of the initial $\mathrm{Ag}_{13}$-cluster is most obvious in the four forward silver atoms in a nearly square formation: in the optimized $\mathrm{Ag}_{13}$-cluster, these form two triangular planes.

\section{Energy calculations}

The final structure is optimized by finding the molecular configuration with the lowest possible energy contents. Quantum mechanical calculations are analytically solved and may not provide perfectly accurate answers, but they give us a good first impression of chemical stability of different Ag-clusters. The complete enthalpy $(H)$ of a structure is made up of the complete electronic energy $\left(E_{\mathrm{e}}\right)$, the zero point energy of the nuclei $\left(Z_{0}\right)$, the vibrational enthalpy $\left(H_{\mathrm{v}}\right)$, enthalpy due to rigid body translation and rotation $\left(H_{\mathrm{t}}\right.$ and $H_{\mathrm{r}}$, respectively), and a pressure term from the ideal gas law equation $(p \mathrm{~V}=R T)$. By correcting the complete enthalpy for vibrational entropy $\left(S_{v}\right)$ and entropy of rigid body translation and rotation $\left(S_{t}\right.$ and $S_{r}$, respectively), the Gibb's free energy $(G)$ of a structure is obtained. Results of the geometrical optimizations can be found in Table A2.

Using the obtained Gibb's free energies, the Gibb's free energy change of a reaction, $\Delta G_{r}$, can be found by subtracting the combined Gibb's free energy of the reactants from the combined 
Gibb's free energy of the reaction products. As an example, we will calculate the Gibb's free energy change of the transformation of $\mathrm{Ag}_{13} \mathrm{O}_{4}$ into $\mathrm{Ag}_{13}(\mathrm{OH})_{4}$ :

$$
\mathrm{Ag}_{13} \mathrm{O}_{4}+2 \mathrm{H}_{2} \mathrm{O} \leftrightarrow \mathrm{Ag}_{13}(\mathrm{OH})_{4}+\mathrm{O}_{2}
$$

The reactions has a highly negative Gibb's free energy change:

$$
\Delta \mathrm{G}_{\mathrm{r}}=\mathrm{G}_{\mathrm{Ag}_{13}(\mathrm{OH})_{4}}+\mathrm{G}_{\mathrm{O}_{2}}-2 \mathrm{G}_{\mathrm{H}_{2} \mathrm{O}}-\mathrm{G}_{\mathrm{Ag}_{13} \mathrm{O}_{4}}=-176 \frac{\mathrm{kJ}}{\mathrm{mol}}
$$

showing that, at atmospheric oxygen pressures and in the presence of water, $\mathrm{Ag}_{13} \mathrm{O}_{4}$ is highly unstable and will almost certainly be transformed in to $\mathrm{Ag}_{13}(\mathrm{OH})_{4}$ under release of oxygen gas.

Table A2. Calculated energy terms for the optimized structures. Energy terms are given in $\mathrm{kJ} / \mathrm{mol}$ for ambient temperature and pressure of $298.15^{\circ} \mathrm{K}$ and 1 bar, respectively.

\begin{tabular}{lllllll}
\hline & $\mathrm{Ag}_{13}$ & $\mathrm{Ag}_{13} \mathrm{O}_{4}$ & $\mathrm{Ag}_{13}(\mathrm{OH})_{4}$ & $\mathrm{H}_{2}$ & $\mathrm{O}_{2}$ & $\mathrm{H}_{2} \mathrm{O}$ \\
\hline $\mathrm{Ee}_{\mathrm{n}}$ & -4977304.6090 & -5766555.5950 & -5773447.0254 & -3060.3891 & -394326.3640 & -200507.2654 \\
$\mathrm{Z}_{0}$ & 9.5152 & 24.2536 & 153.4747 & 26.5347 & 9.9001 & 55.8086 \\
$\mathrm{H}_{\mathrm{v}}$ & 45.7091 & 40.0642 & 73.2393 & 0 & 0.0067 & 0.0054 \\
$\mathrm{H}_{\mathrm{t}}$ & 3.7184 & 3.7184 & 3.7184 & 3.7184 & 3.7184 & 3.7184 \\
$\mathrm{H}_{\mathrm{r}}$ & 3.7184 & 3.7184 & 3.7184 & 2.4789 & 2.4789 & 3.7184 \\
$\mathrm{pV}$ & 2.4789 & 2.4789 & 2.4789 & 2.4789 & 2.4789 & 2.4789 \\
$\mathrm{~S}_{\mathrm{v}}$ & 119.5875 & 94.3738 & 168.5380 & 0 & 0.0076 & 0.0061 \\
$\mathrm{St}$ & 59.3323 & 59.4996 & 59.5099 & 35.0289 & 45.3084 & 43.1723 \\
$\mathrm{~S}$ & 47.2934 & 47.9451 & 47.9927 & 3.8162 & 14.8042 & 13.1094 \\
$\mathrm{H}$ & -4977239.4690 & -5766481.3615 & -5773210.3957 & -3025.1782 & -394307.7810 & -200441.5357 \\
$\mathrm{G}$ & -4977465.6822 & -5766683.1800 & -5773486.4364 & -3064.0233 & -394367.9012 & -200497.8236 \\
\hline
\end{tabular}




\section{A6 Collected literature data}

We have collected data from literature references which have performed AgNP dissolution experiments and which have measured $\mathrm{Ag}^{+}$concentration at equilibrium. We have carefully documented all available information on particles size, standard deviation, synthesis, capping agents and other relevant steps taken during sample preparation. Silver release data have been converted into a loading parameter by expressing the final $\mathrm{Ag}^{+}$concentrations per total AgNP surface area, according to:

$\Gamma=\frac{\left[\mathrm{Ag}^{+}\right]}{S A}=\frac{\left[\mathrm{Ag}^{+}\right]}{S S R \cdot A}$

where $\Gamma$ is the surface loading (in $\mathrm{mol} / \mathrm{m}^{2}$ ), $\left[\mathrm{Ag}^{+}\right]$is the ionic silver concentration (in $\mathrm{mol} / \mathrm{L}$ ), $S A$ is the total AgNP surface area (in $\mathrm{m}^{2} / \mathrm{L}$ ), $S S R$ is the solid solution ratio (i.e., the initial AgNP concentration in $\mathrm{g} / \mathrm{L}$ ), $A$ is the AgNP specific surface area (in $\mathrm{m}^{2} / \mathrm{g}$ ). Using

$$
A=\frac{6}{d \cdot \rho_{\mathrm{Ag}}}
$$

where $d$ is the AgNP diameter (in $\mathrm{m}$ ) and $\rho_{\mathrm{Ag}}$ is the mass density of silver (in $\mathrm{g} / \mathrm{m}^{3}$ ), equation 2 can be rewritten to

$\Gamma=\frac{\left[\mathrm{Ag}^{+}\right] \cdot d \cdot \rho_{\mathrm{Ag}}}{6 \cdot S S R}$

Moreover, an average loading is given for the combined data points of each reference. Data and references can be found in Table A3. 
Appendix A

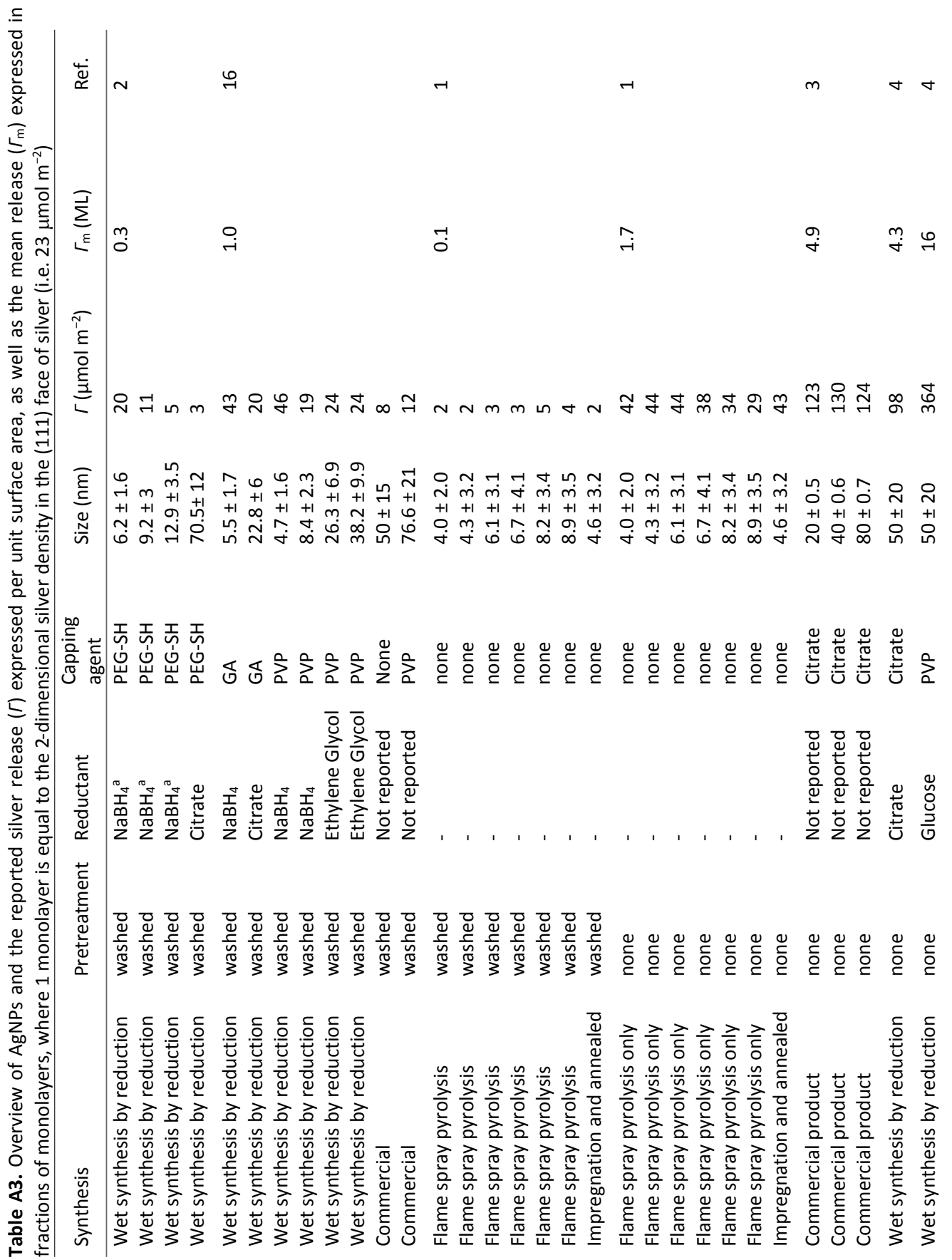




\section{A7 References}

1. G. A. Sotiriou, A. Meyer, J. T. N. Knijnenburg, S. Panke and S. E. Pratsinis, Langmuir, 2012, 28, 15929-15936.

2. T. S. Peretyazhko, Q. Zhang and V. L. Colvin, Environmental Science \& Technology, 2014, 48, 11954-11961.

3. W. Zhang, Y. Yao, N. Sullivan and Y. S. Chen, Environmental Science \& Technology, 2011, 45, 4422-4428.

4. S. Kittler, C. Greulich, J. Diendorf, M. Köller and M. Epple, Chemistry of Materials, 2010, 22, 4548-4554.

5. H. Hofmeister, Encyclopedia of Nanoscience and Nanotechnology, 2004, 3, 431.

6. I. D. Brown and D. Altermatt, Acta Crystallographica Section B, 1985, 41, 244-247.

7. W. Beesk, P. G. Jones, H. Rumpel, E. Schwarzmann and G. M. Sheldrick, Journal of the Chemical Society, Chemical Communications, 1981, DOI: 10.1039/C39810000664, 664665.

8. R. W. G. Wyckoff, American Journal of Science, 1922, 5, 184.

9. I. Persson and K. B. Nilsson, Inorganic Chemistry, 2006, 45, 7428-7434.

10. K. Yvon, A. Bezinge, P. Tissot and P. Fischer, Journal of Solid State Chemistry, 1986, 65, 225-230.

11. B. Standke and M. Jansen, Zeitschrift für anorganische und allgemeine Chemie, 1986, 535, 39-46.

12. H. Ott and H. Seyfarth, Zeitschrift für Kristallographie - Crystalline Materials, 1928, 67, 430-433.

13. U. Wedig, P. Adler, J. Nuss, H. Modrow and M. Jansen, Solid State Sciences, 2006, 8, $753-$ 763.

14. Y. J. Shin, J. P. Doumerc, P. Dordor, C. Delmas, M. Pouchard and P. Hagenmuller, Journal of Solid State Chemistry, 1993, 107, 303-313.

15. S. Ahlert, W. Klein, O. Jepsen, O. Gunnarsson, O. K. Andersen and M. Jansen, Angewandte Chemie International Edition, 2003, 42, 4321.

16. R. Ma, C. m. Levard, S. M. Marinakos, Y. Cheng, J. Liu, F. M. Michel, G. E. Brown, Jr. and G. V. Lowry, Environmental Science \& Technology, 2011, 46, 752-759. 



\section{Appendix B}

\section{Supporting information to Chapter 3}

The $\mathrm{pH}$, time, and size dependency of silver nanoparticle dissolution

Bastiaan Molleman and Tjisse Hiemstra

B1 Solubility of $\mathrm{Ag}_{2} \mathrm{O}$

B2 Particles size distribution of NanoComposix AgNPs

B3 Two methods of sample preparation compared

B4 The effect of sample agitation on AgNP dissolution

$\mathrm{B} 5 \mathrm{Ag}^{+}$retention by ultrafiltration filter units

$\mathrm{B} 6 \mathrm{Ag}^{+}$release on a linear scale

B7 Possible surface structures

B8 The effect of multiple particle sizes on dissolution

B9 Linking the empirical model two the surface structure

B10 Data by Adamczyk et al. 


\section{B1 Solubility of silver oxide}

The solubility of $\mathrm{Ag}_{2} \mathrm{O}(\mathrm{s})$ has been studied in a large number of authors. These experiments have been evaluated by Biedermann and Sillén. ${ }^{1}$ The solubility reaction of $\mathrm{Ag}_{2} \mathrm{O}(\mathrm{s})$ can be given as:

$$
1 / 2 \mathrm{Ag}_{2} \mathrm{O}(\mathrm{s})+1 / 2 \mathrm{H}_{2} \mathrm{O}(\mathrm{l}) \leftrightarrow \mathrm{Ag}^{+}(\mathrm{aq})+\mathrm{OH}^{-}(\mathrm{aq}) \quad \text { with } \log \mathrm{K}=-7.71
$$

The same solubility product has been reported more recently by Duro et al., ${ }^{2}$ although they incorrectly refer to it as silver hydroxide $(\mathrm{AgOH})$. The solubility diagram of $\mathrm{Ag}_{2} \mathrm{O}(\mathrm{s})$ is given below.

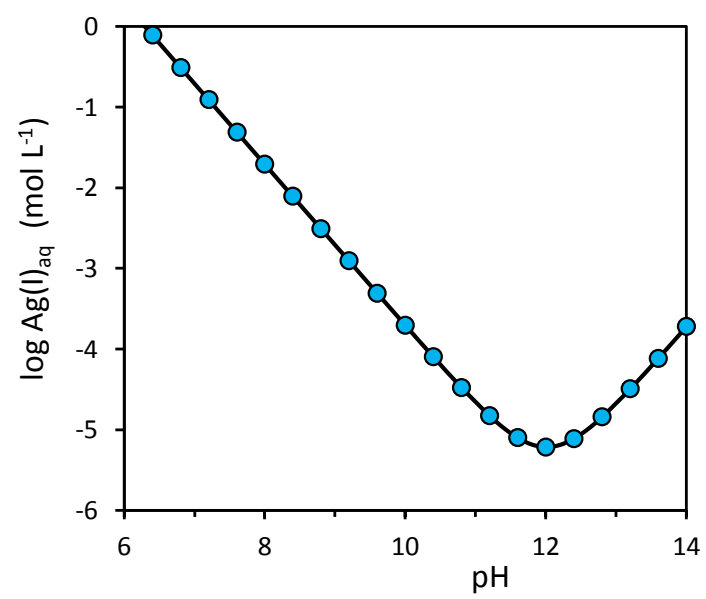

Figure B1. $\mathrm{pH}$ dependent solubility of $\mathrm{Ag}_{2} \mathrm{O}(\mathrm{s})$. At the left $\mathrm{y}$-axis, the unit in $\mathrm{mol} \mathrm{L}^{-1}$. At the right $\mathrm{y}$-axis,

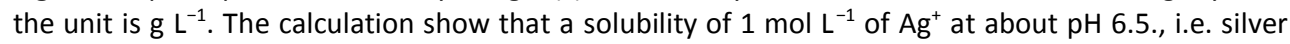
oxide can be very soluble. At pH 7, it is $0.2 \mathrm{~mol} \mathrm{~L}^{-1}$ or more than $20 \mathrm{~g} \mathrm{~L}^{-1}$. If the solubility of $\mathrm{Ag}_{2} \mathrm{O}(\mathrm{s})$ is tested in water and the $\mathrm{pH}$ is left free, the solubility is about a factor 1000 times less. The reason is the strong increase of the $\mathrm{pH}$ as a result of the dissolution process. A pH of about 10.1 is reached and the corresponding solubility is near $25 \mathrm{mg} \mathrm{L}^{-1}$ of $\mathrm{Ag}_{2} \mathrm{O}$. 


\section{B2 Particle size distribution of NanoComposix AgNPs}

In our article, we use the mean diameter and specific surface area $\left(A_{\mathrm{p}}\right)$ as provided by NanoComposix. Figure $\mathrm{B} 2$ gives the particle size distributions for $\mathrm{AgNP}_{5}, \mathrm{AgNP}_{10}$ and $\mathrm{AgNP}_{20}$ as extracted from the material data sheets provided with the product. The figure shows which percentage of particles falls into the different size categories. The dotted lines represent normal distributions having the mean and standard deviation given by the manufacturer.

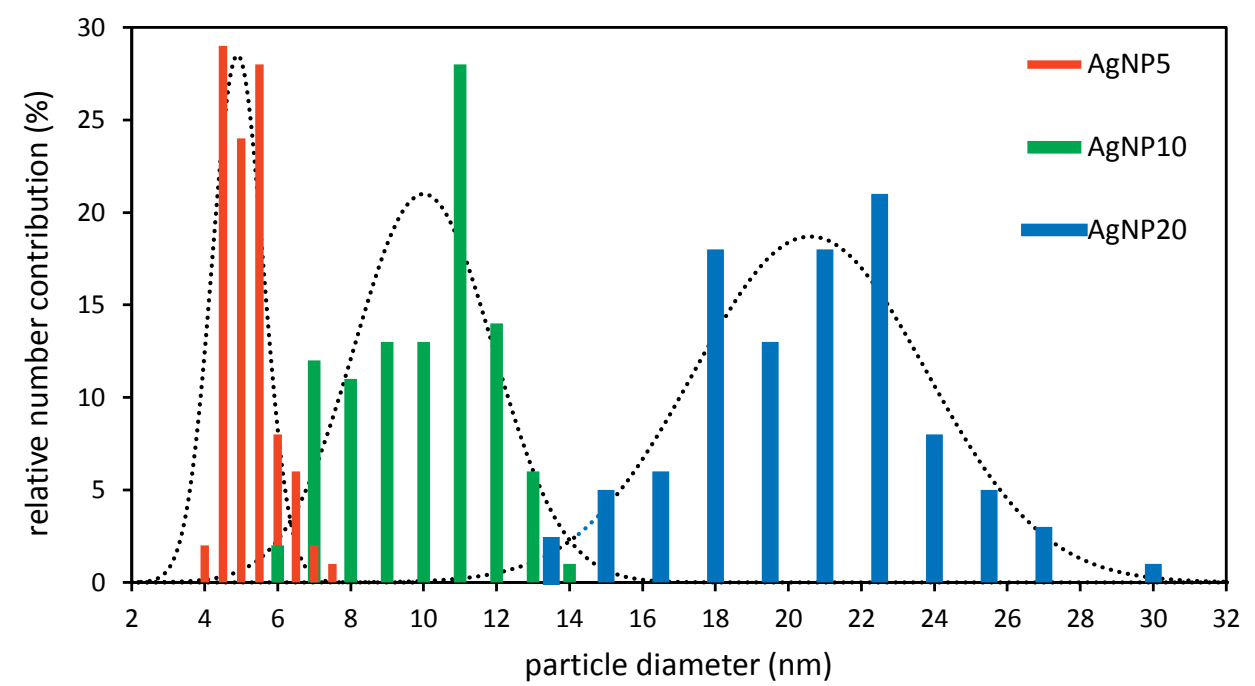

Figure B2. Particle size distributions for AgNP5, AgNP10, and AgNP20 as given by the manufacturer. Relative abundance is based on individual counts. Dotted lines are calculated with a normal distribution function using $4.9 \pm 0.7,9.9 \pm 1.9,20.6 \pm 3.2$, respectively, and corrected for the size intervals $(0.5,1.0$, and 1.5 , respectively).

The $A_{p}$ provided by NanoComposix was calculated from the relative abundance of particle diameters assuming spherical particles. Deviation from the spherical shape will increase the specific surface area. The effect for oblate (lens-shaped) and prolate (egg-shaped) particles has been calculated below showing that $A_{p}$ increases with less than $10 \%$ if one of the axes is $20 \%$ longer or shorter (see below). Given that the great majority of particles appear well rounded in the TEM photographs (provided by NanoComposix), we feel that no correction for non-ideal shape is needed.

Specific surface area of spheroids

A flattened spheroid, having an equatorial radius, $a$, longer than the polar radius, $c$, is known as oblate or lens-shaped. The surface area for oblate particles, $A_{\mathrm{ob}}$, can be calculated using:

$$
A_{\mathrm{ob}}=2 \pi a^{2}\left(1+\frac{1-e^{2}}{e} \tanh ^{-1} e\right) \quad \text { where } e=\sqrt{1-\frac{c^{2}}{a^{2}}}
$$


An elongated spheroid, having a polar radius $(c)$ longer than the equatorial radius $(a)$ is known as prolate or egg-shaped. The surface area for prolate particles, $A_{\text {pro, }}$ can be calculated using:

$$
A_{\text {pro }}=2 \pi a^{2}\left(1+\frac{1-e^{2}}{e} \tanh ^{-1} e\right) \quad \text { where } e=\sqrt{1-\frac{a^{2}}{c^{2}}}
$$

The volume of a spheroid is equal to:

$$
V=\frac{4}{3} \pi a^{2} \mathrm{c}
$$

Note that for a perfect sphere with $a=c=r$, the latter equation reduces to the well-known equation for the volume of a sphere.

Using these formulae we find that for oblate particles with $c$ up to $20 \%$ shorter than $a, A_{p}$ is no more than $10 \%$ larger than for a sphere with $r$ equal to $a$. Similarly, we find that for a prolate spheroid with $c$ up to $20 \%$ longer than $a, A_{\mathrm{p}}$ is no more than $5 \%$ larger than for a sphere with $r$ equal to the average of $c$ and $a$.

\section{B3 Two methods of sample preparation compared}

The $\mathrm{pH}$ and time dependency of the $\mathrm{Ag}^{+}$release have been tested using two different experimental methods. In short, samples for method I were mixed in a single large batch, and then divided up into several sets of duplicates. At each sampling time, one set of duplicates was taken and analyzed destructively. Duplicates for method II were individually mixed, but not divided into sets. At each sampling time, solution was taken from the same batches. The experimental setups are explained in more detail in Material and Methods of the main text.

$\mathrm{Ag}^{+}$release for both experimental setups were compared and found to yield very similar results (see Figure B3). After 1 day, $\mathrm{Ag}^{+}$release is almost exactly similar, after 1 and 2 weeks, method II shows a somewhat lower dissolution, but after 5 weeks, this difference has almost completely disappeared. 


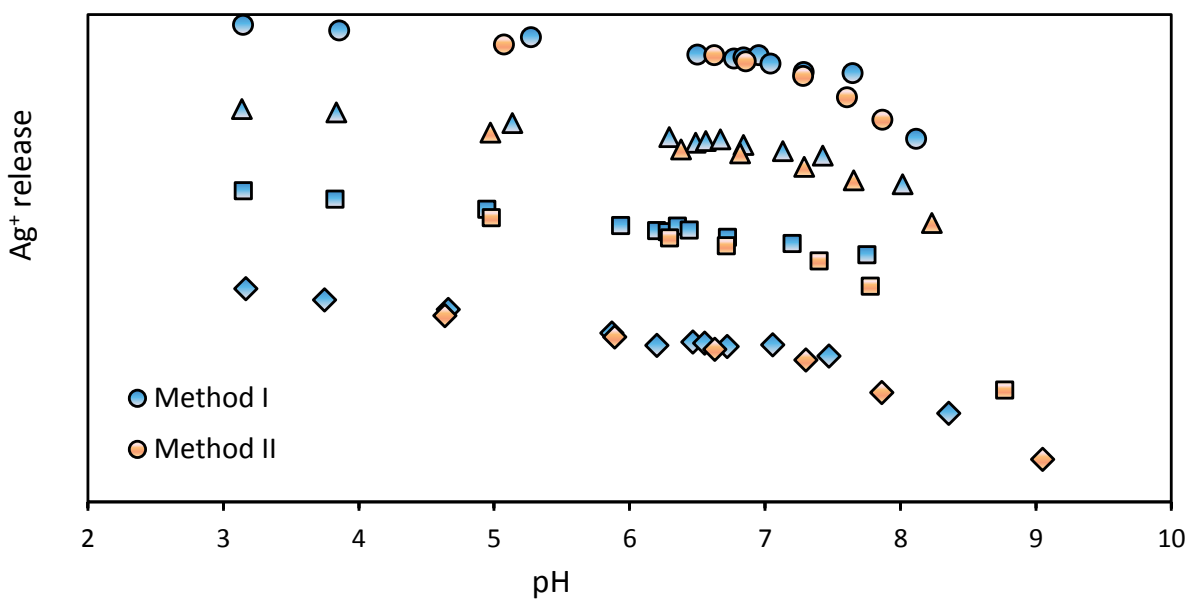

Figure B3. $\mathrm{Ag}^{+}$release measured using the two different experimental setups. Data is plotted on a logarithmic scale, and data points of a single time-step have been multiplied with 10x for clarity. Therefore, this graph does not(!) represent the progression of dissolution, but serves to compare the results between the two different methods at one (!) sampling time. From top to bottom data points represent $\mathrm{Ag}^{+}$release after 5 weeks (circles), 2 weeks (triangles), 1 week (squares), and 1 day (diamonds).

\section{B4 Effect of shaking on AgNP dissolution}

During preliminary experiments, it was observed, that a silver coating was formed on the wall of the sample containers. The silver deposit was visible only in those regions that were intermittently exposed to the sample and air as a result of the shaking motion. This led us to suspect that shaking may cause AgNPs to precipitate out of solution. We reasoned that, similarly to bubbles forming in a soapy suspension, the effect might not occur in a stationary sample. In this work, we have therefore chosen for an unconventional experimental method where samples are not agitated.

\section{Theoretical considerations}

With a mass density of $10.5 \cdot 10^{6} \mathrm{~g} \mathrm{~m}^{-3}$, a $5 \mathrm{~nm}$ spherical AgNP will have a mass of about $7 \cdot 10^{-19}$ g. At a solid to solution ratio of $\sim 10 \mathrm{mg} \mathrm{L}^{-1}$, or $10 \mathrm{~g} \mathrm{~m}^{-3}$, this means approximately $7 \cdot 10^{-20} \mathrm{~m}^{3}$ of solution is available to each particle, which translates to a sphere with a diameter of roughly $500 \mathrm{~nm}$. The maximum travel distance between an oxygen molecule and the particle surface is thus $\sim 250 \mathrm{~nm}$. For a $20 \mathrm{~nm}$ AgNP, this distance is 4 times larger, or approximately $1 \mu \mathrm{m}$.

For the simplified case of 1-dimensional diffusion, the root mean-square distance of diffusion, $V\left\langle x^{2}\right\rangle=V(2 D t)$, can be used to estimate the distance over which the concentration becomes roughly uniform in time, $t$. At room temperature, or $298 \mathrm{~K}$, dissolved oxygen has a diffusion coefficient, $D$, of $2.1 \cdot 10^{-9} \mathrm{~m}^{2} \mathrm{~s}^{-1}$, leading to a 1 second diffusion length of around $\mathrm{V}\left\langle x^{2}\right\rangle=6.5$ $10^{-5} \mathrm{~m}$ or $65 \mu \mathrm{m}$. Although this is a simplified view, the diffusion length in 1 second is greatly 
exceeds the distance between particles. Therefore, from the perspective of diffusion, shaking the samples will not influence the $\mathrm{Ag}^{+}$release kinetics on the timescale that we used.

\section{Experimental}

To test empirically that shaking does not limit AgNP dissolution, we compared the $\mathrm{Ag}^{+}$release found in the preliminary experiments (with shaking for 3 weeks) to the $\mathrm{Ag}^{+}$release found in our final experiments (without shaking). Slightly larger AgNPs were used for the preliminary experiment $\left(\mathrm{AgNP}_{6}, 5.7 \pm 1.0 \mathrm{~nm}\right)$ than for the final experiment $\left(\mathrm{AgNP}_{5}, 4.9 \pm 0.7\right)$. The $\mathrm{pH}$ dependency of $\mathrm{Ag}^{+}$release at high $\mathrm{pH}$ is shown for both experiments in Figure B4.

When the dissolution is expressed per unit surface area, a clear difference is found (Figure B4). This could be due to the use of particles of different size or could be due to our shaking versus non-shaking procedure. If due to a difference in size, the $\mathrm{Ag}^{+}$release of the $5.7 \mathrm{~nm}$ AgNP is expected to be lower because large particles are more stable. The data can be explained assuming a slightly larger size $(7 \mathrm{~nm})$, which could be in line with our observation of the formation of a silver film that may increase the mean particle size in the system in case of shaking. Whatever, we may safely conclude based on the theoretical considerations and the above experimental observations that our procedure without shaking cannot have led to underestimation of the $\mathrm{Ag}^{+}$release compared to a standard procedure with continuously shaking. On the contrary, shaking may induce deviations. 


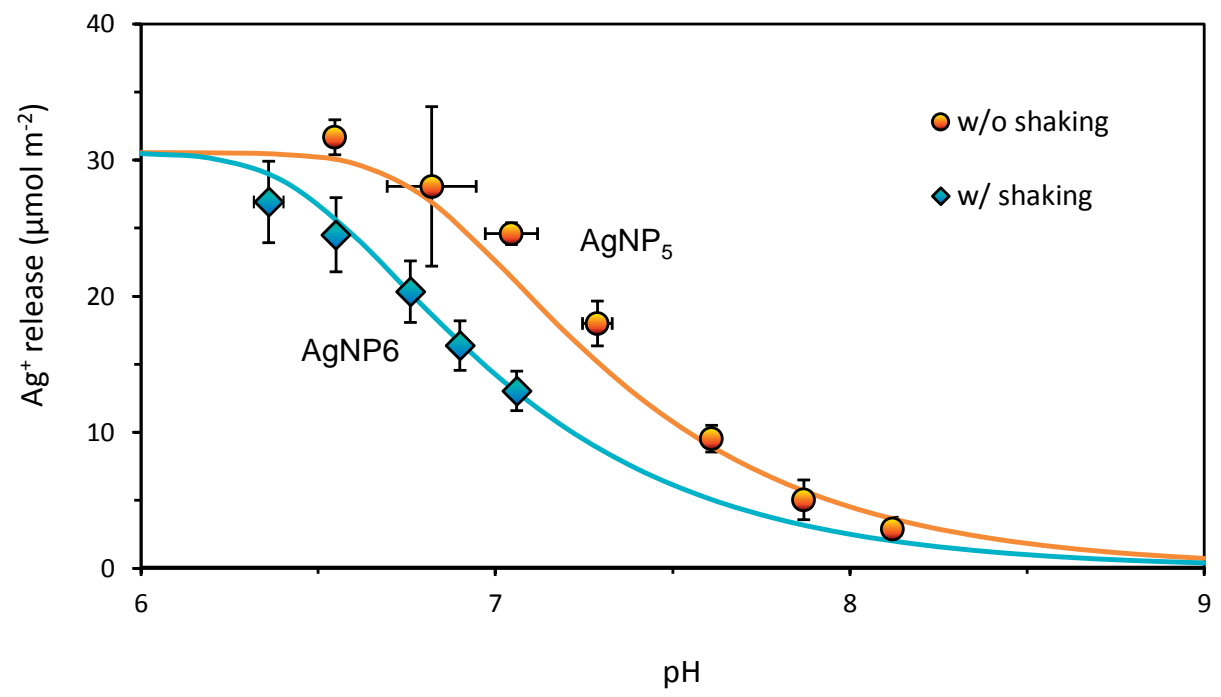

Figure B4. $\mathrm{pH}$ dependent $\mathrm{Ag}^{+}$release curves for $\mathrm{AgNP}_{5}$ (without shaking, circles) and $\mathrm{AgNP}_{6}$ (with shaking, diamonds). The $\mathrm{AgNP}_{6}$ data were obtained in a preliminary experiment without duplicates, the error bars represent a $\sim 10 \%$ error. The transparent symbols are calculated from the $\mathrm{AgNP}_{6}$ data, under the assumption that $15 \%$ precipitated out of solution forming a silver film with negligible contribution to $A_{T}$ and thus to the $\mathrm{Ag}^{+}$release equilibrium. Dotted lines represent the model description of the data using a fitted $\log K_{\mathrm{H} / \mathrm{Ag}}$ value.

\section{$\mathrm{B} 5 \mathrm{Ag}^{+}$retention by ultrafiltration filter units}

To determine the dissolved $\mathrm{Ag}^{+}$concentrations in our samples, the AgNPs were separated from the solution using Microsep ${ }^{\mathrm{TM}}$ Advance Centrifugal Devices (3 kDa). The ultrafiltration membrane in the filter units is made of polyether sulfone, which may adsorb $\mathrm{Ag}^{+}$. This may lead to a lower $\mathrm{Ag}^{+}$concentration in the filtrate than in the sample. To compensate for the $\mathrm{Ag}^{+}$ retention, a volume of sample was filtrated to saturate the filtration membrane; this first filtrate was discarded. A second volume was filtered to obtain a filtrate with $\mathrm{Ag}^{+}$ concentrations equal to those in the sample.

This method to obtain accurate $\mathrm{Ag}^{+}$concentrations was tested for $\mathrm{AgNO}_{3}$ solutions with three different background electrolytes (1 mM): $\mathrm{NaHCO}_{3}(\mathrm{pH} \sim 8), \mathrm{NaNO}_{3}(\mathrm{pH} \sim 5.5)$ and $\mathrm{HNO} 3(\mathrm{pH}$ 3). UPW was centrifuged over the filter units 3 times before the first sample was introduced. Figure $\mathrm{B} 5$ shows $\mathrm{Ag}^{+}$concentrations determined by ICP-MS before and after filtration. Both the first and the second filtrate are analyzed for $\mathrm{Ag}^{+}$concentrations. At $\mathrm{pH} 8$, the ultrafiltration units are seen to retain a significant amount of $\mathrm{Ag}^{+}$, presumably by binding to reactive groups in the filtration membrane. This is supported by the low retention at lower $\mathrm{pH}$ values. At concentration levels relevant to the experimentation $\left(\left[\mathrm{Ag}^{+}\right]>0.1 \mu \mathrm{M}\right)$, the second filtrate is seen to contain $\mathrm{Ag}^{+}$at levels adequately close to the unfiltered sample. Results obtained using this method can thus be considered as representative for the $\mathrm{Ag}^{+}$concentrations in the sample. 

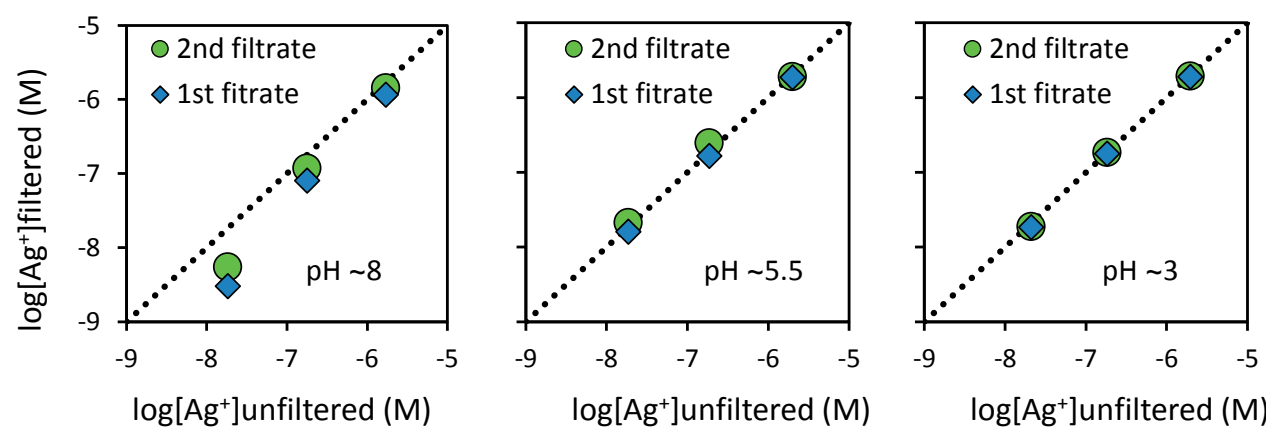

Figure $\mathrm{B5}$. $\mathrm{Ag}^{+}$concentrations in the first and second filtrate plotted against $\mathrm{Ag}^{+}$concentrations in unfiltered samples in $1 \mathrm{mM}$ solutions of $\mathrm{NaHCO}_{3}\left(\mathrm{pH}^{\sim} 8\right), \mathrm{NaNO}_{3}\left(\mathrm{pH}^{\sim} 5.5\right)$, and $\mathrm{HNO}_{3}(\mathrm{pH} \sim 3)$. As results show, the $\mathrm{Ag}^{+}$concentration found in the second filtrate is very close or equal to that found in the unfiltered samples at concentrations above $10^{-7} \mathrm{M}$.

\section{B6 $\mathrm{Ag}^{+}$release at a linear scale}

As mentioned in the text, the largest contribution to total release of $\mathrm{Ag}^{+}$occurs at low $\mathrm{pH}$. Dissolution in the neutral $\mathrm{pH}$ range has the most important impact on the $\mathrm{Ag}^{+}$concentrations with respect to the reaction quotient, $Q$ (see main text), but contributes only marginally to total $\mathrm{Ag}^{+}$release. When plotted on a linear scale, as in Figure $\mathrm{B} 6$, the magnitude of $\mathrm{Ag}^{+}$release at low $\mathrm{pH}$ is immediately apparent. Especially for the larger particles, $\mathrm{Ag}^{+}$release is strongly enhanced at low $\mathrm{pH}$, reaching up to 9 equivalent atomic $\mathrm{Ag}$ layers, whereas dissolution at neutral to high $\mathrm{pH}$ is mostly limited to the first atomic layer. 


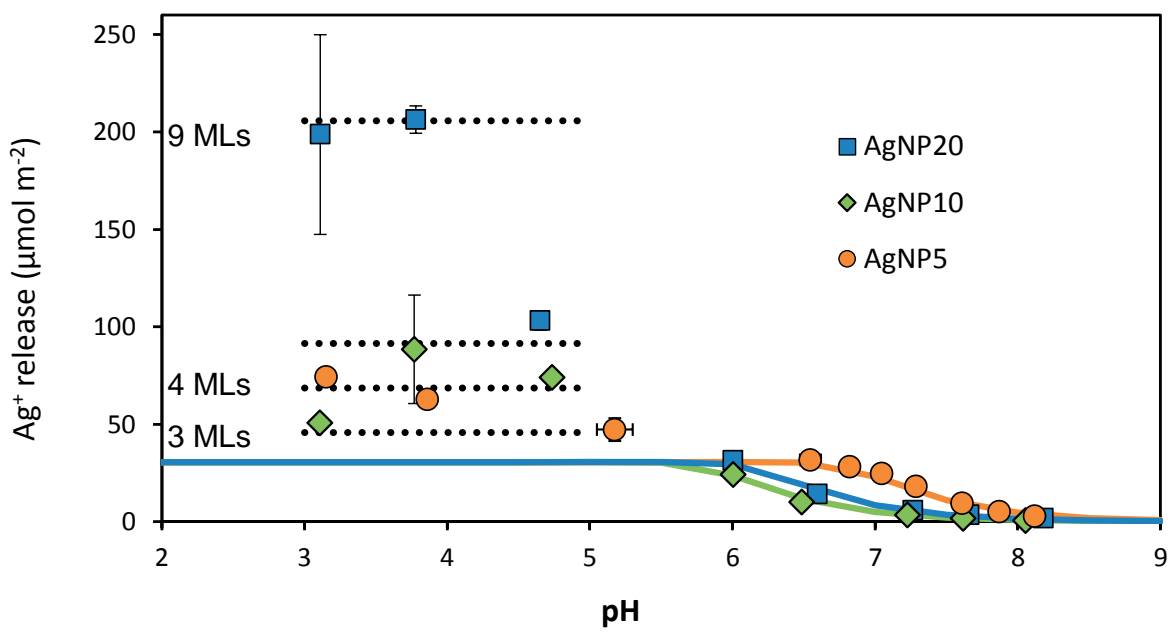

Figure B6. The $\mathrm{pH}$ dependency of $\mathrm{Ag}^{+}$release on a linear scale, together with the expected release at dissolution of a multitude of $\mathrm{Ag}$ monolayers (MLs). With a $\mathrm{Ag}-\mathrm{Ag}$ distance of $0.2889 \mathrm{~nm},{ }^{3}$ a $\mathrm{Ag}$ density of $\sim 14 \mathrm{~nm}^{-2}$ is found on the hexagonally organized [111] face. Dissolution of a single layer of Ag atoms thus releases $23 \mu \mathrm{mol} \mathrm{m}$. The figure shows that at neutral to high $\mathrm{pH}$, less than $2 \mathrm{MLs}$ are dissolved, while at low $\mathrm{pH}$ up to $9 \mathrm{MLs}$ can be released as $\mathrm{Ag}^{+}$.

\section{B7 Possible surface structures}

\section{Oxidation states of the AgNP surface}

Silver at the surface of AgNPs is only partially oxidized. ${ }^{4}$ Two different states of oxidation can be found at the surface of AgNP. Under mildly oxidized conditions, the valence of $\mathrm{Ag}$ at the surface can be represented by $z_{\mathrm{Ag}}=+1 / 3$ v.u. At the [111] faces of icosahedral AgNP, subvalency leads to a surface structure with $\equiv \mathrm{Ag}_{3} \mathrm{OH}$ groups with a density of $4.6 \mathrm{~nm}^{-2} .5$

A higher surface oxidation state can be reached by formation of subvalent silver over multiple layers. Subvalent silver organized in two layers can be found in solids such as $\mathrm{Ag}_{6} \mathrm{O}_{2},{ }^{6} \mathrm{Ag}_{2} \mathrm{~F}^{7}$ and $\mathrm{Ag}_{2} \mathrm{NiO}_{2}{ }^{8}$

For the gas-solid interface, oxidation over multiple atomic layers may occur when metallic silver is exposed to atomic oxygen at high temperature. ${ }^{9}$ According to our bond valence analysis of the reported structures, this leads to full oxidation $\left(z_{\mathrm{Ag}}=+1 \mathrm{v}\right.$.u. $)$ in the first layer and subvalency $\left(z_{\mathrm{Ag}}=+1 / 2 \mathrm{v}\right.$.u. $)$ in the second layer.

For the water-solid interface, formation of subvalent silver over two layers has been suggested in case of strong oxidation. Formation of $\mathrm{Ag}_{6} \mathrm{O}$ octahedra has been proposed in our previous contribution. ${ }^{5}$ However, present attempts to optimize the geometry of such a $\mathrm{Ag}_{6} \mathrm{O}$ structure using MO-DFT pointed to a large instability of the oxygen ion in hexa-coordination with six subvalent silver ions. To reconcile the presence of a higher oxidation state with the formation 
of subvalent silver over two layers without formation of $\mathrm{Ag}_{6} \mathrm{O}$ octahedra, we suggest a new surface structure.

Oxidation of $\mathrm{Ag}$ over multiple layers is structurally possible, if $\mathrm{Ag}$ at the surface is partially replaced by oxygen ions. An oxygen in this position is able to coordinate to three underlying silver leading to the formation $\equiv \mathrm{Ag}_{3} \mathrm{OH}$ with a subvalency of $z_{\mathrm{Ag}}=+1 / 3 \mathrm{v}$.u. for the three $\mathrm{Ag}$ ions in the subsurface. Simultaneously, the remaining surface atoms can also attain a subvalent state by partial oxidation. Depending on the precise surface structure, $\equiv \mathrm{Ag}_{2} \mathrm{OH}$ or $\equiv \mathrm{Ag}_{3} \mathrm{OH}$ may form having a subvalency of $z_{\mathrm{Ag}}=+1 / 2 \mathrm{v}$.u. or $z_{\mathrm{Ag}}=+1 / 3 \mathrm{v}$.u., respectively. The result is $\mathrm{OH}$ groups on top of as well as in between the atoms of the outer silver layer, leading to subvalency in both the surface and the subsurface.

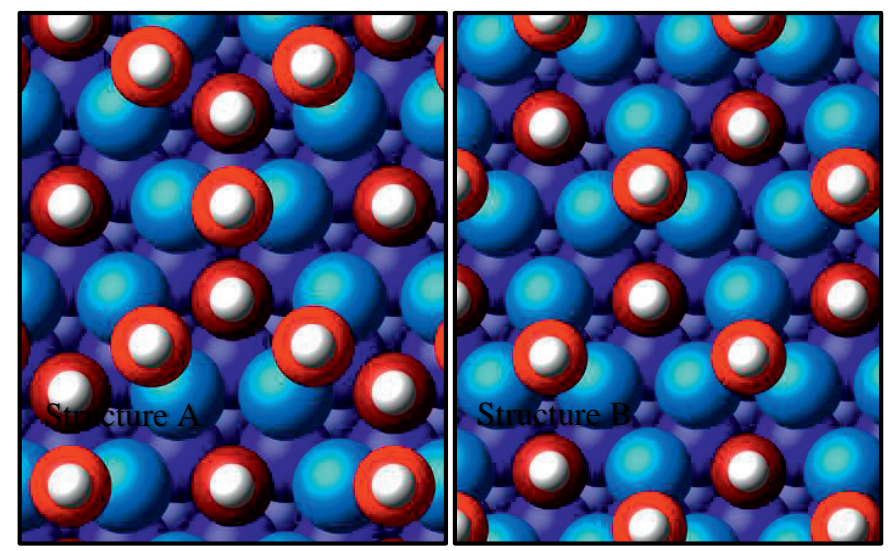

Figure B7. Geometric representations of the [111] face of silver nanoparticles with partially oxidized, i.e. subvalent, silver coordinated to $\mathrm{OH}$ groups. Oxidation occurs over two layers leading to the formation of subvalent $\equiv \mathrm{Ag}_{3} \mathrm{OH}\left(z_{\mathrm{Ag}}=+1 / 3 \mathrm{v}\right.$.u. $)$ in the subsurface. Structure $A$ can be formed without surface restructuring at removal of the original $\equiv \mathrm{Ag}_{3} \mathrm{OH}$ if this group has coordinated to an underlying single $\mathrm{Ag}$ atom that is simultaneously removed. Structure $B$ can only be formed if restructuring of the surface occurs. Formation of structures $A$ and $B$ results in a $\mathrm{Ag}^{+}$release of 31 and $29 \mu \mathrm{mol} \mathrm{m} \mathrm{m}^{-2}$, respectively, in agreement with the model applied in Figure 3.2 of the main text.

\section{Possible surface structures}

Figure B7 shows two typical surface structures with subvalency over two layers. In both structures, the deeper lying $\mathrm{OH}$ groups coordinate to three silver atoms in the subsurface. $\mathrm{A}$ higher subvalency arises in the surface than in the subsurface, resulting in a gradual transition between completely oxidized $\mathrm{Ag}^{+}$in solution to fully reduced metallic $\mathrm{Ag}^{0}$ in the $\mathrm{AgNP}$ core.

Structure A (Figure B7a) can be directly formed at oxidation of a $\equiv \mathrm{Ag}_{3} \mathrm{OH}$ site if it coordinates to a single underlying $\mathrm{Ag}$ atom, forming a silver tetrahedron topped with a hydroxide $\left(\equiv \mathrm{AgAg}_{3} \mathrm{OH}\right.$ ). If the underlying $\mathrm{Ag}$ is removed upon oxidation of a tetrahedral $\equiv \mathrm{Ag}_{3} \mathrm{OH}$ site, the resulting opening in the second layer of silver can be occupied by an oxygen atom, allowing partial oxidation of the underlying $\mathrm{Ag}$ atoms in the third layer. The above process leads to the formation of new $\equiv \mathrm{Ag}_{3} \mathrm{OH}$ sites $\left(z_{\mathrm{Ag}}=+1 / 3 \mathrm{v}\right.$.u. $)$ from subsurface, $\mathrm{Ag}^{0}$. The remaining silver at the 
surface transforms into $\equiv \mathrm{Ag}_{2} \mathrm{OH}$ surface groups $\left(z_{\mathrm{Ag}}=+1 / 2 \mathrm{v}\right.$.u. $)$. Structure $\mathrm{A}$ can be represented with the stoichiometric notation $\equiv \mathrm{Ag}_{5}(\mathrm{OH})_{2}$. Formation of structure $A$ requires the release of four $\mathrm{Ag}^{+}$ions, or $x+z=4$, resulting in a maximum $\mathrm{Ag}^{+}$release of $31 \mu \mathrm{mol} \mathrm{m}{ }^{-2}$.

In structure B (Figure B7b), both the surface and the subsurface have only $\equiv \mathrm{Ag}_{3} \mathrm{OH}$ sites. In contrast to structure $A$, one in four atoms in the subsurface does not coordinate to a hydroxide anion, and may be regarded as metallic. Overall, the silver in this structure is thus less oxidized, with an average subvalence of $\bar{z}_{\mathrm{Ag}}=+1 / 4 \mathrm{~V}$.u.in the subsurface, and $z_{\mathrm{Ag}}=+1 / 3 \mathrm{~V}$.u. in the surface groups. Structure B can only be formed by moving Ag ions to new lattice positions; the necessary restructuring may be possible in case of high surface mobility. ${ }^{10}$ Structure $B$ has the stoichiometric notation $\equiv \mathrm{Ag}_{4.5}(\mathrm{OH})_{1.5}$ and $x+z=3.75$, leading to a maximum $\mathrm{Ag}^{+}$release of 29 $\mu \mathrm{mol} \mathrm{m} \mathrm{m}^{-2}$.

\section{B8 Effect of multiple particle sizes on dissolution}

In this work, a correlation was found between the overall specific surface area $\left(A_{p}\right)$ and the values of $\log K_{\mathrm{H} / \mathrm{Ag}}$ that best described the observed $\mathrm{Ag}^{+}$release. This suggests that within batches, the particle size distribution (see Figure B2) also results in a distribution of surface stabilities. If the chemical heterogeneity resulting from the particle size distribution is large enough, it could affect the slope, $\Delta \log \left(\mathrm{Ag}^{+}\right) / \Delta \mathrm{pH}$. The effect of a distribution of surface stabilities has been investigated by modelling $\mathrm{Ag}^{+}$release for polydisperse and monodisperse nanoparticle suspensions.

\section{Modelling approach}

Monodisperse suspensions were simulated using the value for $A_{p}$ given by the manufacturer and an AgNP concentration of $10 \mathrm{mg} \mathrm{L}^{-1} ; \log K_{\mathrm{H} / \mathrm{Ag}}$ values were calculated using the relation:

$$
\log K_{\mathrm{H} / \mathrm{Ag}}=0.08 A_{\mathrm{p}}+5.2
$$

as was found by linear regression (Chapter 3 ) from the data generated in this work as well as collected data from literature. ${ }^{11,12}$

In simulations of polydisperse suspensions, for each size category, $k$, an individual AgNP concentration was defined, as well as individual values for $A_{\mathrm{p}}$ and $\log K_{\mathrm{H} / \mathrm{Ag}}$. Relative number contributions, $f_{N, k}$, for the different size categories were extrapolated directly from the particle size distributions for $\mathrm{AgNP}_{5}, \mathrm{AgNP}_{10}$, and $\mathrm{AgNP}_{20}$ (Figure B2) and transformed into relative mass contributions, $f_{M, k}$, using:

$$
f_{M, k}=f_{N, k} d_{k}{ }^{3} / \sum f_{N, k} d_{k}{ }^{3}
$$


where $d_{k}$ is the average diameter of particles in each category. The mass concentration of AgNPs was obtained by multiplying $f_{M, k}$ with the overall AgNP concentration used in the simulation of the monodisperse suspension.

The specific surface area for spherical particles of a specific size, $A_{p, k}$ is given by:

$$
A_{\mathrm{P}, k}=\frac{6000}{\pi d_{k} \rho_{\mathrm{Ag}}}
$$

with $d_{k}$ in $\mathrm{nm}$ and a mass density, $\rho_{\mathrm{Ag}}$, equal to that of bulk silver $\left(10.49 \mathrm{~g} \mathrm{~cm}^{-3}\right)$. The individual $\log K_{\mathrm{H} / \mathrm{Ag}}$ values are calculated as for the monodisperse suspensions.

\section{Simulated results}

The results of both simulations for $\mathrm{AgNP}_{5}, \mathrm{AgNP}_{10}$, and $\mathrm{AgNP}_{20}$ are shown in Figure $\mathrm{B} 8$. The dotted lines represent polydisperse suspensions, the solid lines monodisperse. The graph shows that the slope of the polydisperse suspensions is slightly lower than that of the monodisperse suspensions, as suspected in the case of chemical heterogeneity. However, the difference is small, showing that the size distributions of these AgNPs are sufficiently narrow that results can be modelled with a single surface stability constant. It is expected, however, that AgNPs with a wider size distribution, will have a greater chemical heterogeneity, and using a single $\log K$ value may no longer suffice.

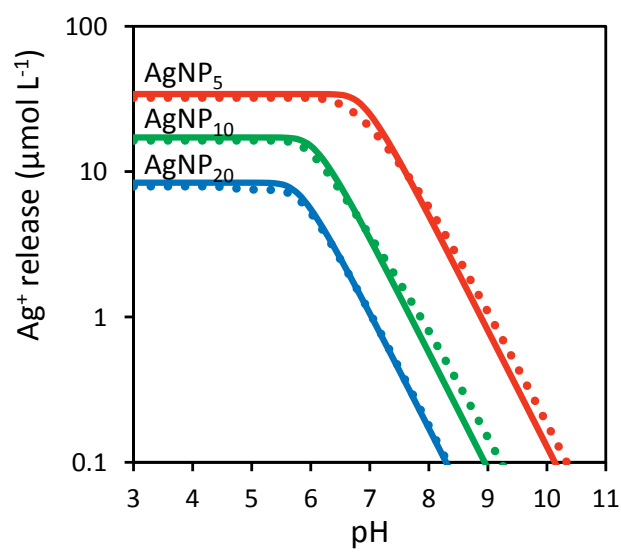

Figure B8. Simulations of $\mathrm{Ag}^{+}$release in monodisperse (full lines) and polydisperse (dotted lines) nanosuspensions with average particle diameters of 5, 10, and $20 \mathrm{~nm}$. In monodisperse suspensions, all particles have the same $\log K_{\mathrm{H} / \mathrm{Ag}}$ value, whereas particles with different $\log K_{\mathrm{H} / \mathrm{Ag}}$ values are defined in the polydisperse suspensions. For the polydisperse systems, we have used the particle size distribution as reported by NanoComposix (see Figure B2). 


\section{B9 Linking the empirical model to the surface structure}

In this work, we have analyzed both the equilibrium $\mathrm{Ag}^{+}$concentrations and the kinetics of $\mathrm{Ag}^{+}$ release. From both perspectives, the results suggest that two different processes are active. Equilibrium concentrations suggest that a surface-based dissolution process controls the $\mathrm{Ag}^{+}$ concentrations at high $\mathrm{pH}$. The mechanistic surface structural model, for which the theoretical base has been laid in our earlier publication, ${ }^{5}$ can be refined to accurately describe the data. At low $\mathrm{pH}$, data suggest that a different, more heterogeneous process is active. The time dependency of the $\mathrm{Ag}^{+}$release has been analyzed using first order kinetics as a premise. This empirical approach points to two independent sources of $\mathrm{Ag}^{+}$release: a fast pool, active below $\mathrm{pH} \sim 7$, and a slow pool, active at $\mathrm{pH}<8$. As shown in Figure $\mathrm{B9}$, the size of the slow pool is nearly identical to the dissolution profile of the surface structural model, suggesting that they represent the same process.

The above strongly suggests that the $\mathrm{Ag}^{+}$source identified as the slow pool is the surface structure which is slowly reaching equilibrium. This shows that $\mathrm{Ag}+$ release due to surface equilibration can be distinguished from dissolution at low $\mathrm{pH}$, based on kinetics as well as on equilibrium concentrations. The fact that the slow pool identified by analyzing kinetics matches the surface structural model so closely, suggests that our surface structures may closely match the actual AgNP surface.

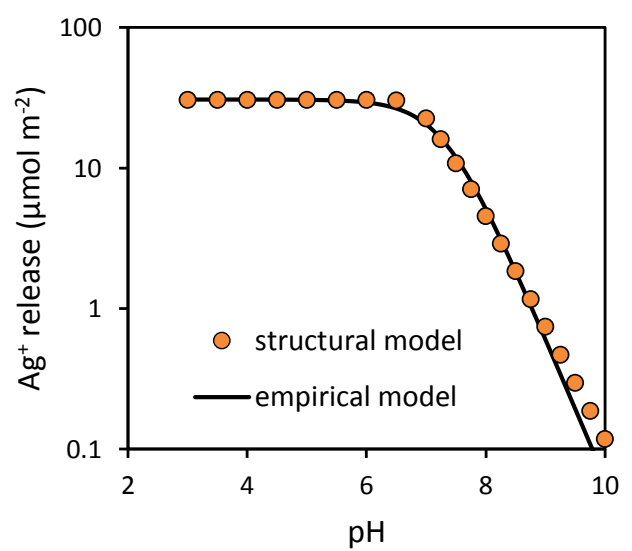

Figure B9. Model predictions of $\mathrm{Ag}+$ release due to equilibration of the surface structure compared to the size of the slow pool. The strong similarity between both sources suggests that they represent the same process.

\section{B10 Data by Adamczyk et al.}

We have applied our final kinetic modelling to data available in literature; notably, short-term data provided by Adamczyk et al. ${ }^{11}$ We have simulated their data using a single set of parameters which adequately describes $\mathrm{Ag}^{+}$release for three AgNP concentrations at $\mathrm{pH} 3.5$, 
as well as for a single AgNP concentration at $\mathrm{pH} 6.2$ (see Figure B10). This is a notable improvement over modeling efforts by Adamzcyk et al., ${ }^{11}$ who have not defined $\mathrm{pH}$ as an input parameter and therefore needed to define separate models for the two $\mathrm{pH}$ values.
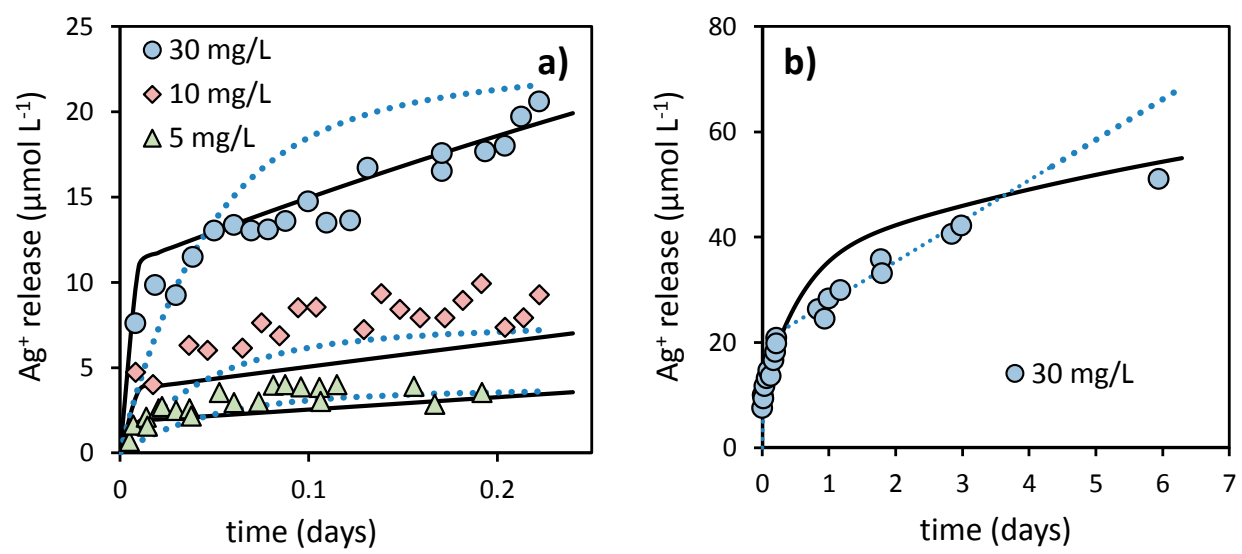

Figure B10. $\mathrm{Ag}^{+}$release data by Adamzcyk et al. ${ }^{11}$ at $\mathrm{pH} 3.5$, measured for three different AgNP concentrations on short timescales (a) and for a single AgNP concentration on a longer timescale (b). Model lines represent our own final model (full lines) and the model developed by Adamzcyk et al. ${ }^{11}$ using the parameters they present as their best fit (dotted lines).

Our model captures a number of striking trends, which can be observed in the data. The high release that occurs at the very beginning of the experiment (Figure B10a) is well described and is due to the near instantaneous oxidative release of surface sites with adsorbed molecular oxygen, i.e. $\equiv \mathrm{Ag}_{3} \mathrm{OH}-\mathrm{O}_{2}$ sites. This is followed by a slower rate of release, which in our model is the result of stripping of patches. At even longer timescales (after $\sim 2$ days), $\mathrm{Ag}^{+}$release is even slower (see Figure B10b). At this point, undersaturation has strongly decreased due to AgNP dissolution, and patch-wise release has run its course. The ongoing release can be attributed to equilibration of the surface, which is slow as a result of the rate-limiting step of oxygen adsorption to the surface. In accordance with the data, our model predicts that the system, even at these acid conditions, will reach eventually reach equilibrium. It can be seen that the model formulated by Adamzcyk et al. ${ }^{11}$ assumes continuous dissolution of the AgNPs without reaching any equilibrium. This assumption provides good data description on the midterm (1-3 days, see Figure B10b), but is clearly seen to fail on the longer term.

\section{Parameterization}

A few of the parameters, as optimized for our own data, need to be adjusted in order to obtain the best possible data description.

The rate constant for oxygen adsorption on the AgNP surface, $k_{\text {ads, }}$ has been increased twofold. As the rate constant for desorption, $k_{\mathrm{ads}}$, remained unchanged, the equilibrium constant, 
$K_{\mathrm{O}_{2}}^{*}$, is also increased twofold. This also implies that rate limitation by a low value for $\vartheta_{2}$ occurred at a later stage. These differences may be related to the presence of citrate in our systems, which may compete for binding sites, thus reducing the surface loading with oxygen.

Furthermore, the rate constants for oxidation and reduction, $k_{\text {ox }}$ and $k_{\text {red }}$ have both been adapted resulting in a lower value for the equilibrium constant $(\Delta \log K=6)$. It implies that the AgNP material used by Adamczyk et al. ${ }^{11}$ has a larger stability towards oxidation. This is expected since the particles are larger and this finding is in line with our data and those of Peretyazhko et al. ${ }^{12}$, as shown in Fig. $3.3 \mathrm{~b}$ of the main text.

Finally, patch-wise release plays a considerably smaller role in the experiments by Adamczyk et al. ${ }^{11}$ than in our own experiments. Patch-wise release is highly variable between the various particles used in our experiments, but the trend is that larger particles release proportionally more $\mathrm{Ag}^{+}$through this process. The fact that patch-wise release is relatively unimportant for these $12 \mathrm{~nm}$ AgNPs may, again, be related to the absence of capping agents. As we show in Figure 3.5 (main text), AgNPs with a higher surface tension on the edges of the theoretical disk-like depletion islands, have a larger critical diameter for patch nucleation at the same undersaturation. Here, the interesting implication is that citrate may thus stabilize AgNPs at circum-neutral conditions, where the surface equilibrium dominates, whereas it stimulates patch-wise release.

\section{B11 References}

1. G. Biedermann and L. G. Sillén, Acta Chemica Scandinavica, 1960, 14, 717-725.

2. L. Duro, M. Grivé, E. Cera, C. Domènech and J. Bruno, Update of a thermodynamic database for radionuclides to assist solubility limits calculation for performance assessment, 2006.

3. I. K. Suh, H. Ohta and Y. Waseda, Journal of Materials Science, 1988, 23, 757-760.

4. A. Henglein, Chemistry of Materials, 1998, 10, 444-450.

5. B. Molleman and T. Hiemstra, Langmuir, 2015, 31, 13361-13372.

6. W. Beesk, P. G. Jones, H. Rumpel, E. Schwarzmann and G. M. Sheldrick, Journal of the Chemical Society, Chemical communications, 1981, 664-665.

7. H. Ott and H. Seyfarth, Zeitschrift für Kristallographie-Crystalline Materials, 1928, 67, 430-433.

8. M. D. Johannes, S. Streltsov, I. I. Mazin and D. I. Khomskii, Physical Review B, 2007, 75, 180404(R).

9. N. M. Martin, S. Klacar, H. Grönbeck, J. Knudsen, J. Schnadt, S. Blomberg, J. Gustafson and E. Lundgren, The Journal of Physical Chemistry C, 2014, 118, 15324-15331.

10. J. Sun, L. He, Y. C. Lo, T. Xu, H. Bi, L. Sun, Z. Zhang, S. X. Mao and J. Li, Nature Materials, 2014, 13, 1007-1012.

11. Z. Adamczyk, M. Oćwieja, H. Mrowiec, S. Walas and D. Lupa, Journal of Colloid and Interface Science, 2016, 469, 355-364.

12. T. S. Peretyazhko, Q. Zhang and V. L. Colvin, Environ. Sci. Technol., 2014, 48, 1195411961. 



\section{Appendix C}

\section{Supporting information to Chapter 4}

Size and shape dependency of surface energy of metallic nanoparticles

Bastiaan Molleman and Tjisse Hiemstra

C1 Edge and corner contributions

C2 Tolman for non-spherical particles

C3 How surface energy depends on the radius of tension

C4 Nucleation of water cavities

C5 Equimolar surface and Tolman lengths

C6 Interpretation of additional excess energy data

C7 Truncated octahedra

C8 Twin plane energy

C9 Surface enthalpy

C10 References 


\section{C1 Edge and corner contributions}

As we discuss in the main text, cylindrical and spherical geometry is used to calculate the surface area contribution of edges and corners, respectively. We imagine the surface plane as lying on the surface of the atoms, which are considered as hard spheres with a diameter equal to the closest interatomic distance $\left(d_{\mathrm{a}}\right)$ in the crystal lattice.

\section{Surface area contribution of edges}

When two surfaces meet at an angle, an edge is formed, as is shown in Figure C1 (left panel). In our approach, the edge that connects two surfaces is taken to be a section of a cylinder, which fits exactly over the outermost surface of the edge atoms. The top and the bottom of this cylinder are formed by great circles on the corner atoms, perpendicular to both connecting surfaces. The length of the cylinder is thus equal to the distance between the cores of the corner atoms, i.e. $I=d_{\mathrm{a}}(s-1)$, where $d_{\mathrm{a}}$ is the interatomic distance and $s$ is the number of atoms in an edge, including the two corner atoms.
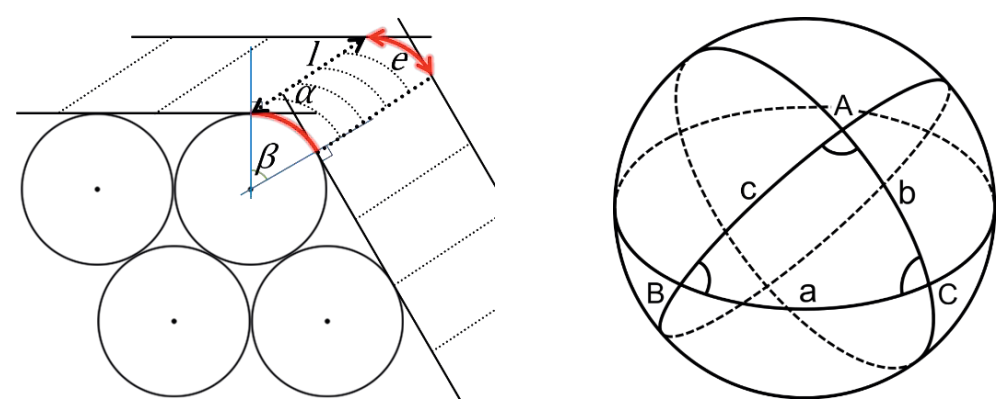

Figure C1. Surface area contribution of edges and corners. The left panel shows a cross-section of an idealized edge, with the shells and cores of atoms in black. The curved surface in between the thick dotted lines and the red curves, which is attributed to the edge has an area of $e \cdot l$. The dihedral angle $\alpha$ is the angle between facets; $\beta$ is needed for the length of $e$. The right panel shows a sphere with three great circles, enclosing the spherical triangle $A B C$, with internal angles $A B C, A C B$, and $B A C$. For a spherical triangle, the spherical excess is equal to $\triangle=\angle A B C+\angle A C B+\angle B A C-\pi$.

A facet ends where the surface is tangent with the shells of the atoms of the edge. Only the section of the cylinder that stretches between the two facets contributes to the surface area. If we call the length of the section $e$, then the cylindrical section has an area equal to $e \cdot I$. The length of $e$ is determined by the dihedral angle $\alpha$. As we see in the figure, the length of the red section is equal to $\beta \cdot r$, if $\beta$ is in rad. From the figure, we can tell that $\beta=2 \pi-2 \cdot 1 / 2 \pi-\alpha=\pi-\alpha$; if, in addition, $r=1 / 2 d_{\mathrm{a}}$, then the total surface area of the edge can be given as: $e \cdot I=1 / 2 d_{\mathrm{a}}^{2}(\pi-$ $\alpha)(s-1)$.

\section{Surface area contribution of corners}

A corner atom connects to several edges. It thus has several great circles around it, which from the bottom-circles of the edge cylinders. This leaves a spherical polygon on the shell of the 
corner atom, which is not covered by the surface area attributed to the edges or the planes. A spherical triangle is shown as an example in the right panel of Figure $\mathrm{C} 1$.

The surface area of a spherical polygon, which we attribute to the corner, follows from the spherical excess $(\Delta)$, according to $r^{2} \Delta .{ }^{1}$ The spherical excess follows from the sum of the internal angles $\left(\Sigma \theta_{k}\right)$ and the number of corners in the polygon $(p)$, according to $\Delta=\Sigma \theta_{k}-\pi$ ( $p$ $-2)$. The internal angles $\left(\theta_{k}\right)$ of the spherical polygon on the corner atoms, which is formed by the great circles perpendicular to the adjoining edges, follow from the angles between these edges $\left(\eta_{k}\right)$ in the same way that $\theta$ follows from $\alpha$ (see above), i.e. $\theta=\pi-\eta$. It follows that $\sum \theta_{k}$ $=p \pi-\sum \eta_{k}$ and the spherical excess can thus be expressed as $\Delta=2 \pi-\sum \eta_{k}$. The area of a corner is thus equal to $1 / 4 d_{\mathrm{a}}^{2}\left(2 \pi-\sum \eta_{k}\right)$

The angles between edges $\eta$ are readily observed from the surface facets, and are limited to $1 / 2 \pi, 1 / 3 \pi$, and $2 / 3 \pi$ for square, triangular, and hexagonal facets respectively. An overview is given in Table C1. Interestingly, the summed contribution of all corners of geometrically shaped particles treated here is invariably equal to $d_{\mathrm{a}}^{2} \pi$.

Table C1. Overview of geometrical properties of corner atoms on regularly shaped particles in the FCC crystal lattice.

\begin{tabular}{|c|c|c|c|c|c|}
\hline Particle geometry & $z_{j}^{a}$ & $\begin{array}{l}{[111]^{\Delta}{ }^{b}} \\
\eta=1 / 3 \pi\end{array}$ & $\begin{array}{l}{[111] \bullet^{\mathrm{b}}} \\
\eta=2 / 3 \pi\end{array}$ & $\begin{array}{l}[100]]^{\mathrm{b}} \\
\eta=1 / 2 \pi\end{array}$ & $\Delta^{c}$ \\
\hline \multirow[t]{2}{*}{ Icosahedron } & 12 & 5 & & & $1 / 3 \pi$ \\
\hline & 2 & 5 & & & $1 / 3 \pi$ \\
\hline Truncated decahedron \{ & 10 & 2 & & 2 & $1 / 3 \pi$ \\
\hline Octahedron & 6 & 4 & & & $2 / 3 \pi$ \\
\hline Cuboctahedron & 12 & 2 & & 2 & $1 / 3 \pi$ \\
\hline Truncated octahedron & 24 & & 2 & 1 & $1 / 6 \pi$ \\
\hline \multicolumn{6}{|c|}{ a Number of times the $f^{\text {th }}$ corner is found in a particular particle geometry } \\
\hline \multicolumn{6}{|c|}{$\begin{array}{l}\text { Number of facets connecting at a corner, where } \eta \text { is the angel between the sides of a } \\
\text { triangular }(\boldsymbol{\Delta}) \text { or hexagonal }(-111] \text { facet, or a square }(\boldsymbol{\square}) \text { [100] facet. }\end{array}$} \\
\hline \multicolumn{6}{|l|}{ c } \\
\hline
\end{tabular}

\section{C2 Tolman for non-spherical particles}

The classical Tolman equation has been derived for spherical particles, however, an adapted version for faceted and spheroidal particles can be obtained with relative ease. To demonstrate this, we will first consider a number of crucial steps in the derivation of the Tolman equation.

An important intermediate result in the derivation of the Tolman equation is that the change in surface tension is proportional to the change in pressure difference between the two phases, according to: ${ }^{2}$

$d \gamma=-\frac{\Gamma}{\rho_{1}-\rho_{2}} d\left(p_{1}-p_{2}\right)$ 
in which $\gamma$ is the surface tension $\left(\mathrm{J} \mathrm{m}^{-2}\right), \Gamma$ is the excess adsorption $\left(\mathrm{mol} \mathrm{m}^{-3}\right)$, and $\rho_{1}$ and $\rho_{2}$ are the bulk densities $\left(\mathrm{mol} \mathrm{m}^{-3}\right)$ in the first and the second phase considered, respectively, while $p_{1}$ and $p_{2}$ are the pressures $\left(\mathrm{J} \mathrm{m}^{-3}\right)$ in said phases.

Using the Laplace equation, the pressure difference is expressed in terms of surface tension $\gamma$ and radius $r\left(p_{1}-p_{2}=2 \gamma / r\right)$, leading to:

$$
d \gamma=-\frac{\Gamma}{\rho_{1}-\rho_{2}} d\left(\frac{2 \gamma}{r}\right)
$$

If the term $\Gamma /\left(\rho_{1}-\rho_{2}\right)$ is equated to the Tolman length $\delta$ (which is valid as long as $\delta<r$ ), the above equation can be solved to yield the Tolman equation in the well-known form given in the main text (eq 6). ${ }^{2}$

The Laplace equation

The Laplace equation in its traditional form is valid for spherical particles. There are several ways to derive the Laplace equation. According to one of the described derivations, ${ }^{3}$ the Laplace equation can be written as:

$p_{1}-p_{2}=\gamma \frac{d A}{d V}$

The difference in pressure depends on the change of surface area $(d A)$ with change of volume $(d V)$ at a given surface tension $\gamma$. In the above equation, the derivatives $d A$ and $d V$ can be related to the radius $r$ of a spherical particle, i.e. $d A / d r$ and $d V / d r$, and with $A=4 \pi r^{2}$ and $V=$ $4 / 3 \cdot \pi r^{3}$, the traditional formulation of the Laplace equation can be obtained.

\section{Facetted particles}

In our approach, Laplace expressions for non-spherical faceted particles, will be obtained by expressing surface area as a function of an equivalent radius. For this, we use the relationship between surface area and volume, which is well-defined for faceted particles. Formulae for surface area and volume, as a function of edge-length $I$, are given in Table C2 for selected particle geometries. 
Table C2. Surface area and volume of a selection of faceted particles as a function of edge-length $I$.

\begin{tabular}{llll}
\hline Particle geometry & Surface area & Volume & $c^{\text {a }}$ \\
\hline Cuboctahedron & $(6+2 \sqrt{3}) l^{2}$ & $\frac{5}{3} \sqrt{2} l^{3}$ & 1.105 \\
Octahedron & $2 \sqrt{3} l^{2}$ & $\frac{1}{3} \sqrt{2} l^{3}$ & 1.183 \\
Truncated octahedron & $(6+12 \sqrt{3}) l$ & $8 \sqrt{2} l^{3}$ & 1.099 \\
Icosahedron & $(5 \sqrt{3}) l^{2}$ & $\frac{5}{12}(3+\sqrt{5}) l^{3}$ & 1.065 \\
Truncated decahedron & $\left(5+\frac{5}{2} \sqrt{3}\right) a^{2}$ & $\frac{5}{4} \sqrt{5+2 \sqrt{5}}\left(1+\frac{2}{3} \sqrt{1-\frac{2}{5-\sqrt{5}}}\right) a^{3}$ & 1.100 \\
\hline
\end{tabular}

a Ratio between surface area of the faceted particle and a spherical particle of equal volume

Oblate and prolate spheroids.

For spheroidal particle, a similar shape factor can be established. The surface area for oblate and prolate spheroids with an equatorial radius $a$ and a polar radius $b$ can be calculated using the following equations:

$$
\begin{aligned}
& A_{\text {oblate }}=2 \pi a^{2}+\frac{2 \pi b^{2}}{\sqrt{1-b^{2} / a^{2}}} \cdot \operatorname{arctanh}\left(\sqrt{1-\frac{b^{2}}{a^{2}}}\right) \\
& A_{\text {prolate }}=2 \pi a^{2}+\frac{2 \pi a b}{\sqrt{1-a^{2} / b^{2}}} \cdot \arcsin \left(\sqrt{1-\frac{a^{2}}{b^{2}}}\right)
\end{aligned}
$$

The volume for both types of spheroidal particles is equal to $4 / 3 \cdot \pi a^{2} b$. Using the above formulae, a shape factor can be coupled to the ratio between the equatorial and the polar radius $a / b$. This is shown in Figure $\mathrm{C} 2$.

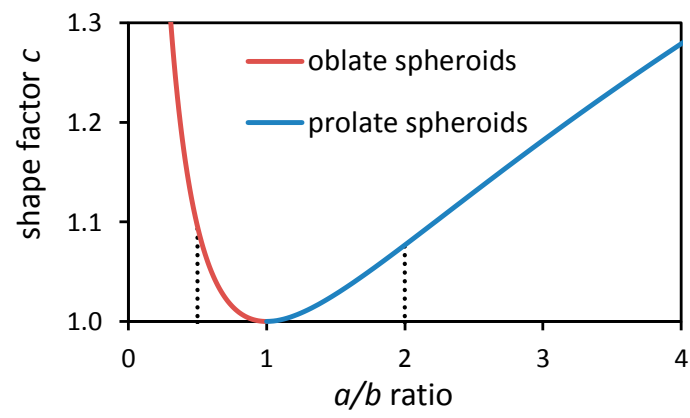

Figure C2. Shape factor $c$ for oblate and prolate spheroidal particles, plotted against the ratio $a / b$ between the equatorial and polar axis. Below a ratio of 1 particles are oblate, above they are prolate. The vertical dotted lines are positioned at $a / b$ ratios of 0.5 and 2 , we expect that most nanoparticle particles will fall in between these limits. 


\section{Generalized Tolman equation}

Using the shape factor $c$, the Laplace equation for faceted and spheroidal particles becomes $\Delta p=2 c \gamma / r$. This adapted Laplace equation can be readily used in the derivation of the Tolman equation, leading to:

$$
\gamma_{\mathrm{r}}=\frac{\gamma_{\infty}}{1+2 c \delta / r_{\mathrm{s}}}=\gamma_{\infty}\left(1+\frac{2 c \delta}{r_{\mathrm{e}}-\delta}\right)^{-1}
$$

The effect of the introduction of $c$ in the Tolman equation depends on the value of the Tolman length and the particle size. For the Tolman lengths that we derived for metallic nanoparticles in this work, the effects are very limited for particles larger than $\sim 2 \mathrm{~nm}$ as shown in Figure C3.

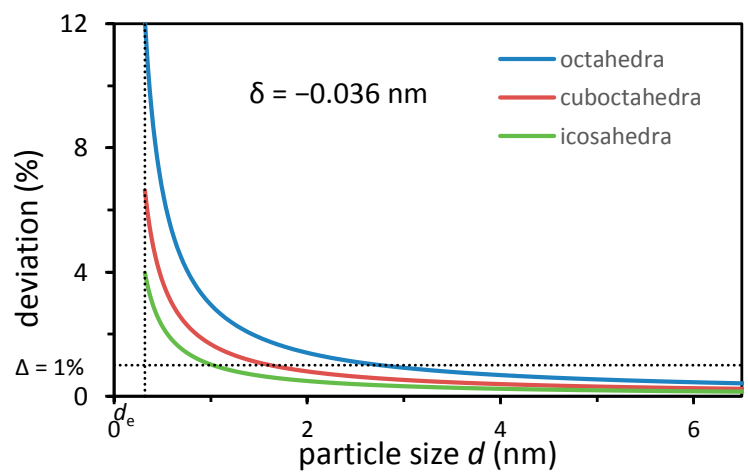

Figure C3. The deviation (\%) of the adapted Tolman equation (eq C4) from the classical Tolman equation (eq 4.6) for octahedral, cuboctahedral, and icosahedral particles (from top to bottom). The lines are calculated using a Tolman length of $-0.036 \mathrm{~nm}$, which is the value that we will later establish for cuboctahedral gold nanoparticles (see Results and Discussion). The horizontal dotted represents a deviation of $1 \%$; the vertical dotted line represents the equimolar diameter $d_{\mathrm{e}}$ for a single gold atom, calculated using equation 4.1 (main text).

\section{Concluding remarks}

Above we have treated shapes with sharp corners and edges. However, the physical surface area that we formulate in this work explicitly includes the surface area of rounded edges end corners. Given the limited difference between a spherical Tolman approach and a faceted Tolman approach, we feel that such details can be left untreated.

We are also aware, if the surface of tension is located at a uniform distance from the equimolar surface, their geometries are not necessarily identical for non-spherical particles. This is the case for cuboctahedra, truncated octahedra and truncated decahedra, as well as for oblate and prolate particles. For applications of equation $\mathrm{C} 5$ in this work, the shape change is minor. However, for very small, non-spherical water droplets, this may be relevant. 


\section{C3 How surface energy depends on the radius of tension}

In the main text we explain that upon choosing a radius of tension $r_{\mathrm{s}}$, a surface energy value can be calculated in two ways. Thermodynamically, using the Tolman equation, and atomically, by scaling the excess particle energy to the surface area. Crucial for determining the position of the surface of tension is that both calculated surface energy values depend differently on the chosen value for the radius of tension $r_{s}$. This is illustrated in Figure C4. Because of the opposite dependence on $r_{s}$, the calculated lines intersect; this is universally seen. The true radius of tension $r_{s}$ and size-dependent surface energy $\gamma_{r}$ are found where the lines intersect, i.e. at the $r_{s}$ value where both methods yield the same surface energy.

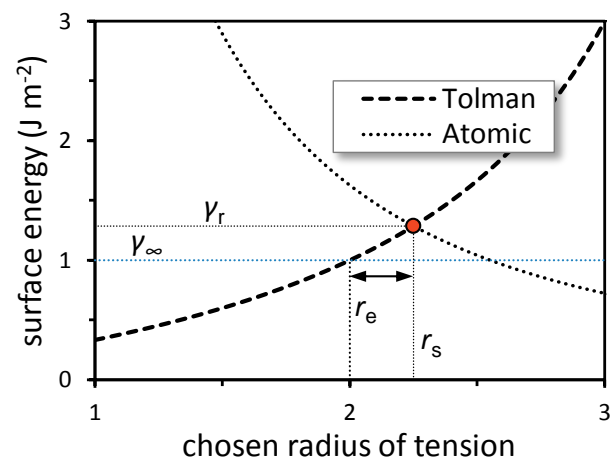

Figure C4. Relation between surface energy and the radius of tension $r_{\mathrm{s}}$ for the thermodynamic (dashed line) and the atomic (dotted line) method of calculating surface energy. Lines have been calculated for a spherical particle with an equimolar radius $r_{\mathrm{e}}$ of $2 \mathrm{~nm}$, and an excess particle energy $\Delta E_{\mathrm{S}}$ of $81.8 \mathrm{aJ}$. The consistent value of $r_{\mathrm{s}}$ and the corresponding surface energy $\gamma_{\mathrm{r}}$ are found where the lines cross, as indicated with a red dot. Also indicated is the planar surface energy, $\gamma_{\infty}$. The difference between $r_{\mathrm{e}}$ and $r_{\mathrm{s}}$ is the Tolman length given with the horizontal arrow.

\section{C4 Nucleation of water cavities}

Very recently, the nucleation of cavities in water has been studied with state-of-the-art advanced MD simulations. ${ }^{4}$ The Gibbs free energy of formation of cavities in water was calculated as a function of cavity size for negative pressures $p$ in the range of -100 to -200 $\mathrm{MPa}$. These simulated Gibbs free energy curves are given in Figure C5 with symbols. If the cavity volume is very small, energy is needed to enlarge it, while for large volumes, Gibbs free energy is released at enlargement of the cavity. In the latter case, the cavity can grow spontaneously. However, if the cavity is smaller than a critical value, it may spontaneously collapse. On the top of the energy barrier, the critical particle is in an instable state. 


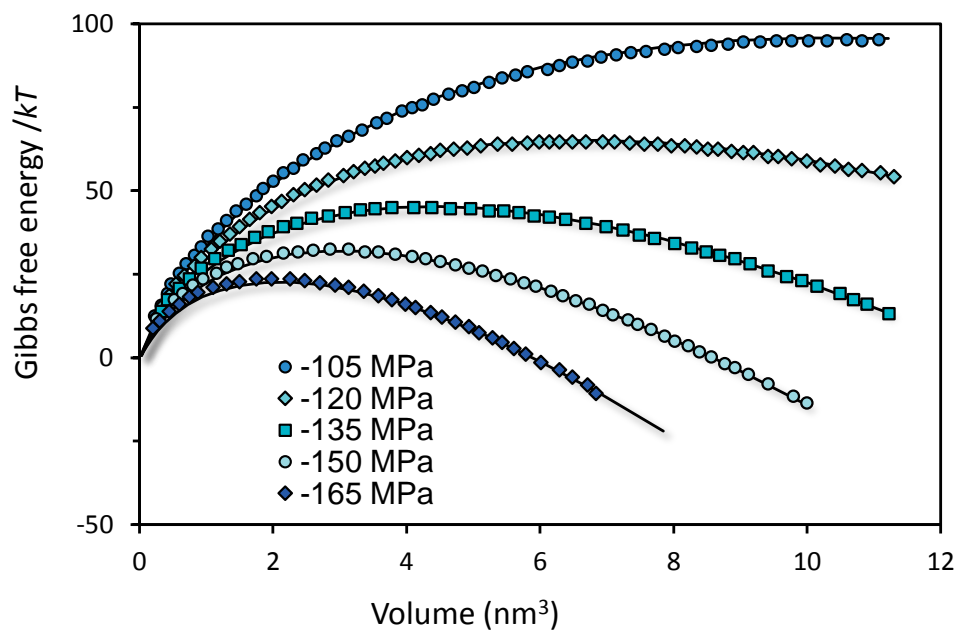

Figure C5. Gibbs free energy of cavity formation in water as a function of the equimolar cavity diameter for various values for the applied negative pressure. The symbols are values of Menzl et al. ${ }^{4}$ that were obtained with advanced MD simulations. The lines have been calculated with homogeneous nucleation theory using a size-dependent surface tension (eq C6) according to the Tolman approach with a mean shape factor of $c=1.1$ (see text). The curves were calculated using the Tolman length as the only adjustable parameter leading to $\delta=0.067 \mathrm{~nm}$.

The generated MD data have been described by Menzl et al. ${ }^{4}$ with classical nucleation theory allowing the surface tension to be size-dependent by introducing a Tolman length. ${ }^{4}$ The authors applied an expression that is based on the surface of tension with corresponding radius $\left(r_{s}\right)$, whereas in their data treatment, the calculated radius is based on the equimolar volume, making it equivalent to $r_{\mathrm{e}}$. This principal difference is the cornerstone of the thermodynamic treatment of Tolman. It implies that the radius in their expressions is to be replaced by $r_{\mathrm{e}}-\delta$, where appropriate. The proper expression to be applied in critical nucleation theory is:

$\Delta G\left(r_{\mathrm{e}}\right)=4 \pi c\left(r_{\mathrm{e}}-\delta\right)^{2} \frac{\gamma_{\infty}}{1+2 c \delta /\left(r_{\mathrm{e}}-\delta\right)}+\frac{4 \pi r_{\mathrm{e}}^{3}}{3} p$

in which $c$ is the shape factor for deviation from the perfect sphere. In equation $\mathrm{C5}$, the first term gives the contribution of surface Gibbs free energy and the second term gives the contribution of the formation of the water cavity.

A second point is that Menzl et al. ${ }^{4}$ have made the surface tension $\gamma_{\infty}$ of water in the planar limit to an adjustable parameter, in order to get an excellent fit. However, it leads to a significantly higher value for the surface tension $\gamma_{\infty}$ of water than found experimentally. Considering the planar surface tension of water $\gamma_{\infty}$ as an adjustable parameter is doubtful since it may be assume that the advanced MD model applied is able to reproduce the experimental value correctly. 
In Figure C5, the given lines have been calculated with the above expression for homogeneous nucleation. In our treatment of their data, a good fit could not be achieved when the Tolman length $\delta$ is considered as the only adjustable parameter. The simulation experiments of Menzl et al. ${ }^{4}$ showed that the particles shape is non-spherical. If the shape factor $c$ is introduced and used as an adjustable parameter, an excellent fit is found for the full data set, with only minor deviations, as is shown in Figure $\mathrm{C5}$. The data is best described with a size independent shape factor of $c=1.1$ and $\delta=+0.067 \mathrm{~nm}$. The Tolman length is much lower than the high value found by Menzl et al. ${ }^{4}(\delta=+0.195 \mathrm{~nm}$ ) and closer to the value estimated by Tolman $\delta=0.1 \mathrm{~nm}$ for spherical water droplets and recently found with simulations $(\delta=+0.05-0.10 \mathrm{~nm}) .^{5}$

The same shape factor is taken for all sizes. Menzl et al., ${ }^{4}$ showed that the particles vary in shape, and in addition, the surfaces of the droplets are quite irregular. By extracting the surface areas and volumes from the MD results, one may in principle calculate the shape factors involved. However, this is beyond the scope of the present paper.

\section{C5 Equimolar surface and Tolman lengths}

\section{The equimolar surface}

The equimolar surface is defined as the surface within which all the mass would be located in case of a uniform density up to the equimolar surface. While this is fairly straightforward for spherical particles, it is less so for crystalline particles with a polyhedral shape. Rather than establishing an equimolar radius, we will establish a position of the equimolar radius with respect to the center of the surface atoms.

We assume that the mass of an atom is distributed homogeneously within the atomic radius, which we define as half the interatomic distance, i.e. $r_{a}=1 / 2 d_{a}$. Figure 4.4 (main text) shows that atoms in the crystal structure overlap. At the surface, the density is thus lower. It follows that the equimolar surface is located between the cores and the outer shell of surface atoms.

The equimolar surface is located such that the missing sections between surface atoms can be exactly filled in with the sections extending over the equimolar surface. The red dotted lines in Figure 4.4 of the main text are located exactly between atomic layers, and the overlapping sections from different layers (colored) have exactly the same size. The exact location of the equimolar surface thus follows from the distance between atomic layers.

From the atomic positioning in the FCC lattice, it may be calculated that the distance between [100] and [111] planes is equal to $\sqrt{ } 1 / 2 d_{a}$, and $\sqrt{2} / 3 d_{a}$, respectively. The equimolar surface is located at half that distance, i.e. $\sqrt{ } 1 / 2 r_{\mathrm{a}}$ and $\mathrm{V}^{2} / 3 r_{\mathrm{a}}$, from the centers of surface atoms. 
Specific Tolman lengths for crystal faces

Above we have defined the position of the equimolar surface relative to the centers of surface atoms. In a similar fashion, we can calculate the positions of the surfaces of tension will also be defined, we can calculate the Tolman length.

In our definition, the physical surface (see Figure 4.2c, main text) is placed on top of the outer shells of surface atoms. In other words, the physical surface is located at a distance of $r_{\mathrm{a}}$ from the centers of surface atoms. This leads to a Tolman length of $(\sqrt[V]{1} / 2-1) r_{\mathrm{a}}$ for the [100] face and $\left(\mathrm{V}^{2} / 3-1\right) r_{\mathrm{a}}$ for the [111] face, leading to $\delta_{100}=-0.146 d_{\mathrm{a}}$ and $\delta_{111}=-0.092 d_{\mathrm{a}}$.

Method A (see Figure 4.2a, main text) places the surface of tension at the center of the surface atoms. Above we have thus given the position of the equimolar surface relative to this surface of tension, leading to $\delta_{100}=0.354 d_{\mathrm{a}}$ and $\delta_{111}=0.408 d_{\mathrm{a}}$.

For the surface of tension defined in Method B, as given in Figure 4.2b of the main text, the position is more complex to calculate. Moreover, the location may vary for particles of different shapes, depending on the number of edges. We will here demonstrate the calculation for cuboctahedral particles.

To obtain the distance between the surface of Method B and the center of surface atoms, we calculate the full height of a particle in terms of edge-length $(s)$, which in this method is taken as $s d_{\mathrm{a}}$. For a cuboctahedron, the distance between two opposite [100] faces is equal to the diagonal of the [100] face, or $\sqrt{ } 2 s d_{\mathrm{a}}$. The distance between the cores of two opposite [100] faces is equal to the diagonal of a [100] face defined according to method A, i.e. $\sqrt{ } 2(s-1) d_{\mathrm{a}}$. It follows that the distance of the surface of tension from method $B$ from the cores is equal to $1 / 2 \sqrt{ } 2 d_{\mathrm{a}}$ or $\sqrt{ } 1 / 2 d_{\mathrm{a}}$ at the [100] face.

Using the same principles, though following a much more complicated route, it can be calculated that the distance between the surface of tension and the centers of surface atoms is equal to $\mathrm{V}^{2} / 3 \cdot d_{\mathrm{a}}$ at the [111] face. For cuboctahedra, the Tolman length for the surface of tension defined in method $B$ is thus equal to $\sqrt{ } 1 / 2 r_{a}-\sqrt{ } 1 / 2 d_{a}$ for the [100] face and $\sqrt{ } 2 / 3 r_{a}-V^{2} / 3 d_{a}$ for the [111] face, leading to $\delta_{100}=-0.354 d_{\mathrm{a}}$ and $\delta_{111}=-0.408 d_{\mathrm{a}}$.

\section{C6 Interpretation of additional excess energy data}

Size dependency of surface energy of other metallic nanoparticles

In the main text, we identified the physical surface as thermodynamically consistent with the surface of tension. We also showed that with scaling to this surface, the size dependency for surface energy $\left(\mathrm{J} \mathrm{m}^{-2}\right)$ is greatly reduced with respect to trends previously published in literature.6, 7 A low size-dependency of surface energy is universally observed when computational energy data are scaled to the physical surface area, as shown with additional data in Figure C6, for a variety of particle shapes. 

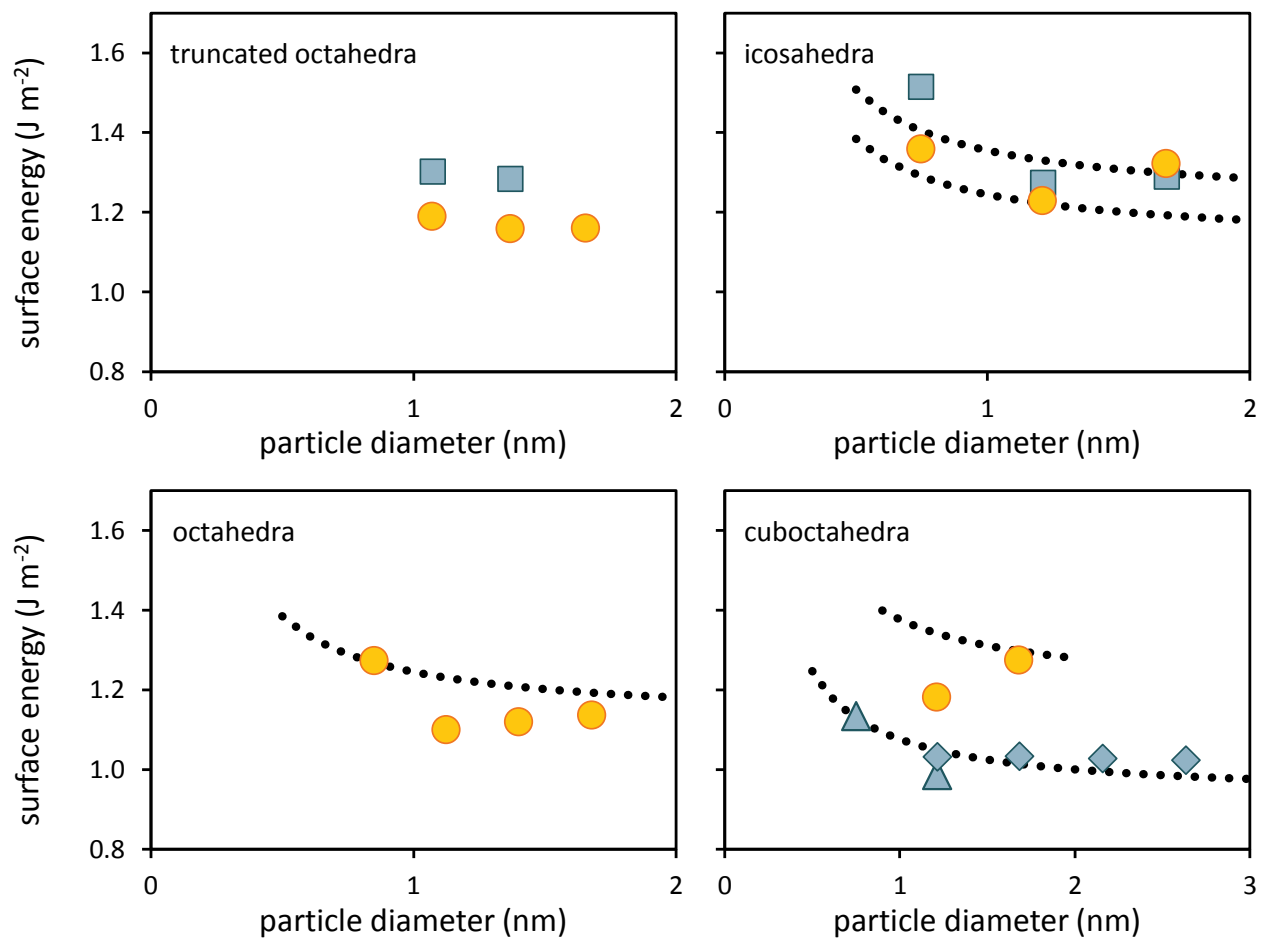

Figure C6. Surface energy data for noble metal nanoclusters in a variety of particle shapes scaled to the physical surface area. Computational data were taken from Liu et al. ${ }^{8}$ (DFT-LDA, silver: squares), Barnard and Curtis $^{9}$ (DFT-GGA, gold: spheres), Medasani et al. ${ }^{6}$ (DFT-GGA, silver: triangles), and Oliveira et al. ${ }^{10}$ (SCC-DFTB, silver: diamonds). Tolman functions were generated (dotted lines) using restricted assumptions, which are described below.

Consistency of the physical surface for other metallic nanoparticles

Liu et al. ${ }^{8}$ calculated planar surface energies for the silver [111] face and [100] face, being 0.55 and $0.69 \mathrm{eV}$ atom ${ }^{-1}$ respectively. Expressing the surface area of the [111] and [100] face per atom, being respectively $0.072 \mathrm{~nm}^{2}$ and $0.083 \mathrm{~nm}^{2}$, yields $\gamma_{[111]}=1.22 \mathrm{~J} \mathrm{~m}^{-2}$ and $\gamma_{[100]}=1.33 \mathrm{~J}$ $\mathrm{m}^{-2}$. Using $d_{\mathrm{a}, \mathrm{Ag}}=0.289^{11}$ and Table C3, we find a surface tension $\gamma_{\infty}=1.22 \mathrm{~J} \mathrm{~m}^{-2}$ and a Tolman length $\delta=-0.027 \mathrm{~nm} \delta$ for icosahedral silver clusters. As no macroscopic surface energy data are available in the works by Medasani et al. ${ }^{6}$ and Oliveira et al., ${ }^{10}$ a macroscopic surface energy of $\gamma_{\infty}=0.93 \mathrm{~J} \mathrm{~m}^{-2}$ was fitted to the data for silver cuboctahedra. ${ }^{6,10}$

The model lines for the AuNP have been calculated using a calculated guess of the surface energy for the planar crystal faces $\gamma_{[100]}$ and $\gamma_{[111]}$, as these lack in the paper of Barnard and Curtis. ${ }^{9}$ We found that the surface energy of the two silver truncated octahedra with $N=38$ and $N=79$ atoms from Liu et al. ${ }^{8}$ is between 1.08 and 1.09 times higher than the surface energy of the identically shaped gold truncated octahedra from Barnard and Curtis. ${ }^{9}$ Assuming 
that the same ratio is valid for the planar crystal faces, we get the approximated values of $\gamma_{[100]}$ $=1.23 \mathrm{~J} \mathrm{~m}^{-2}$ and $\gamma_{[111]}=1.12 \mathrm{~J} \mathrm{~m}^{-2}$ for gold, which we applied. Using $d_{a, A u}=0.288^{11}$ and Table 3 , we can generate values for the surface of tension $\gamma_{\infty}$ and the Tolman length $\delta$ for the different shapes. For icosahedral gold clusters, $\gamma_{\infty}=1.12 \mathrm{~J} \mathrm{~m}^{-2}$ and $\delta=-0.026 \mathrm{~nm}$; for octahedral gold clusters, $\gamma_{\infty}=1.12 \mathrm{~J} \mathrm{~m}^{-2}$ and $\delta=-0.026 \mathrm{~nm}$; and for cuboctahedral gold clusters, $\gamma_{\infty}=1.19 \mathrm{~J} \mathrm{~m}^{-2}$ and $\delta=-0.036 \mathrm{~nm}$.

Overall, the data description by the Tolman equation is good. Individual data points may deviate because of uncertainties in the energy calculation or due to the intricacies in energetics of nanocrystals. Considering the planar surface energy values are the primary input parameter, our method of estimation performs well.

\section{C7 Truncated octahedra}

The truncated octahedra shown in Figure 4.7a of the main text are non-regular, meaning they have two different edge-lengths. ${ }^{7}$ As such, these particles are not covered by the general formulas in Table 4.1 of the main text. We provide dedicated formulae for these particles here.

If $s_{1}$ is the number of atoms in the edge between two [111] faces, and $s_{2}$ denotes the edge between a [111] and a [100] face, then [111] and [100] facets have the following surface areas:

$$
\begin{aligned}
& A_{f,[111]}=\sqrt{3}\left(\left(s_{1}-1\right)\left(s_{2}-1\right)+\frac{\left(s_{1}-1\right)^{2}+\left(s_{2}-1\right)^{2}}{4}\right) \\
& A_{f,[100]}=\left(s_{2}-1\right)^{2}
\end{aligned}
$$

The surface area of edges and corners can be found using the formulae in Table 1 of the main text.

In the truncated octahedra shown in Figure 4.7a of the main text, edge-length $s_{1}$ was constant with particle size while $s_{2}$ increased. It results in a variable surface area ratio of the [100] and the [111] faces, which leads to different values $\delta$ and $\gamma_{\infty}$. These have been calculated using $d_{a}$ $=0.288^{11} \mathrm{~nm}$ and $\gamma_{[111]}=0.79 \mathrm{~J} \mathrm{~m}^{-2}$ and $\gamma_{[100]}=0.92 \mathrm{~J} \mathrm{~m}^{-2} ;{ }^{7}$ values for $\delta$ and $\gamma_{\infty}$ are given below in Table C3. 
Table C3. Edge-lengths, surface area ratios, macroscopic surface energy values and overall Tolman lengths for the truncated octahedra of Figure 4.7a of the main text.

\begin{tabular}{|c|c|c|c|c|}
\hline \multicolumn{2}{|c|}{ Edge lengths } & \multirow{2}{*}{$A_{[100]} / A_{[111]}$} & \multirow{2}{*}{$\gamma_{\infty}\left(\mathrm{J} \mathrm{m}^{-2}\right)$} & \multirow{2}{*}{$\delta(\mathrm{nm})$} \\
\hline$s_{1}$ & $S_{2}$ & & & \\
\hline 2 & 3 & $0.348 / 0.652$ & 0.835 & -0.0319 \\
\hline 2 & 5 & $0.456 / 0.544$ & 0.849 & -0.0336 \\
\hline 2 & 7 & $0.505 / 0.495$ & 0.856 & -0.0344 \\
\hline 2 & 9 & $0.533 / 0.467$ & 0.859 & -0.0348 \\
\hline 2 & 11 & $0.551 / 0.449$ & 0.862 & -0.0351 \\
\hline
\end{tabular}

We note that the shape factor $c$ also varies with size for the truncated octahedra described above. The smallest of the above particles is close to a regular truncated octahedron, while the largest rather resembles a cuboctahedron. The shape factor for these particles can thus be expected to be in between those of a regular truncated octahedron and a cuboctahedron. Figure C3 shows that a very limited effect of shape correction is to be expected. It has therefore not been calculated for these particles. Instead, the value for regular truncated octahedra was used in all cases.

\section{C8 Twin plane energy}

As we explain, the total surface energy values from Ali et al. ${ }^{7}$ include an internal strain contribution due to twinning. The difference between the total surface energy from Ali et al. ${ }^{7}$ and the size dependent surface energy can thus be interpreted as twinning energy. The total twinning energy for a cluster (aJ) is found after multiplying the difference $\left(\mathrm{J} \mathrm{m}^{-2}\right.$ or aJ nm $\left.\mathrm{m}^{-2}\right)$ with the total surface area $\left(\mathrm{nm}^{2}\right)$. This value is scaled to the total twin-plane surface area for icosahedra as shown in Figure 8 of the main text.

Icosahedral particles have 30 triangular twin-planes: three shared twin-planes for each of its 20 tetrahedral subunits. The exact definition of the twin-plane for icosahedra can be debated. Two possible surface area definitions are shown in Figure C7; though the resulting twin-plane energy values vary, the trend is not affected by the choice. For our analysis, we use the smaller of the two definitions, indicated by the darker blue in Figure $\mathrm{C7}$. 


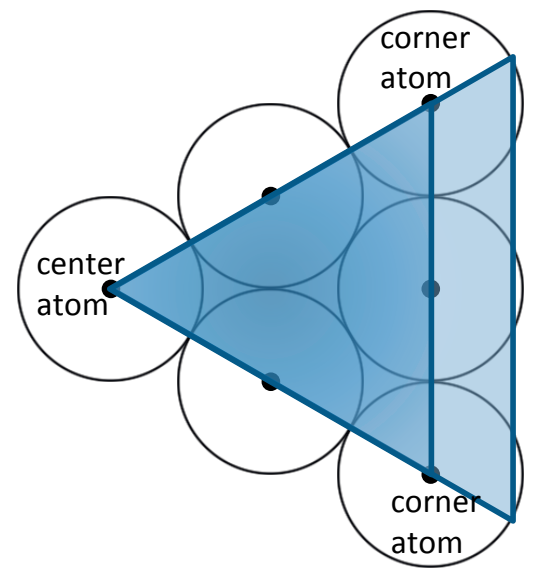

Figure C7. Total twinning energy for icosahedra plotted against twin-plane area. The right panel shows two possible ways of defining the triangular twin-plane area. There was little difference between the trends found for these two definitions, we have used the smaller of the triangles. In an icosahedron, 30 of these triangular twin-planes are found.

\section{C9 Surface enthalpy}

Relating surface enthalpy to the enthalpy of vaporization and atomization

Surface formation can be considered as breaking of intermolecular or interatomic bonds, which requires energy. For a solid or liquid particle, the surface enthalpy contribution to the

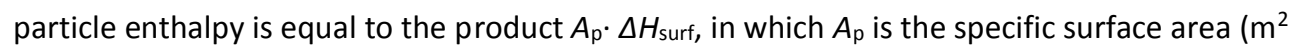
$\left.\mathrm{mol}^{-1}\right)$ and $\Delta H_{\text {surf }}$ is the surface enthalpy $\left(\mathrm{J} \mathrm{m}^{-2}\right)$. In the simplest approach, the excess surface enthalpy $\left(\mathrm{J} \mathrm{mol}^{-1}\right)$ is calculated assuming a spherical morphology and constant value for $\Delta H_{\text {surf }}$. The specific surface area of a particle can be related to the number of atoms $N$, using the particle radius found according to:

$$
A_{\mathrm{p}}=4 \pi r^{2} \frac{N_{\mathrm{A}}}{N}=4 \pi \frac{N_{\mathrm{A}}}{N}\left(\frac{3 M N}{4 \pi N_{\mathrm{A}} \rho}\right)^{2 / 3}=\left(4 \pi \frac{N_{\mathrm{A}}}{N}\right)^{1 / 3}\left(\frac{3 M}{\rho}\right)^{2 / 3}
$$

where $N_{\mathrm{A}}$ is Avogadro's number $\left(\mathrm{mol}^{-1}\right), M$ is the molar mass $\left(\mathrm{g} \mathrm{mol}^{-1}\right)$, and $\rho$ is the bulk density $\left(\mathrm{g} \mathrm{m}^{-3}\right)$. The upper limit of the specific surface area is determined by the radius of a single atom or molecule $(N=1)$.

The result of this approach is given in Figure C8 with full lines for the formation of water nanodroplets and silver nanoparticles. At room temperature, surface enthalpy values $\left(\Delta H_{\text {surf }}\right)$ are respectively $118 \mathrm{~mJ} \mathrm{~m}^{-2}$ for water ${ }^{12}$ and $1.52 \mathrm{~J} \mathrm{~m}^{-2}$ for gold (Table 4.2 main text). These values refer to the slope of the full lines in Figure $\mathrm{C} 8$. The value for gold has been derived (next section), using the relationships of Tyson and Miller. ${ }^{13}$ 
With this simplified approach, the experimental energy of formation of a single molecule or atom in the gas phase is close to the enthalpy of formation $\left(\Delta H_{f}\right)$ of the equilibrium phase amended with a surface enthalpy contribution in the size limit. In other words, a major part of the enthalpy of vaporization or atomization is explained by the surface enthalpy that a single liquid molecule or solid atom would have. Introducing a size dependency for the surface enthalpy allows us to close the gap and equate the surface enthalpy of a single molecule or atom formation with the enthalpy of vaporization or atomization, as shown in Figure $\mathrm{C} 8$ with dotted lines.
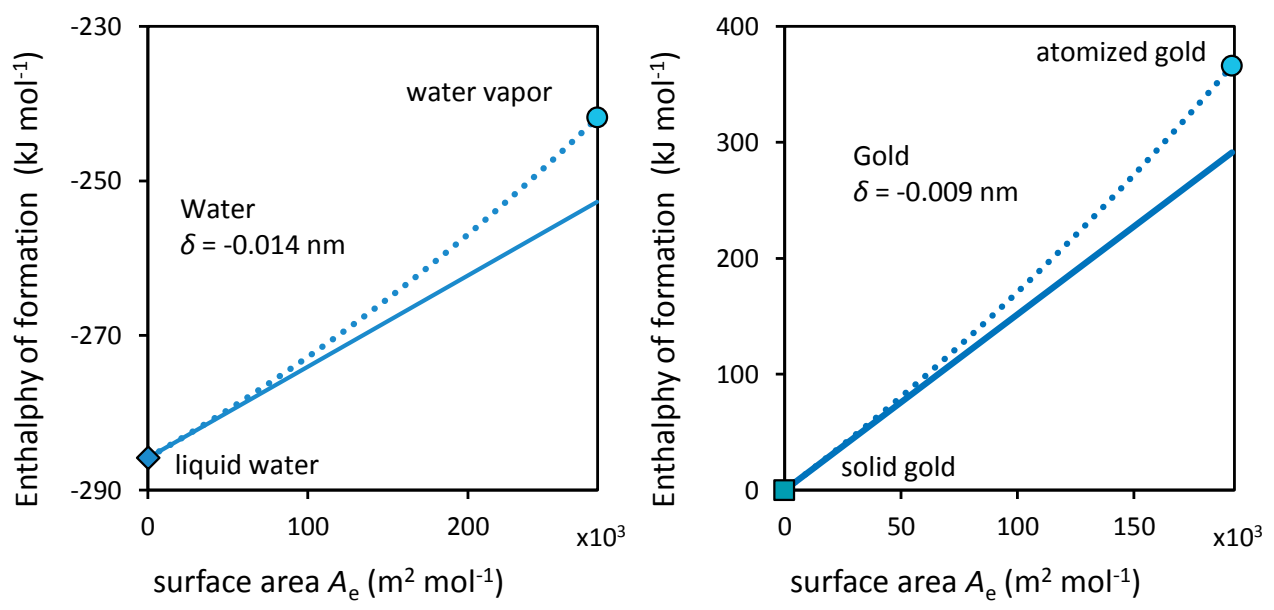

Figure C8. Molar enthalpy of water and gold modified by surface enthalpy, ranging from bulk material to a single molecule or atom. The enthalpy of surface formation for a particle with the size of a single molecule or atom already explains a major part of the enthalpy of evaporation or atomization if a constant surface enthalpy is assumed (solid line). The two values can be unified by introducing size dependency of the surface enthalpy. The uplift of the curve (dotted line) is equivalent with a negative value for the Tolman length.

This size dependency of the surface enthalpy in Figure C8 is obtained using the thermodynamic approach of Tolman (eq 4.6, main text), applying a Tolman length of $\delta=$ $-0.014 \mathrm{~nm}$ and $\delta=-0.009 \mathrm{~nm}$, respectively for water and gold. When the same analysis is performed for silver, a Tolman length of $-0.006 \mathrm{~nm}$ is found. Note that the value for Tolman length of water is for surface enthalpy, and therefore different from the Tolman length in the main text, which is for the surface Gibbs free energy. In case of surface enthalpy, the values for the Tolman length are negative, which is equivalent in Figure $c 8$ with an increase of the slope and an uplift of the curve relating the formation of surface area to the enthalpy change. The diamond and square in Figure C 8 are the enthalpy of the bulk liquid and solid, respectively, and the spheres are the enthalpies of the constituting molecule or atom in the gas phase. The difference between both types of values is the enthalpy of vaporization and atomization. 


\section{Thermodynamic surface data for gold}

While there are ample measurements for the size dependency of surface tension in liquid metals at high temperature, to our knowledge there are none for solid metals. Although the development of computational techniques has created a large body of data, the variation within those data is large. Moreover, the present approach requires a generic single surface energy value, whereas ab initio techniques mostly are applied to specific crystal faces. For this reason, we choose to base ourselves on the only work to date that specifies surface energy for solid metals, based on empirical data.

Tyson and Miller ${ }^{13}$ primarily focus on the solid-vapor surface tension, which they estimate to have a value of 1.18 times the liquid-vapor surface tension at the melting temperature $\left(T_{M}\right)$. Using the data available at the time, this correlation leads to a surface tension of $1.33 \mathrm{~J} \mathrm{~m}^{-2}$ for solid gold at $T=T_{\mathrm{M}}$. Using the latest experimental data, ${ }^{14-16}$ an average of $\Delta G_{\text {surf, (I) }}=1.13$ $\pm 0.02 \mathrm{~J} \mathrm{~m}^{-2}$ is found for liquid gold at the melting temperature, suggesting a value of $\Delta G_{\text {surf, (s) }}$ $=1.34 \mathrm{~J} \mathrm{~m}^{-2}$ for solid gold.

Additionally, Tyson and Miller ${ }^{13}$ devoted a section in their paper to surface entropy. In short, they argued that surface entropy is linked to the surface area per mole of surface atoms $\left(A_{m}\right)$, estimated using $1.612 N_{\mathrm{A}}^{1 / 3} V_{\mathrm{m}}^{2 / 3}$, where $N_{\mathrm{A}}$ is Avogadro's number and $V_{\mathrm{m}}$ is the molar volume $\left(\mathrm{m}^{3} \mathrm{~mol}^{-1}\right)$. The entropy contribution is found as the sum of contributions from 3 different temperature intervals (Figure $\mathrm{C9}$ ). At heating from $0 \mathrm{~K}$ to the Debye temperature $\left(T_{\mathrm{D}}\right)$, the entropy increases linearly from 0 to $0.8 R / A_{\mathrm{m}}$, where $R$ is the gas constant $R=8.134 \mathrm{~J} \mathrm{~mol}^{-1}$ $\mathrm{K}^{-1}$. Between the $T_{\mathrm{D}}$ and $1 / 2 T_{\mathrm{M}}$, the surface entropy is constant at $0.8 R / A_{\mathrm{M}}$, and between $1 / 2 T_{\mathrm{M}}$ and $T_{\mathrm{M}}$, it increases linearly from $0.8 R / A_{\mathrm{M}}$ to $1.8 R / A_{\mathrm{M}}$.

The surface entropy for solid gold at the melting temperature, as it follows from these relationships $\left(0.23 \mathrm{~mJ} \mathrm{~m}^{-2} \mathrm{~K}^{-1}\right)$, exceeds the surface entropy for liquid gold, as found from the temperature dependence of the surface tension $\left(0.15 \pm 0.01 \mathrm{~mJ} \mathrm{~m}^{-2} \mathrm{~K}^{-1}\right) \cdot{ }^{14-16}$ We have plotted the temperature dependence of surface entropy ${ }^{13}$ for solid gold in Figure C9, using the theoretical value $\Delta S_{\text {surf }}=0.23 \mathrm{~mJ} \mathrm{~m}^{-2} \mathrm{~K}^{-1}$ at $T=T_{\mathrm{M}}$, a melting temperature of $T_{\mathrm{M}}=1337 \mathrm{~K}$, and $T_{\mathrm{D}}=0.2 T_{\mathrm{M}}$.

With the above information for solid gold, one is able to calculate the temperature dependency of the surface enthalpy using $\Delta G_{\text {surf }}=1.34 \mathrm{~J} \mathrm{~m}^{-2}$ at the melting temperature. The corresponding enthalpy follows from $\Delta H_{\text {surf }}=\Delta G_{\text {surf }}+\mathrm{T} \Delta S_{\text {surf. }}$ The temperature dependency of $\Delta G_{\text {surf follows from: }}{ }^{13}$

$$
\Delta G_{\text {surf }}-\Delta G_{\text {surf }}\left(T_{\mathrm{M}}\right)=\int_{T}^{T_{\mathrm{M}}} \Delta S_{\text {surf }} d T
$$

The results of these calculations are summarized in Table 2 (main text) and visualized in Figure c9. 


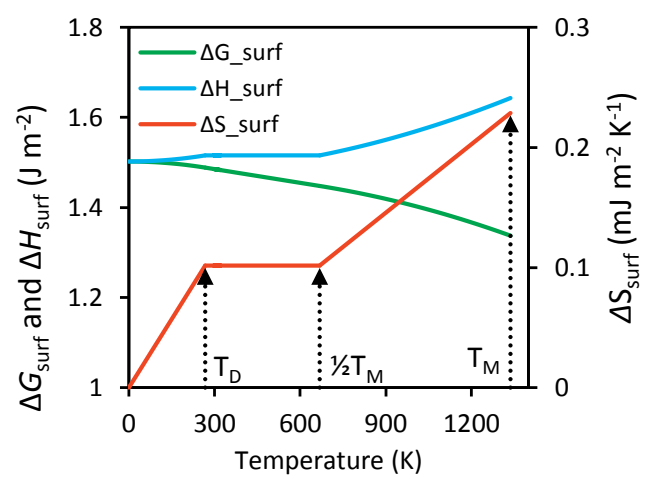

Figure C9. Temperature dependence of surface free energy $\left(\Delta G_{\text {surf }}\right)$ and surface entropy $\left(\Delta S_{\text {surf }}\right)$ according to Tyson and Miller, ${ }^{13}$ as well as the surface enthalpy ( $\left.\Delta H_{\text {surf }}\right)$ that follows from it. Surface free energy and surface enthalpy values correspond to the primary (left) $y$-axis, surface entropy to the secondary (right) $y$-axis. The dotted arrows indicate important temperatures for estimating surface entropy: the Debye temperature $\left(T_{\mathrm{D}} \approx 0.2 T_{\mathrm{M}}\right)$, half of the melting temperature $\left(1 / 2 T_{\mathrm{M}}\right)$ and the melting temperature $\left(T_{\mathrm{M}}\right)$.

\section{Thermodynamic surface data for silver}

The above procedure has also been performed for silver. Averaging recent experimental data, ${ }^{17-19}$ we obtain a surface Gibbs free energy $\Delta G_{\text {surf, (I) }}$ for liquid silver at the melting temperature of $0.934 \pm 0.03 \mathrm{~J} \mathrm{~m}^{-2}$. Using the above discussed energetic difference between the surface of solid and liquid metals at $T_{\mathrm{M}}$, i.e. $\Delta G_{\text {surf, (s) }}=1.18 \Delta G_{\text {surf, (l), }}{ }^{13}$ we find $\Delta G_{\text {surf, (s) }}=$ $1.10 \mathrm{~J} \mathrm{~m}^{-2}$ at $T=T_{\mathrm{M}}$, in accordance with the value of $1.09 \mathrm{~J} \mathrm{~m}^{-2}$, given by Tyson and Miller. ${ }^{13}$ For the surface entropy for solid silver at the melting temperature, we used $\Delta S_{\text {surf }}=0.23 \mathrm{~mJ}$ $\mathrm{m}^{-2} \mathrm{~K}^{-1}$, equal to $1.8 R / A_{\mathrm{M}}{ }^{13}$ This value corresponds very well with the temperature dependency of the surface tension of molten silver $0.21 \pm 0.05 \mathrm{~mJ} \mathrm{~m}^{-2} \mathrm{~K}^{-1} \cdot{ }^{17-19}$ Results are given in Table 4.4 of the main text.

\section{C10 References}

1. I. Todhunter, Spherical Trigonometry: For the Use of Colleges and Schools, MacMillan and co., London, 1886.

2. R. C. Tolman, The journal of chemical physics, 1949, 17, 333-337.

3. H. Vehkamäki, Classical nucleation theory in multicomponent systems, Springer Science \& Business Media, 2006.

4. G. Menzl, M. A. Gonzalez, P. Geiger, F. Caupin, J. L. Abascal, C. Valeriani and C. Dellago, Proceedings of the National Academy of Sciences, 2016, 113, 13582-13587.

5. M. H. Factorovich, V. Molinero and D. A. Scherlis, Journal of the American Chemical Society, 2014, 136, 4508-4514.

6. B. Medasani, Y. H. Park and I. Vasiliev, Physical Review B, 2007, 75, 235436.

7. S. Ali, V. S. Myasnichenko and E. C. Neyts, Physical Chemistry Chemical Physics, 2016, 18, 792-800.

8. D. Liu, J. Lian and Q. Jiang, The Journal of Physical Chemistry C, 2009, 113, 1168-1170. 
9. A. S. Barnard and L. A. Curtiss, ChemPhysChem, 2006, 7, 1544-1553.

10. L. F. Oliveira, N. Tarrat, J. Cuny, J. Morillo, D. Lemoine, F. Spiegelman and M. Rapacioli, The Journal of Physical Chemistry A, 2016, 120, 8469-8483.

11. I. K. Suh, H. Ohta and Y. Waseda, Journal of Materials Science, 1988, 23, 757-760.

12. T. Hiemstra, Geochimica et Cosmochimica Acta, 2015, 158, 179-198.

13. W. R. Tyson and W. A. Miller, Surface Science, 1977, 62, 267-276.

14. T. Dubberstein and H. P. Heller, High Temperatures-High Pressures, 2015, 44, 393-406.

15. I. Egry, G. Lohoefer, E. Schwartz, J. Szekely and P. Neuhaus, Metallurgical and Materials Transactions $B, 1998,29,1031-1035$.

16. R. Novakovic, E. Ricci, F. Gnecco, D. Giuranno and G. Borzone, Surface science, 2005, 599, 230-247.

17. J. Lee, W. Shimoda and T. Tanaka, Materials transactions, 2004, 45, 2864-2870.

18. R. Novakovic, E. Ricci, D. Giuranno and A. Passerone, Surface science, 2005, 576, 175187.

19. S. Ozawa, K. Morohoshi, T. Hibiya and H. Fukuyama, Journal of Applied Physics, 2010, $107,014910$. 


\section{Appendix D}

\section{Supporting information to Chapter 5}

Structural approach to surface energy of nanoparticles

Bastiaan Molleman and Tjisse Hiemstra

D1 Properties of low index surfaces in the FCC metals

D2 Total number of atoms in particle geometries

D3 Derivation of zero-coordination energies

D4 Additional shape description

D5 Five-fold twinned particles

D6 Surface enthalpy and surface Gibbs free energy

D7 Surface energy crystal faces: comparison with recent MO/DFT methods

D8 Surface of tension and Tolman lengths

D9 Optimized edge-lengths

D10 References 


\section{D1 Properties of low index surfaces in the FCC metals}

In the main text, we discuss the strong proportional relationship between the surface density of broken bonds $(X)$ and the surface energy. The surface structure of a variety of low-index surfaces was studied to calculate the number of broken bonds present per unit surface area. The various low index surface planes have very different structures: some with atoms in a single interface position, some with atoms in 2 or 3 different interface positions. In Table D1, we provide an overview of the different low-index surfaces and the surface densities and coordination numbers of their respective atoms. Coordination numbers and surface densities were found with the help of CrystalMaker ${ }^{\circledR}$. The surface density of broken bonds $X$ follows from eq 5.1, i.e. $\sum \Gamma_{i} \Delta \mathrm{CN}_{i}$, with $\Delta \mathrm{CN}_{i}=\mathrm{CN}_{i}-\mathrm{CN}_{\mathrm{B}}$, using $\mathrm{CN}_{\mathrm{B}}=12$ for the FCC metals.

Table D1. Overview of properties of low index surfaces of the FCC metals.

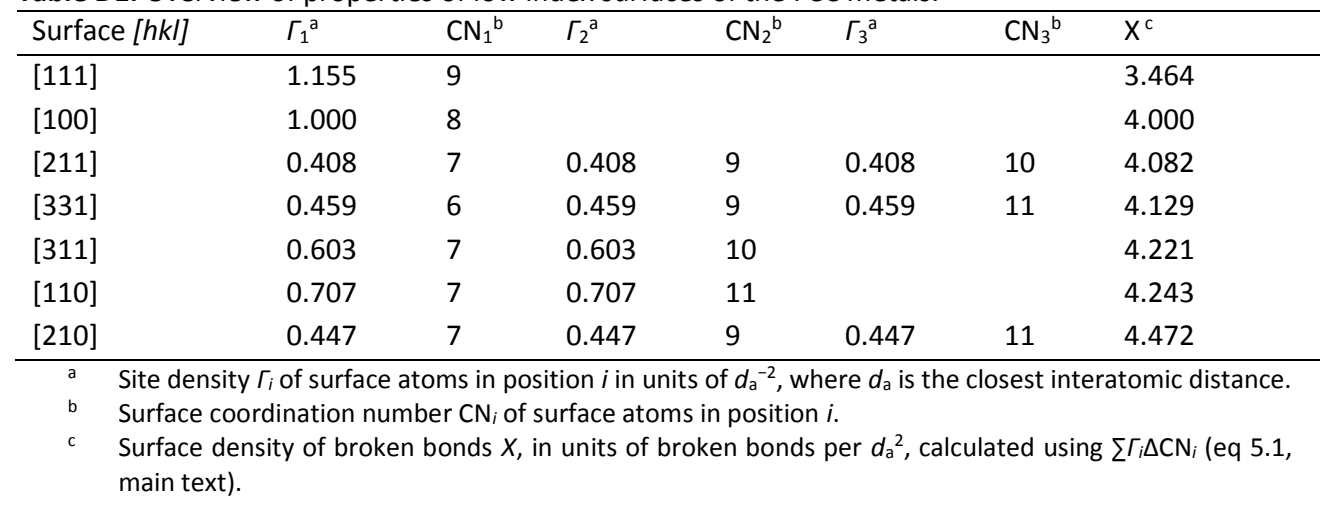

For the low index surfaces of the FCC metals, the surface density of broken bonds is proportional with the surface energy, as shown in Figure D1 for a variety of metals calculated using different computational methods. The figure shows data for: (a) copper, gold, and silver calculated using density functional theory (DFT) in the full-potential screened Korringa-KohnRostoker (FKKR) method; ${ }^{1}$ (b) iridium, rhodium, platinum, and palladium calculated using density functional theory (DFT) in the full-potential screened Korringa-Kohn-Rostoker (FKKR) method; ${ }^{2}$ (c) platinum, palladium, and gold calculated using DFT in the generalized gradient approximation (GGA) using the Perdew-Burke-Ernzerhof (PBE) functional; ${ }^{3}$ and (d) nickel and platinum calculated using DFT in the generalized gradient approximation (GGA) using the Perdew-Burke-Ernzerhof (PBE) functional. ${ }^{4}$ 

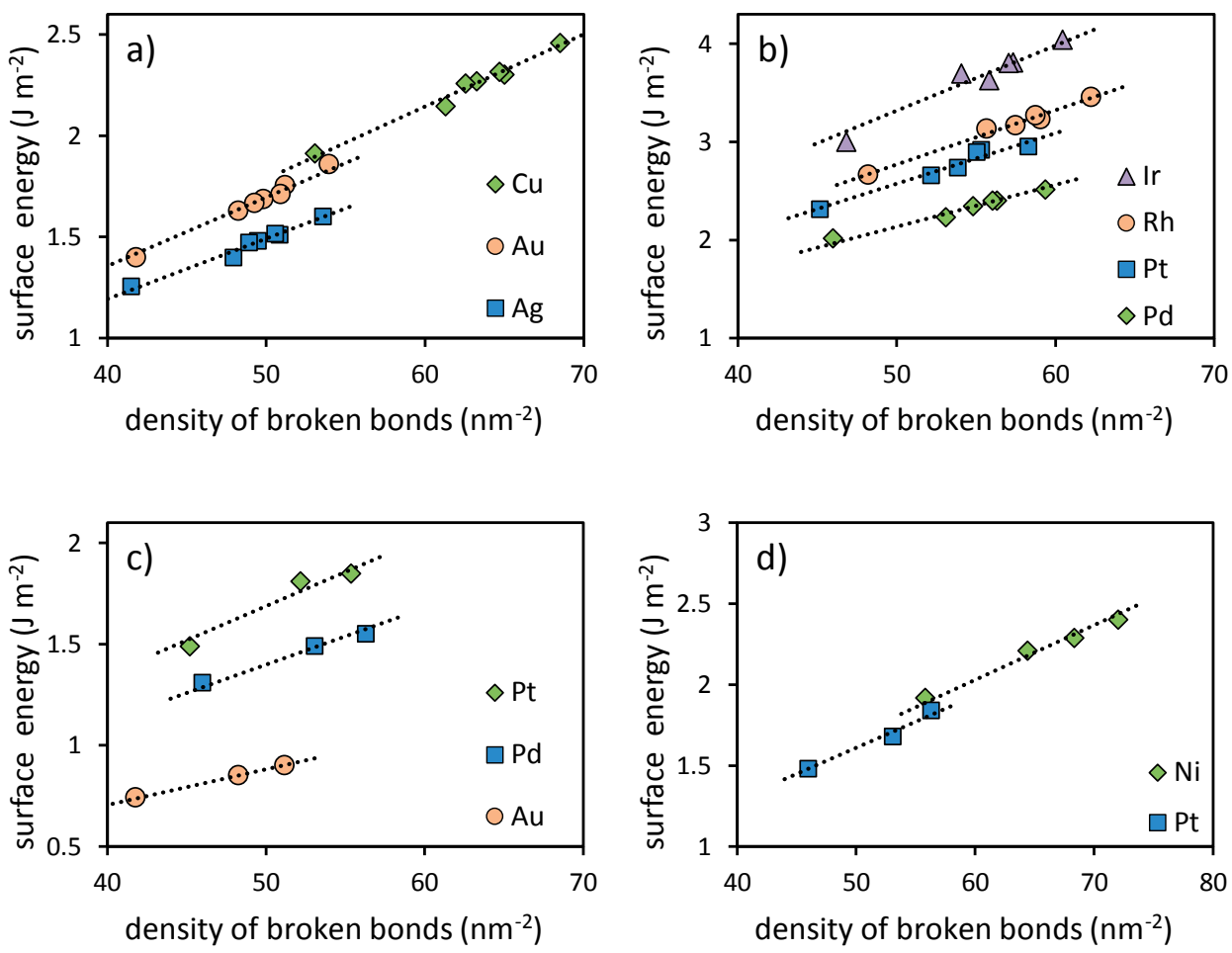

Figure D1. The relationship between surface energy and surface density of broken bonds for FCC metals. Shown are surface energy data for: (a) copper, gold, and silver calculated using DFT-LDA; $;^{1}$ (b) iridium, rhodium, platinum, and palladium calculated using DFT-LDA; ${ }^{2}$ (c) platinum, palladium, and gold calculated using DFT-GGA; ${ }^{3}$ and (d) nickel and platinum calculated using DFT-GGA. ${ }^{4}$

It is not certain that the proportionality found above is universal for FCC metals, e.g. surface energy values calculated for aluminum ${ }^{3}$ do not correlate as well. However, it appears to be valid for all FCC metals in groups 9 through 11, which are the metals of primary interest for nanoparticles.

An interesting side-note is that while the data for nickel and platinum in Figure D1d have very different values, they have the same slope. As we discuss in the main text, the slope represents the average bond energy. Thus while the same approximate bond energy is found for these two metals, the surface energy is much higher for nickel. The reason is the smaller interatomic distance in that metal, which leads to a higher surface density of broken bonds, and thus a higher surface energy, even at the same bond energy. 


\section{D2 Total number of atoms in particle geometries}

In Table 5.2 (main text), we present formulae for calculating the number of the different kinds of surface atoms found on the selected particle geometries. This information is used in the surface coordination model, which calculates the total coordination energy (J) for particles of different size. To convert this output to particle stabilities $\left(\mathrm{J} \mathrm{mol}^{-1}\right)$, the total number of atoms in a particle $N_{\mathrm{T}}$ is needed. Below, we derive the formulae for $N_{\mathrm{T}}$.

Octahedra, cuboctahedra, icosahedra, and regular truncated decahedra (with $s_{1}=s_{2}$ ) can be enlarged by placing a monolayer of atoms at the surfaces. The total number of atoms in the larger particle $N_{\mathrm{T}}$ is equal to that of the initial particle plus the number added by the monolayer. These numbers depend on the edge length $s$, expressed in a number of atoms.

In octahedra, an added monolayer increases edge-length with 2 atoms, leading to:

$$
N_{\mathrm{T}, s}=N_{\mathrm{T}, s-2}+N_{\mathrm{S}, \mathrm{s}}
$$

with $N_{\mathrm{T}, \mathrm{s}}$ for $s=1$ and $s=2$ equal to 1 and 6 respectively. The total number of surface atoms (facet, edge, and corner) $N_{\mathrm{S}, s}$ for a particles with edge-length $s$ is found using the formulae in Table 5.2 of the main text.

Analysis of the particle structure reveals that for cuboctahedra, truncated decahedra, and icosahedra, addition of a monolayer increases the edge-length $s$ with 1 atom. For a particle with edge length $s$, the total number of atoms $N_{\mathrm{T}, s}$ can be given as:

$N_{\mathrm{T}, s}=N_{\mathrm{T}, s-1}+N_{\mathrm{S}, \mathrm{s}}$

where, $N_{\mathrm{T}, s}$ for $s=1$ is equal to 1 ; as above, $\mathrm{N}_{\mathrm{S}, \mathrm{s}}$ is found using Table 5.2 of the main text.

Truncated octahedra are more complex and the total number of atoms is best calculated from the untruncated octahedra. A truncated octahedron with edges of $s$ atoms, is formed by truncating an octahedron with edges of $3 s-2$ atoms. The number of atoms removed from the six corners is equal to $\Sigma(s-1)^{2}$. Using these principles, $N_{T}$ can be reliably calculated for truncated octahedra, though the method is not very streamlined.

As an alternative to the above approach, the systematic build-up of the various geometrically shaped nanoclusters along a certain direction can be analyzed and formulated. The derivation is unimpressive but laborious, and we will not present it here. Rather, the set of summarized formulae is given below, in which the total number of atoms in a particle ( $\left.N_{\text {T.S }}\right)$ are written out as a function of the edge length $s$.

For octahedra the total number of atoms for a particle with edges of $s$ atoms is:

$N_{\mathrm{T}, s}=1 / 3\left(2 s^{3}+s\right)$ 
Cuboctahedra, icosahedra, and regular truncated decahedra with equal edge-lengths, i.e. $s_{1}=$ $s_{2}$, have the same total number of atoms for a particle with edges of $s$ atoms, equal to:

$N_{\mathrm{T}, s}=1 / 3(2 s-1)\left(5 s^{2}-5 s+3\right)$

For truncated decahedra with edge-lengths $s_{1}$ and $s_{2}$, the total number of atoms is equal to:

$N_{\mathrm{T}, s}=5 / 6\left(s_{1}{ }^{2}-s_{1}\right)\left(s_{1}+3 s_{2}-2\right)+s_{1}+s_{2}-1$

For truncated octahedra with edge-lengths $s_{1}$ and $s_{2}$, the total number of atoms is:

$$
\begin{aligned}
N_{\mathrm{T}, \mathrm{S}}=1 / 3\left(s_{1}+\right. & \left.2 s_{2}-2\right)\left(s_{1}+2 s_{2}-1\right)\left(2 s_{1}+4 s_{2}-3\right)-\left(s_{1}+2 s_{2}-2\right)^{2} \\
& -\left(s_{1}{ }^{2}-s_{1}\right)\left(2 s_{2}-1\right)
\end{aligned}
$$

\section{D3 Derivation of zero-coordination energies}

Using the appropriate value for the zero-coordination energy, $E_{0}$, the surface coordination model (equation 5.3, main text) calculates the external excess energy $\Delta E_{s}$ of metallic nanoparticles. Vice versa, if the external excess energy is known for particles of a given structure, the corresponding value of $E_{0}$ can be calculated. For a collection of structures, plotting $\Delta E_{S}$ against the sum term of equation 5.3, i.e. $\sum N_{i}\left(1-\left(\Delta C N_{i} / C N_{B}\right)^{1 / 2}\right)$, will give a linear correlation with a slope equal to $E_{0}$.

In Figure D2 (next page), the excess energy, calculated using MO/DFT for a variety of gold and silver nanoparticles, is plotted against the sum-term of equation 5.3 of the main text for the corresponding structures. The structures used have no twinning or other features leading to internal energy contributions. Therefore, the excess energy calculated for these particles is expected to be exclusively external. The figure shows a strong linear correlation between the computationally calculated particle energy data and the surface coordination energy.

Figure D2a shows excess energy data for gold nanoparticles by Barnard and Curtis ${ }^{5}$ calculated using DFT-GGA. A good correlation is found with the coordination energy, though individual data points may slightly deviate from the trendline. Using the slope or zero-coordination energy of $E_{0}=0.59$ aJ to calculate surface coordination energies, the average difference from energies values generated by MO/DFT is approximately zero, having a standard deviation of 0.26 aJ.

Figure D2b shows excess energy of silver nanoclusters, calculated by Medasani et al. ${ }^{6}$ using MO/DFT-GGA. An excellent correlation is found with a slope of 0.44 aJ. Note that two of the data points by Medasani et al. ${ }^{6}$ are for polyhedral clusters that are not described in Table 5.1 of the main text. 

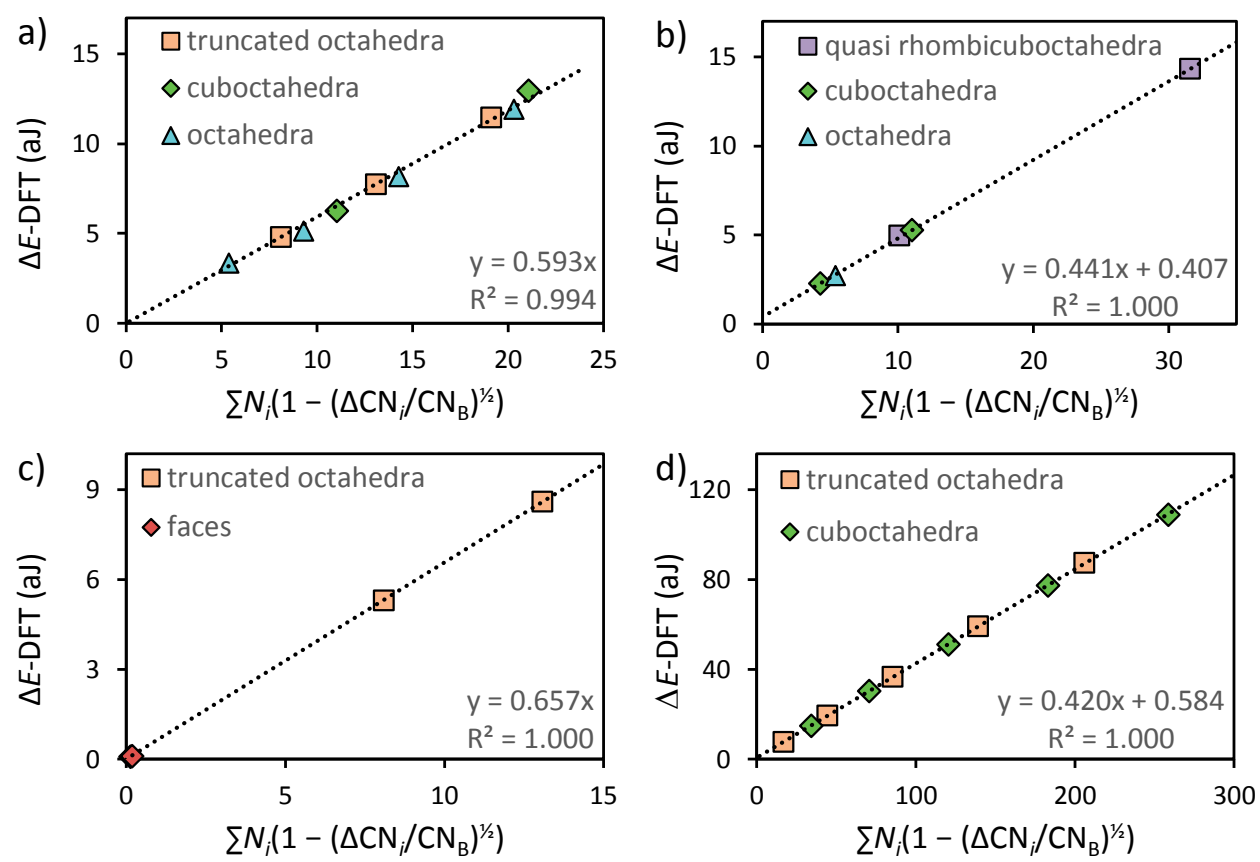

Figure D2. Relationship between the sum-term of equation 5.3 and excess particle energy $\Delta E$, as calculated using various computational methods. Shown are (a) gold clusters based on DFT-GGA, ${ }^{5}$ (b) silver clusters based on DFT-GGA, ${ }^{6}$ (c) silver clusters based on DFT-LDA, ${ }^{7}$ and (d) gold clusters using MD-EAM. ${ }^{8}$ The slope of the line yields the zero coordination energy $E_{0}$.

Liu et al., ${ }^{7}$ have calculated energies for silver surfaces and truncated octahedra using DFT-LDA, as shown in Figure D2c. The data for the truncated octahedra and the [111] face almost perfectly proportional to the surface coordination value, all suggesting a zero coordination energy of $E_{0}=0.66 \pm 0.01$ aJ per atom. Contrasting to this, the [100] face surface energy suggests a value of 0.60 aJ per atom.

Figure D2d shows molecular dynamics data calculated by Ali et al. ${ }^{8}$ using the embedded atom method. Data have been calculated for truncated octahedra and cuboctahedra over a large size-range. Again, the computational data are linearly correlated to the sum-term of equation 5.3 , the resulting slope corresponds to a zero-coordination value of $E_{0}=0.42$ aJ.

The results by Medasani et al. ${ }^{6}$ and Ali et al. ${ }^{8}$ (respectively Figure D2b and D2d) are not perfectly proportional to the results from the surface coordination model. Instead, a small positive intercept is found of 0.41 aJ and 0.58 aJ, respectively. Forcing the trendline through the origin yields slightly higher slopes. Compared to the computational data, values calculated with these higher $E_{0}$ values underestimate $\Delta E_{\mathrm{S}}$ for the largest particles, and overestimate it for the smaller particles. While the intercept is small, in both cases it significant from the statistical perspective. It suggests that for these data, the coordination energy of clusters is 
underestimated by a constant amount of energy, in contrast to the data by Barnard et al. ${ }^{5}$ and Liu et al. ${ }^{7}$

\section{D4 Additional shape description}

Table 5.1 of the main text describes a set of common polyhedral geometries in the FCC lattice, which does not include the shape shown below (Figure D2). This shape is used by Medasani et al. ${ }^{6}$ in 2 sizes, containing 43 and 249 atoms. These clusters have been reproduced in Crystal Maker $^{\circledR}$ : surface properties are listed in Table D2.

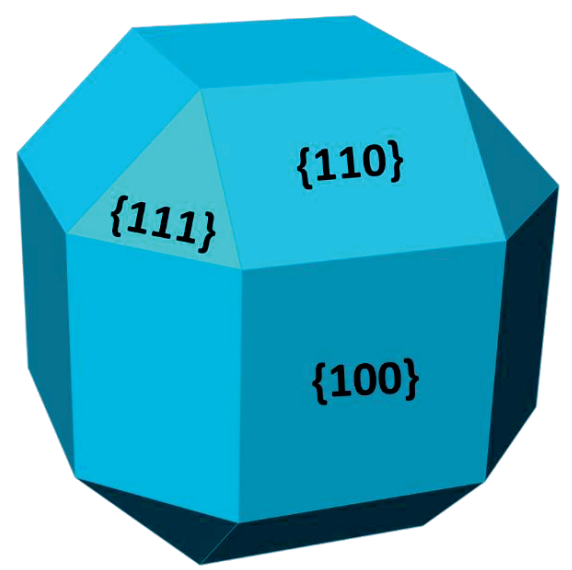

Figure D3. An additional shape used by Medasani et al., ${ }^{6}$ having [111], [100] and [110] facets. It is a rhombi-cuboctahedron-like particle.

As Figure D3 shows, this shape has three types of crystal faces: the [111] and [100] face, with 9 and 8-fold coordinated atoms, respectively, and the [110] face, which has two atoms with coordination numbers of 11 and 7. The edges between the [111] and the [110] face have a coordination number of 7 , while atoms on the edge between the [100] and the [110] face have a coordination number of 6 . Corner atoms are located where a [111] face, a [100] face and two [110] faces meet, and have a coordination number of 5. A full overview of surface properties is for the two sizes, $N_{T}=43$ and $N_{T}=249$, is given below in Table D2 
Table D2. Surface structural properties of a rhombi-cuboctahedron-like particle.

\begin{tabular}{lllllllllrrr}
\hline face $^{\mathrm{a}}$ & $\mathrm{CN}_{i}^{\mathrm{b}}$ & $N_{i 43}{ }^{\mathrm{c}}$ & $N_{i 249^{\mathrm{d}}}$ & $\mathrm{edge}^{\mathrm{e}}$ & $\mathrm{CN}_{i}^{\mathrm{b}}$ & $N_{i 43}{ }^{\mathrm{c}}$ & $N_{i 249}{ }^{\mathrm{d}}$ & corner $^{\mathrm{f}}$ & $\mathrm{CN}_{i}^{\mathrm{b}}$ & $N_{i 43}{ }^{\mathrm{c}}$ & $N_{i 249^{d}}$ \\
\hline$[111]$ & 9 & 0 & 0 & {$[100][110]$} & 6 & 0 & 24 & {$[110]^{2}[100][111]$} & 5 & 24 & 24 \\
{$[100]$} & 8 & 6 & 30 & {$[111][110]$} & 7 & 0 & 24 & & & & \\
& 7 & 0 & 12 & & & & & & & & \\
{$[110]$} & 11 & 12 & 48 & & & & & & & & \\
\hline
\end{tabular}

a Surface facets, as identified by their miller index ([111], [100], or [110])

b Coordination number of atoms of type $i$

c Number of times facet, edge or corner atoms of type $i$ is found on the particle with $N_{\mathrm{T}}=43$

d Number of times facet, edge or corner atoms of type $i$ is found on the particle with $N_{\mathrm{T}}=249$

e Edges, as identified by the two intersecting surface facets

$f$ Corners, as identified by the surfaces intersecting at the corner atom

\section{D5 Five-fold twinned particles}

\section{Twin-plane twin-axis atoms}

In the surface coordination model, discreet energy contributions are calculated for individual surface atoms. This approach was extended to the description of internal energy. In literature, a distinction is generally made between internal strain and twin-plane energy. It suggests that atoms in the twin-planes are thought to contribute differently to internal energy.

Fivefold twinned particles have a radial symmetry, with five twin-planes meeting in a central axis. The structure of the twin planes of icosahedra and regular truncated decahedra are illustrated in Figure D4. Icosahedra (Figure D4a) have triangular twin-planes, stretching between each of its 30 edges to the central atom. The two sides of twin-planes are axis shared between five different twin-planes, leading to 12 twin-axis. Truncated decahedra (Figure D4b) have five trapezoidal planes with the base forming the twin-axis.
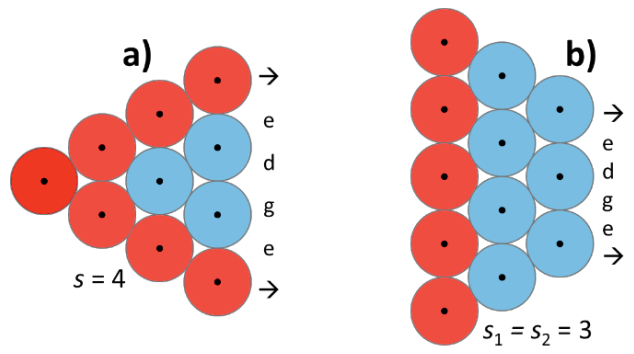

Figure D4. Schematic representation of the twin-planes of icosahedra (a) and decahedra (b). Light red atoms indicate twin-axis atoms while blue atoms indicate non-twin-plane atoms, the dark red atom in Fig.S4a) represents the atom at the centre of an icosahedron. The edge, as well as the edge-lengths, $s$ for icosahedra (a) or s1 and s2 for decahedra (b) are given in the figure. 
The number of atoms at the twin-plane and twin-axis are calculated using the number of atoms present at the edges, $s$, which includes the corner atoms. For icosahedra, the twelve twin-axis have a length of $s-1$; the central atom (dark red in Figure D4a) is also treated as a twin-axis atom, leading to:

$N_{a x}=1+12(s-1)$

The number of atoms in each of the thirty twin-planes is equal to the sum of natural numbers up to $s-2$, leading to:

$N_{t p}=30 \sum_{k=1}^{s-2} k=30 \frac{(s-1)(s-2)}{2}$

For truncated decahedra, the number of atoms in the single twin-axis is equal to the sum of the edges minus one, leading to:

$N_{a x}=s_{1}+s_{2}-1$

The number of atoms in each of the five twin planes is equal to the sum of natural numbers from the outer edge $s_{2}$ until the first row of atoms after the central axis, leading to:

$N_{t p}=\sum_{k=s_{2}}^{s_{1}+s_{2}-2} k=5 \frac{\left(\left(s_{1}+s_{2}-1\right)\left(s_{1}+s_{2}-2\right)-s_{2}\left(s_{2}-1\right)\right)}{2}$
$=5 \frac{\left(s_{1}-1\right)\left(s_{1}+2 s_{2}-2\right)}{2}$

Figure D4 shows that three types of atoms can be distinguished in the twin-planes of icosahedra, versus two types in decahedra. These different positions may be associated with a different energy. However, in our analysis in the main text, we use a single category of twinatoms, in which we combine all twin atoms described. In this approach, a strain energy of $2.0 \cdot 10^{-3}$ aJ per atom is found, and an energy of $1.3 \cdot 10^{-3}$ aJ per twin atom.

A more detailed modelling of twinning energies, differentiating between the twin-plane atoms and twin-axis leads to kinds of twinning atoms, is performed using linear regression. It leads to a somewhat lower strain energy of $1.7 \cdot 10^{-3} \pm 3.1 \cdot 10^{-5}$ aJ per atom. For the twin-plane we find a very similar energy of $1.3 \cdot 10^{-3} \pm 5.8 \cdot 10^{-5}$ aJ per atom, but the twin-axis has a much higher energy of $9.8 \cdot 10^{-3} \pm 0.90 \cdot 10^{-3}$ aJ per twin-axis atom. Using this three atom model, we have decreased the intercept form 0.58 aJ to 0.41 aJ, for the best results.

\section{Marks decahedra}

In literature, a modified version of the truncated decahedra described above is often used, where the high-energy atoms that are present on the outer edge are removed, as shown in 
Figure D5. This modified structure, known as the Marks decahedron, is energetically more favorable due to a higher coordination number on has corners and edges, as we show in the main text.
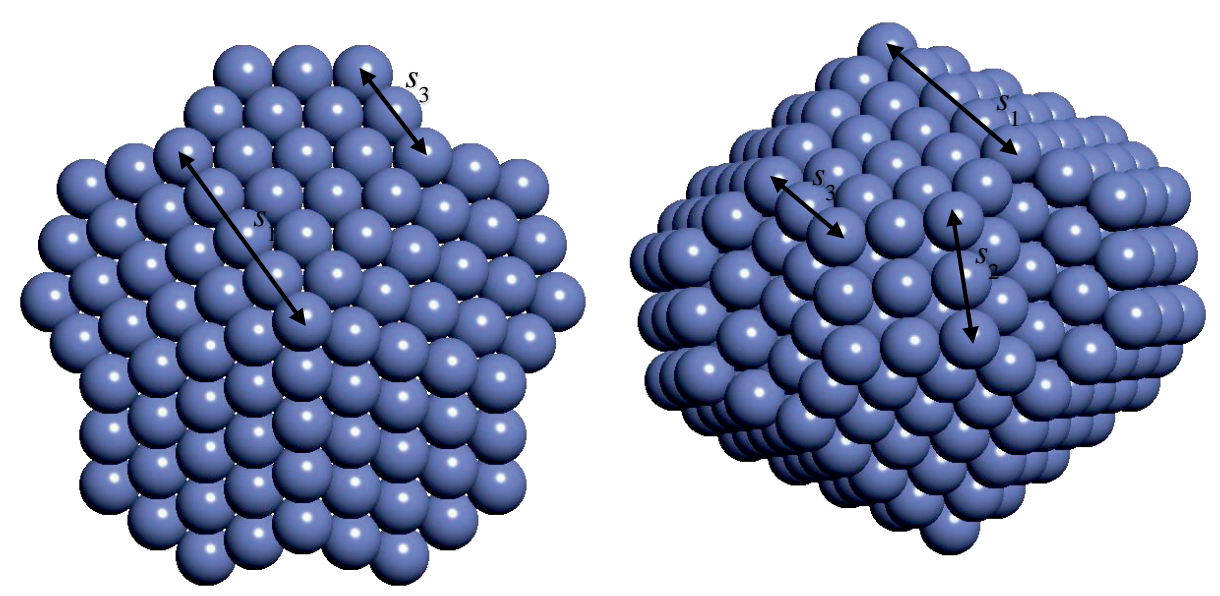

Figure D5. A Marks decahedron see from the top and from the side. The three different edge-lengths, $s_{1}, s_{2}$, and $s_{3}$, that are used to describe the particle (see Table D3) are indicated in the figure, where the top view only shows $s_{1}$ and $s_{3}$. The Marks decahedron is formed from an truncated decahedron by removing the high energy atoms at the edge of the twin-plane, it leads to a shorter edge-length $s_{1}$.

The number of face, edge, and corner atoms for this particle geometry is given below in Table D3, as well as coordination numbers. The formulae given in Table D3 are based on the edgelengths $s_{1}, s_{2}$ and $s_{3}$ as indicated in Figure D5. The total number of atoms $N_{\mathrm{T}}$ in a Marks decahedron can be given as follows:

$$
\begin{gathered}
N_{\mathrm{T}}=5\left(\left(s_{2}+\frac{s_{1}+s_{3}}{3}-1\right) \frac{\left(s_{1}+s_{3}-1\right)\left(s_{1}+s_{3}-2\right)}{2}-s_{2}\left(s_{3-1}\right)^{2}\right. \\
\left.-\frac{\left(s_{3}-1\right)\left(s_{3}-2\right)\left(2 s_{3}-3\right)}{6}\right)+s_{1}+s_{2}+s_{3}-2
\end{gathered}
$$

All formulae are valid as long as $s_{1} \geq 3, s_{2} \geq 2$, and $s_{1}-s_{3} \geq 1$. 
Table D3. Surface structural properties of Marks decahedra.

\begin{tabular}{llll} 
Type of surface atom & $\mathrm{CN}_{i}^{\mathrm{f}}$ & $\mathrm{N}_{\mathrm{i}}^{\mathrm{g}}$ \\
\hline facets $^{\mathrm{a}}$ & {$[111]$} & 9 & $5\left(s_{1}-1\right)\left(s_{1}-2\right)+10\left(s_{1}+s_{2}-4\right)\left(s_{3}-2\right)$ \\
& {$[100]$} & 8 & $5\left(s_{1}-s_{3}-1\right)\left(s_{2}-2\right)$ \\
& {$[111] ;[111]^{\mathrm{d}}$} & 8 & $10\left(s_{1}-2\right)$ \\
edges $^{\mathrm{b}}$ & {$[111] ;[111]^{\mathrm{e}}$} & 10 & $5\left(s_{2}+s_{3}-3\right)$ \\
& {$[111] ;[111]$} & 8 & $20\left(s_{3}-2\right)$ \\
& {$[111] ;[100]$} & 7 & $10\left(s_{1}+s_{2}-s_{3}-3\right)$ \\
& $5 \cdot[111]$ & 6 & 2 \\
corners $^{\mathrm{c}}$ & $4 \cdot[111]$ & 7 & 10 \\
& $2 \cdot[111] ;[100]$ & 6 & 20
\end{tabular}

a Surface facets, as identified by their miller index ([111] or [100])

b Edges, as identified by the two intersecting surface facets

c Corners, as identified by the surfaces intersecting at the corner atom

d Edge of the twin-plane; dihedral angle is smaller than $180^{\circ}$

e Edge of the twin-plane; dihedral angle is larger than $180^{\circ}$

f Coordination number of atoms of type $i$

$\mathrm{g}$ Number of times facet, edge or corner atoms of type $i$ is found on a particular particle geometry

Twinning energy of icosahedra and decahedra

The twinning energy model that we have developed in the main text is applied to gold and silver icosahedra and decahedra studied by Barnard and Curtis ${ }^{5}$ and Liu et al. ${ }^{7}$ The dotted lines in Figure D6 are predictions with the twinning model using the approach with 2 types of internal atoms. The dashed lines are predictions are predictions with an alternate twinning model with 3 types of atoms, which is describes above. The symbols refer to the twinning energy $\Delta E_{\text {twin }}$ that is calculated as the difference between the reported excess particle energy $\Delta E$ and the external excess energy $\Delta E_{S}$ calculated with the coordination model using the appropriate $E_{0}$ value. 

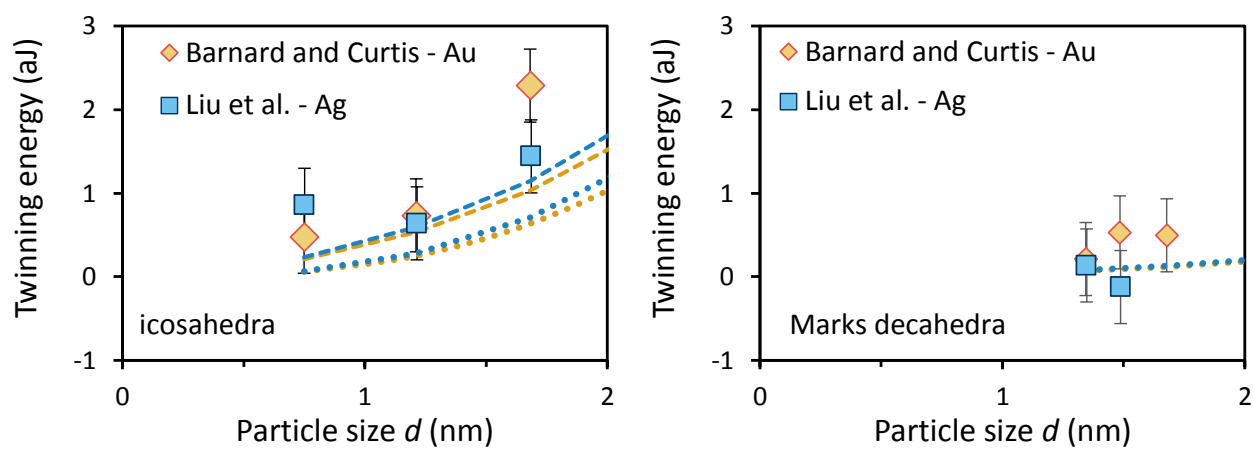

Figure D6. Twinning energy for twinned nanoparticles of gold (yellow diamonds) and silver (blue squares), derived respectively from data by Barnard and Curtis ${ }^{5}$ and Liu et al. ${ }^{7}$ The left panel shows icosahedral particles, the right panel shows Marks decahedra. The error bars represent an uncertainty of 0.26 aJ, equal to the standard deviation of the FCC-particles of Barnard and Curtis for the surface coordination model. The dotted lines represent the twinning energy as predicted with the twinning energy model described in the main text. Particle size is a mass based diameter, according to $d=$ $\left(6 / \pi \cdot N_{\mathrm{T}} / N_{\mathrm{A}} \cdot M / \rho\right)^{1 / 3}$.

The figure shows that the twinning model with two parameters slightly underestimates the computational twinning energies for icosahedra. For decahedra, results are described to within the data uncertainty of the data. The twinning model with three parameters leads to better results for icosahedra. 


\section{D6 Surface enthalpy and surface Gibbs free energy}

Deriving the surface enthalpy and the Gibbs free energy for solid metals

Values for the surface enthalpy $\Delta H_{\text {surf }}$ and surface Gibbs free energy $\Delta G_{\text {surf }}$ of solid metals can be calculated from surface tension data measured for molten metals, based on the relationships proposed by Tyson and Miller. ${ }^{9}$ According to this approach, surface Gibbs free energy at the melting temperature $\Delta G_{\text {surf }}\left(T_{\mathrm{M}}\right)$ is a factor 1.18 higher for the solid metal than for the liquid phase. We similarly estimated the surface entropy at the melting temperature $\Delta S_{\text {surf }}\left(T_{M}\right)$ of the solid phase to be a factor 1.18 higher than the temperature dependency of the surface tension of the liquid phase.

The surface Gibbs free energy can be extrapolated to any temperature using the relationship: ${ }^{9}$

$$
\Delta G_{\text {surf }}\left(T_{\mathrm{M}}\right)-\Delta G_{\text {surf }}(T)=-\int_{T}^{T_{M}} \Delta S_{\text {surf }} d T
$$

The temperature dependency of $\Delta S_{\text {surf }}$ was assumed to follow the pattern outlined by Tyson and Miller. ${ }^{9}$ They estimate surface entropy $\Delta S_{\text {surf }}$ increases linearly from 0 at absolute zero, to $\sim 0.44 \Delta S_{\text {surf }}\left(T_{\mathrm{M}}\right)$ at the Debye temperature $\left(T_{\mathrm{D}}\right)$, estimated at $0.2 T_{\mathrm{M}}$. Between $T_{\mathrm{D}}$ and $0.5 T_{\mathrm{M}}$, surface entropy is constant at $\sim 0.44 \Delta S_{\text {surf }}\left(T_{M}\right)$, and increases linearly from $\sim 0.44 \Delta S_{\text {surf }}\left(T_{M}\right)$ to $\Delta S_{\text {surf }}\left(T_{\mathrm{M}}\right)$ between $0.5 T_{\mathrm{M}}$ and $T_{\mathrm{M}}$. The surface enthalpy is found using $\Delta H_{\text {surf }}=\Delta G_{\text {surf }}+\mathrm{T} \Delta S_{\text {surf }}$.

The Gibbs free energy calculated in this manner depends on both the surface tension of the liquid phase at the melting temperature and its temperature dependency. Experimentally determined surface tension values and temperature dependencies can vary considerably between literature sources. We have therefore tried to collect a complete overview of reported measurements, omitting sources in which the well-known influence on surface tension measurements of oxygen ${ }^{10}$ and the use of magnetic levitation of liquid metal drops ${ }^{11}$ were not strictly controlled or corrected for. From each reference, the surface tension at the melting temperature and the temperature dependency was used to calculate the surface enthalpy and surface Gibbs free energy at room temperature. An average value and standard deviation was calculated based on the results. Average surface Gibbs free energy values at room temperature are presented in Table D4. 
Table D4. Experimental and predicted surface Gibbs free energy data for elemental metals at standard conditions ( $T=298 \mathrm{~K}, P=1 \mathrm{~atm})$.

\begin{tabular}{llllll}
\hline & $\mathrm{d}_{\mathrm{a}}{ }^{\mathrm{a}}$ & $\Delta \mathrm{G}_{\mathrm{a}}{ }^{\mathrm{b}}$ & $\Delta G_{\mathrm{s},[111]^{\mathrm{c}}}$ & $\Delta G_{\mathrm{s},[100]^{c}}$ & $\Delta G_{\mathrm{s}, \exp }{ }^{d}$ \\
\hline $\mathrm{Ni}$ & 0.249 & 384.6 & $1.83 \pm 0.08$ & $2.17 \pm 0.09$ & $2.36 \pm 0.02$ \\
$\mathrm{Cu}$ & 0.255 & 297.7 & $1.35 \pm 0.06$ & $1.60 \pm 0.07$ & $1.69 \pm 0.06$ \\
$\mathrm{Ag}$ & 0.289 & 246.0 & $0.87 \pm 0.04$ & $1.03 \pm 0.04$ & $1.24 \pm 0.06$ \\
$\mathrm{Au}$ & 0.288 & 326.3 & $1.16 \pm 0.05$ & $1.38 \pm 0.06$ & $1.45 \pm 0.01$
\end{tabular}

a Closest interatomic distance $(\mathrm{nm})$, from crystallographic data by Suh et al. ${ }^{12}$

b Standard Gibbs free energy of atomization $\left(\mathrm{kJ} \mathrm{mol}^{-1}\right)$, from Cox et al..$^{13}(\mathrm{Cu}$ and $\mathrm{Ag})$ and Schumm et al. ${ }^{14}$ ( $\mathrm{Ni}$ and $\mathrm{Au}$ )

c Predicted surface Gibbs free energy of the [111] and the [100] face, according to $E_{0}\left(1-\left(\mathrm{CN}_{i} / \mathrm{CN}_{\mathrm{B}}\right)^{1 / 2}\right) \cdot \Gamma_{i}$, with $E_{0}$ being $15 \pm 5 \%$ higher than the Gibbs free energy of atomization, leading to the given uncertainty margins.

d Experimental surface Gibbs free energy $\left(\mathrm{J} \mathrm{m}^{-2}\right)$, calculated from collected surface energy data of liquid metals. Uncertainty margins refer to the standard deviation of collected data.

In the main text, an excellent agreement is found between experimental surface enthalpy values and those calculated from the enthalpy of atomization for the [111] and the [100] face using the surface coordination model. This is not the case for surface Gibbs free energy. As Table D3 shows, the experimental surface Gibbs free energy is significantly higher than the prediction of the surface coordination model. It suggests that $\Delta H_{\mathrm{a}}$ relates differently to $\Delta H_{\mathrm{s}}$ than $\Delta G_{\mathrm{a}}$ to $\Delta G_{\mathrm{s}}$.

A quick analysis shows that, for the metals in Tables 5.3 and D4, the surface Gibbs free energy is about $2 \%$ lower than the surface enthalpy, whereas the Gibbs free energy of atomization is about $12 \%$ lower than the enthalpy of atomization. This implies that the surface entropy contribution $T \Delta S_{S}$ is equal to approximately $2 \%$ of the surface enthalpy, whereas the entropy change at atomization $T \Delta S_{\mathrm{a}}$ is equal to $\sim 12 \%$ of $\Delta H_{\mathrm{a}}$. This difference implies that the entropy gain, with respect to the enthalpy gain, is substantially higher when all bonds are broken than when only part of the bonds are broken.

The reason for this may be a large increase in entropy upon breaking the last bond and entering the gas phase. This behaviour can be described with e.g. a power function with $n=$ 0.08 , as shown in Figure D7. Given this change of entropy with coordination, the Gibbs free energy is a roughly constant fraction of the enthalpy for all types of surface atoms. 

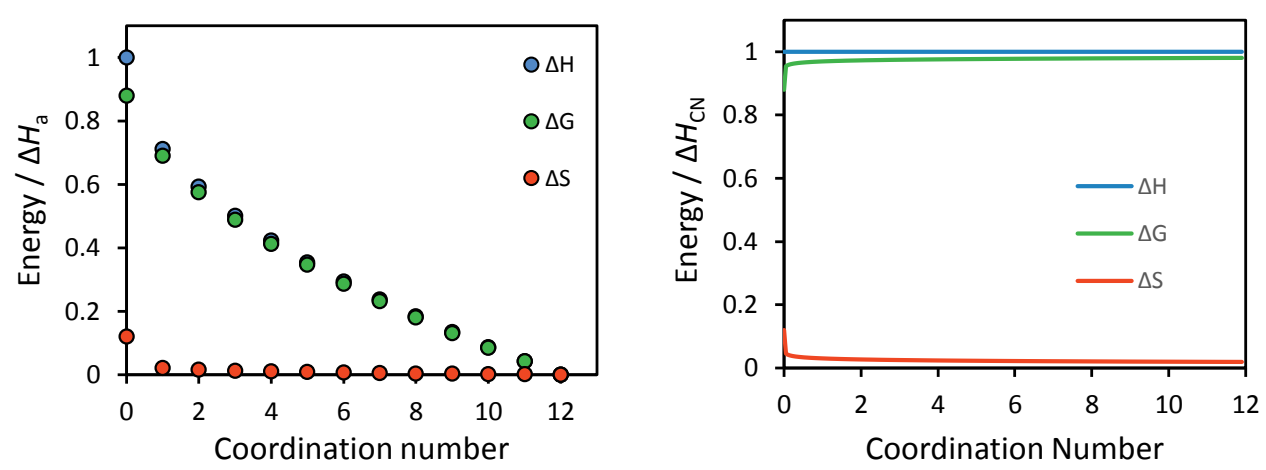

Figure D7. The energy of atoms as it varies with coordination number. The left panel shows the energies relative to the enthalpy of atomization, while the right panel shows the energies relative to the enthalpy of an atom at similar coordination. Note the large increase in entropy at $\mathrm{CN}=0$ and the associated drop in Gibbs free energy.

The different patterns of coordination dependency of enthalpy and entropy discussed above are reminiscent of our earlier findings on the size dependency of surface enthalpy and surface enthalpy. ${ }^{15}$ There, we found that surface entropy increases relatively more strongly towards smaller size than surface enthalpy. The two must not be confused however as the latter has the additional factor of an increasing number of broken bonds per unit surface area.

\section{D7 Surface energy crystal faces: comparison with recent MO/DFT methods}

In the main test we compare the two most common MO/DFT methods, the local density approximation (LDA), and the Perdew-Burke-Ernzerhoff generalized gradient approximation (PBE-GGA), to the results of the $\mathrm{CN}$-model. Here we additionally compare literature data generated using the PBE-GGA adapted for solids (PBEsol) ${ }^{16,17}$ and highly advanced meta-GGA methods. Of the latter, the strongly constrained and appropriately normed (SCAN) was used with the addition of the revised Vydrov-Van Voorhis 2010 (rVV10) functional to correctly describe long range van der Waals interaction. The other meta-GGA method, used the Tao-Perdew-Staroverov-Scuseria (TPSS) functional. ${ }^{17}$

Figure D8 shows MO/DFT data plotted against the predictions of the $\mathrm{CN}$-model. For all methods, the data for silver agree very well with the CN-model. Copper data found with PBEsol are also very close, performing markedly better than LDA, however, the PBEsol data for gold are not as close to the CN-model as the LDA-data (see Figure 5.10, main text). Data obtained using the SCAN-rVV10 functional ${ }^{16}$ agrees quite well, to the values found using the surface coordination model. However, the data generated using the TPSS functional ${ }^{17}$ are extremely high for copper, and quite low for gold. Interestingly, none of the methods in Figure D8 perform markedly better than the LDA. 

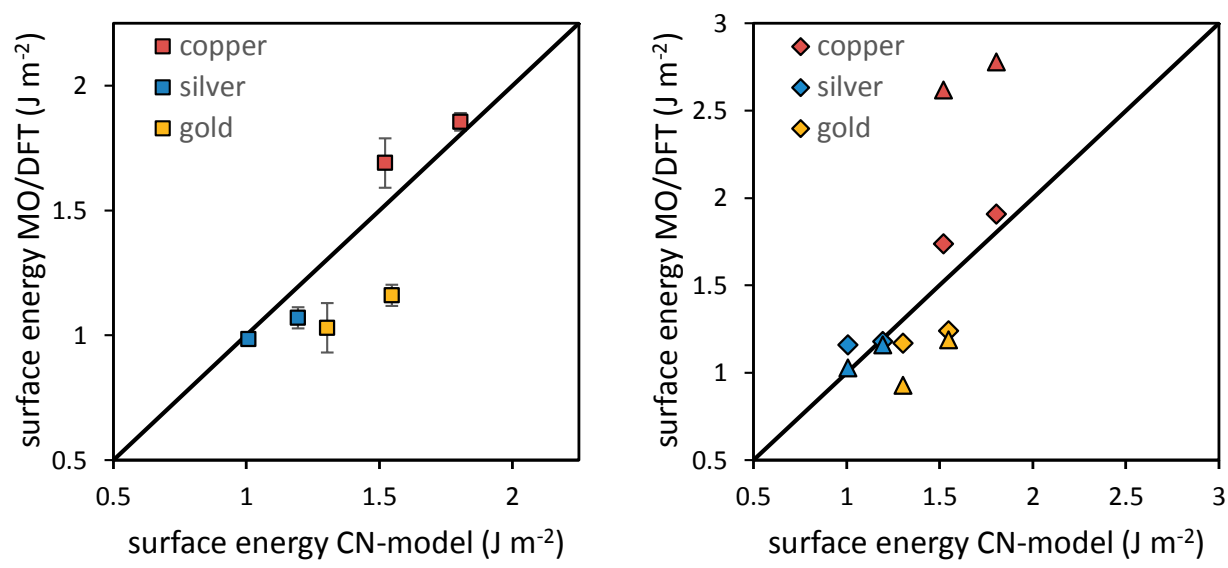

Figure D8. Surface energies of two major low index faces ([111] and [100]) calculated for three metals with MO/DFT versus the surface energies according to the $\mathrm{CN}$-model. The left panel shows the average value of two references using GGA-PBEsol; ${ }^{16,17}$ the right panel shows two meta-GGA functionals: SCAN$\mathrm{rVV}^{10}{ }^{16}$ (diamonds) and TPSS ${ }^{17}$ (triangles). The surface energies according to the $\mathrm{CN}$-model are calculated using only the cohesive energy and the interatomic distance as input (eq 5.5). The diagonal gives the 1:1 relation.

\section{D8 Surface of tension and Tolman lengths}

In our very recent contribution, ${ }^{18}$ we have established that for the calculation of thermodynamically consistent surface energy values, excess particle energy must be scaled to the surface of tension. The position of this surface, relative to the equimolar surface, is referred to as the Tolman length $\delta$. The latter can be used, together with the macroscopic surface tension $\gamma_{\infty}$, to calculate a surface energy value for a particle of a given size (eq 5.6, main text). By definition, surface energies obtained in this way, i.e. using the Tolman equation, have the same value as those found by value scaling the excess particle energy to the surface of tension. A different position in the interface gives a different surface area as well as a different Tolman length and there is only one position where both lead to the same surface energy value. This is where, according to thermodynamics, the surface energy performs its work, and therefore it is to this plane that the surface energy has to be scaled.

We evaluated the agreement of surface energy values obtained from scaling to surface area and applying the Tolman equation (adapted for non-spherical particles) for three different definitions of particle surface, using excess particle energy data for gold cuboctahedra by Ali et al. $^{8}$ An excellent agreement between the surface area scaled excess energy and thermodynamic surface energy value was found using the physical surface, which was defined to be located at half the interatomic distance $d_{\mathrm{a}}$ from the cores of surface atoms. The physical surface was therefore considered to be consistent as the surface of tension. In this section, we will determine the location of the surface of tension and the size-dependency of surface 
energy to the highest precision using the excess energy results according to our surface coordination model.

Figure D9 shows excess energies, calculated with the CN-model (blue symbols), scaled to a surface area located at a distance $r_{x}$ from the cores of surface atoms. This is a modification of the physical surface as described in in Molleman and Hiemstra, ${ }^{18}$ using $2 r_{\mathrm{x}} d_{\mathrm{a}}$ instead of $d_{\mathrm{a}}{ }^{2}$ for the edge area, and $4 r_{x}{ }^{2}$ for the corner surface. The Tolman length for a surface at $r_{x}$ is equal to the sum of the shape dependent Tolman lengths of the physical surface and $r_{x}$, minus the position of the physical surface with respect to the cores of surface atoms $\left(0.5 d_{a}\right)$, leading to $\delta_{\mathrm{x}}=\delta_{\text {phys }}-0.5 d_{\mathrm{a}}+r_{\mathrm{x}}$. The value of $r_{\mathrm{x}}$ was optimized to obtain consistency between the scaled surface energy and the surface energy according to the Tolman equation using $\delta_{\mathrm{x}}$. The latter is shown as full lines in Figure D9.

Our analysis reveals Tolman lengths between -0.015 and $-0.019 \mathrm{~nm}$, which is smaller, i.e. less negative, than we previously determined using the data by Ali et al. ${ }^{8}$ However, the value of $r_{\mathrm{x}}$ is only $\sim 5-15 \%$ smaller than $0.5 d_{a}$, which means that the location of the surface of tension, with respect to the cores of surface atoms, is very close to the physical surface we describe in our recent work. ${ }^{18}$

An important point for evaluating the size-dependency of surface energy is the impact of the intercept that is sometimes found in the correlation between excess energy and coordination values (Figure D2). The intercept is very evident in the computational data by Medasani et al. ${ }^{6}$ and Ali et al., ${ }^{8}$ but not found in the data of Barnard and Curtis, ${ }^{5}$ and Liu et al. ${ }^{7}$ The presence of an intercept, yes or no, changes the calculated size dependency of the surface energy and the location of the surface of tension.

If an additional constant energy contribution can be added to the results of the $\mathrm{CN}$-model, as suggested by the presence of an intercept, higher surface energies and thus slightly larger Tolman lengths are found. As shown Figure D9, the agreement between scaled surface energies (red symbols) and the Tolman equation (full red line) is poorer than for the $\mathrm{CN}$-model sec. The latter cannot be prevented by changing the Tolman length, though a variable Tolman length leads to an excellent description. 


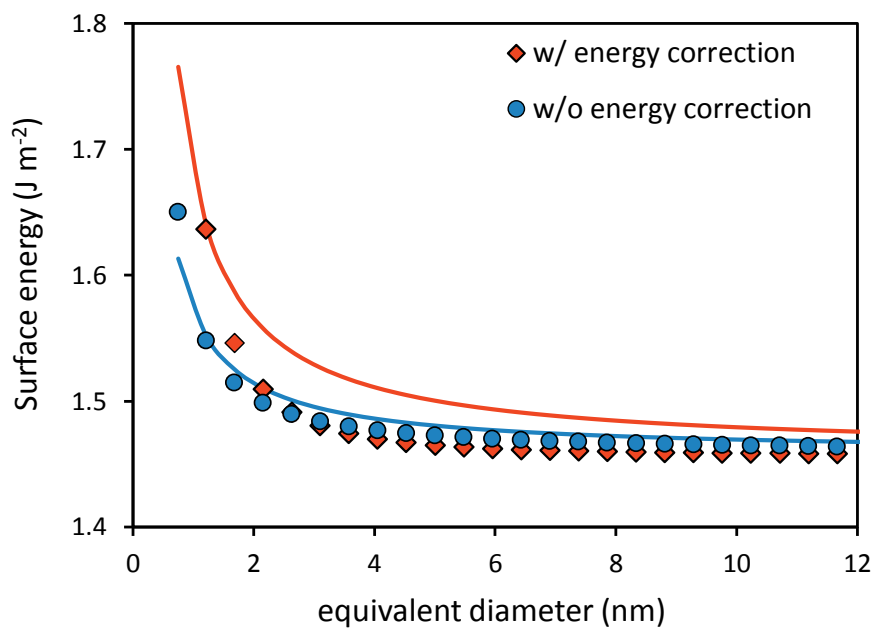

Figure D7. Surface energy values for gold cuboctahedra. The particle energy is calculated from the standard enthalpy of atomization ( 0.61 aJ, see Table 5.3, main text) using the surface coordination model, which can be adjusted with an energy correction for the corner atoms, as some computational data suggest. Markers represent excess energy scaled to the surface of tension and lines represent surface energy as calculated using the Tolman equation, using a Tolman length appropriate to the location of the surface of tension. Blue markers refer to uncorrected result; red markers are for particle energies corrected with 0.85 aJ, equivalent to what was found for the data of Ali et al. ${ }^{8}$ For the uncorrected particle energy (blue markers), a Tolman length of $-0.015 \mathrm{~nm}$ leads to good agreement between scaled and thermodynamic surface energies. For the adjusted surface energies, a Tolman length of $-0.020 \mathrm{~nm}$ gives the best overall agreement.

\section{D9 Optimized edge-lengths}

For particles with a single type of edge, such as cuboctahedra and octahedra, the shape cannot be varied. However, in particles with different types of edges, such as truncated octahedra and Marks decahedra the shape varies if the ratio between edge-lengths is changed. The different shapes have a different overall surface energy, which depends on ratio between the total surface area contributing facets, and a different surface to volume ratio. For mathematical representations, with 1-dimensional edges, the ratio edge-lengths can be perfectly optimized to give the lowest product of overall surface energy and surface to volume ratio. However, the $\mathrm{CN}$ model deals with discreet particles, which are built up of atoms. The particles thus grow in fixed increments. Nevertheless, more and less optimal shapes exist. These have been investigated for Marks decahedra a truncated octahedra. Optimal edgelengths are presented in Table D5. 
Table D5. Optimized edge-lengths and corresponding total number of atoms for marks decahedra and truncated octahedra. Definitions for $s_{1}, s_{2}$, and $s_{3}$ are given elsewhere in the supporting information.

\begin{tabular}{|c|c|c|c|c|c|c|}
\hline \multicolumn{4}{|c|}{ Marks decahedra } & \multicolumn{3}{|c|}{ Truncated octahedra } \\
\hline$s_{1}$ & $s_{2}$ & $s_{3}$ & $N_{\mathrm{T}}$ & $s_{1}$ & $s_{2}$ & $N_{\mathrm{T}}$ \\
\hline 3 & 2 & 2 & 75 & 2 & 2 & 38 \\
\hline 4 & 2 & 2 & 146 & 3 & 2 & 79 \\
\hline 4 & 3 & 2 & 192 & 3 & 3 & 201 \\
\hline 5 & 3 & 2 & 318 & 4 & 3 & 314 \\
\hline 5 & 3 & 3 & 434 & 4 & 4 & 586 \\
\hline 6 & 3 & 3 & 645 & 5 & 4 & 807 \\
\hline 6 & 4 & 3 & 766 & 5 & 5 & 1289 \\
\hline 7 & 4 & 3 & 1067 & 6 & 5 & 1654 \\
\hline 7 & 5 & 3 & 1228 & 6 & 6 & 2406 \\
\hline 8 & 5 & 3 & 1634 & 7 & 6 & 2951 \\
\hline 8 & 5 & 4 & 1965 & 8 & 6 & 3564 \\
\hline 9 & 5 & 4 & 2516 & 8 & 7 & 4794 \\
\hline 9 & 6 & 4 & 2802 & 9 & 7 & 5635 \\
\hline 10 & 6 & 4 & 3493 & 9 & 8 & 7279 \\
\hline 10 & 7 & 4 & 3839 & 10 & 8 & 8384 \\
\hline 10 & 7 & 5 & 4395 & 10 & 9 & 10502 \\
\hline 11 & 7 & 5 & 5341 & 11 & 9 & 11907 \\
\hline 12 & 7 & 5 & 6392 & 11 & 10 & 14559 \\
\hline 12 & 8 & 5 & 6913 & 12 & 10 & 16300 \\
\hline 13 & 8 & 5 & 8154 & 12 & 11 & 19546 \\
\hline 13 & 9 & 5 & 8755 & 13 & 11 & 21659 \\
\hline 13 & 9 & 6 & 9716 & 13 & 12 & 25559 \\
\hline 14 & 9 & 6 & 11292 & 14 & 12 & 28080 \\
\hline 15 & 9 & 6 & 13003 & 15 & 12 & 30745 \\
\hline 15 & 10 & 6 & 13829 & 15 & 13 & 35659 \\
\hline 16 & 10 & 6 & 15780 & 16 & 13 & 38780 \\
\hline 16 & 10 & 7 & 17206 & 16 & 14 & 44492 \\
\hline 17 & 10 & 7 & 19462 & 17 & 14 & 48105 \\
\hline 17 & 11 & 7 & 20548 & 17 & 15 & 54675 \\
\hline 18 & 11 & 7 & 23079 & 18 & 15 & 58816 \\
\hline 18 & 12 & 7 & 24280 & 18 & 16 & 66304 \\
\hline 18 & 12 & 8 & 26141 & 19 & 16 & 71009 \\
\hline 19 & 12 & 8 & 29142 & 19 & 17 & 79475 \\
\hline 20 & 12 & 8 & 32328 & 20 & 17 & 84780 \\
\hline 20 & 13 & 8 & 33839 & 20 & 18 & 94284 \\
\hline 21 & 13 & 8 & 37350 & 21 & 18 & 100225 \\
\hline 21 & 13 & 9 & 39841 & 22 & 18 & 106386 \\
\hline 22 & 13 & 9 & 43757 & 22 & 19 & 117440 \\
\hline 22 & 14 & 9 & 45613 & 23 & 19 & 124285 \\
\hline 23 & 14 & 9 & 49889 & 23 & 20 & 136521 \\
\hline 23 & 15 & 9 & 51895 & 24 & 20 & 144086 \\
\hline 24 & 15 & 9 & 56546 & 24 & 21 & 157564 \\
\hline 24 & 15 & 10 & 59832 & 25 & 21 & 165885 \\
\hline 25 & 15 & 10 & 64948 & 25 & 22 & 180665 \\
\hline 25 & 16 & 10 & 67349 & 26 & 23 & 205920 \\
\hline 26 & 16 & 10 & 72875 & 27 & 23 & 215861 \\
\hline 26 & 17 & 10 & 75446 & 27 & 24 & 233425 \\
\hline 26 & 17 & 11 & 79377 & 28 & 24 & 244230 \\
\hline 27 & 17 & 11 & 85588 & 29 & 24 & 255331 \\
\hline 28 & 17 & 11 & 92064 & 29 & 25 & 274981 \\
\hline 28 & 18 & 11 & 95080 & 30 & 25 & 286994 \\
\hline 29 & 18 & 11 & 102016 & 30 & 26 & 308210 \\
\hline 29 & 18 & 12 & 106842 & 31 & 26 & 321171 \\
\hline 30 & 18 & 12 & 114343 & 31 & 27 & 344013 \\
\hline 30 & 19 & 12 & 117839 & 32 & 27 & 357958 \\
\hline 31 & 19 & 12 & 125835 & 32 & 28 & 382486 \\
\hline 31 & 20 & 12 & 129536 & 33 & 28 & 397451 \\
\hline 31 & 20 & 13 & 135137 & 33 & 29 & 423725 \\
\hline
\end{tabular}




\section{D10 References}

1. I. Galanakis, G. Bihlmayer, V. Bellini, N. Papanikolaou, R. Zeller, S. Blügel and P. Dederichs, EPL (Europhysics Letters), 2002, 58, 751.

2. I. Galanakis, N. Papanikolaou and P. Dederichs, Surface science, 2002, 511, 1-12.

3. N. E. Singh-Miller and N. Marzari, Physical Review B, 2009, 80, 235407.

4. R. Tran, Z. Xu, D. W. Balachandran Radhakrishnan, W. Sun, K. A. Persson and S. P. Ong, Scientific Data, 2016, 3.

5. A. S. Barnard and L. A. Curtiss, ChemPhysChem, 2006, 7, 1544-1553.

6. B. Medasani, Y. H. Park and I. Vasiliev, Physical Review B, 2007, 75, 235436.

7. D. Liu, J. Lian and Q. Jiang, The Journal of Physical Chemistry C, 2009, 113, 1168-1170.

8. S. Ali, V. S. Myasnichenko and E. C. Neyts, Physical Chemistry Chemical Physics, 2016, 18, 792-800.

9. W. R. Tyson and W. A. Miller, Surface Science, 1977, 62, 267-276.

10. P. S. Yen and R. Datta, Journal of Colloid and Interface Science, 2014, 426, 314-323.

11. I. Egry, G. Lohoefer and G. Jacobs, Physical review letters, 1995, 75, 4043.

12. I. K. Suh, H. Ohta and Y. Waseda, Journal of Materials Science, 1988, 23, 757-760.

13. J. Cox, D. D. Wagman and V. A. Medvedev, CODATA key values for thermodynamics, Hemisphere Publishing Corp., New York, 1989.

14. R. Schumm, D. Wagman, S. Bailey, W. Evans and V. Parker, National Bureau of Standards, USA, 1973.

15. B. Molleman and T. Hiemstra, Physical Chemistry Chemical Physics, 2018, Submitted.

16. A. Patra, J. E. Bates, J. Sun and J. P. Perdew, Proceedings of the National Academy of Sciences, 2017, 201713320.

17. L. Vega, J. Ruvireta, F. Viñes and F. Illas, Journal of chemical theory and computation, 2018, 14, 395-403.

18. B. Molleman and T. Hiemstra, Physical Chemistry Chemical Physics, 2018, 20, $20575-$ 20587. 


\section{Summary}

Silver nanoparticles (AgNPs) find many useful applications in science and technology in various spectroscopic techniques and different forms of catalysis. However, they are most well-known for their antibacterial activity, which is of interest for a variety of consumer products and medical applications.

Due to their widespread use, there is increasing concern that nanoparticles may end up in the environment. It has been shown that presence of nanoparticles can be harmful, not only for bacteria, but also for a wide variety of higher organisms. While current environmental levels of silver nanoparticles are below the no effect concentrations, the use of AgNP-contaminated sewage sludge may lead to an accumulation in agricultural soil. No effect concentrations could be exceeded in the next 50 years.

Once in the environment, silver nanoparticles may interact with the different components of the environmental matrix, such as organic matter, chloride, sulfide. The interaction may induce a number of so called physical and chemical transformations such as aggregation, surface modifications, and oxidation. These transformations may alter mobility and the toxicological properties of silver nanoparticles. It is an important challenge, therefore, to explore the different transformation and the conditions under which these are expected to occur.

A transformation of particular interest is oxidation, in which the silver nanoparticles dissolve as ionic silver $\left(\mathrm{Ag}^{+}\right)$. There are strong indications that the antibacterial action of silver nanoparticles is related to the release of silver ions. For higher organisms, too, toxicology seems to depend on dissolved ionic silver. $\mathrm{Ag}^{+}$release is thus an especially relevant process to understand, not only when focusing on the environmental aspects of silver nanoparticles, but also for antibacterial applications of silver nanoparticles.

Silver ions are released from silver nanoparticles upon oxidation of silver nanoparticles in an aqueous environment. When pristine silver nanoparticles are added to a solution containing dissolved oxygen, a phase of fast initial dissolution is seen, followed by a phase in which dissolution gradually slows down and eventually stops. This is a remarkable observation, because the reaction between oxygen and solid silver has very high equilibrium concentrations of ionic silver. In the dissolution of AgNPs, much lower concentrations are found. Nevertheless, once stable concentrations of silver nanoparticles have been attained, they can remain stable for months, without any apparent further dissolution.

The long-term stability of silver nanoparticles can be understood if the AgNP surface is passivated by a layer of oxide, which prevents oxygen from reacting with the metallic silver 
underneath. However, the structure of such a layer must be radically different from standard silver oxide, $\mathrm{Ag}_{2} \mathrm{O}$, as the latter is highly soluble at neutral $\mathrm{pH}$, and cannot possibly for a stable surface layer under the experimental conditions for which literature sources report stabilization. A possible structure for a stable surface layer can be found based on subvalent silver compounds.

Subvalency is found in a number of layered silver minerals which show a bilayer of hexagonally organized silver. The silver in these compounds is not fully oxidized but has an average charge between 0 and 1 valence units. This property is made possible by the semi-metallic nature of the subvalent compounds, which allows delocalization of electrons. The remaining valence electrons are equally distributed among silver atoms, leading to average silver valence of $+1 / 3-$ $2 / 3$, depending on the compound.

Spectroscopic measurements have suggested the existence of two oxidation states on the silver nanoparticles surface. The first oxidation state, which is attained under mild oxidation by addition of silver ions, suggests an average valence of roughly $+1 / 3$ per surface atom. It leads to a surface structure composed of groups of three surface atoms, with a combined charge of +1 , coordinating to a hydroxide to achieve neutralization. The result is an uncharged surface structure which is composed of a monolayer of $\equiv \mathrm{Ag}_{3} \mathrm{OH}$ groups. It is referred to as the primary surface structure

The second oxidation state, which is attained at strong oxidation using oxygen at a low $\mathrm{pH}$, translates to a surface charge which is approximately two times higher. This may be attained by presence of $\equiv \mathrm{Ag}_{3} \mathrm{OH}$ groups on two levels. The first level is a non-continuous outer layer. In the atomic layer below that, additional $\equiv \mathrm{Ag}_{3} \mathrm{OH}$ groups may be found where this is allowed by openings in the outer layer. This is referred to as the secondary surface structure.

These structures are hypothetical, but stability of the $\equiv \mathrm{Ag}_{3} \mathrm{OH}$ group is supported by molecular orbital calculations using density functional theory. It is revealed that the energy of a tiny silver nanoparticle, comprised of 13 atoms, is strongly reduced when surface atoms are partially oxidized to a valence of $+1 / 3$ and neutralized by hydroxide groups. A much lower stability is found at a higher oxidation and neutralization by oxide $\left(\mathrm{O}^{2-}\right)$. It is for this reason that I consider $\equiv \mathrm{Ag}_{3} \mathrm{OH}$ groups placed in two atomic layers as the more probable option.

Trends from surface complexation modelling suggest that the $\mathrm{Ag}_{3} \mathrm{OH}$ groups will not become protonated or deprotonated at normal $\mathrm{pH}$ levels $(\mathrm{pH}>4)$. The surface is therefore expected to be neutral. However, charge may develop as a consequence of water ordering at the surface.

The two surface structures are believed to be in equilibrium with each other. Increasingly oxidative conditions will have an increasing proportion of the surface covered by the secondary structure. Transformation of the primary structure into the secondary structure occurs under influence of oxygen and $\mathrm{pH}$ had leads to release of $\mathrm{Ag}^{+}$ions. This is in line with the fact that the final concentrations of silver that are reached in dissolution experiments 
show a good correlation with the AgNP surface area present in solution. It strongly suggests a surface controlled reaction.

The release of silver ions from the silver nanoparticle surface has been investigated experimentally. I have performed an extensive set of measurements to establish the $\mathrm{pH}$ dependency of the dissolution reaction. Dissolution of three sizes of nanoparticles was followed over time in the $\mathrm{pH}$ range between 3 and 9. Two distinct dissolution regimes were identified.

The first dissolution regime was occurs at circumneutral to high $\mathrm{pH}$. The $\mathrm{pH}$ dependency of the equilibrium concentrations of $\mathrm{Ag}^{+}$was in excellent agreement with a surface controlled equilibrium, and could not be interpreted as a solid state equilibrium. The equilibrium reaction between the two surface structures under release of $\mathrm{Ag}^{+}$was modelled in ECOSAT using a Langmuir equation. Data could be excellently described using the reaction:

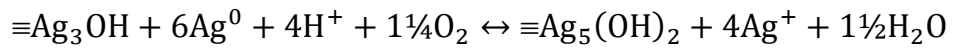

The reaction indicates that the primary surface group $\equiv \mathrm{Ag}_{3} \mathrm{OH}$ becomes oxidized and dissolves as ionic silver $\left(\mathrm{Ag}^{+}\right)$. Of the 6 metallic silver atoms $\left(\mathrm{Ag}^{0}\right)$, which represent the silver found in the two atomic layers below a primary surface group, one dissolves as $\mathrm{Ag}^{+}$, while the remaining five form surface groups on two atomic layers. I must stress that the stoichiometry indicated in the above reaction is strongly dependent on the molecular view of the secondary surface structure. However, the experimental data are in good agreement with the $\mathrm{pH}$ dependency suggested by the reaction.

At a pristine particle, the $\equiv \mathrm{Ag}_{3} \mathrm{OH}$ surface group is expected to be present at a surface density of site density of $7.6 \mu \mathrm{mol} \mathrm{m}{ }^{-2}$. As the above reaction suggest the release of 4 silver ions per surface group, a maximum silver release through equilibration of around $30 \mu \mathrm{mol} \mathrm{m}^{-2}$ is found, in good agreement with the data.

Another dissolution regime was observed at low $\mathrm{pH}$. Dissolution was much faster, and led to much higher concentrations than could be explained using the equilibration alone. However, the $\mathrm{pH}$ dependency of the dissolution was much lower than for equilibration reaction: a clear bend is observed in the relationship between $\mathrm{pH}$ and dissolved $\mathrm{Ag}^{+}$concentrations. Despite the very $\mathrm{Ag}^{+}$release, full dissolution was never observed, even at $\mathrm{pH} \sim 3$.

At short reaction times, the dissolution at low $\mathrm{pH}$ led to erratic concentration levels, pointing to a poorly controlled reaction. It was hypothesized that cavities in the surface could grow out laterally, stripping of entire facets. Classical nucleation theory was used to show that the size of a critical cavity, which can spontaneously grow, decreases at conditions of high undersaturation. It is thought that a number of critical cavities can form immediately after mixing, which grow out during the course of the experiment. The released $\mathrm{Ag}^{+}$contributes for a less strongly undersaturated solution in which equilibrium between the two surfaces can be established. 
The time dependency of the dissolution reaction was analyzed using two different approaches. In the first approach, $\mathrm{Ag}^{+}$release over time was described using first order kinetics using two different pools. A slow pool, representing the equilibration reaction, and a fast pool, representing stripping. The kinetic analysis thus supported the presence of two dissolution regimes which was also established based on the $\mathrm{pH}$ dependency. While the two kinetically distinct Ag-pools were unmistakable, the data description using this rather simple approach was not optimal.

A more accurate kinetic description was achieved with a more detailed model, distinguishing different steps in the $\mathrm{Ag}^{+}$release reaction, which can be rate limiting depending on the conditions. The first step is presumed to be the adsorption of oxygen to the nanoparticle surface. Depending on the storage conditions, adsorbed oxygen may already be present on the nanoparticle surface prior to the dilution in oxygenated solution. The adsorbed oxygen immediately reacts when activated by a proton, and the remainder of the reaction steps of the dissolution reaction occur at a much higher rate. At low to neutral $\mathrm{pH}(\sim 6-7)$, the activation of adsorbed oxygen by a proton occurs at a high rate, and dissolution is fast. However, the adsorbed oxygen is consumed faster than it is replenished, due to a slow adsorption reaction, which leads to a rate limitation that can be detected in the time dependency of $\mathrm{Ag}^{+}$ concentrations. At acidic $\mathrm{pH}$, the cavitation followed by lateral stripping process occurs, which circumvents this rate-limiting step leading to much higher release rates. At high $\mathrm{pH},(\sim 7-9)$, the release of $\mathrm{Ag}^{+}$is limited by the activation rate of the adsorbed oxygen, which has a first order dependency on proton concentrations.

The equilibrium concentrations of $\mathrm{Ag}^{+}$were measured for three different particle sizes. Using the Langmuir adsorption model, an equilibrium constant was fitted for the release reaction of the three different particles. This led to a size dependency in the $\log K$ values, which could also be found for $\mathrm{Ag}^{+}$release data of other particles, published in the literature. Using the dissolution reaction, a surface energy could be derived from the size dependency of $\mathrm{Ag}^{+}$ release. A value of $\sim 0.7 \mathrm{~J} \mathrm{~m}^{-2}$ was calculated for metallic silver, covered with subvalent silver. It emphasizes that surface energy plays an important role in the release of ionic silver from silver nanoparticles.

Surface energy is an important topic in various fields of science and has received a great deal of attention over the years. There is a general believe that surface energy of nanoparticles is different than that for the bulk, and that this effect is stronger the smaller the particles get. For metallic nanoparticles, this size-dependency is interpreted in to completely opposite ways. The first interpretation is based heavily on the classical work of Tolman on water droplets, leading to the expectation that surface energy will be lower for smaller particles. The second interpretation is that, as a result of an increasing contribution of high energy edge and corner atoms, surface energy is higher for smaller particles. To understand the effect of surface energy on silver ion release, we must understand the direction of size dependency as well as the size at which this starts to make a difference. 
In my approach, we applied the classical work of Tolman in a thermodynamically consistent way to metallic nanoparticles. The work of Tolman states that the change in surface energy with size is related to the change in chemical potential and the Tolman length $\delta$, which is equal to the distance between the equimolar surface and the surface of tension. As the change in chemical potential is a function of the surface energy, the equation can be solved to yield an expression which relates the surface energy to $\delta$. If, in addition the chemical potential at different sizes is known, the Tolman length can be derived.

Practically, the above can be done by scaling the total surface energy $(J)$ of metallic nanoparticles to a surface. For this surface a Tolman length can be calculated, if the equimolar surface area is defined. The Tolman length, in combination with the macroscopic surface energy, translates to a surface energy at any specific size. If this surface energy is the same as the surface energy found through scaling, the surface in question is equivalent to the surface of tension, and the calculated surface energy is thermodynamically consistent.

To apply the above method to faceted metallic nanoparticles, the Tolman equation, which is based on spherical particles, was amended with a shape factor $c$. Three different surface definitions were tested for thermodynamic consistency. Only the physical surface, which is positioned at half the closest interatomic distance from the cores of surface atoms, was found to yield thermodynamically consistent surface energy values. Using this surface, which had a Tolman length of around $-0.03 \mathrm{~nm}$, a very limited size dependency of surface energy was found, which led to an increase of around $10 \%$ in particles smaller than $1 \mathrm{~nm}$. This is negligible compared to previous assertions in literature and will likely not affect $\mathrm{Ag}^{+}$release.

The behavior of surface energy for metallic nanoparticles is completely different than that of the surface energy of water nano-droplets. I investigated the energy of evaporation of water and atomization of silver to better understand the reasons for the different size dependencies of surface energy. By attributing a surface to a free water molecule of silver atom, a total surface enthalpy and surface free energy contribution could be calculated. It was found that these were very similar to the enthalpies and Gibbs free energies of evaporation or atomization. Using a Tolman length, a perfect agreement could be achieved. This demonstrated that the surface enthalpy for water and silver had a very similar size dependency, with a negative Tolman length. The surface Gibbs free energy however was different. The reason for this was the surface entropy, which is similar in absolute magnitude for both surfaces, but relatively much smaller in silver, compared to the surface enthalpy. The surface entropy has a stronger size dependency than the surface enthalpy, and in water, this leads to a negative size dependency of the surface Gibbs free energy. In silver, however, the surface enthalpy is much (10x) higher, and the surface entropy does not affect it to the same extend. At high temperature, the surface entropy contributes much more, and a negative sizedependency is expected.

My study of particle stability was extended by the development of a model, which predicts the total surface energy contribution based on the coordination and abundance of surface 
atoms. Different crystal faces have atoms with different coordination numbers and different densities, giving rise to a different surface energy. Additionally, corner and edge atoms, which have a low coordination and a high energy, contribute to varying degrees, depending on shape and particle size. The coordination model allows an accurate calculation of the precise energy contribution of the various types of surface atoms. Overall, it is seen that corner atoms, while having a high energy, contribute little to overall surface energy in all but the smallest particles due to a low abundance. Edge atoms, are much more prominently present, and contribute significantly up to even $100 \mathrm{~nm}$. The coordination model was works exceptionally well, closely matching with results for nanoparticles and macroscopic crystal faces from computational methods.

In addition to external surface energy, some particles have an internal energy contribution due to a suboptimal arrangement of the atoms. This is the case in e.g. fivefold twinned particles such as icosahedra and decahedra. The higher internal energy is compensated by a low external energy, because fivefold twinning allows facets with lower energy surfaces. The internal energy contributions due to twinning are isolated by subtracting the external energy contribution, calculated by the coordination model, from computationally calculated particle energies. Based on these internal energies, an additional model for the energy of twinning is developed. This model identifies an energy contribution of the twin plane, and, in case of icosahedra, an additional energy contribution due to internal strain. The latter appears to be wholly absent from decahedral particles, but is the main contributor to twinning energy in icosahedra.

The coordination model is applied to find realistic surface enthalpy values for metallic nanoparticles. This is an important result, as computational methods are not yet able to reliably produce absolute surface energy values. Large differences are found between methods, and as surface energy for different crystal faces is very hard to determine experimentally, it is not certain which result can be considered as true. In describing the computationally generated particle data with the coordination model, a strikingly consistent relationship to the (computational) cohesive energies is found. This is extrapolated to experimental values for the cohesive energy, or enthalpy of atomization, to find particle energies which are expected to be close to real values. This is verified by comparing predicted surface energies for macroscopic crystal faces to extrapolated experimental results for the overall surface energy: good agreement is found for four different elemental metals. Surface energies can be calculated after thermodynamically consistent scaling to the surface of tension. Slightly less negative Tolman lengths $(\sim-0.02 \mathrm{~nm})$ are found using this method than those established using computational data, but the size dependency of surface energy is similar.

Finally, the relative stability of particles is calculated by comparing total particle energies as a function of size. It is found that icosahedral particles are most stable at small size, while above $\sim 5 \mathrm{~nm}$, Marks decahedra are the most stable shape. The latter are only slightly more stable 
than truncated octahedra. However, octahedra, cuboctahedra and Ino decahedra are considerable less stable. These results are all for purely metallic nanoparticles, and cannot be directly applied to silver nanoparticles under aqueous conditions, as these are expected to have an oxidic surface layer.

This work highlights the complexity of the silver nanoparticles under environmental conditions and the many aspects and variation which can play a role in this topic. Given the different crystal faces, the different surface energies and the different shape factors, surface energy and therefore stability is expected to be quite different for differently shaped particles. This may influence the interaction in the environment. However, shape will be much more influential for environmental reactivity and $\mathrm{Ag}^{+}$release. This is due to both the lower stability of small particles, and the higher surface area at similar loading.

This research does not offer clear answers as to what the environmental fate of silver nanoparticles will be. However, a great deal of insight is gained into the surface structure, oxidation, dissolution, and stability of silver nanoparticles. Therefore, this research may serve as a solid base for future research, offering a framework from which our understanding can be extended, both on the fundamental and the applied side. 


\section{List of publications}

\section{Published}

Molleman, B.; Hiemstra, T. Size and shape dependency of surface energy of metallic nanoparticles: Unifying the atomic and thermodynamic approach. Physical Chemistry Chemical Physics 2018, 20, 20575-20587

Molleman, B.; Hiemstra, T. Time, pH, and size dependency of silver nanoparticle dissolution: the road to equilibrium. Environmental Science: Nano 2017, 4, 1314-1327

Molleman, B.; Hiemstra, T. Surface structure of silver nanoparticles as a model for understanding oxidative dissolution of silver ions. Langmuir 2015, 31, 13361-13372.

Koopmans, G.F.; Hiemstra, T.; Regelink, I.C.; Molleman, B.; Comans, R.N.J. Asymmetric flow field-flow fractionation of manufactured silver nanoparticles spiked into soil solution. Journal of Chromatography A 2015, 1392, 100-109.

Van der Ploeg, M.J.C.; Handy, R.D.; Waalewijn-Kool, P.L.; van den Berg, J.H.J.; Herrera Rivera, Z.E.; Bovenschen, J.; Molleman, B.; Baveco, J.M.; Tromp, P.; Peters, R.J.; Koopmans G.F.; Rietjens, I.M.C.M.; Van den Brink, N.W. Effects of silver nanoparticles (NM-300K) on Lumbricus Rubellus earthworms and particle characterization in relevant test matrices including soil. Environmental Toxicology and Chemistry 2014, 33, 743-752.

Hiemstra, T.; Mia, S.; Benoit, P.; Molleman, B. Natural and pyrogenic humic acids at goethite and natural oxide surfaces interacting with phosphate. Environmental Science and Technology 2013, 47, 9182-9189.

\section{In preparation}

Molleman, B.; Hiemstra T. Structural approach to surface energy of nanoparticles: Role of corners, edges, faces, crystal twinning, and internal strain. To be submitted to ACS Nano. 


\section{SENSE}

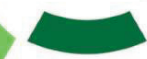

Netherlands Research School for the

Socio-Economic and Natural Sciences of the Environment

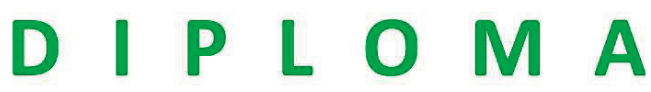

For specialised PhD training

The Netherlands Research School for the Socio-Economic and Natural Sciences of the Environment (SENSE) declares that

\section{Bastiaan Molleman}

born on 14 September 1984 in Amsterdam, the Netherlands

has successfully fulfilled all requirements of the

Educational Programme of SENSE.

Wageningen, 11 October 2019
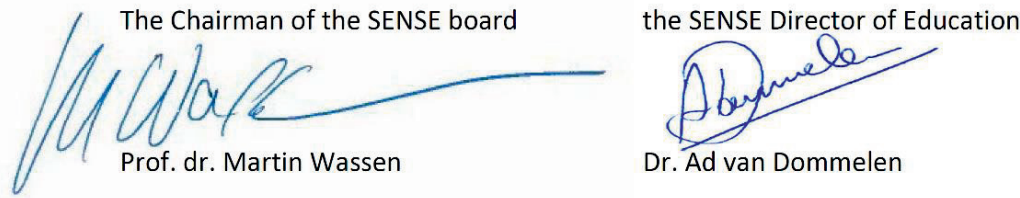

Dr. Ad van Dommelen

The SENSE Research School has been accredited by the Royal Netherlands Academy of Arts and Sciences (KNAW)

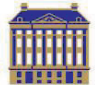

$\begin{array}{llllllllllllllllllllll}K & O & N & I & N & K & L & I & J & K & E & N & E & D & E & R & L & A & N & D & S & E\end{array}$

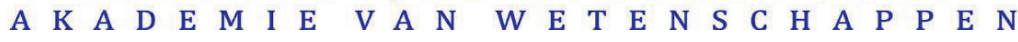




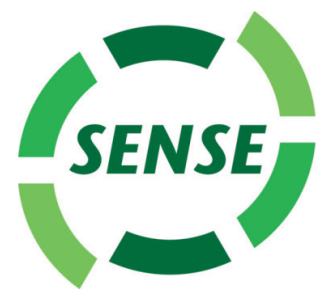

The SENSE Research School declares that Bastiaan Molleman has successfully fulfilled all requirements of the Educational PhD Programme of SENSE with a work load of $39.4 \mathrm{EC}$, including the following activities:

\section{SENSE PhD Courses}

- Environmental research in context (2012)

o Research in context activity: 'Developing publications with multiple disciplinary perspectives on metallic nanoparticles and writing press release on $\mathrm{PhD}$ research outcomes' (2018)

\section{Other PhD and Advanced MSc Courses}

- PhD competence assessment, Wageningen Graduate Schools (2012)

o Project planning and time management, Wageningen Graduate Schools (2012)

- Scientific publishing, Wageningen Graduate Schools (2012)

- Colloid science, Wageningen University (2013)

- Summer school "Experimental Analytical Techniques for Characterization of Nanoparticles and their Effects", InterNano (2015)

- Intellectual property and valorisation awareness, NanoNextNL (2015)

o Writing grant proposals, Wageningen Graduate Schools (2015)

- Career assessment, Wageningen Graduate Schools (2016)

- Career orientation, Wageningen Graduate Schools (2016)

- PhD summer school "Smart solutions for the urban metropole", Climate-KIC (2016)

\section{Management and Didactic Skills Training}

- Convener at the 2nd Wageningen PhD symposium (2014)

- Supervising MSc student with thesis entitled 'Interaction of Ag with natural organic matter: ion adsorption and nanoparticle formation' (2012)

o Supervising MSc student with thesis entitled ' $\mathrm{Ag}^{+}$-release from silver nanoparticles: The effect of environmental conditions' (2015)

\section{Oral and Poster Presentations}

- The oxide structure on silver nanoparticles. 11th Conference on Colloid Chemistry, 28-30 May 2018, Eger, Hungary

- Interaction of silver and natural organic matter: Adsorption and AGNP formation in the environment. Micro Nano Conference, 11-12 December 2013, Ede, the Netherlands

o Fate of silver nanoparticles in soil. Nanocity, 28-29 October 2014, Utrecht, The Netherlands

- What limits the toxicity of silver nanoparticles? Nanocity, 23 May 2016, Amsterdam, The Netherlands

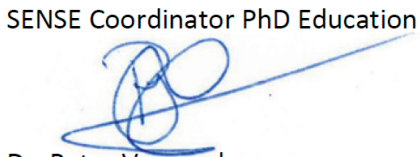

Dr. Peter Vermeulen 
The research described in this thesis was financially supported by NanoNextNI.

Financial support from Wageningen University for printing this thesis is gratefully acknowledged.

Cover design by Filipa Ferreira Lopes Ferraz

Printed by DigiForce | ProefschriftMaken on FSC-certified paper 


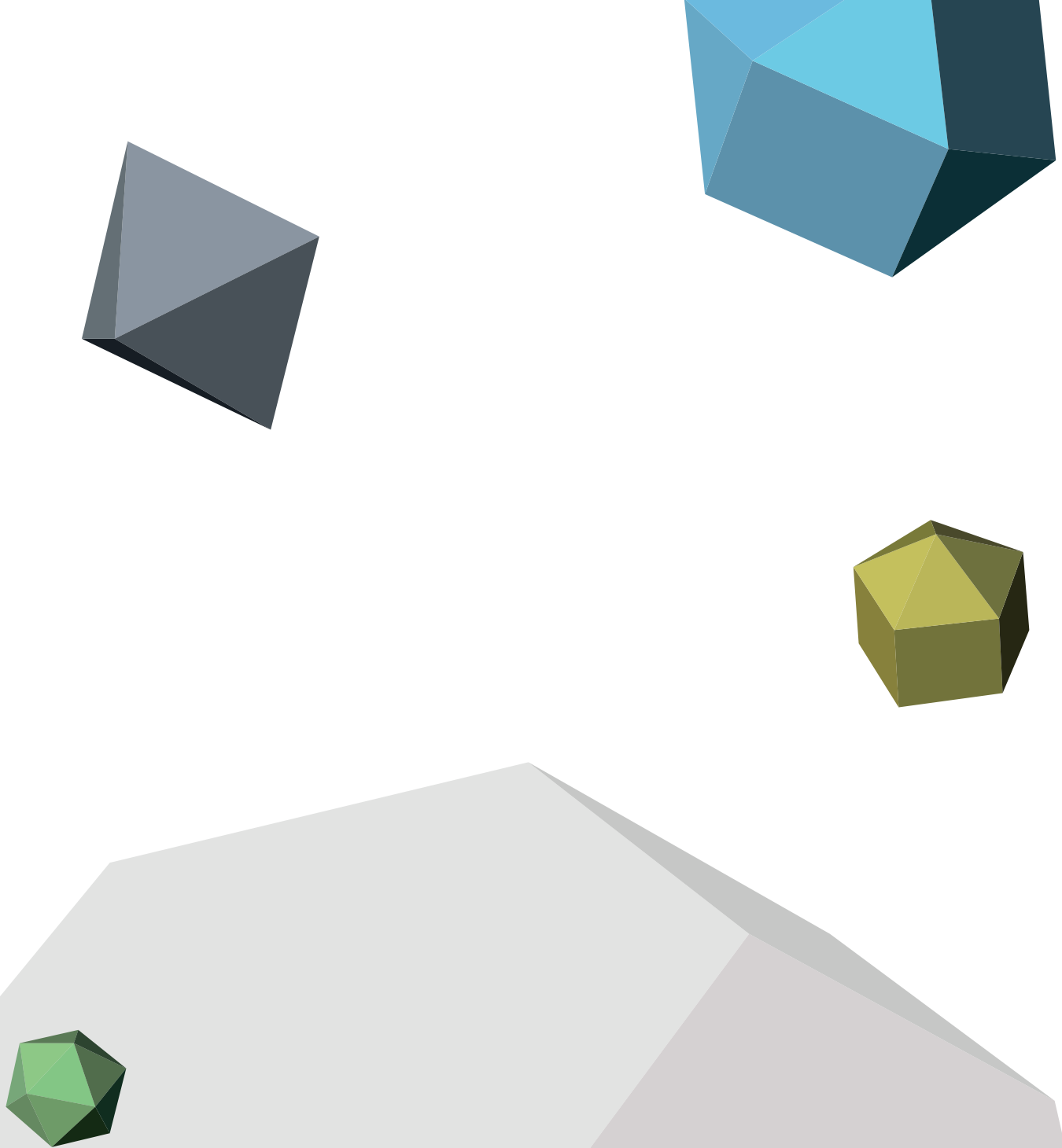